\title{
Carbon intensive but decarbonizing quickly? Retrospective and Prospective Life Cycle Assessments of South African pome fruit.
}

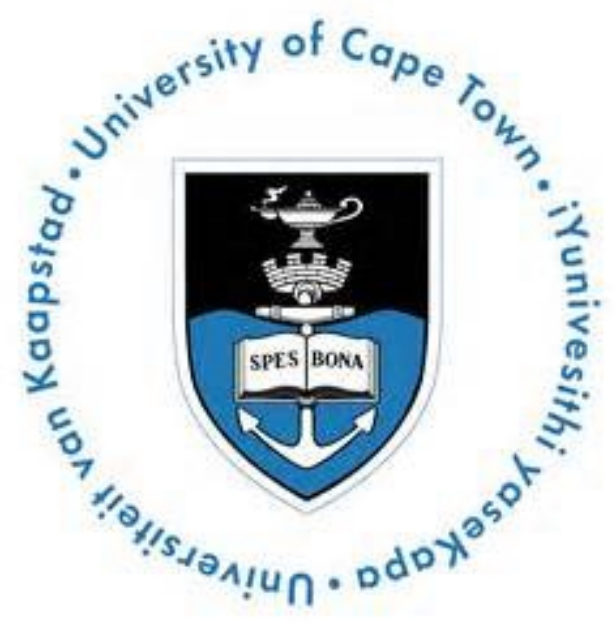

Thesis presented in partial fulfilment for the degree of Masters of Science in Engineering Department of Chemical Engineering University of Cape Town Lorren de Kock

Supervised by:

Prof. Harro von Blottnitz

Dr. Valentina Russo

December 2017 
The copyright of this thesis vests in the author. No quotation from it or information derived from it is to be published without full acknowledgement of the source. The thesis is to be used for private study or noncommercial research purposes only.

Published by the University of Cape Town (UCT) in terms of the non-exclusive license granted to UCT by the author. 


\section{Declaration}

I know the meaning of plagiarism and declare that all the work in the document, save for that which is properly acknowledged, is my own. This thesis/dissertation has been submitted to the Turnitin module (or equivalent similarity and originality checking software) and I confirm that my supervisor has seen my report and any concerns revealed by such have been resolved with my supervisor.

Signed by candidate

Lorren de Kock 


\section{Abstract}

The South African economy has in the past been categorised as carbon intensive due to an energy and capital intensive development path and an associated set of economic activities termed the minerals-energy complex. International export markets, specifically the European Union (EU), are systematically applying pressure on imported products with a high carbon footprint through potential trade barriers, border tariffs and consumer lobbying. The objective of this research is to determine whether South African pome fruit has a higher global warming potential (GWP) per kg fruit compared to pome fruit cultivated and packaged in other countries. Following on from this finding, is to determine whether the Greenhouse Gas (GHG) emissions for pome fruit in South Africa are declining, ,as could be expected based upon the declining carbon intensity of the South African economy since 1990 and efficiency improvements in the industry itself.

The Attributional Life Cycle Assessment (ALCA) methodology is used to determine the Global Warming Potential (GWP) per $\mathrm{kg}$ fruit for multiple boundaries within the value chain, retrospectively for the years 2000, 2010 and prospectively for 2020 . The product system boundary includes the farm, packhouse, controlled atmosphere store (CA) and cold store (CS). For the Life Cycle Inventory (LCl), the temporal variations in pome fruit cultivation, packing and storing for the export and local market are taken into account for each of the years studied. Using the single issue characterisation methods - the GHG Protocol and the IPCC GWP 2013 100a the results for each of the years under study are compared at a value chain, boundary and activity level. The results indicate that the baseline GWP result for South African pome fruit in the year 2000 was relatively high compared to similar international LCA research on apples and pears during this period. However, the results for the years 2010 and 2020 clearly indicate a sustained decline in relative GHG emissions of South African pome fruit according to the GWP indicator result per kg fruit and the normalised results for the industry. It is clear that there has been an increase in eco-efficiency in a number of farming and agro-processing practices since 2000 which correlates to the declining $\mathrm{CO}_{2} \mathrm{e}$ emissions in the boundaries and value chain of South African pome fruit. The carbon intensity and efficiency of the pome fruit value chain is also determined for each year using the $\mathrm{kg} \mathrm{CO}_{2} \mathrm{e}$ per $\mathrm{kg}$ fruit and the industry revenue for a specific year (ZAR 2010 adjusted for PPI). The findings support the hypothesis that the carbon intensity of the pome fruit industry has indeed declined since the year 2000 . This decline in carbon intensity represents a relative decoupling of $\mathrm{CO}_{2} \mathrm{e}$ emissions from economic growth of the industry from 2000 to 2020. 


\section{Dedication}

This thesis is dedicated to my father John Eric Landman: 2 February 1949 - 13 May 2006.

\section{Acknowledgements}

Thank you firstly to my supervisor Prof. Harro von Blottnitz for giving me the opportunity to pursue a postgraduate degree in the subject of Life Cycle Assessment. His passion for environmental advocacy and sustainability is an inspiration, and I am eternally grateful for his contribution to my academic and personal growth. Thank you to my co-supervisor Dr. Valentina Russo for all the time spent on answering questions I had, checking my results and reviewing my draft write ups. I am grateful for all her words of encouragement these last 3 years. I am also indebted to all the people in the pome fruit industry who made the time to meet with me and provide the much needed information. Thank you to the Confronting Climate Change initiative, as it was the starting point of this research and provided some of the much needed data for the LCls.

This academic journey has been challenging and simultaneously truly enjoyable as I have learnt to persevere with the reward of gaining new knowledge from the research process. My goal at the age of 35 years was to pursue a career in environmental sustainability which was a significant change to the industries in which I had been working. I landed up in the field of agricultural sustainability and was very fortunate to further enrich my knowledge in sustainability by being admitted as a Masters student at the University of Cape Town. My research on Life Cycle Assessment has been truly valuable and I hope to apply my knowledge gained in the field of LCA further in my future career.

The journey has not been without its challenges. I had to balance a full time job with family commitments during the first year of my studies and then the arrival of my second child, Inge, during the second. Thank you to my husband Danie, for the financial and personal support during these 3 years and my two daughters; Megan and Inge for joining me on this journey.

Thank you to my father for planting the seed of curiosity and love of learning. Thank you to my mother who always believed in me and through all life's challenges endeavoured to support my dreams. 


\section{Table of Contents}

Page

Declaration ............................................................................................................

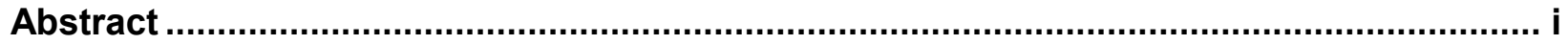

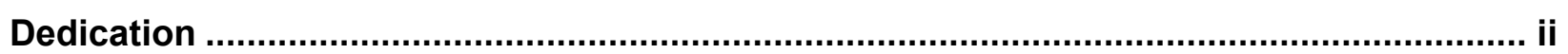

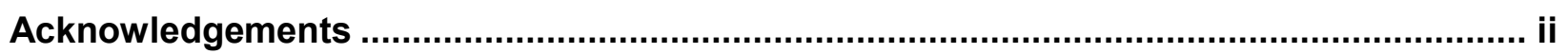

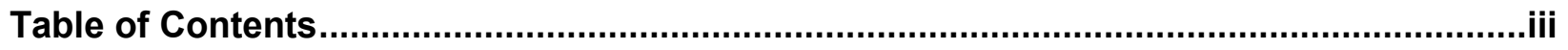

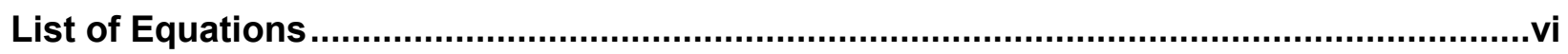

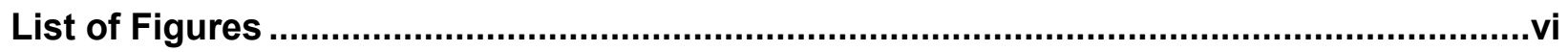

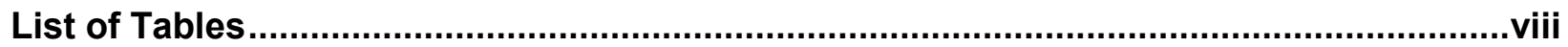

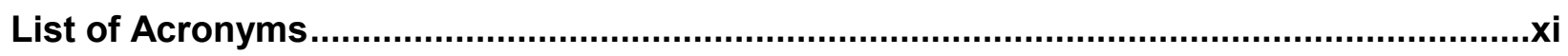

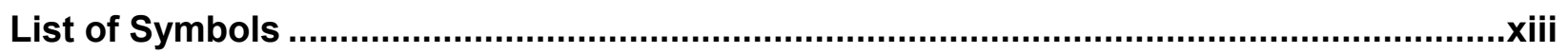

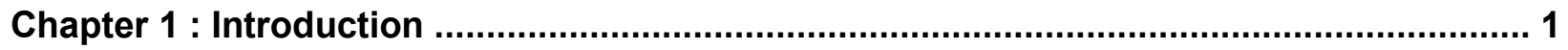

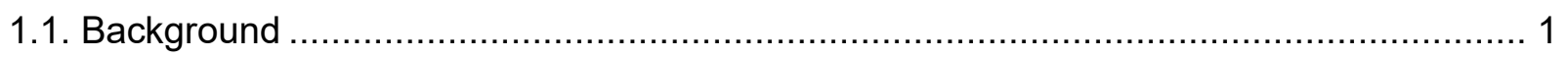

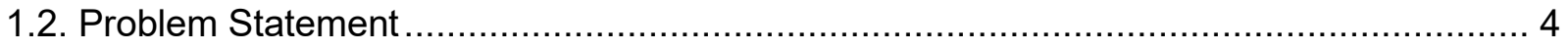

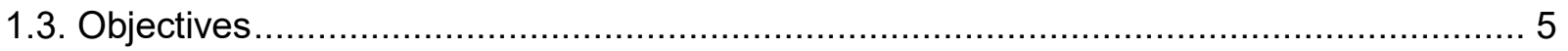

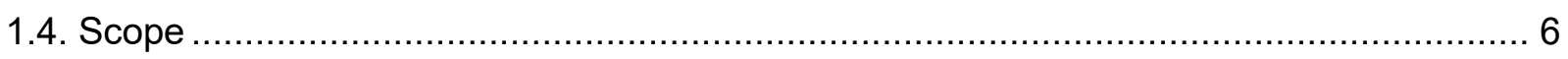

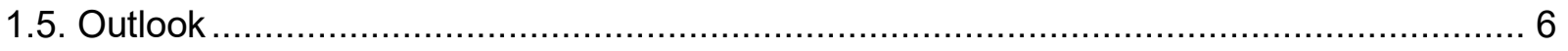

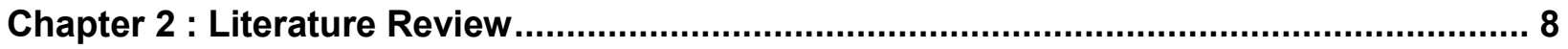

2.1. Carbon intensity of the South African economy ............................................... 8

2.2. Life Cycle Assessment Definitions and Typologies .............................................11

2.3. The Attributional Life Cycle Methodology ...................................................13

2.4. Applications of Life Cycle Assessment on pome fruit globally and in South Africa .........14

2.5. Limitations and further research areas .............................................................. 18

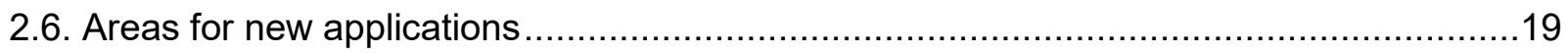

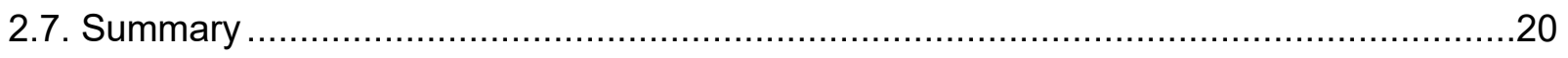

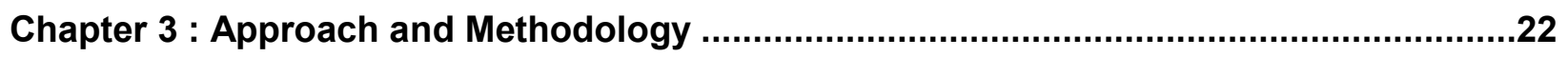

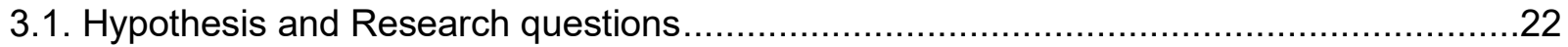

3.2. Specific objectives/ Methods (flowchart from hypothesis) .....................................22

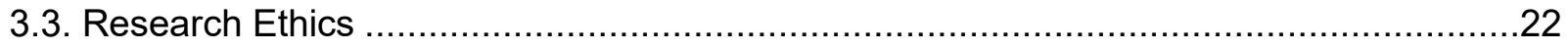

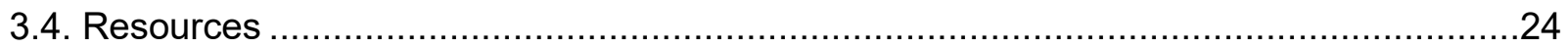




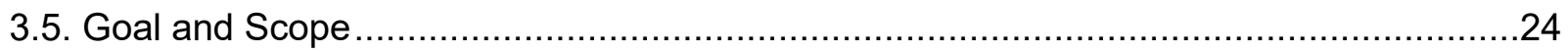

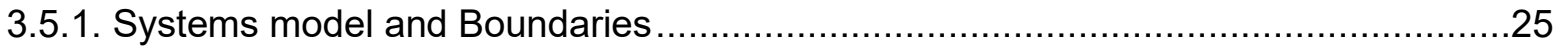

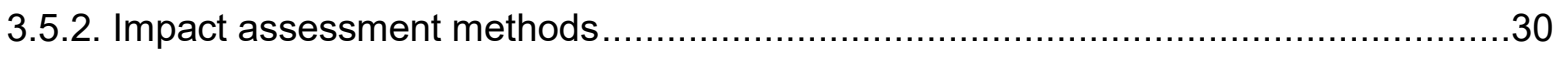

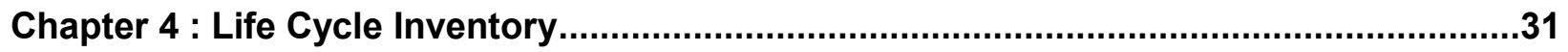

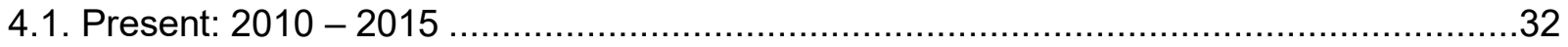

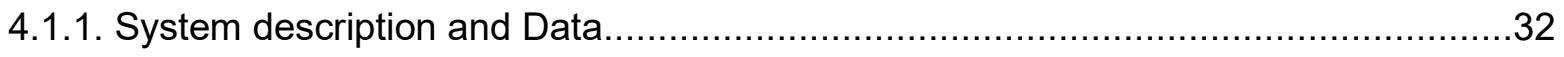

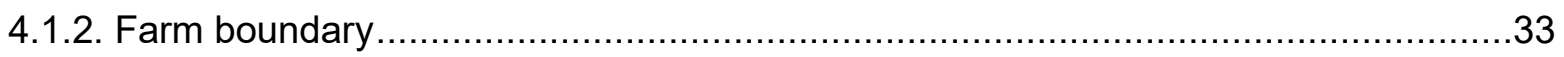

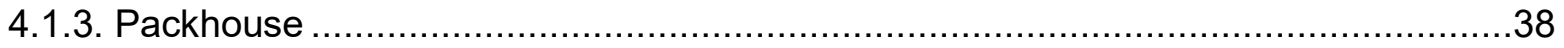

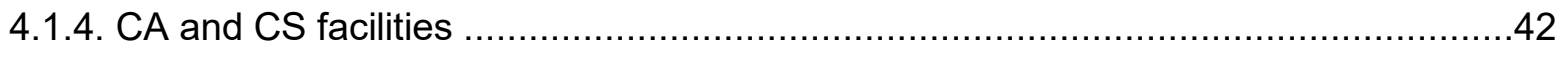

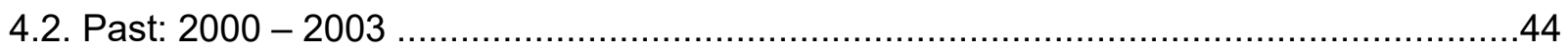

4.2.1. System Description and Data .............................................................. 44

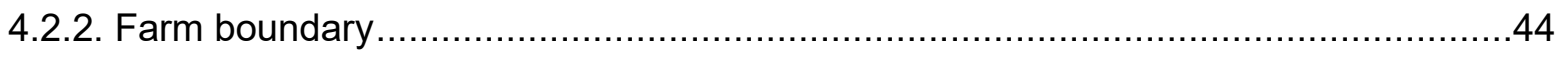

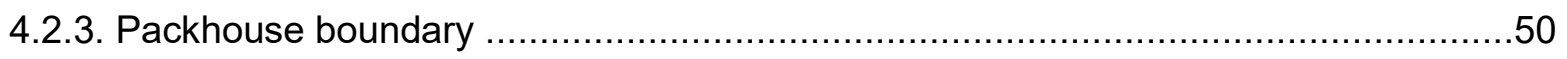

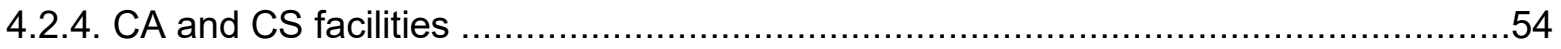

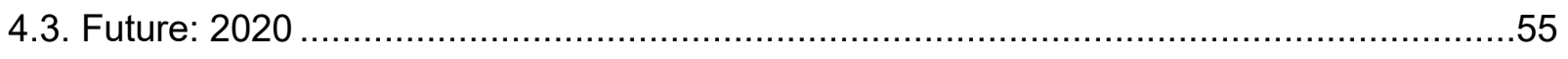

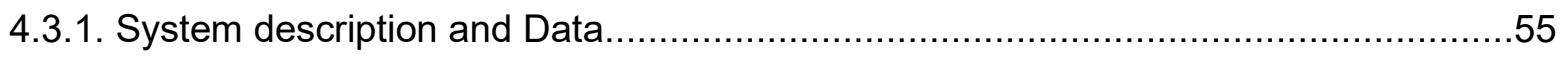

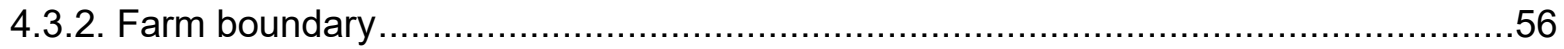

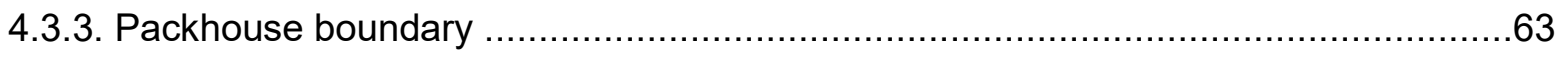

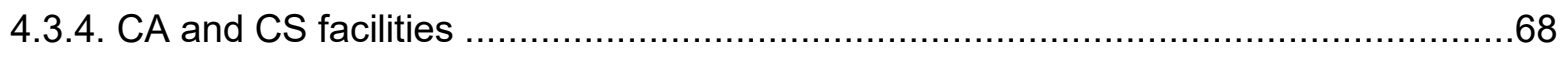

Chapter 5 : Time series Attributional Life Cycle Assessment results..............................70

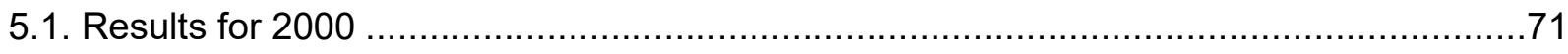

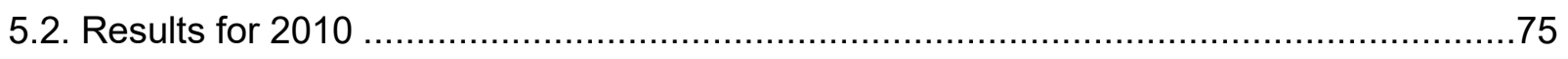

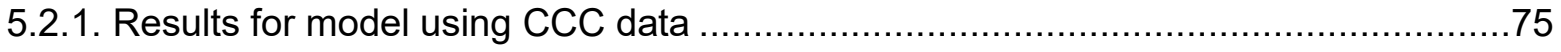

5.2.2. Results for 2010 model using refined electricity consumption values ....................78

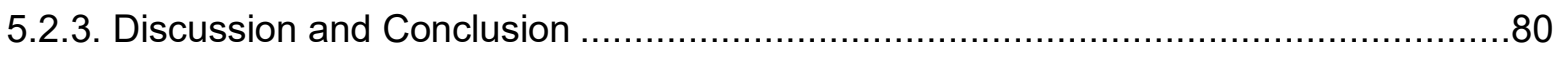

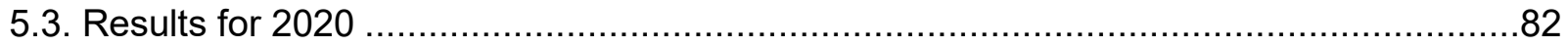

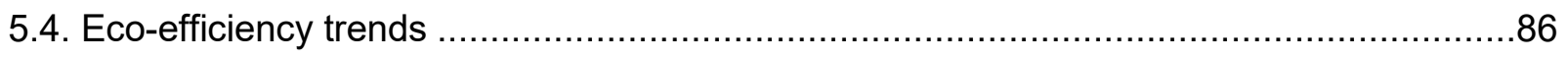

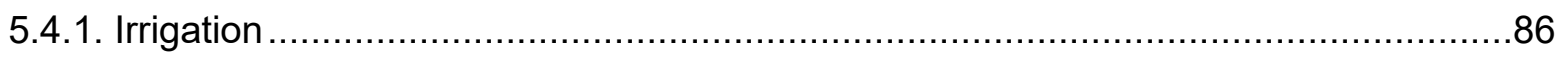

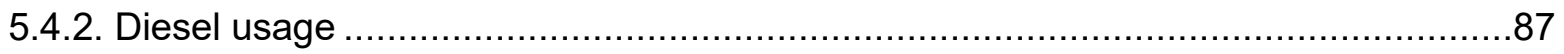

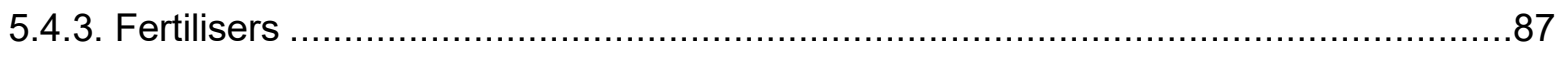

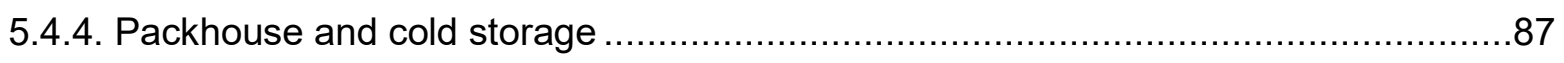


Chapter 6 : Interpretation and Discussion

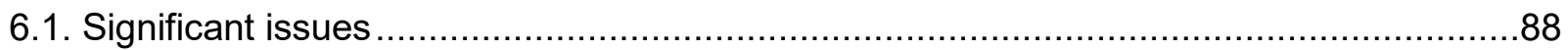

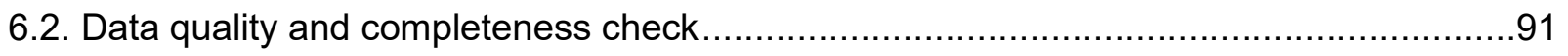

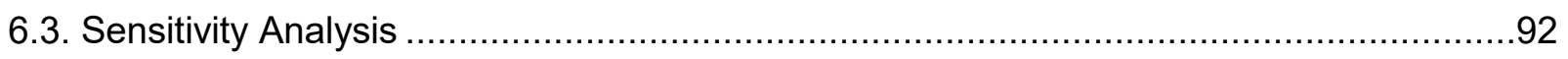

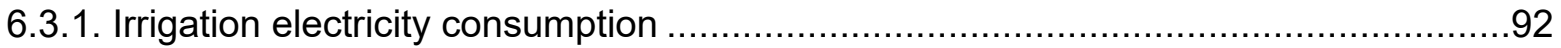

6.3.2. Proportion of fruit intake into packhouse from CA store ..................................93

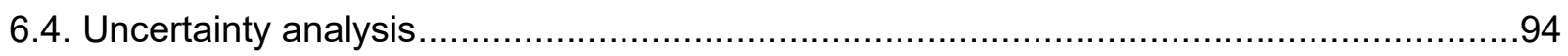

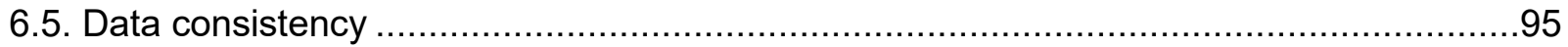

6.6. Industry revenues and resulting carbon intensity and efficiency of the South African pome

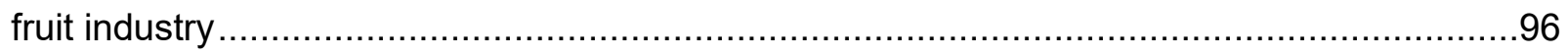

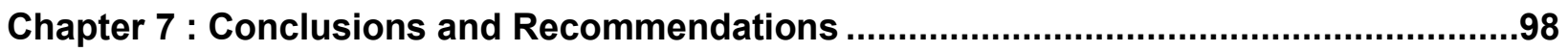

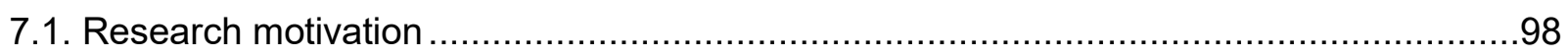

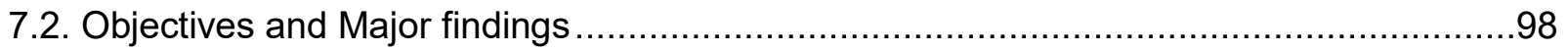

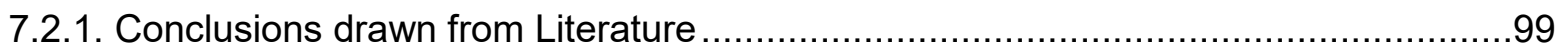

7.2.2. LCIA results and carbon intensity of the industry ...................................... 101

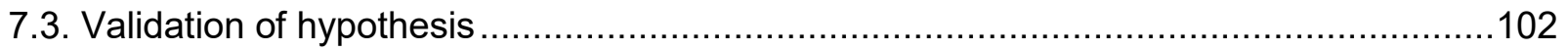

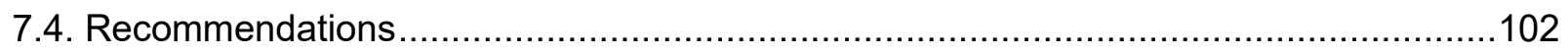

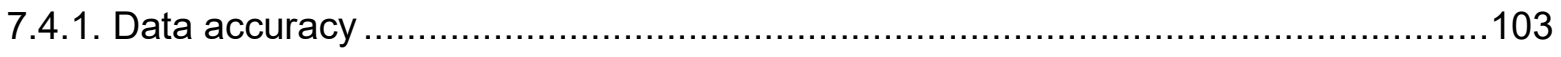

7.4.2. Reducing high GWP of electricity in South Africa ......................................103

7.4.3. Continuing along the decarbonisation path............................................... 103

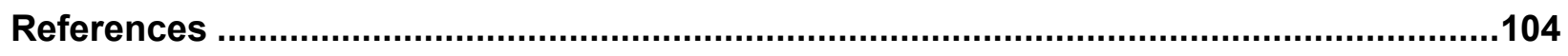

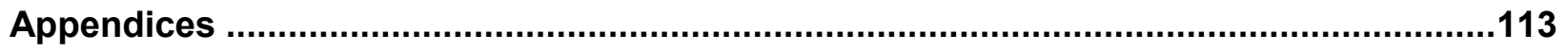

Appendix I : Life Cycle Inventory models for South African pome fruit industry .................114

Appendix II : Emissions to air, water and soil ...................................................... 117

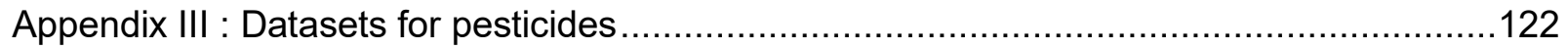

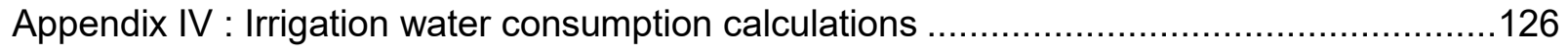

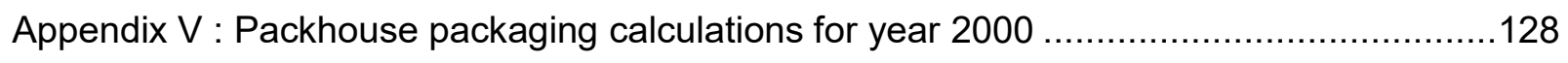

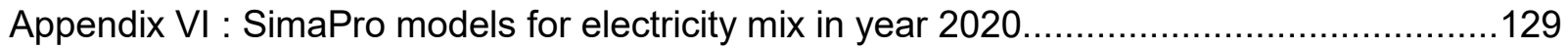

Appendix VII : Sankey diagrams (IPPC GWP 2013 100a) ..................................... 131

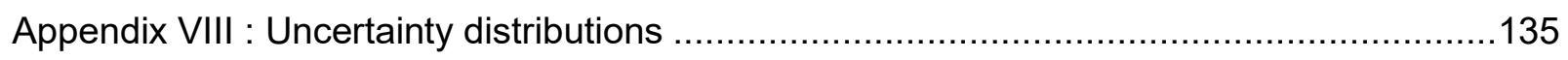




\section{List of Equations}

Equation 1: Formula to determine carbon intensity of pome fruit industry in year i. ................ 5

Equation 2: Formula to determine carbon efficiency indicator for each year......................... 5

Equation 3: Relationship between electricity consumption and economic output by Inglesi-Lotz \&

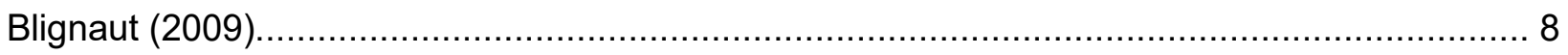

\section{List of Figures}

Figure 1: Pome fruit export volume per market in the 2013/2014 season (PPECB, 2014) ......... 1

Figure 2: South African surface water withdrawal in 2000 (du Plessis, 2007) ....................... 3

Figure 3: Carbon dioxide emissions from fuel combustion and cement production per real GDP (inflation adjusted) for South Africa (derived from "IEA - Report", n.d.) ................................. 4

Figure 4: South Africa has achieved relatively little decoupling of real GDP and CO2 emissions (OECD, 2013)

Figure 5: Preliminary economic size of the object of investigation (Frischknecht \& Stucki, 2010)

Figure 6: Phases of an LCA (International Organisation for Standardisation 2006a)

Figure 7: Climate change indicator results for five orchards in New Zealand (Milà i Canals,

Burnip \& Cowell, 2006: 232). 16

Figure 8: Contribution analysis of Ecoinvent dataset "Apple $\{G L O\}$ | production | Alloc Def, $U$ using impact assessment method GHG Protocol v 1.01.... 17

Figure 9: Workflow of research approach. .23

Figure 10: Schematic of pome fruit supply chain evolved from Ortmann (2005) ....................26

Figure 11: Apples in bulk bins in CA store (Fruitlogistica Exhibitors, 2016) .........................27

Figure 12: Pome fruit value chain product system diagram (inputs and outputs) ....................29

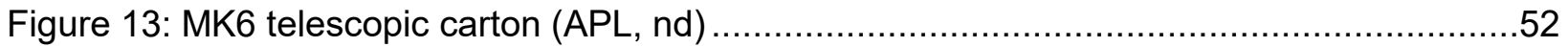

Figure 14: Wooden bin used for harvesting and storage in the CA Store. Source: Google images.

Figure 15: 2-way white block pallet $(23 \mathrm{~kg})$ used for export and local market. Source: Google images. .53

Figure 16: Planting configuration of apple trees around year 2010. .33

Figure 17: Single tree trellising for optimum picking. .57 


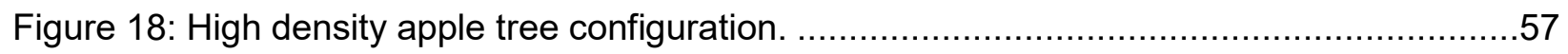

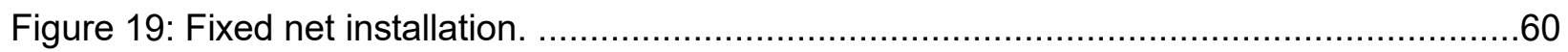

Figure 20: Projected total output in GWh from national grid derived from Eskom Annual reports.

Figure 21: Predicted packhouse PV capacity by year 2020 using CAGR. .65

Figure 22: Reusable plastic container used for apples (Singh, Chonhenchob \& Singh, 2006)...66 Figure 23: Example of apples packaged in flow wrap packaging format. Source: Freshplaza.com .67

Figure 24: Projected installed capacity (kWp) of PV at cold rooms by year 2020. .69

Figure 25: Elements of the LCIA phase (SANS 14042)...... 71

Figure 26: Impact category results for pome fruit value chain boundaries in year 2000 according to GHG Protocol and IPCC method. .73

Figure 27: Contribution of processes within pome fruit value chain in year 2000 to total GWP according to GHG Protocol and IPCC impact assessment methods.

Figure 28: Impact category climate change results for 2010 CCC pome fruit value chain boundaries for 2010 according to GHG Protocol and IPPC method.

Figure 29: Contribution of processes within 2010 CCC pome fruit value chain to total GWP (GHG Protocol \& IPCC) .

Figure 30: Impact category climate change results for 2010 (electricity agro-processing) pome fruit value chain boundaries according to the GHG Protocol and IPPC method.

Figure 31: GWP results for year 2010 after adjusting electricity consumption of CA and CS (GHG Protocol).

Figure 32: GWP results for year 2010 with adjustment to electricity consumption in CA and CS (IPCC).

Figure 33: Contribution of activities in year 2020 according to GHG Protocol and IPCC method.

Figure 34: Normalised GWP results for pome fruit industry.

Figure 35: LCIA GWP indicator results for all boundaries using GHG Protocol method. 89

Figure 36: LCIA GWP indicator results for all boundaries using the IPCC method. .90

Figure 37: GWP results per activity in pome fruit value chain according to GHG Protocol method.

Figure 38: GWP results with both scenarios of $25 \%$ and $75 \%$ fruit intake from CA (GHG

Protocol). .94

Figure 39: GWP results for pome fruit with error bars indicating the $95 \%$ confidence interval. ..95 
Figure 40: Carbon intensity trend since year 2000 for pome fruit industry. 97

Figure 41: Carbon efficiency indicator trend since the year 2000 for pome fruit industry.

\section{List of Tables}

Table 1: Yields per total hectare (bearing and non-bearing) from 2010 - 2015 derived from Hortgro (2015)...

Table 2: Comparison of ALCA and CLCA approach interpretation from Ekvall \& Andrae (2006)

Table 3: Relationships between the distinctions of ALCA/CLCA and retrospective/prospective.13

Table 4: Results from literature and other studies for LCA on apples \& pears for impact category

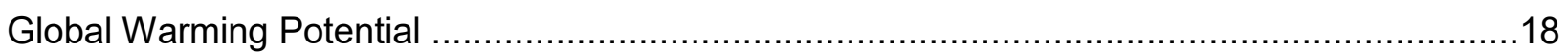

Table 5: Geographical spread of pome fruit cultivation in South Africa (Hortgro, 2015) ............28

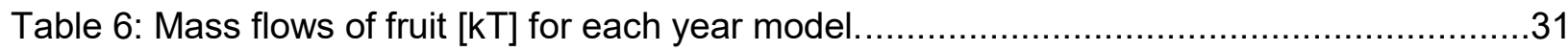

Table 7: Yield for apples and pears for the year 2000. Production includes local and export market, processed and dried (Deciduous Fruit Producers Trust, 2000)................................45

Table 8: Age grouping of apple and pear orchards as percentage of total hectares for $2006 \ldots 45$

Table 9: Water consumption figures of apples [kL/ha] for three regions ................................48

Table 10: Blue Water expected water consumption values per ton and per hectare for South

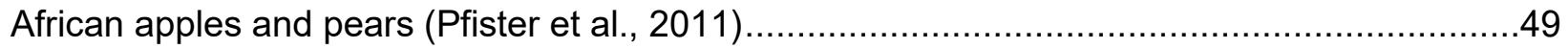

Table 11: Water consumption per ha per pome fruit growth phase (Hortgro, 2007).................49

Table 12: Total values for packhouse boundary for year 2000 ...........................................51

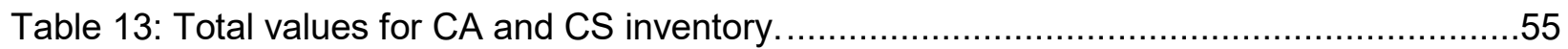

Table 14: Average tonnes/ha of apples and pears for year 2010 (Hortgro, 2014)....................33

Table 15: Total values for CCC inputs extrapolated to industry farming output for 2009/2010...34

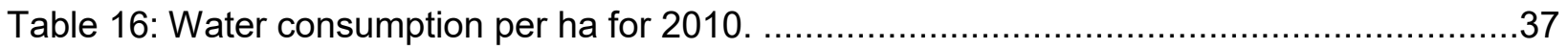

Table 17: Total values for Packhouse boundary sourced from CCC database 2011-2014

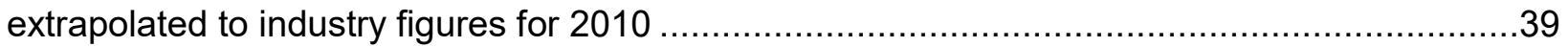

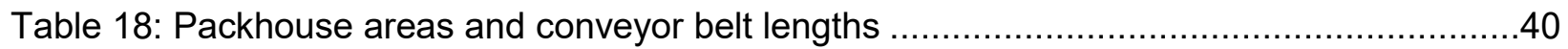

Table 19: Average water consumption per ton fruit in packhouses $(2010-2015) \ldots \ldots \ldots \ldots \ldots \ldots . . . . .41$

Table 20: Inputs for CA and RA store boundary from CCC database from 2011- 2014

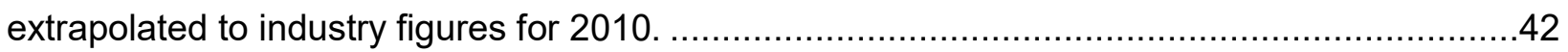

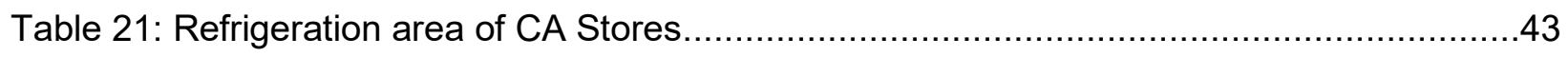


Table 22: Refrigeration area of CS.

Table 23: Updated and original grid electricity consumption values for CA and CS facilities for the year 2010. 43

Table 24: Projections for land occupation and total yield for year 2020 derived from BFAP (2016: 108) .56

Table 25: Projected annual generation in 2020 per technology type. 63

Table 26: Total inputs for packhouse boundary in year 2020. .64

Table 27: Inputs for CA and CS operations in year 2020. 69

Table 28: LCIA results for 2000 pome fruit value chain and boundaries using GHG Protocol impact assessment method

Table 29: LCIA results for 2000 pome fruit value chain and boundaries using IPCC impact assessment method.

Table 30: Contribution of activities across pome fruit value chain in year 2000 to total GWP according to GHG Protocol method.

Table 31: Contribution of activities across pome fruit value chain in year 2000 to total GWP (IPCC)......

Table 32: LCIA results for 2010 CCC pome fruit value chain (GHG Protocol). .....................76

Table 33: LCIA results for 2010 CCC pome fruit value chain (IPCC). .76

Table 34: Contribution of activities across 2010 CCC pome fruit value chain to total GWP according to GHG Protocol method.

Table 35: Contribution of activities across 2010 CCC pome fruit value chain to total GWP according to IPCC method.

Table 36: GWP results for 2010 (electricity agro-processing) value chain and boundaries using from GHG Protocol method.

Table 37: GWP results for 2010 (electricity agro-processing) value chain and boundaries from IPCC method.

Table 38: Contribution of activities across 2010 (electricity agro-processing) pome fruit value chain to total GWP according to GHG Protocol method.

Table 39: Contribution of activities across 2010 (electricity agro-processing) pome fruit value chain to total GWP according to IPCC method.

Table 40: GWP results comparison for electricity input for packhouse, CA and CS per kg fruit. 82 Table 41: LCIA results accumulated and per boundary according to GHG Protocol method.....82 Table 42: LCIA results accumulated and per boundary according to IPCC method. .83 
Table 43: Contributions of activities to total GWP of pome fruit value chain according to GHG

Protocol.

Table 44: Contributions of activities to total GWP of pome fruit value chain according to IPCC

method.

Table 45: Irrigation practices for each time period..................................................... 86

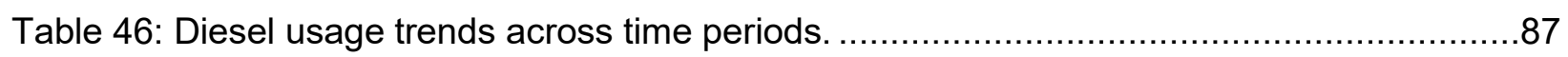

Table 47: Changes in nitrogen fertiliser application across time periods. ............................87

Table 48: Changes in packhouse and cold storage inputs and outputs. ................................87

Table 49: GWP indicator results for South African pome fruit for each year. .........................88

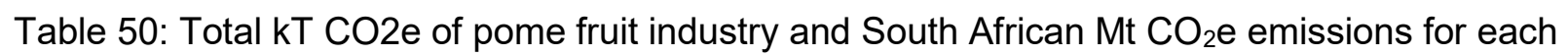

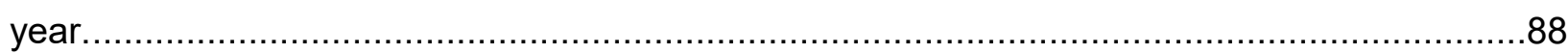

Table 51: GWP results for $2010 \mathrm{LCl}$ and $2010 \mathrm{LCl}$ with new irrigation electricity value. ...........93

Table 52: GWP results per ton pome fruit. ...........................................................96

Table 53: Annual industry revenue for Grade 1 and 2 apples and pears adjusted for PPI to 2010

ZAR.

.96

Table 54: GWP results for boundaries in global pome fruit industry and in this research.........100 


\section{List of Acronyms}

ACDI African Climate and Development Initiative

ALCA Attributional Life Cycle Assessment

BFAP Bureau for Food and Agricultural Policy

CA Controlled Atmosphere

CAGR Compound Annual Growth Rate

CCC Confronting Climate Change initiative

CLCA Consequential Life Cycle Assessment

Combuds Commercial Agricultural Budgets

COP Conference of the Parties

CPI Consumer Price Index

CS Cold Store

DD Deep Decarbonisation

DDPP Deep Decarbonisation Pathways Project

DEA-DP Department of Environmental Affairs and Development Planning

DoA Department of Agriculture

DoE Department of Energy

EP Environmental Purchasing

EPD Environmental Product Declarations

EU European Union

FAO Food and Agricultural Organisation of the United Nations

GDP Gross Domestic Product

GHG Green House Gas

GWP Global Warming Potential

HDPE High Density Polyethylene

IEA International Energy Agency

IPAP Industrial Policy Action Plan

IPCC International Panel on Climate Change

IRP Integrated Resource Plan

ISO International Standards Organisation

LCA Life Cycle Assessment

LCI Life Cycle Inventory

LCIA Life Cycle Impact Assessment 


$\begin{array}{ll}\text { LDPE } & \text { Low Density Polyethylene } \\ \text { NCCRP } & \text { National Climate Change Response Policy } \\ \text { NDP } & \text { National Development Plan } \\ \text { NERSA } & \text { National Energy Regulator of South Africa } \\ \text { OECD } & \text { Organisation for Economic Co-operation and Development } \\ \text { PH } & \text { Packhouse } \\ \text { PP } & \text { Polypropylene } \\ \text { PPA } & \text { Power Purchase Agreement } \\ \text { PPECB } & \text { Perishable Products Export Control Board } \\ \text { PPI } & \text { Producer Price Index } \\ \text { PPP } & \text { Purchasing Price Parity } \\ \text { PSEE } & \text { Private Sector Energy Efficiency } \\ \text { PV } & \text { Photovoltaic } \\ \text { RA } & \text { Regulated Atmosphere } \\ \text { REIPPP } & \text { Renewable Energy Independent Power Producers Programme } \\ \text { SANS } & \text { South African National Standards } \\ \text { SSEG } & \text { Small Scale Embedded Generation } \\ \text { UNFCCC } & \text { United Nations Framework Convention on Climate Change } \\ \text { USD } & \text { United States Dollars } \\ & \end{array}$




\section{List of Symbols}

\section{Chemical compounds}

CFCs Chlorofluorocarbons

CH4 Methane

$\mathrm{CO}_{2}: \quad$ Carbon dioxide

$\mathrm{CO}_{2} \mathrm{e}$ : Carbon dioxide equivalent

HFCs: Hydrofluorocarbons

K: $\quad$ Potassium

N: Nitrogen

$\mathbf{N}_{\mathbf{2}} \mathrm{O}$ : Dinitrogen monoxide

P: Phosphorus

PFCs: Perfluorocarbons

SF $_{6}$ : Sulphur hexafluoride

Mathematical and Modelling symbols

\section{Units of Measure}

GWh Gigawatt hours

kg Kilogram

kWh Kilowatt hour

L Litres

m Metres

$\mathrm{m}^{2} \quad$ Square metres

$\mathbf{m}^{3} \quad$ Cubic metres

Mt Megaton (1 million metric tonnes)

MWp Megawatt Peak 


\section{Chapter 1 : Introduction}

\subsection{Background}

Global trade in agriculturally produced food goods, especially fresh and processed fruit and vegetables, has increased sharply in the last 30 years due to increasing populations, rising incomes, consumer demand and all year round availability. The fresh and processed fruit and vegetable exports from developing countries made up $16.7 \%$ of total agricultural exports in 1980 and this increased to $21.8 \%$ by 2000 (Diop \& Jaffee, 2004: 237)

Production of fruit in South Africa increased significantly after the fruit sector was deregulated in 1997. Production volumes in tonnes grew by an annual average rate of $3.16 \%$ between 1997 and 2011 (Ntombela, 2012: 1). This growth is attributed to the growing export opportunities in export markets such as the European Union (EU) and the Middle and Far East; more efficient fruit production practices and the improvement of export cold chain and transporting systems. The export market generates a significant amount of revenue for South African fruit industry, as exported fruit has a greater unit price than on the local market.

In 2012, South Africa exported 500 thousand tons of pome fruit. The South African pome fruit exports contributed to $7.6 \%$ of total global pome fruit exports, making the country the seventh largest exporter globally. In general, $48 \%$ of pome fruit produced is exported (National Agricultural Marketing Council, 2014). The recent markets, based on production volumes, for South African pome fruit are in Figure 1 for the 2013/2014 season.

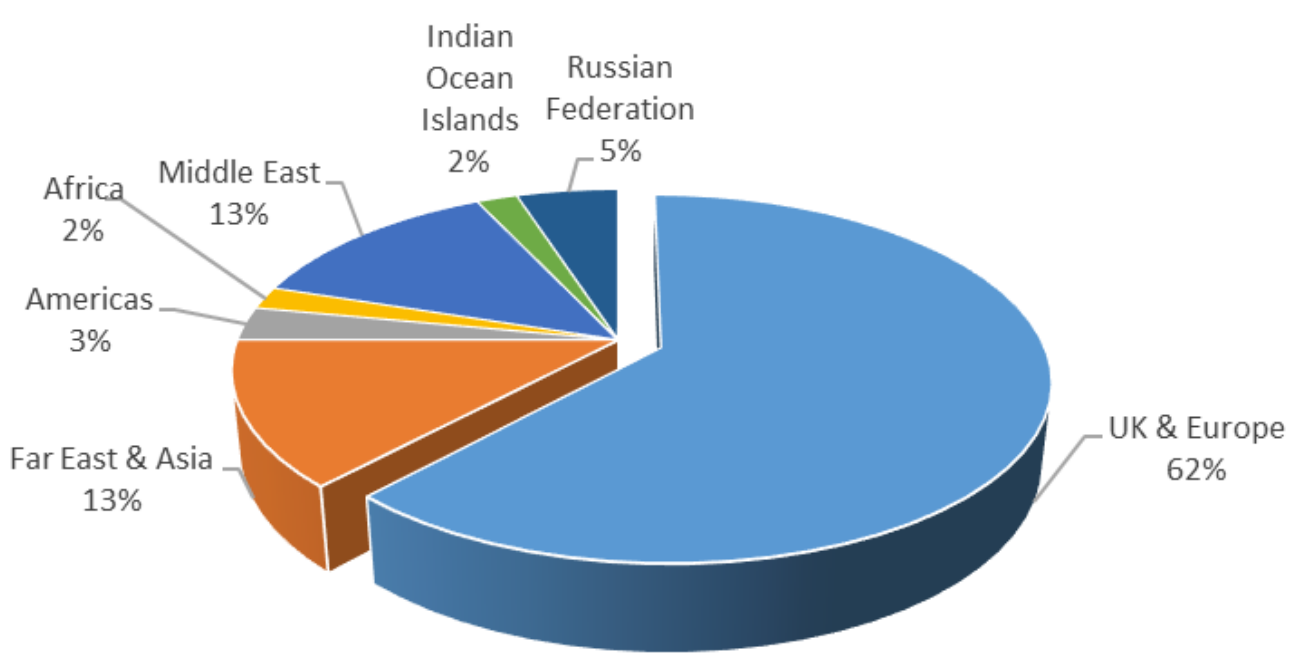

Figure 1: Pome fruit export volume per market in the 2013/2014 season (PPECB, 2014) 
The total turnover of the pome fruit industry was R8.2 billion in the 2014/2015 year (local and export). The United Kingdom and the Europe Union (EU) accounted for $62 \%$ of the total South African pome fruit exports in the 2013/2014 season at a value of R 3.4 billion (Hortgro, 2015). $96 \%$ of pome fruit is cultivated in the Western and Eastern Cape on approximately 32000 ha of land (Gush \& Taylor, 2014: 10) with an average yield of approximately 35 tons per hectare from 2010 to 2015, which included bearing and non-bearing hectares, as indicated in Table 1. Pome fruit is the largest fruit grouping amongst the deciduous fruit in terms of production volumes and area planted, earning $78 \%$ of the total deciduous fruit industry income. Pome fruit is thus considered important due to the contribution to GDP, foreign exchange earnings and employment creation (Gush \& Taylor, 2014: 18). It is thus argued by many stakeholders who benefit from this industry, that market access for South African pome fruit to the UK and EU is sustained.

\begin{tabular}{|c|c|c|r|r|r|r|r|}
\cline { 2 - 8 } \multicolumn{1}{c|}{} & \multicolumn{2}{c|}{$\begin{array}{c}\text { Hectares } \\
\text { [bearing \& non-bearing] }\end{array}$} & \multicolumn{2}{c|}{$\begin{array}{c}\text { Total production } \\
\text { [tonnes] }\end{array}$} & \multicolumn{2}{c|}{ Tonnes/Hectare } & \multicolumn{1}{c|}{$\begin{array}{c}\text { Tonnes/ } \\
\text { Hectare }\end{array}$} \\
\hline Year & \multicolumn{1}{c|}{ Apples } & \multicolumn{1}{c|}{ Pears } & \multicolumn{1}{c|}{ Apples } & \multicolumn{1}{c|}{ Pears } & \multicolumn{1}{c|}{ Apples } & \multicolumn{1}{c|}{ Pears } & Pome fruit \\
\hline $\mathbf{2 0 0 9 / 2 0 1 0}$ & 21554 & 11322 & 753167 & 373738 & 34.9 & 33.0 & 34.3 \\
\hline $\mathbf{2 0 1 0 / 2 0 1 1}$ & 21920 & 11561 & 768125 & 359877 & 35.0 & 31.1 & 33.7 \\
\hline $\mathbf{2 0 1 1 / 2 0 1 2}$ & 22167 & 11703 & 813191 & 360853 & 36.7 & 30.8 & 34.7 \\
\hline $\mathbf{2 0 1 2 / 2 0 1 3}$ & 22501 & 12034 & 907826 & 392249 & 40.3 & 32.6 & 37.6 \\
\hline $\mathbf{2 0 1 3 / 2 0 1 4}$ & 22925 & 12211 & 792324 & 413933 & 34.6 & 33.9 & 34.3 \\
\hline $\mathbf{2 0 1 4 / 2 0 1 5}$ & 23625 & 12697 & 920406 & 410840 & 39.0 & 32.4 & 36.7 \\
\hline
\end{tabular}

Table 1: Yields per total hectare (bearing and non-bearing) from 2010 - 2015 derived from Hortgro (2015)

However, the industry faces potential risks due to the perception that South African pome fruit has a high carbon footprint. The South African economy has in the past been categorised as a carbon intensive economy due to an energy and capital intensive development path and an associated set of economic activities termed the minerals-energy complex. All economic sectors rely heavily on coal fired electricity (Brent et al., 2002) with the consequence that South Africa ranks as one of the 20 largest emitters of GHG emissions. South Africa exports a substantial amount of its $\mathrm{CO}_{2}$ emissions embodied in its products, up to $30 \%$ in some cases, which is high in global comparison (Merven et al., 2014; Carbon Trust, 2011).

Products with high embodied carbon are at risk due to the growing awareness and demand for sustainable products especially from retailers and consumers in Europe and other developed countries. This in turn puts pressure on the value chains of agri-food products to be less resource intensive and have minimal impact on the natural environment, which if not implemented could translate to the creation of non-tariff trade barriers based on consumption embodied emissions (G.P. \& Hertwich, 2007). Recent research demonstrates that sustainability claims related to climate-impacts of products are understood by and influencing purchasing decisions of a currently small but growing sector of consumers in Europe (Buerke \& Gaspar, 2014). A representative study of attitudes toward environmental issues of German citizens highlighted an increased 
awareness of global and intergenerational cause-relations. $63 \%$ of those surveyed stated that sufficient protection of the environment and climate are the basic conditions for constructively solving future challenges such as globalisation. Only $18 \%$ of the respondents agreed with the statement that economic growth is superior to environmental protection. The continuation of the current modern lifestyle is increasingly perceived as a paradox as it leads to environmental destruction and a level of resource consumption which exceeds planetary boundaries (Umwelt Bundesamt, 2013).

Product supply chains with low carbon emissions are one of the key factors focussed upon within environmental sustainability, along with the sustainable use of water and the fostering of biodiversity. Agriculture in South Africa and Africa is the most vulnerable to environmental risks from climate change which will affect crop yields negatively (IPCC, 2014: 1218). The biggest challenge for the agricultural sector in South Africa is the low and variable rainfall and absence of rivers and lakes with reliable all year round yield. $90 \%$ of fruit and vegetable crops in South Africa are therefore irrigated (Gush \& Taylor, 2014: 1) which in turn uses 60\% of the total available surface water (du Plessis, 2007) translating into high electricity consumption to irrigate crops (Figure 2). Dependence on electricity generated from coal drives up the $\mathrm{CO}_{2} \mathrm{e}$ emissions released throughout the value chain from cultivation, to packaging and cold storage.

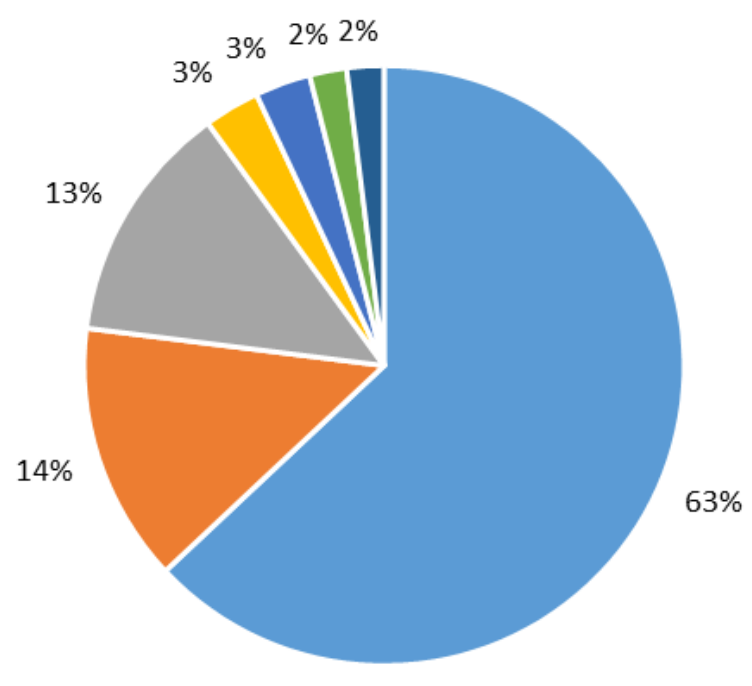

- Irrigation

- Urban/domestic

- Commercial

Mining

- Livestock

- Electricity

- Rural domestic

Figure 2: South African surface water withdrawal in 2000 (du Plessis, 2007)

Under the current circumstances it would be applicable to determine the trajectory of the carbon intensity of the national economy and various economic sectors. If the embodied carbon of products is declining it will count favourably for export markets, specifically for pome fruit. Figure 3 is derived from the International Energy Agency (IEA) indicator results of $\mathrm{kg}$ carbon dioxide 
$\left(\mathrm{CO}_{2}\right)$ emitted per real GDP linked to the Consumer Price Index (CPI) with base year 2005 for South Africa. The figure shows the relationship between inflation adjusted GDP with base year 2005 and $\mathrm{CO}_{2}$ emissions from fuel combustion (2005 USD/MtCO 2 ) each year since 1990.

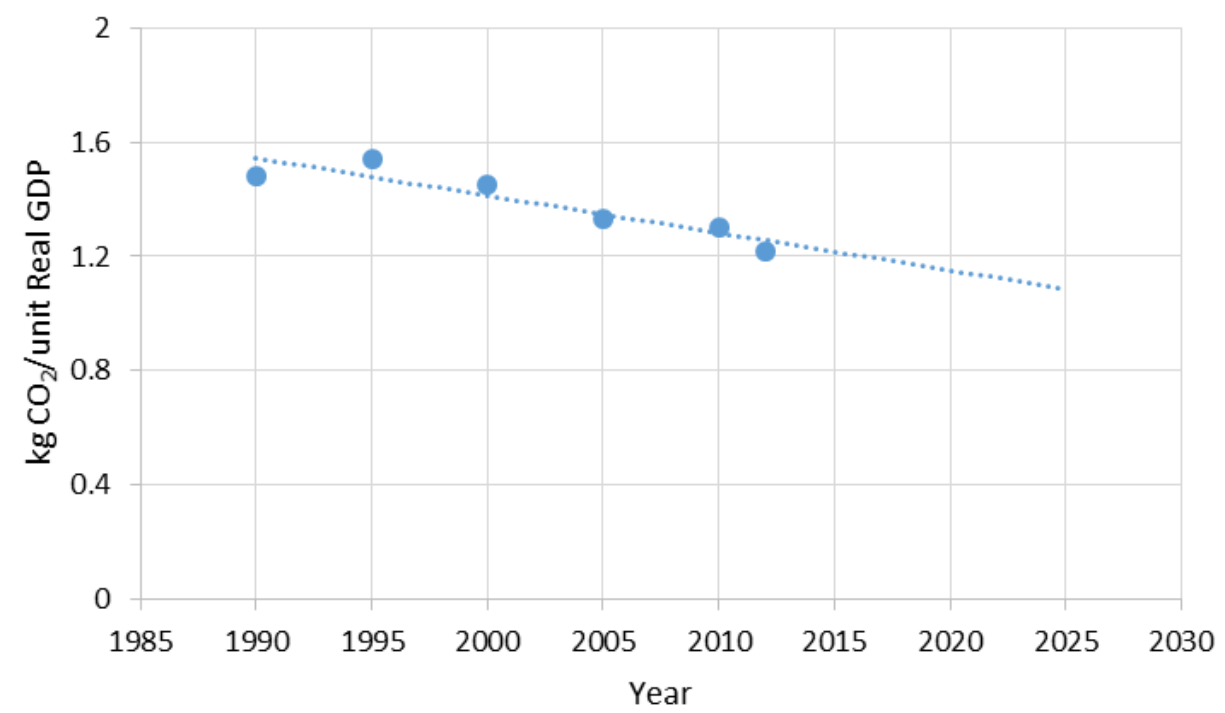

Figure 3: Carbon dioxide emissions from fuel combustion and cement production per real GDP (inflation adjusted) for South Africa derived from International Energy Agency (IEA), (2015)

It is clear that the carbon intensity of the South African economy has been declining since 1995 and is projected to continue a downward trend. From further investigation, one of the main reasons for the downward trend is due to real GDP more than doubling (108\% increase) in the period 1990 to 2012 ("Statistics South Africa", n.d.). The $\mathrm{CO}_{2}$ emissions have also increased but to a lesser degree at $48 \%$ from 1990 to 2012 according to the International Energy Agency (IEA, 2015). This indicates a relative decline or decoupling of $\mathrm{CO}_{2}$ emissions from economic growth, as the $\mathrm{CO}_{2}$ emissions. Even though there is a relative and not absolute decoupling of economic growth from $\mathrm{CO}_{2}$ emissions, the national economy and potentially other economic sectors are following a decarbonisation trajectory. The concept of decoupling, according to Ward et al. (2016), is described as either 'relative' (weak) or 'absolute' (strong). Relative decoupling, in the case of the South African $\mathrm{CO}_{2}$ emissions and GDP, refers to higher rates of economic growth than the rate of growth in $\mathrm{CO}_{2}$ emissions. Therefore, relative decoupling implies a gain in efficiency rather than removal of the link between national $\mathrm{CO}_{2}$ emissions and GDP. Absolute decoupling in this case, refers to declining $\mathrm{CO}_{2}$ emissions in parallel with economic growth.

\subsection{Problem Statement}

The South African fruit industry faces a twofold challenge. Firstly, the potential high risk of losing a part of the R 3.4 billion (2013/2014) annual revenue injection from the EU and UK market, due to trade barriers for products with high embodied carbon. Then secondly, the mitigation of carbon 
emissions within the fruit value chain and adaptation of agricultural practices to climate change is key to ensure the economic and social sustainability and climate resilience of the industry. The understanding of the trend in GHG emissions within the pome fruit industry over the course of 20 years is fundamental in developing mitigation strategies within this sector.

\subsection{Objectives}

The first objective of the research is to determine whether the GWP of the South African pome fruit industry is high compared to the GWP of pome fruit globally for each of the years 2000, 2010 and 2020. From here, the second objective is to determine whether there is a downward trend in the carbon intensity of the South African pome fruit value chain from cultivation at farm to cold store (CS) gate since the year 2000.

The first objective will be met through a literature review of temporally valid LCA studies done globally on pome fruit cultivation and agro-processing for impact category GWP which will then be compared to the GWP results for the South African pome fruit value chain in this research. These findings will indicate whether the GWP of South African pome fruit is relatively high for each of the years observed. The second objective will be met by determining the carbon intensity of the pome fruit industry for each year and using these results for a trend analysis. The carbon intensity per unit of revenue generated by the pome fruit industry will be calculated using the ratio of absolute $\mathrm{kg} \mathrm{CO}_{2} \mathrm{e}$ of the industry to gross industry revenue in the specific year adjusted to ZAR 2010 linked to the Producer Price Index (PPI). The PPI indicates changes in producer prices of locally produced commodities including exports, and is defined as "A measure of the change in the prices of goods either as they leave their place of production or as they enter the production process" (Statistics South Africa, 2014). The formula used to calculate the carbon intensity of the pome fruit industry in South Africa is in Equation 1.

$$
\text { Carbon intensity }_{i}=\frac{\text { total } \mathrm{kg} \mathrm{CO}_{2} e_{i}}{\text { total industry revenue PPI (ZAR 2010)i }}
$$

Where $i=$ year of $L C A$

Equation 1: Formula to determine carbon intensity of pome fruit industry in year i.

In addition, an International Standards Organisation (2012) compatible carbon efficiency indicator is also determined as the inverted value of the carbon intensity as shown in Equation 2.

Carbon efficiency indicator $i=\frac{\text { total industry revenue PPI }(Z A R 2010) i}{\text { total } \mathrm{kgCO}_{2} e_{i}}$

Where $i=$ year of $L C A$

Equation 2: Formula to determine carbon efficiency indicator for each year. 
It is proposed that the declining carbon intensity of the South African economy in Figure 3, has influenced the trajectory of carbon intensity of the pome fruit value chain.

\subsection{Scope}

The product system studied in this dissertation is defined as the South African pome fruit value chain from cultivation up to and including the cold store (CS). This includes only commercial fruit farming enterprises and not small holder or small scale farms. It does not include nursery cultivation of trees, transport to local and international markets or the use phase at the consumer. This is thus a cradle to gate study as defined by Publicly Available Standard (PAS) 2050:2011 and the International Standards Organisation (ISO) 14044: 2006 guidelines. The functional unit is $1 \mathrm{~kg}$ of grade 1 and 2 pome fruit (all varieties of apples and pears grown in South Africa) at the CS gate. Firstly a retrospective LCA is conducted for the years 2000 and 2010 and then a prospective LCA for the year 2020. The impact category Global Warming Potential (GWP) is determined for each of the years for the defined system and takes into account the following greenhouse gasses (GHG) released from activities in the product system:

- $\mathrm{CO}_{2}$ - Carbon dioxide;

- $\mathrm{N}_{2} \mathrm{O}$ - Nitrous oxide;

- $\mathrm{CH}_{4}-$ Methane;

- chlorofluorocarbons (CFCs);

- hydrofluorocarbons (HFCs);

- perfluorocarbons (PFCs) and;

- $\mathrm{SF}_{6}$ - Sulphur hexafluoride.

All results are expressed in carbon dioxide equivalents $\left(\mathrm{CO}_{2} \mathrm{e}\right)$, which include all the $\mathrm{GHGs}$, expressed as GWP with time horizon 100 years of South African pome fruit. Figure 12 indicates the foreground and the background processes that are included in the models.

The results from the time series LCAs are compared to the GWP results of pome fruit value chains from LCAs conducted in other countries in the literature. This comparison is to determine whether South African pome fruit had or has a relatively high carbon footprint. Thereafter, the carbon intensity and carbon efficiency indicator value of the South African pome fruit value chain is calculated according to the formulae in Equation 1 and Equation 2.

\subsection{Outlook}

Following the introduction and background of the research in Chapter 1, the literature review provides background for the carbon intensity of the South African economy, definitions and typologies of LCA and the application of ALCA on pome fruit internationally and locally in Chapter 2. The hypothesis of the research follows in Chapter 3 along with the goal and scope of the ALCA 
in the research and data sources used. From here the chapter sequence aligns with the phases of the LCA methodology of Inventory Analysis in Chapter 4 for the pome fruit value chain for the years 2000, 2010 and 2020 then Impact Assessment in Chapter 5 and Interpretation of results in Chapter 6 . Chapter 6 also includes a sensitivity and uncertainty analysis which falls under the Interpretation phase of the LCA methodology. The conclusions and recommendations are in Chapter 7 which revisits the motivation for this research followed by findings and validation of the hypothesis. 


\section{Chapter 2 : Literature Review}

The literature review will first provide the background to the South African national GHG emissions profile and reasons for the relatively high carbon intensity of the economy by international comparison. Mitigation interventions at a national and the agricultural sectoral level follow, indicating an ongoing transition to decarbonisation. Thereafter the different LCA definitions and typologies are discussed and reasons for applying the Attributional Life Cycle Assessment (ALCA) methodology in this research. The GWP results of LCA studies conducted on pome fruit internationally are analysed and limitations and further research areas identified.

\subsection{Carbon intensity of the South African economy}

As indicated in Section 1.1, South Africa is ranked one of the 20 largest emitters of GHG emissions globally. The main contributors to South Africa's relatively high GHG emissions is the energy sector and the high electrical intensity of the economy (Inglesi-Lotz \& Blignaut, 2012). The South African energy sector, which is a major input to all stages of the pome fruit value chain, is mainly dependent on coal as the primary energy provider and is the largest contributor to total national GHG emissions at $67 \%$. The energy sector includes the following activities (Stevens \& Witi, 2013: 23):

- Exploration and exploitation of primary energy sources primarily coal;

- Conversion of primary energy sources into more useable energy forms in refineries and power plants;

- Production and distribution of fuels derived from coal and;

- Final use of fuels in stationary and mobile applications (transport sector).

The energy sector alone saw an 88\% increase in GHG emissions from 1990 to 2010. Figure 4 shows that the percentage change of $\mathrm{CO}_{2}$ emissions to GDP year on year from the year 2000 to 2009 has increased, placing South Africa into Zone 2 of the graph (OECD, 2013). This indicates that there has not been an absolute decoupling of $\mathrm{CO}_{2}$ emissions from GDP. In addition, 92\% of electricity output is generated from coal (Burton \& Winkler, 2014). This carbon intensive electricity is a major input into the economy which is also categorised as being electricity intensive. Electrical intensity is the measure of electricity consumption and economic output presented in Equation 3. This value increases during periods of high economic growth and development and thereafter decreases when a shift to a service based economic structure takes place (Medlock \& Soligo, 2001).

$$
\text { Electricity intensity }=\frac{\text { electricity consumption }}{\text { output }}
$$

Equation 3: Formula to determine electricity intensity by Inglesi-Lotz \& Blignaut (2009) 


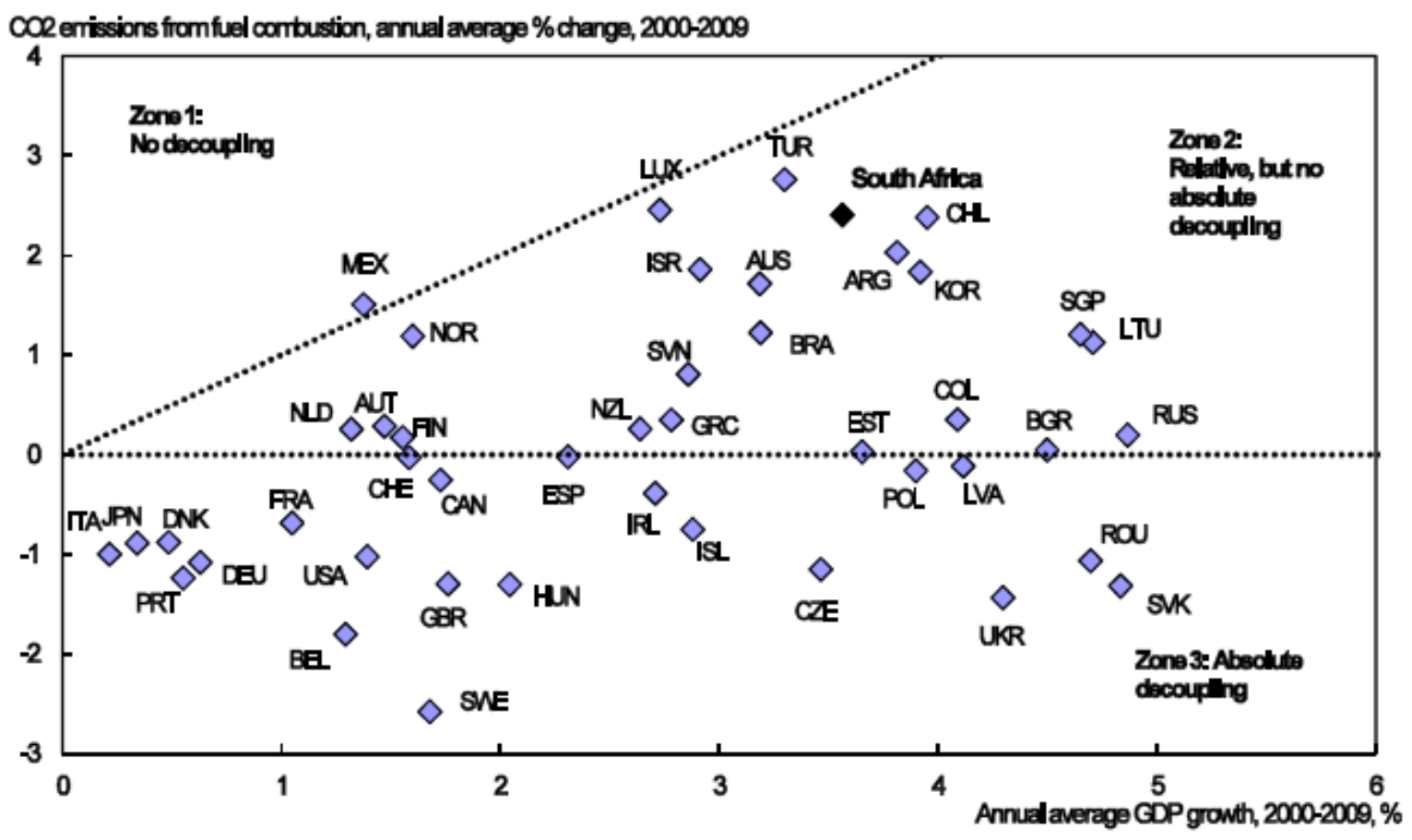

Figure 4: South Africa has achieved relatively little decoupling of real GDP and CO2 emissions (OECD, 2013)

This relationship between economic maturity and electrical intensity is comparable to the environmental Kuznet's Curve (Stern, 2003). The study by Inglesi-Lotz \& Blignaut (2012) compared South Africa's electrical intensity on a national and sectoral level to other member states of the Organisation for Economic Cooperation and Development. The findings during the study period 1990 to 2007 indicated that South Africa's electrical intensity was much higher than the OECD countries with an increase of $117 \%$ at a national level and $482 \%$ at a sectoral level. The reasons range from the cheap electricity which has hampered electrical efficiency initiatives, low production levels and lack of policy implementation such as the Energy Efficiency Strategy put forward by the Department of Energy in 2005.

However, since 1990 there has been a trend of decarbonisation due to the GDP growing at a faster rate than GHG emission as discussed in Section 1.1. This relative decoupling of the economy from $\mathrm{CO}_{2}$ e emissions supports the concept that economic growth and development can be compatible with decarbonisation (Waisman et al., 2015: 38). In the South African Deep Decarbonisation Pathways Project (DDPP), it was found that decreasing energy poverty and increasing access to electricity is compatible with Deep Decarbonisation (DD). In addition, DD can lead to improved income distribution which in turn reduces poverty and unemployment (Waisman et al., 2015: 45). At the Fifteenth session of the Conference of the Parties (COP 15) in 2009, South Africa pledged to voluntary reduce emissions of GHG as part of the Copenhagen Accord (National Treasury, 2013: 21). Following on from this, the National Climate Change Response Policy (NCCRP) was adopted in 2011 to promote adaptation and mitigation measures for a more sustainable growth trajectory (Department of Environmental Affairs, 2014: 2). The 
National Development Plan: Vision for 2030, which takes into account the recommendations of the NCCRP and promotes the adoption of a framework to transition to a sustainable low carbon economy, identifies key mitigation strategies to stabilise and then reduce GHG emissions (National Treasury, 2013: 26):

- An appropriate mix of pricing mechanisms which includes a carbon tax;

- An expanded renewable energy programme;

- An effective mix of energy efficiency and demand management incentives;

- Regulations to promote green buildings and construction practices and;

- Investment in an efficient public transport system.

Since then, there have been initiatives set up by the South African government in collaboration with the private sector to encourage the transition to a climate resilient, low carbon economy and society. Mitigation initiatives include the Industrial Policy Action Plan (IPAP), the Renewable Energy Independent Power Producer Plan (REIPPP) and the Private Sector Energy Efficiency (PSEE) programme for small, medium and large enterprises among others (ibid). Other measures include the potential introduction of a carbon tax, environmental legislation and support programmes for adaptation. South Africa is also a signatory to the Twenty-first session of the Conference of the Parties (COP 21) in 2015 in Paris ${ }^{1}$.

In the agricultural sector and specifically the fruit and wine industry, there are initiatives to measure and reduce carbon emissions which include, among others, energy audits and the Confronting Climate Change (CCC) Initiative ${ }^{2}$ currently funded by the various industry bodies. The use of renewable energy sources, specifically solar PV, for energy intensive activities in agriculture such as irrigation and cooling of product (Janse van Vuuren, Pineo \& Basson, 2016) not only reduces the carbon footprint of products but also ensures energy security and cost savings. The University of Stellenbosch have also recently released an energy management guideline commissioned by Winetech ${ }^{3}$ in 2014 for wineries. Apart from mitigation initiatives, climate change adaptation was addressed through the recently completed Smart Agriculture for Climate Resilience (SmartAgri) ${ }^{4}$ project between the Western Cape Department of Agriculture (WCDoA), the Western Cape Department of Environmental Affairs and Development Planning (WCDEA-DP) and the University of Cape Town's African Climate and Development Initiative $(A C D I)$. Some of the outputs of this project is a Climate Change Response Framework for the Western Cape agricultural sector and a road map for stakeholders to achieve greater climate resilience. These initiatives and other 'green' projects in the agricultural space can be viewed on

\footnotetext{
1 https://www.environment.gov.za/mediarelease/southafricasignsparisagreementonclimate

2 www.climatefruitandwine.co.za

3 http://winetech.co.za/Media/Default/Documents/Energy\%20guidelines Short\%20Version\%20(Oct\%202014).pdf

4 http://www.acdi.uct.ac.za/research/smartagri
} 
the GreenAgri ${ }^{5}$ portal jointly developed by the WCDoA and GreenCape - a sector development agency that supports businesses operating in the green economy.

\subsection{Life Cycle Assessment Definitions and Typologies}

The application of the life cycle concept offers the means to understand, manage and reduce the environmental impacts associated with a product, process or activity by considering all lifecycle stages, from 'cradle-to-grave'. In this study, an Attributional Life Cycle Assessment (ALCA) approach is used to determine the carbon intensity of the South African pome fruit value chain.

ALCA is defined as an approach to determine environmental impacts caused by a product system (Marvuglia et al., 2013) and includes the relevant physical flows to and from the system (Ekvall \& Andrae, 2006). A Consequential Life Cycle Assessment (CLCA) is defined as the approach to quantify the impact of changes outside the product system due to changes in supply or demand within the product system through chains of cause-effect relationships. Table 2 gives a comparison of the attributional and consequential LCA approach.

\begin{tabular}{cc}
\hline Attributional & Consequential \\
\hline Average data. & $\begin{array}{c}\text { Marginal data on bulk production processes in } \\
\text { background system. }\end{array}$ \\
\hline Unit processes within product life cycle. & $\begin{array}{c}\text { How environmental relevant physical flows to and } \\
\text { from life cycle change with changes within the life } \\
\text { cycle. }\end{array}$ \\
\hline $\begin{array}{c}\text { Inputs and outputs attributed to functional unit by } \\
\text { linking and/or partitioning the unit processes of the } \\
\text { system according to normative rules. }\end{array}$ & Allocation avoided by system expansion. \\
\hline $\begin{array}{c}\text { Use of physical inputs and outputs to a product } \\
\text { system. }\end{array}$ & Uses economic models to quantify causal \\
relationships.
\end{tabular}

Table 2: Comparison of ALCA and CLCA approach interpretation from Ekvall \& Andrae (2006) and (International Standards Organisation, 2006)

The Life Cycle Inventory (LCI) modelling approach is dependent on the economic size of the product system to be investigated according to Frischknecht \& Stucki (2010). The theory postulates that the economic size of a system determines the degree to which economic relations change from a decision, which in turn impacts the environmental size of the system. The cumulative environmental impacts of a product or system depend on mainly three aspects:

- The amounts of intermediate goods and services required;

- The suppliers of the intermediate goods and services;

5 http://www.greenagri.org.za/ 
- The environmental impacts of each individual unit process included in the product system at stake.

Therefore changes in economic relations within an economic system will directly affect the scale of environmental impacts of the object under investigation.

This 'economic size criterion' classifies objects under investigation into three groups to which the most appropriate LCI models are assigned namely; ALCA, Decisional and CLCA and delimits the three classes on their relative economic sizes of $0.1 \%$ and $1 \%$, respectively compared to their contribution to a total in Figure 5. The total is defined either as economical (i.e. total of economic sector or country) or political (i.e. the total of a country or region). The environmental impact results from these three $\mathrm{LCl}$ models differ as demonstrated by the impacts per kWh of electricity from different energy mixes in Frischknecht \& Stucki (2010). For the purposes of this LCA, the total value of fresh pome fruit production in the 2013/2014 year was R6.78 billion (Hortgro, 2015). The relative share of this industry to the Gross Domestic product of South Africa for this year was approximately $0.17 \%$, which falls into the medium economic size prescribed by Frischknecht \& Stucki (2010). This classifies the modelling approach to be either ALCA or decisional, however, the purpose of this study is to report on environmental impacts of the pome fruit industry and not as a decision support. Therefore the ALCA approach is adopted.

\begin{tabular}{ll}
\hline Economic size & Relative share \\
\hline Small & $<0.1 \%$ \\
Medium & $0.1 \%$ to $<1 \%$ \\
Large & $>1 \%$ \\
\hline
\end{tabular}

Figure 5: Preliminary economic size of the object under investigation in relation to the total size of an economic or political system (Frischknecht \& Stucki, 2010)

An ALCA can be retrospective, in that it determines the historical environmental impact from a current product state or prospective when looking at the impacts of the product system in a future state (Sandén \& Karlström, 2007:1470). As with ALCAs, CLCAs can also be retrospective and prospective as described by Weidema (2003:16) to provide causal explanations of the consequences of past or future actions. Table 3 provides an explanation on the differences between the temporal distinctions of the LCA methodologies.

The objective of the study is to determine the trend with regards to carbon emitted by the South African pome fruit value chain using a retrospective ALCA for the years 2000 and 2010 and a prospective ALCA for the year 2020. In all cases average data is used to determine the GWP of the product system in the past and future. The definitions and applications discussed align with the proposed methods to be applied in this research. 


\begin{tabular}{|l|l|l|}
\hline Attributional & Consequential \\
\hline Retrospective & $\begin{array}{l}\text { Allocation of responsibility to past } \\
\text { actions (Who shall we blame for the } \\
\text { way things are?) }\end{array}$ & $\begin{array}{l}\text { Causal explanation of consequences of } \\
\text { past actions (What would have happened } \\
\text { if we had or had not done this?) }\end{array}$ \\
\hline Prospective & $\begin{array}{l}\text { Allocation of responsibility for future } \\
\text { actions (Who shall we blame for the } \\
\text { way things will become?) }\end{array}$ & $\begin{array}{l}\text { Causal explanation of likely } \\
\text { consequences of future actions (What will } \\
\text { happen if we do or don't do this?) }\end{array}$ \\
\hline
\end{tabular}

Table 3: Relationships between the distinctions of ALCA/CLCA and retrospective/prospective.

\subsection{The Attributional Life Cycle Methodology}

The International Organisation for Standardisation (ISO) 14040 framework is used for the attributional LCA time series study. LCA systematically determines the environmental impacts of product systems from raw material acquisition to final disposal also referred to as "cradle to grave" (Weidema et al., 2013:6). The ISO 14040:2006 methodology identifies four main steps as set out in Figure 6 (ISO, 2006a):

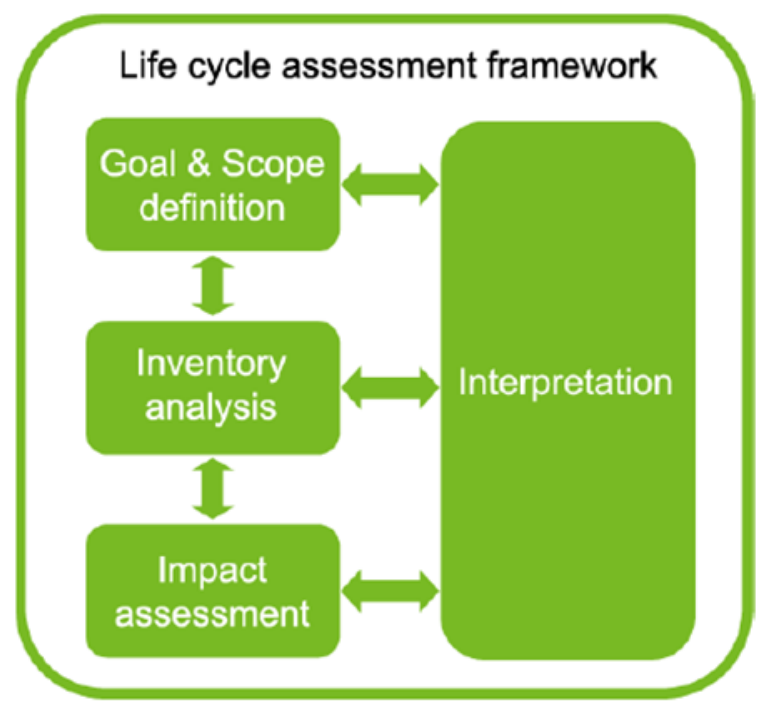

Figure 6: Phases of an LCA (International Organisation for Standardisation 2006a)

The Goal and Scope Definition (SANS, 2002a) needs to be clearly defined and consistent with the intended application. The goal of the study needs to address the intended application, reasons for the study and the intended audience. The scope of the study can understandably change due to the iterative approach of LCA, but the initial system boundaries, unit processes and data categories are required. This stage requires the functional unit and reference flow of the study and a simplified system model.

In the Inventory Analysis, the material flows of all inputs and outputs to and from the system are quantified followed by the data collection. All data sources, procedures and assumptions made 
for the relevant inputs and outputs of the system model need to be documented. The data collected must be validated with the next step being the allocation of the data to the unit processes.

The Impact Assessment is the third phase in the LCA process (SANS, 2002b) with the purpose to quantitatively assess a product system's $\mathrm{LCl}$ analysis results through the use of environmental impact categories and category indicators. For example, the impact category climate change has the category indicator GWP based on infrared radiative forcing $\left(\mathrm{W} / \mathrm{m}^{2}\right)$ with indicator result $\mathrm{kg}$ of $\mathrm{CO}_{2}$-equivalents. The classification process takes place when the $\mathrm{LCl}$ results are assigned to the impact categories where after the category indicator results are calculated through the characterization step. A number of impact assessment methods or characterisation models have been implemented in LCA software and analysis tools that can be used to obtain the LCl Analysis results depending on the goal of the study. The LCA software SimaPro ${ }^{6}$ is used for this research.

The Interpretation of the Results involves three stages which are the identification of the significant issues such as inventory data categories or impact categories, the evaluation of the results according to completeness, sensitivity and uncertainty and finally the reporting of conclusions and recommendations.

\subsection{Applications of Life Cycle Assessment on pome fruit globally and in South Africa}

LCA is a methodology used to assess the environmental impacts of a product or service through the several identified stages of the product's life. LCAs provide a holistic view of a system, and can thus be used to identify opportunities for improvement and decision making. LCAs typically examine environmental impacts over the complete cradle-to-grave life cycle (e.g. from raw material extraction to processing, manufacture, distribution, use, maintenance and disposal or recycling), although the scope can be reduced to consider smaller portions of the product or service life cycles; for example cradle-to-farm gate, cradle-to-port or cradle-to-consumer (Pineo, 2015: 5).

Up until 2002, the application of the LCA methodology on products and services in South Africa was focussed on the resources industry (metallurgical, fuels, energy), water treatments, waste treatments, paper, sugar and automotive industries (Brent et al., 2002). Since the initial findings on the status of Life Cycle Assessment in South Africa in the paper by Brent et al. (2002), there has been an expansion in areas already covered and new applications as indicated by the published research. The expansion of the use of LCAs in manufacturing and mining has given

\footnotetext{
6 SimaPro is a sustainability software application developed for LCAs on products and services: https://www.pre-
} sustainability.com/SimaPro 
rise to region specific characterisation and normalisation factors for LCIA impact category mined abiotic resource depletion (Strauss, Brent \& Hietkamp, 2006). New applications include LCAs within the water sector by Landu \& Brent (2007), Friedrich (2006) and Friedrich, Pillay \& Buckley (2009) where there has been a focus on water use and quality, mainly due to this being a significant constraint on economic expansion and environmental welfare.

LCAs have also been done in the municipal solid waste sector (Friedrich \& Trois, 2013) and textile industries ${ }^{7}$. From an agricultural perspective, environmental LCAs have been conducted on a wide range of agricultural products from livestock such as pork (Devers, Mathijs \& Kleynhans, 2012), beef $^{8}$, dairy (Notten \& Mason, 2010) and wool production (Brent, 2004), to wheat (Pineo, 2015), sugar cane (Mashoko, Mbohwa \& Thomas, 2010), and fruit (König, 2015). Alternative energy sources from the agricultural sector in South Africa have also been explored using LCA, and include the use of bagasse from the sugar cane industry for co-generation of electricity and production of fuel (Botha \& von Blottnitz, 2006). CLCA studies in South Africa have been attempted with a focus on decision support in coal based power generation (Notten \& Petrie, 2003) and Design for the Environment (DftE) in waste management

Internationally, LCAs in the agricultural sector have been used to determine resource intensity and environmental impacts of a wide range of products. ALCA, specifically on pome fruit cultivation, has been done in countries such as New Zealand (Milà i Canals, Burnip \& Cowell, 2006), Switzerland (Mouron, Nemecek, et al., 2006) and (Mouron, Scholz, et al., 2006) at farm level and in China (Liu et al., 2010) and Canada (Keyes, Tyedmers \& Beazley, 2015) for multiple boundaries within the value chain.

The Milà i Canals, Burnip \& Cowell (2006) study, applied the ALCA method to three commercial and two reference apple orchards in New Zealand to determine whether there were environmental improvement opportunities in these production systems. The findings were that more than $50 \%$ of environmental impact results was due to energy related emissions. Impact category climate change was dominated by energy related $\mathrm{CO}_{2}$ emissions which contributed between 34 to $50 \%$ of total $\mathrm{CO}_{2}$ emissions depending on the orchard. The significant contributors were from the production and application of fertilisers, specifically urea, and agricultural machinery use. For the farm boundary, the GWP per tonne of grade 1 and 2 apples ranged between 0.04 to $0.095 \mathrm{~kg}$ $\mathrm{CO}_{2}$ (Figure 7).

7 http://tgh.co.za/case studies/screening-life-cycle-assessment-of-textiles-retailed-in-south-africa/ 8 http://tgh.co.za/case studies/life-cycle-assessment-of-south-african-and-namibian-beef-retailed-insouth-africal 


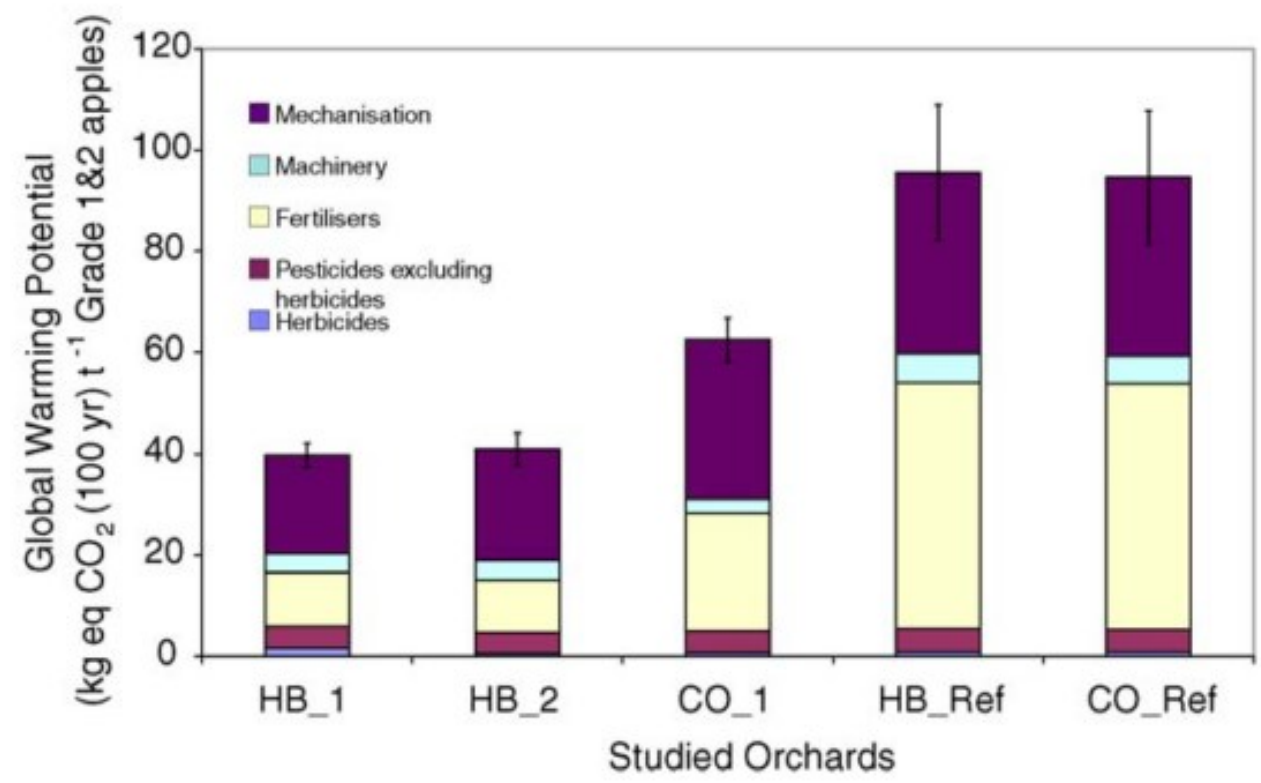

Figure 7: Climate change indicator results for five orchards in New Zealand (Milà i Canals, Burnip \& Cowell, 2006 : 232)

Swiss apple orchards have benefited from at least two ALCA studies. The first is the Mouron, Nemecek, et al. (2006) paper which investigated to what extent the management of orchards affects the environmental impacts. The ALCA method was used to determine the environmental impacts and then a Principal Component Analysis (PCA) performed to group the environmental impacts according to their correlation. It was found that impact categories energy use, aquatic ecotoxicity and aquatic eutrophication were influenced independently of each other and can be managed by keeping the use of machinery, pesticides and fertilisers to a minimum. The conclusion was that the farming system (organic vs. integrated) is not the only driver of environmentally sound apple farming but is also heavily dependent on the orchard management. In the second study by (Mouron, Scholz, et al., 2006), the purpose was to understand the relationship between income and environmental impacts at farm level. Using ALCA it was found that an increase in environmental impacts such as ecotoxicity, non-renewable energy use and eutrophication does not lead to an increase in farm income and in addition an increase in machinery use, pesticide and fertiliser application does not lead to increased yield. Rather a higher farm income with high eco-efficiency is attributed to the choice of apple cultivars and high investment in pre-harvest labour hours.

An ALCA was conducted in China in 2010 by Liu et al. (2010) on the pear value chain which included the orchards, agro-processing and delivery to market boundaries. The fossil energy use and GWP was determined for five production chains covering different regions in China over the course of a production season. It was found that the application of synthetic fertilisers and storage during the processing stage had the largest impact on GHG emissions and fossil energy use. However, a comparison on the performance of the different production chains was more complex 
and did not depend on different farming and storage practices but on site specific factors such as topography, market demands and local farming practices. Even with the conclusions dependent on site specific factors, the LCA approach was still recommended to guide the selection of inputs into the production chains with GHG and fossil energy mitigation potential. A similar LCA on conventional and organic apples was done in Nova Scotia, Canada by Keyes, Tyedmers \& Beazley (2015) which covered multiple boundaries and transport to markets. There are similarities with the South African industry due to $57 \%$ of electricity generation in Nova Scotia is based on imported coal. The results for conventional apple farming, packhouse and cold storage are in Table 4.

Another Swiss ALCA study on pome fruit in this review led to the creation of the ecoinvent unit process dataset "Apple \{GLO\} | Production | Alloc Def U" by Stoessel et al. (2012). The purpose of this research titled "Life cycle inventory and carbon and water footprint of fruits and vegetables: application to a Swiss retailer", was to create $\mathrm{LCl}$ data for fruits and vegetables and an environmental decision support tool for Swiss retailers. The carbon assessment found that the main contributors to $\mathrm{CO}_{2} \mathrm{e}$ emissions were the air transport of products that are imported and greenhouse heating for out of season produce. It was recommended that retailers use this information from the ALCA to decide from where to source produce and also work in collaboration with producers to improve the environmental impacts of certain products. Consumers were also encouraged to buy local and in season produce to avoid the impacts from air transport and greenhouse heating. Figure 8 shows the result of $0.27 \mathrm{~kg} \mathrm{CO} \mathrm{CO}_{2} \mathrm{e} / \mathrm{kg}$ apples for impact category climate change for a global apple at farm gate using the Greenhouse Gas Protocol V1.01/ $\mathrm{CO}_{2} \mathrm{e}$ (kg) impact assessment method.

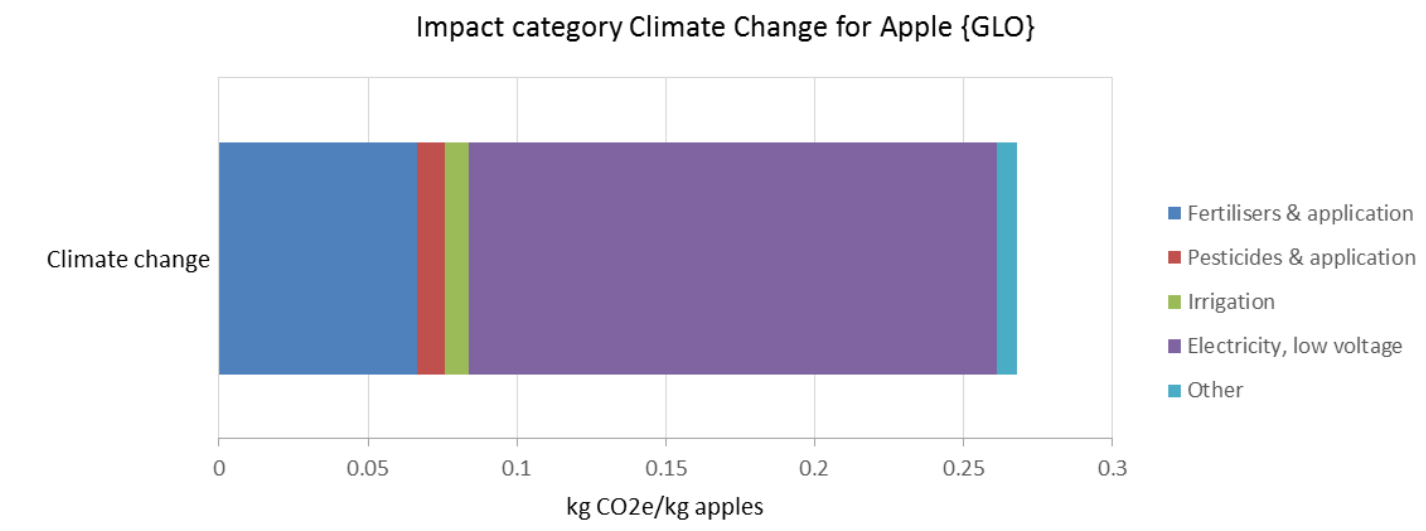

Figure 8: Contribution analysis of ecoinvent dataset "Apple $\{G L O\} \mid$ production | Alloc Def, U using impact assessment method GHG Protocol v 1.01

A summary of results from the literature and other sources for each boundary in apple and pear value chains is in Table 4. 


\begin{tabular}{|c|c|c|c|c|}
\hline Source & $\begin{array}{l}\text { Geographical } \\
\text { area }\end{array}$ & $\begin{array}{l}\text { Impact Assessment } \\
\text { method }\end{array}$ & Boundaries & $\begin{array}{l}\mathrm{Kg} \mathrm{CO}{ }_{2} \mathrm{e} / \mathrm{kg} \\
\text { fruit }\end{array}$ \\
\hline \multirow{4}{*}{$\begin{array}{l}\text { Confronting Climate } \\
\text { Change Benchmark } \\
\text { report (Blignaut \& de } \\
\text { Kock, 2015) }\end{array}$} & \multirow{4}{*}{$\begin{array}{l}\text { South Africa, } \\
\text { Western and } \\
\text { Eastern Cape }\end{array}$} & \multirow[t]{4}{*}{ PAS 2050: 2011} & Farm & 0.20 \\
\hline & & & CA Store & 0.17 \\
\hline & & & Packhouse & 0.11 \\
\hline & & & Cold Store & 0.17 \\
\hline \multirow[t]{4}{*}{ (König, 2015) } & \multirow[t]{4}{*}{ South Africa } & \multirow[t]{4}{*}{ IPCC 2013 GWP 100a } & Farm & 0.29 \\
\hline & & & Packhouse & 0.13 \\
\hline & & & Cold Store & 0.19 \\
\hline & & & Domestic transport & 0.06 \\
\hline \multirow{3}{*}{$\begin{array}{l}\text { Apple }\{\text { GLO }\} \mid \\
\text { production | Alloc Def, } \\
\cup \quad \text { (Stoessel et al., } \\
2012)\end{array}$} & \multirow[t]{3}{*}{ Global } & \multirow[t]{3}{*}{ IPCC 2013 GWP 100a } & Seedling production & \multirow{3}{*}{0.27} \\
\hline & & & Farm & \\
\hline & & & Transport to retailer & \\
\hline $\begin{array}{l}\text { (Milà i Canals, Burnip } \\
\& \text { Cowell, 2006) }\end{array}$ & New Zealand & & Farm & $0.04-0.095$ \\
\hline $\begin{array}{l}\text { (Mouron, Nemecek, et } \\
\text { al., 2006) }\end{array}$ & Switzerland & $\begin{array}{l}\text { GWP } 100 \text { years } \\
\text { (Houghton et al., 1996) }\end{array}$ & Farm & $0.05-0.12$ \\
\hline \multirow[t]{3}{*}{ (Liu et al., 2010) } & \multirow[t]{3}{*}{ China } & \multirow[t]{3}{*}{ IPCC 2007} & Farm & $0.06-0.38$ \\
\hline & & & $\begin{array}{l}\text { Processing (no } \\
\text { packaging) }\end{array}$ & $0.005-0.16$ \\
\hline & & & Transport & $0.003-0.007$ \\
\hline \multirow{2}{*}{$\begin{array}{l}\text { (Keyes, Tyedmers \& } \\
\text { Beazley, 2015) }\end{array}$} & \multirow[t]{2}{*}{ Canada } & \multirow{2}{*}{$\begin{array}{l}\text { ReCiPe H (IPCC } 2013 \\
\text { GWP 100a) }\end{array}$} & Farm & 0.14 \\
\hline & & & Packaging \& CS & 0.19 \\
\hline
\end{tabular}

Table 4: Results from literature and other studies for LCA on apples \& pears for impact category Global Warming Potential

\subsection{Limitations and further research areas}

A general limitation of ALCA is the uncertainty of the models due to the fact that they are a representation of reality. This uncertainty stems from the following (Finnveden, 2000):

- Not all the environmental impacts are considered;

- Geographic regional specific data is not always available;

- Uncertainties in describing the real world and future scenarios;

- Data gaps and assumptions and;

- Choice of methodologies used.

With the focus on fruit production systems and value chains in this research, Cerutti et al. (2011) identified limitations with the application of ALCA in this sector at farm level. Orchard systems, more than any other food production system, is a complex interlink between the natural and 
technical sphere. Cerutti et al. (2011) suggest that the standardisation of environmental assessment methods, ALCA included, needs to consider these complexities going forward to ensure comparability and credibility of the results. Data availability to determine resource intensity of fruit farming is also limited.

From the literature reviewed in Section 2.4, it was found that most of the LCAs on pome fruit were conducted at farm level only, except for the ALCA on pears in China by Liu et al. (2010) and an ALCA on organic and conventional apple cultivation in Canada by Keyes, Tyedmers \& Beazley (2015). Further research in applying the ALCA method for multiple boundaries in the fruit value chain in other geographical areas, specifically developing countries, could enrich the available data and shed light on practices in these areas. In addition these studies were based on a snapshot of the environmental impacts and did not include a retrospective or prospective view. ALCAs which included a prospective and retrospective view are mainly in industries other than agriculture. From international literature the application of prospective ALCAs have taken place in the energy sector to determine impacts of future energy mixes (Curran, Mann \& Norris, 2005; Weinzettel et al., 2008; Raugei \& Frankel, 2009), new technologies for energy production and storage (Collet et al., 2011; Wender \& Seager, 2011), future transport systems (Spielmann et al., 2005) and other novel carbon mitigation technologies (Sathre \& Masanet, 2013). The closest prospective ALCAs have come to the agricultural sector were applications in food waste management (Lundie \& Peters, 2005) and a decision support tool for the case of local food production in sustainably designed systems (Yang \& Elliot-Campbell, 2017).

For the fruit sector in South Africa, the first ALCA was done by König (2015) to identify environmental hotspots in the value chain and the implementation of possible clean technologies to reduce these impacts. According to the known literature, the application of ALCA to determine trends in the environmental impacts of agricultural products has not been attempted in South Africa or internationally at this point in time. This research attempts to conduct one of the first retrospective and prospective ALCAs on an agricultural product across multiple boundaries to determine the trend of the environmental impact category Climate Change.

\subsection{Areas for new applications}

In South Africa the uptake and use of LCA has been slow and mainly used for exported products due to international trade pressure and a few local applications (Brent et al., 2002:168) to manage resource intensity and environmental burdens of products and systems. Up until recently there have been relatively few LCA studies done within the agricultural sector despite concerns regarding the resource intensity and environmental impact of this sector and the pressures from developed countries importing South African agricultural products. An understanding of the trends in GHG emissions from the agricultural and specifically the fruit sector is necessary in the formulation of sector specific mitigation and adaptation strategies. In addition, with South Africa being a major exporter of carbon, up to $30 \%$ of embodied carbon in export products (Brent et al., 2009), it is imperative to understand the trend of embodied carbon in export agricultural products 
over time in order to manage the trade related risks associated with stricter and binding international climate-change trade limitations. Building up regional Life Cycle Inventories for the agricultural sector also has multiple strategic benefits as found in the Australian Agricultural LCl project and include (Pineo, 2015):

- Supporting agri-businesses and industries;

- Enabling local producers to gain access to international markets;

- Ensuring that Australian primary producers can easily and objectively demonstrate that their products are being produced in a responsible manner;

- Provides intensity and impact benchmarks for key commodities and sub-sectors.

In the South African context, the application of a time series ALCA on the pome fruit value chain will contribute to regional agricultural LCls and add new knowledge with regards to identifying 'hot spots' and trends of environmental impacts in the South African agricultural sector. This research will build on existing LCAs done on pome fruit by including regional data in the LCls, address data and scenario uncertainty through uncertainty and sensitivity analysis and provide insight into the trends of environmental impacts in the pome fruit industry.

\subsection{Summary}

Over the last decade there has been a shift within companies, governments and global organisations to examine the environmental impact of products and services across the economy, particularly for primary industries such as agriculture which is constrained by limited land and water resources. This has resulted in environmental product declarations (EPDs) and delivery agreements, whereby the supplier is required to demonstrate their environmental sustainability and implement on-going programmes to improve their performance. Procurement strategies aligned with environmental purchasing (EP) is also gaining traction at the retailer level pressured by consumer expectations. Although this movement has been driven primarily by global and regional organisations (e.g. UN, IPCC, EU) and developed countries (e.g. UK, Australia and New Zealand), the less developed countries such as South Africa have, and will continue to be, impacted due to their role in global value chains (Pineo, 2015).

The carbon intensity of the South African economy has been on the decline since 1990. This relative decoupling of economic growth from carbon dioxide emissions has been due partly to the transition from a capital intensive primary sector economy to a services based economy and the extraordinary economic growth since the late 1990s. Decarbonisation of the economy has been encouraged by government through policy and regulation as well as programmes in collaboration with the private sector. Within the agricultural sector, specifically fruit and wine, the various industry bodies have developed the CCC initiative to measure GHG emissions and provide support to stakeholders in climate change mitigation and adaptation. Various other mitigation and 
adaptation projects and support have been initiated by the WCDoA and Green Cape among others.

LCA in South Africa has been applied mainly in the resources and manufacturing sectors with some agricultural applications in alternative energy sources from sugar and oil crops, wool production and livestock. Specifically for pome fruit, LCAs have been done in Europe, China, Canada and New Zealand. Most LCAs have only focussed on the farm boundary with a few including seedling production, packaging, cold storage and transport to market. A regional LCA on pome fruit was done by König (2015) and included multiple boundaries using data from the CCC initiative. The limitations and drawbacks of these pome fruit LCA studies include among others data gaps, data uncertainties and the lack of regional geographic data. These limitations are attempted to be addressed in this ALCA, especially the data uncertainty using Monte Carlo analysis and scenario uncertainty using sensitivity analysis.

Globally the application of LCA for decision support and policy decisions is widespread and accepted. In South Africa there has been a slow recognition of LCA to fulfil this function but it is now expanding to all sectors of industry due to international pressure and the transition to a greener economy (Department of Environmental Affairs and Energy, 2013). The time series ALCAs that are attempted in this research to determine the trend of the GWP of South African pome fruit will be the first attempt to apply retrospective and prospective ALCAs on a regional agricultural product, identify environmental 'hot spots' in the value chain and inform stakeholders of the trend in the carbon intensity of the industry. 


\section{Chapter 3 : Approach and Methodology}

\subsection{Hypothesis and Research questions}

Given the high but declining carbon intensity of the South African economy $\left(\mathrm{kg} \mathrm{CO}_{2} \mathrm{e} / \mathrm{Real}\right.$ GDP 2005 USD, as presented in chapter 1), and modernisation in the pome fruit industry (discussed in chapter 2), it is hypothesised that the relative global warming potential (GWP; i.e. per kg fruit produced in the pome fruit value chain in South Africa) was high by international comparison but has decreased since the year 2000 leading to a decreasing carbon intensity of this industry and its products. To test this hypothesis, a time series ALCA is developed and presented for the South African pome fruit value chain for the years 2000, 2010 and 2020 with results for the midpoint impact category Climate Change. In addition, trends in eco-efficiency are identified which align with the decreasing trend in carbon intensity and increasing trend of the carbon efficiency indicator.

\section{From the above, the research questions are formulated as follows:}

1. Can the GWP indicator result of South African pome fruit be reconstructed for the year 2000 , and was it relatively high compared to global results?

2. By 2010 , had the GWP result and carbon intensity of the South African pome fruit value chain decreased relative to 2000 ?

3. Is there an ongoing decarbonisation representing a true decoupling of productivity in this industry from carbon emissions? Can such trends be used to project the carbon intensity of South African pome fruit for $2020 ?$

\subsection{Specific objectives/ Methods (flowchart from hypothesis)}

Figure 9 shows the steps taken to support the hypothesis in Section 3.1. The steps follow the phases of an LCA presented in Section 2.3.

\subsection{Research Ethics}

Ethics relates to the sources of the data and objectivity in the interpretation of the results. Research ethics were considered and no clearance was required from the EBE ethics in research committee. All raw data required for the LCAs (foreground processes) is kept anonymous. This includes economic and consumption data throughout the value chain. 


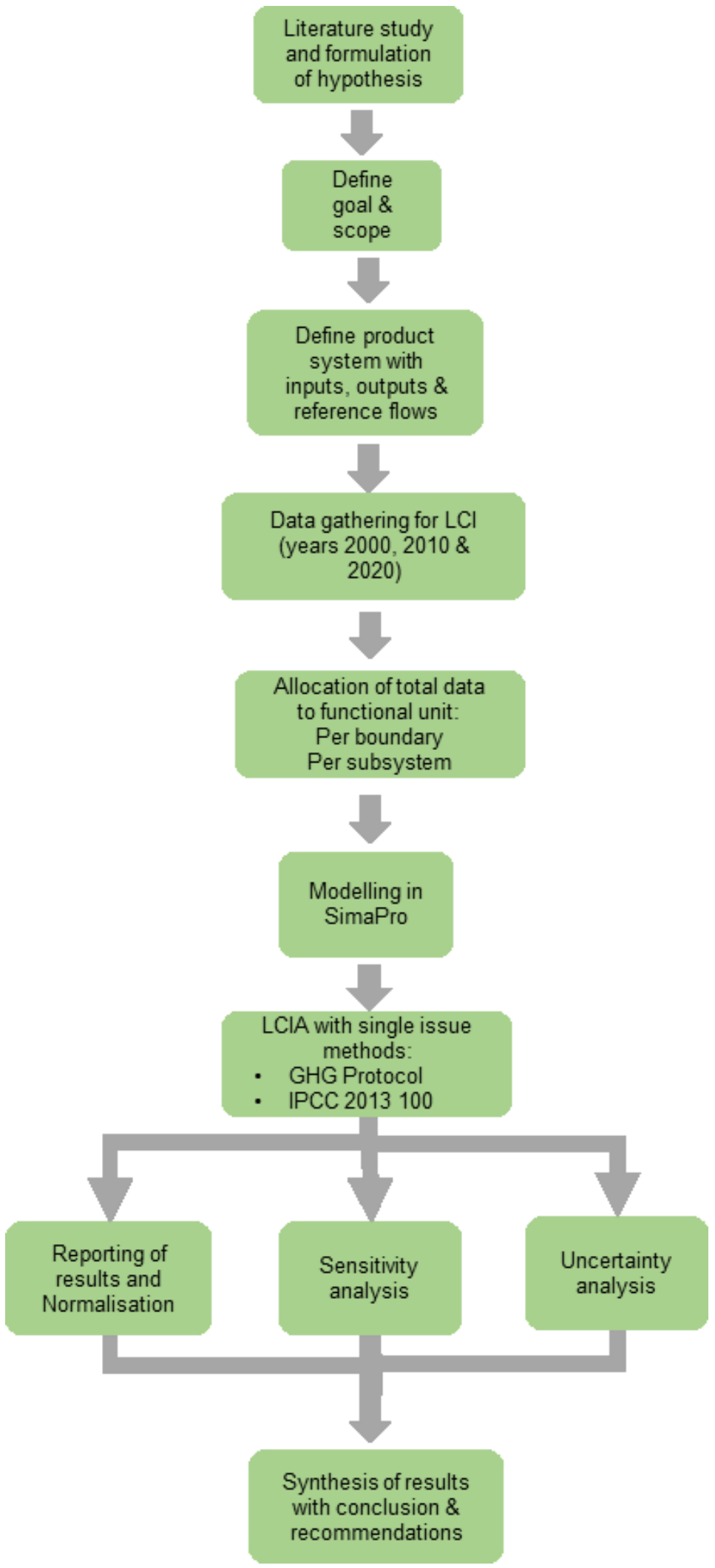

Figure 9: Workflow of research approach 


\subsection{Resources}

Resources used for the data gathering stage of the Life Cycle Inventory (LCI) include the following:

- Commercial Enterprise Budgets (Combuds) for pome fruit cultivation from the Western Cape Department of Agriculture;

- Consumption data from the Confronting Climate Change database;

- Macro-economic data from Hortgro and National Agricultural Marketing Council;

- ecoinvent v. 2.2, 3.0 and 3.3 database for foreground and background processes;

- South African energy mix data from Eskom Annual reports, Integrated Resource Plan 2010 - 2050 and National Development Plan Vision 2030;

- Water consumption data from the Water Research Council research papers and regional and international literature;

- Consultation with industry experts.

The system modelling for the Life Cycle Impact Assessment for the ALCA study was done on SimaPro v. 8.3 LCA software.

\subsection{Goal and Scope}

The goal of the LCA presented in the remainder of this dissertation is to substantiate the hypothesis that the GWP results and subsequent carbon intensity of the South African pome fruit industry is high by global comparison, but declining over time. The ALCA time series approach for 10 yearly intervals follows the ISO 14040:2006 framework and is cradle to gate. The following boundaries are included in the pome fruit value chain:

1. Farm;

2. Packhouse $(\mathrm{PH})$;

3. Controlled Atmosphere Store (CA);

4. Cold Store (CS);

Data gathering included all inputs into the value chain as defined in the system diagram in Figure 12. The year $2010 \mathrm{LCl}$ was completed first using the primary data available. The structure and inputs for the $\mathrm{LCl}$ for 2010 was thereafter applied to the other $\mathrm{LCl}$ for the years 2000 and 2020.

For the year 2000, foreground data was gathered from Western Cape agriculture commercial enterprise budgets (Combuds), agricultural records from industry bodies, literature and the Ecoinvent $v 2.2$ database. For the year $2010 \mathrm{LCl}$, primary data from the CCC database and other data sources such as industry experts and research papers were used. For the year 2020, numerous government documents such as the Integrated Resource Plan $(2010$ - 2050) from the Department of Energy (DoE) and the South African National Development Plan Targets for 2030 were referenced. Predictions on future yields and prices is based on data from the Bureau for 
Food and Agricultural Policy (BFAP). Data for unit processes in each boundary was also sourced the expert opinion of consultants and technical role players in the industry.

The functional unit across the value chain is $\mathbf{1} \mathbf{~ k g}$ of packaged pome fruit for the export and local market at the CS gate. Pome fruit refers only to the apple and pear varietals currently grown in South Africa. Allocation of the environmental burdens is done using a mass allocation for all boundaries except the Packhouse boundary where an economic allocation is applied to the fruit for market and fruit for processing. The mass ratio of export and local market fruit to fruit for processing differs each year as follows with fruit waste making up the balance (Deciduous Fruit Producers Trust, 2000; Hortgro, 2015; BFAP, 2016):

- Year 2000: 52\% : 38\%

- Year 2010: 70\%: 29\%

- Year 2020: 66\% : 33\%

An economic allocation is applied to the Packhouse output to ensure that the ratio of export and local fruit to processed fruit is consistent for all years (approximately $90 \%$ to 10\%) and thus comparable. It is assumed that $25 \%$ of pome fruit intake into the packhouse boundary is first stored in the CA facility before being packed in the packhouse. The remainder is sent directly to the packhouse from the farm for packing. The impact assessment is done using the IPCC 2013 GWP (100a) and Greenhouse Gas Protocol characterisation models to determine the indicator result GWP for mid-point impact category Climate change. Two impact assessment methods are used to highlight and compare differences in the results.

A sensitivity analysis on specific inputs is done to identify the inputs and activities which have the largest impact. As part of the sensitivity analysis, an uncertainty analysis on the models for each year is done to determine and quantify the uncertainty introduced into the results of an LCIA due to the cumulative effects of data uncertainty and variability (SANS, 2002: 2).

\subsubsection{Systems model and Boundaries}

Information for the pome fruit value chain is sourced from a paper by Ortmann (2005) and personal experience as the technical support for the Confronting Climate Change initiative. The pome fruit growing regions in South Africa are concentrated in the South Western, Southern and North Eastern regions, with the largest producing region being the Grabouw, Elgin, Villiersdorp \& Vyeboom area and second largest the Ceres area. The fruit supply chain is graphically represented in Figure 10 as evolved from Ortmann (2005) and from an LCA perspective in Figure 12.

The farm boundary includes all activities at the farm up until the fruit is offloaded at the packhouse gate. These activities on farm level do not include seed production or tree nursery activities. Background activities include the production of farming inputs such as machinery, fuel and 
electricity. The foreground activities include the irrigation, fertilising, harvesting and transport during the production of pome fruit. From the farm, the fruit is transported in crates (plastic or wooden) in small trucks or trailers pulled by tractors for shorter distances or larger vehicles for longer distances to the centralised packhouses which are generally off-site (Ortmann, 2005). Good examples of these centralised packhouse which include CA and CS facilities are Two-ADay and Kromco in the Elgin area and Ceres Fruit Growers (CFG) in Ceres.

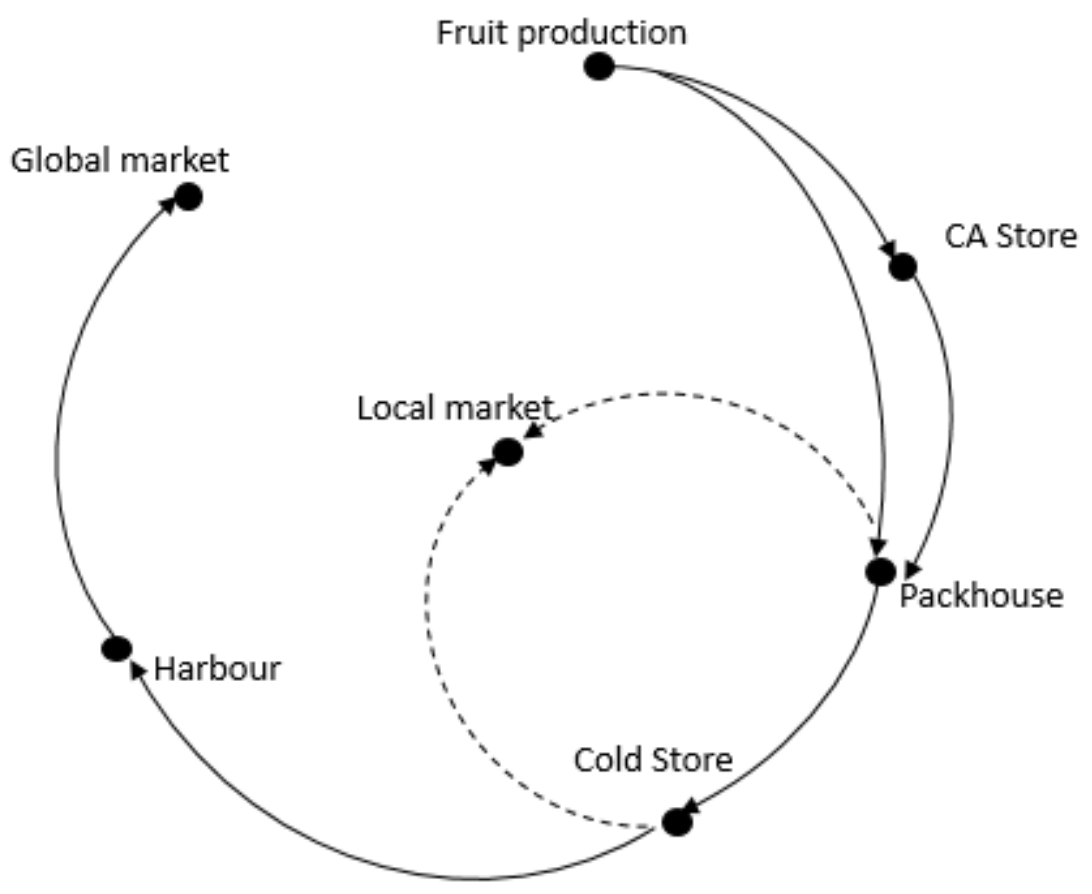

Figure 10: Schematic of pome fruit supply chain evolved from Ortmann (2005)

At these packhouses the pome fruit is either sent directly for packing at the packhouse or first stored in the CA store in bulk bins (Figure 11) for a period of time where after it is sent to the packaging lines according to the market timing. The $\mathrm{CA}$ facility is air tight with higher $\mathrm{CO}_{2}$ concentrations and much lower $\mathrm{O}_{2}$ concentrations $\left(1-3 \% \mathrm{O}_{2}\right.$ and $\left.1.5-15 \% \mathrm{CO}_{2}\right)$ in the atmosphere and cooled to $0.5^{\circ} \mathrm{C}$ to extend the storage life of the fruit (Bodegom et al., 2013). From here the fruit is taken to the packaging lines where it is graded and sorted and thereafter packed into corrugated cardboard boxes which are then packed onto pallets with dimensions $1 \mathrm{x}$ 1.2 metres. Thereafter, the pallets of packed fruit are stored in the CS facility until transported to the local market or harbour. 


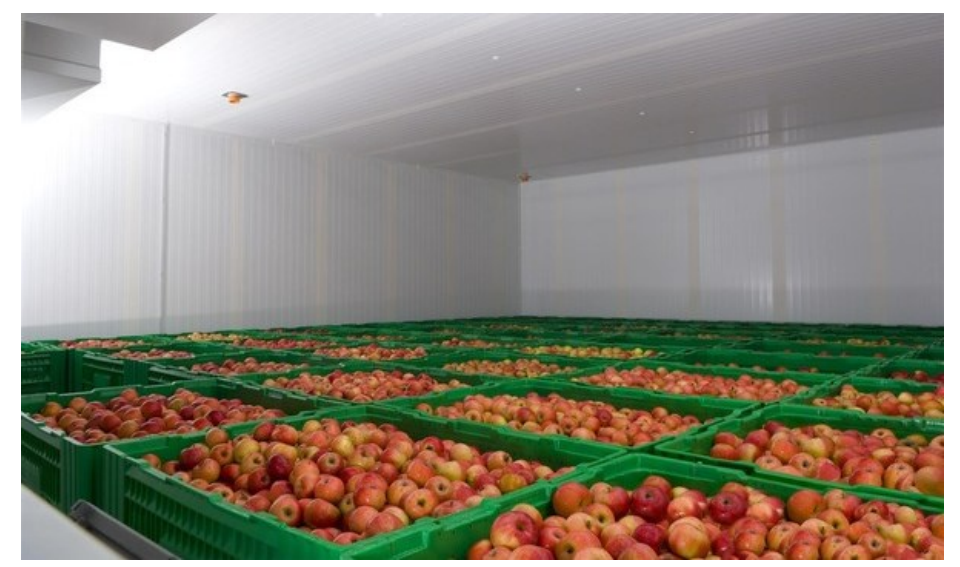

Figure 11: Apples in bulk bins in CA store (Fruitlogistica Exhibitors, 2016)

In South Africa, road transport is predominantly used to transport fruit from the packing facilities to the ports and local markets. CA, CS and packhouses are situated within the producing areas. The rail infrastructure and rolling stock required for fruit transportation is not always available and this mode is slower and less reliable than the road. However, for large volumes of fruit this mode would be more efficient (Ortmann, 2005). Trucks used for transporting fruit to harbours have four different trailer types:

- trailers for containers;

- trailers with insulated roofs and plastic tarpaulins for the sides called taut liners;

- refrigerated trailers called reefers and;

- for shorter distances, flat bead trailers.

Shipping is either via containers (refrigerated or ambient) or break bulk which is when the fruit is stored in the hold of a conventional vessel. Air freight is seldom used due to cost and limited volumes. Pome fruit is shipped out to export markets from the Cape Town, Port Elizabeth and Durban harbours.

The CCC carbon emission calculator tool also follows this supply chain sequence when annual data is captured. For the time series, attributional LCA the value chain in Figure 12 is modelled for each of the years. The boundaries for this study is as follows:

- The systems boundary is graphically represented in Figure 10 and Figure 12 and includes the farm, packhouse, CA and CS facilities (dotted line).

- The temporal boundary is 1 year of producing, packaging and shipping of pome fruit to export and local markets for years 2000, 2010 and 2020. This year represents commercial pome fruit production across the lifespan of the orchard. End of life of the orchard and seedling production is not included.

- The geographical boundary includes all activities within the pome fruit value chain within South Africa. The growing regions at a provincial level with total hectares are in Table 5. 


\begin{tabular}{|c|c|}
\hline Province & Hectares \\
\hline Western Cape & 27808 \\
\hline Eastern Cape & 6627 \\
\hline Free State & 489 \\
\hline Mpumalanga & 188 \\
\hline Limpopo & 20 \\
\hline Total & 35132 \\
\hline
\end{tabular}

Table 5: Geographical spread of pome fruit cultivation in South Africa (Hortgro, 2015). 


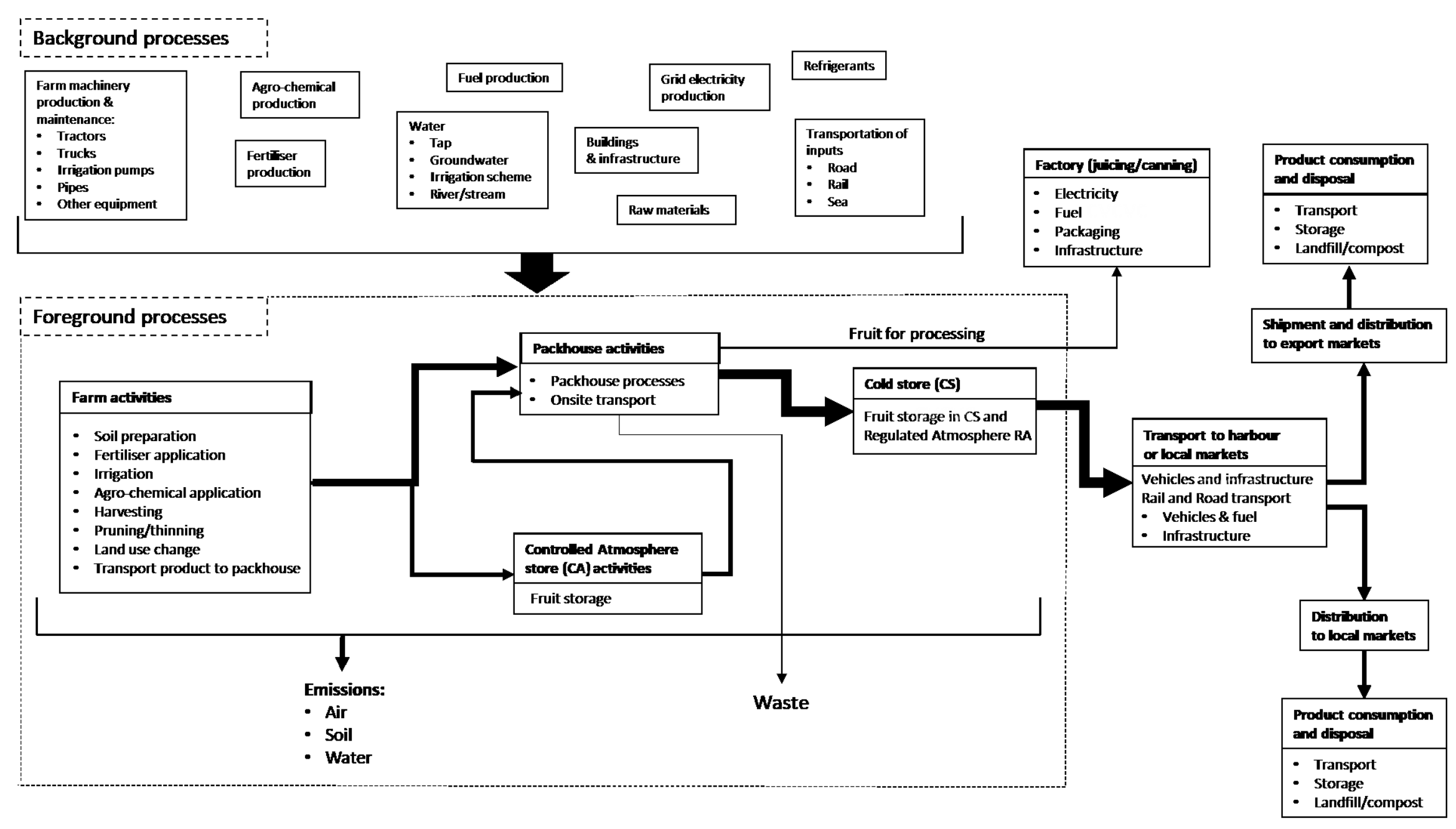

Figure 12: Pome fruit value chain product system boundary (dotted line) 


\subsubsection{Impact assessment methods}

The impact assessment methods used for the time series LCA for the years 2000, 2010 and 2020 are the Greenhouse Gas Protocol and the IPCC 2013 GWP, as available on the SimaPro v. 8.3 software. These single issue methods measure the global warming potential (GWP) in carbon dioxide equivalents $\left(\mathrm{CO}_{2} \mathrm{e}\right)$ of each greenhouse gas emitted throughout the pome fruit value chain. The use of these single issue methods are aligned with the objectives of the research in Section 1.3. Only the GHG emissions per functional unit for the value chain is required to support the hypothesis. The indicator results are in $\mathrm{kg} \mathrm{CO}_{2}$ e per $1 \mathrm{~kg}$ of pome fruit at an activity, boundary and value chain level. The results of the two impact assessment methods will be compared and discussed for each year in Chapter 5 .

The Greenhouse Gas Protocol (GHG Protocol) based on the Product Life Cycle Accounting and Reporting Standard (Greenhouse Gas Protocol, 2011) uses the same characterization factors for each substance as the IPCC 2013 GWP (100a) method but also requires fossil and biogenic carbon to be reported separately (PRé, 2013). According to the GHG Protocol standard, carbon is to be reported as follows:

- Fossil carbon (carbon originating from fossil fuels);

- Biogenic carbon (carbon originating from biogenic sources such as plants and trees);

- Carbon from Land transformation (direct impacts) and;

- Carbon uptake (CO2 that is stored in plants and trees as they grow).

The SimaPro software is aligned with the GHG Protocol in reporting carbon in the four categories. For this study only ecoinvent datasets are used to develop the LCls and it is only the ecoinvent datasets that specify carbon in these four categories. In order to compare the results from the GHG Protocol v. 1.02 and the IPCC 2013 GWP 100a methods, the single total GWP result from the GHG Protocol method calculated by SimaPro (carbon uptake component is subtracted from the total of the other three carbon categories) is compared to the IPCC method GWP total.

Since these are single-impact methods, normalization factors are not provided for these impact assessment methods in the SimaPro software. A normalisation of the results (to understand their share of the total) is done using national $\mathrm{CO}_{2}$ emissions for each year. 


\section{Chapter 4 : Life Cycle Inventory}

A LCl is essentially a product system which is made up of a collection of unit and system processes connected through flows of intermediate products within the system boundary and elementary and product flows across the boundary (SANS, 2002). The data within the boundaries of the LCls in this study are categorised as follows:

- Energy inputs, raw material inputs, ancillary inputs, other physical inputs;

- Products;

- Emissions to air, water and soil and other environmental aspects where applicable to the GWP impact category.

The mass flows for each year in the product system is in Table 6. The material flow is shown diagrammatically in Figure 12 and indicates a flow of fruit to the CA store and Packhouse from the farm. Note that $25 \%$ of total farm output is sent to the CA with the rest sent directly to the packhouse for packing. After storage in the CA for a specified period, the fruit then flows to the packhouse and then the export and local fruit is sent to the cold store before transported to local or international markets. Fruit for processing is sent for canning or juicing and waste is sent either to landfill or sold as animal feed or composted.

\begin{tabular}{|l|r|r|r|}
\hline Boundaries & $\mathbf{2 0 0 0}$ & $\mathbf{2 0 1 0}$ & $\mathbf{2 0 2 0}$ \\
\hline Farm [kT] & & & \\
\hline Farm output & 858 & 1126 & 1410 \\
\hline CA [kT] & & & \\
\hline Farm input & 214 & 281 & 352 \\
\hline CA output & 214 & 281 & 352 \\
\hline Packhouse [kT] & 643 & & \\
\hline Farm input & 214 & 281 & 1060 \\
\hline CA input & $\mathbf{8 5 8}$ & $\mathbf{1 1 2 6}$ & $\mathbf{1 4 0 9}$ \\
\hline Total & 442 & 749 & 935 \\
\hline PH output: Export and local & 322 & 369 & 459 \\
\hline PH output: Processing & 93 & 8 & 14 \\
\hline PH output: Waste & $\mathbf{8 5 7}$ & $\mathbf{1 1 2 6}$ & $\mathbf{1 4 0 8}$ \\
\hline Total & & & \\
\hline CS [kT] & 442 & 749 & 935 \\
\hline PH input & 442 & 749 & 935 \\
\hline CS output &
\end{tabular}

Table 6: Mass flows of fruit [kT] for each year model. 
The following sub-sections discuss the data included in the LCI for each year for each of the boundaries included in the scope of the LCA. The LCl for the year 2010 is discussed first as it is viewed as the reference year for the past and future $\mathrm{LCl}$ models. The structure of the $\mathrm{LCl}$ as well as certain data extrapolations performed for the other years are based on the year 2010 .

\subsection{Present: $2010-2015$}

This section describes the data collection and modelling of the South African pome fruit sector used in the 2010 LCA.

\subsubsection{System description and Data}

For the year 2010, the raw data from the 'Confronting Climate Change' initiative database is the primary source (Confronting Climate Change, 2015) (Confronting Climate Change, 2017). This initiative was started in 2008 by the growing need to measure and manage carbon emissions in the South African fruit and wine value chain due to export market access risks. Managing the perceptions of these markets is possible by providing objective data on carbon emissions within these value chains and the mitigation measures put in place to reduce these emissions. Producers and role players in the fruit and wine industry are encouraged to measure their carbon emissions and identify 'hot spots' within the supply chain as well as introduce strategies to reduce overall emissions $^{9}$. The project is now in Phase 4 and funded by the various fruit and wine industry bodies and the Western Cape Department of Agriculture. The project continues to be coordinated by Hortgro and the management and implementation is done through consulting firm Blue North Sustainability (Pty) Ltd ${ }^{10}$.

Workshops are the main medium of creating awareness and collecting data from business entities. Usage of the tool on the website is free of charge and consists of an online tool and a carbon footprint report which is generated from the data filled in by the user. The data and subsequent report is for internal purposes and is not used for marketing or certification, therefore there is no incentive to manipulate data. The data used for the 2010 LCA is from 65 business units which cover the pome fruit value chain from the farm boundary up until delivery to regional and international markets. This data is sourced from a large proportion of business units in the pome fruit growing and processing regions in South Africa and include the Western Cape, Eastern Cape and Kwa-Zulu Natal for the years 2011 to 2015 . It can thus be seen as a relatively reliable representation of the industry. The mass flows for the 2010 model used actual industry outputs for each boundary coupled with the activities and unit process from the CCC database. The CCC data was extrapolated to the industry figures.

\footnotetext{
9 Information on objectives of project: http://climatefruitandwine.co.za/?menu=5

10 Blue North Sustainability: http://bluenorth.co.za/
} 
Unit process models from the ecoinvent version 3 database are discussed in the following sections. The $\mathrm{LCl}$ for 2010 is available in Appendix I.

\subsubsection{Farm boundary}

The SimaPro dataset created for the farm in 2010 is:

- Pome fruit (ZA) | Production | 2010

The pome fruit farm sample consists of 65 farms across South Africa. The values in the datasets represent one year of pome fruit production taking into account the establishment phase with no commercial production until the end of the productive life expectancy of the orchard at age 25 years (Greef \& Kotze, 2007). Note that pome fruit trees only start producing fruit for commercial use after the vegetative phase from year 1 to 3 (Flore, DeGrandt-Hoffman \& Perry, 1984). All farms are farmed conventionally and none in the sample make use of organic methods.

The yields per hectare for the year 2010 for apples and pears in Table 7 are obtained from Hortgro (2014). Tree densities of approximately 1250 per hectare and planting configurations as seen in Figure 13 was typical for the year 2010.

\begin{tabular}{|c|r|r|r|}
\hline Fruit & Total production & \multicolumn{1}{|l|}{ Total hectares } & \multicolumn{2}{|l|}{ Tonnes/ha } \\
\hline Apples & 753167 & 22925 & 32.85 \\
\hline Pears & 373738 & 12211 & 30.60 \\
\hline
\end{tabular}

Table 7: Average tonnes/ha of apples and pears for year 2010 (Hortgro, 2014)

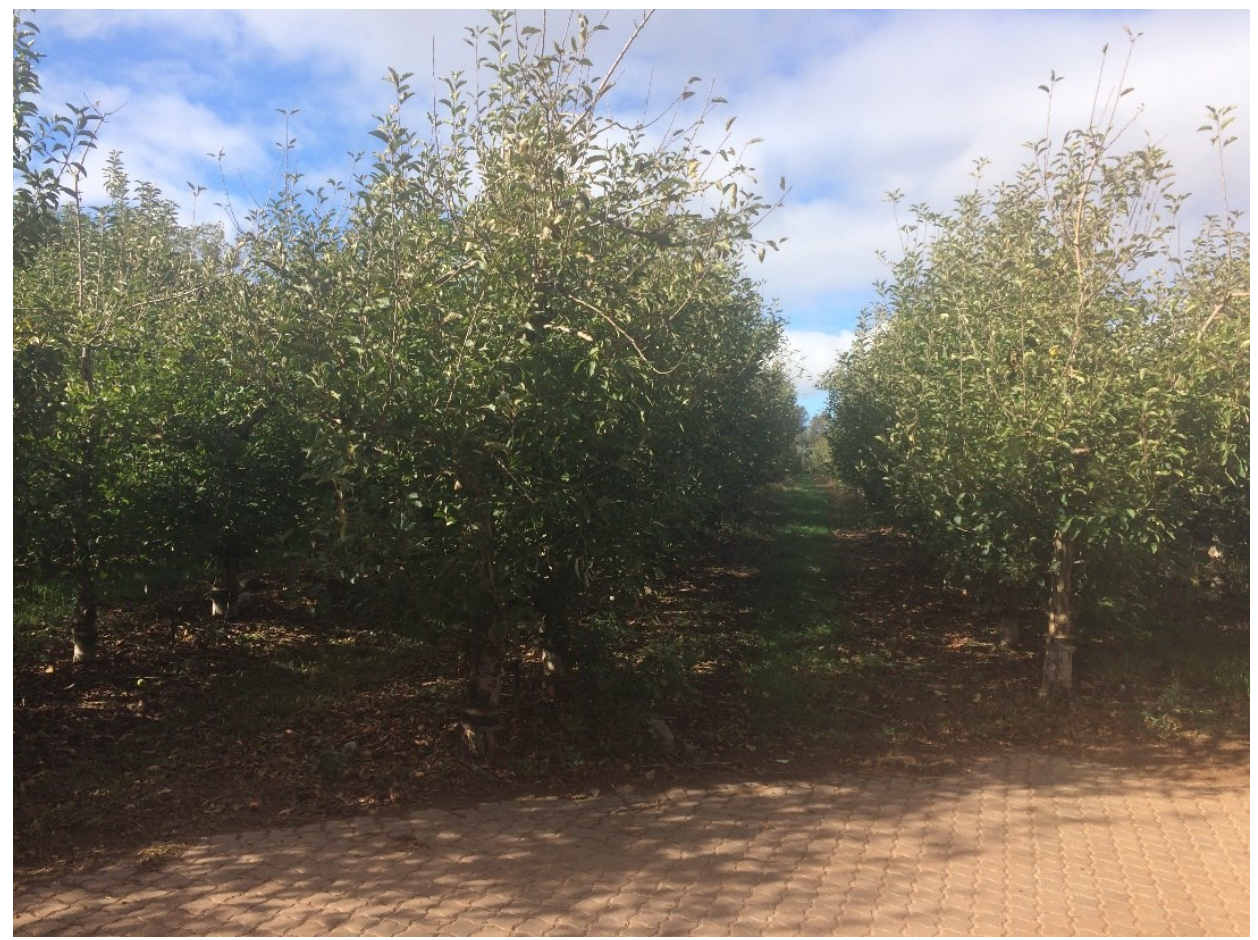

Figure 13: Planting configuration of apple trees around year 2010. 
The inputs for cultivation of pome fruit vary per farm for many reasons which include soil types, climate, gradient and the age of trees. For the SimaPro model, the total value of the inputs and outputs from the CCC data of the farming operations extrapolated to industry output are in Table 8.

The CCC data is a sample of the total pome fruit production in South Africa and there are differences in the yield/ha figure compared to the Hortgro data in Table 7. The CCC data yield per hectare for pome fruit ranges from 4 tonnes/ha on a farm with a young orchard which is not yet commercially productive up to 66 tonnes/ha for a high tree density, mature orchard. This reflects the relatively high variation in farming practices from one farm to another.

\begin{tabular}{|c|c|c|c|}
\hline \multirow{18}{*}{$\begin{array}{l}\frac{2}{0} \\
\frac{0}{0} \\
\frac{1}{7} \\
0 \\
0 \\
\frac{8}{\pi} \\
\frac{1}{0}\end{array}$} & Input and output material/process & UoM & Total \\
\hline & Total production tonnage & tons & $4.84 \mathrm{E}+08$ \\
\hline & Hectares (productive and non-productive) & ha & $3.29 \mathrm{E}+04$ \\
\hline & Grid electricity (orchard activity) & $\mathrm{kWh}$ & $1.19 \mathrm{E}+08$ \\
\hline & Diesel (orchard activity) & $\mathrm{L}$ & $8.91 \mathrm{E}+06$ \\
\hline & Diesel (delivery to packhouse/market) & $\mathrm{L}$ & $2.37 \mathrm{E}+06$ \\
\hline & Nitrogen fertilizer & $\mathrm{kg}$ & $2.35 \mathrm{E}+06$ \\
\hline & Phosphorus & $\mathrm{kg}$ & $7.29 \mathrm{E}+05$ \\
\hline & Potassium & $\mathrm{kg}$ & $2.76 \mathrm{E}+06$ \\
\hline & Compost & $\mathrm{kg}$ & $8.31 \mathrm{E}+06$ \\
\hline & Solid manure & $\mathrm{kg}$ & $1.38 \mathrm{E}+05$ \\
\hline & Liquid manure/slurry & $\mathrm{L}$ & $4.20 \mathrm{E}+03$ \\
\hline & Lime & $\mathrm{kg}$ & $1.00 \mathrm{E}+07$ \\
\hline & Insecticides & $\mathrm{kg}$ & $4.25 \mathrm{E}+06$ \\
\hline & Fungicides & $\mathrm{kg}$ & $1.46 \mathrm{E}+06$ \\
\hline & Herbicides & $\mathrm{kg}$ & $2.71 E+05$ \\
\hline & Transport distance from farm to packhouse & $\mathrm{km}$ & $5.00 \mathrm{E}+01$ \\
\hline & Land use change from grassland & ha & $7.21 \mathrm{E}+02$ \\
\hline
\end{tabular}

Table 8: Total values for CCC inputs extrapolated to industry farming output for 2009/2010.

\section{Land transformation}

For the transformation from virgin land to agricultural land, the number of hectares was obtained from the CCC database and the following resource from nature is used in SimaPro:

- Transformation, from grassland.

For the transformation to permanent cropland, which indicates the current surface area of pome fruit orchards from the CCC sample data, the following resources from nature are used:

- Transformation, from permanent crop, fruit, intensive.

- Transformation, to permanent crop, fruit, intensive. 
For the land occupied by the farm, the ecoinvent v. 3.3 unit process: Occupation, permanent crop, fruit, intensive is used. A lifespan of 25 years was specified for the orchard. The hectares of land occupied is the total of productive and non-productive hectares from the CCC database.

\section{Fertilisers}

The main fertilisers used in pome fruit production are Nitrogen, Phosphorus and Potassium. According to the CCC data from 2011 to 2014, the average application in $\mathrm{kg}$ of these fertilisers per hectare are as follows:

- Nitrogen: $103 \mathrm{~kg}$

- Phosphorus: $42 \mathrm{~kg}$

- Potassium: $152 \mathrm{~kg}$

The SimaPro processes used to represent fertilisers in the pome fruit farm model are:

- Nitrogen fertiliser, as $\mathrm{N}\{\mathrm{GLO}\} \mid$ market for | Alloc Def, $U$

- Phosphate fertiliser, as P2O5 \{GLO\}| market for | Alloc Def, U

- Potassium fertiliser, as K2O \{GLO\}| market for | Alloc Def, U

CCC provides amounts for pure $\mathrm{P}$ and $\mathrm{K}$. Therefore a conversion is done to convert $\mathrm{P}$ to $\mathrm{P}_{2} \mathrm{O}_{5}$ and $\mathrm{K}$ to $\mathrm{K}_{2} \mathrm{O}$.

In the fruit industry the application of inorganic fertiliser via fertigation is gaining favour. The inorganic fertiliser is diluted in the irrigation water and applied directly to the root zone via drip irrigation (Kangueehi, 2014: 4). The SimaPro process "Fertilising, by broadcaster \{GLO\}| Market for | Alloc Def, U" is the only process available for the application of non-soluble fertiliser. This process is adapted for South Africa by replacing the diesel allocation used for Europe by the South African diesel mix.

The SimaPro processes for lime and organic fertilisers include the following:

- Lime $\{G L O\} \mid$ market for | Alloc Def, $U$

- Compost $\{$ GLO\}| market for | Alloc Rec, $U$

- Manure, solid, cattle $\{G L O\} \mid$ market for | Alloc Rec, $U$

- Manure, liquid, cattle $\{$ GLO $\} \mid$ market for | Alloc Rec, $U$

The formulae in Nemecek \& Kagi (2007) are used to calculate the emissions to air, soil and water from fertiliser use. The updates to the dinitrogen monoxide emissions are from Nemecek et al. (2014). The heavy metal emissions from agriculture included in the Ecoinvent data are Cadmium $(\mathrm{Cd})$, Chromium (Cr), Copper (Cu), Lead (Pb), Mercury (Hg), Nickel (Ni) and Zinc (Zn). These emissions to water via leaching and erosion and soil are calculated for the year 2010 and are in Appendix II. 


\section{Pesticides and Agro-chemicals}

Data on pesticide use on farms is not available at a detail level in the CCC database. The CCC tool only requires the $\mathrm{kg}$ active ingredients applied for the audit year for the groupings insecticides, fungicides and herbicides. The proprietary name and hence active ingredients are not available. This detail data required for the SimaPro modelling exercise for 2010 is obtained from Dabrowski, Shadung \& Wepener (2014) who conducted a prioritization exercise on pesticides used in South Africa based on their environmental mobility and effects on human health. Pesticide use in South Africa was obtained from the AgroTrak ${ }^{\mathrm{TM}}$ database managed by a market research company GfK Kynetec for the year 2009. The sales data was available at a product per crop level. This is a limitation in the data as it is based on the sales of the active ingredients in pesticides and not on actual application at farm level. The study first screened the pesticides based on amount sold and toxicity endpoints and then prioritized them according to quantity of use (QI), toxicity potential (TP), environmental exposure potential (EEP) and hazard potential (HP) (Dabrowski, Shadung \& Wepener, 2014: 32).

The quantity of active ingredients applied on pome fruit was determined using the QI per active ingredient in Dabrowski, Shadung \& Wepener (2014: 34) as well as the percentage of this active ingredient used per crop. Where the figure for $\mathrm{QI}$ was not available, this was derived from the values of the 'Weighted Hazard Potential' (WHP) calculated from the HP and Qтот values for that active ingredient. To obtain the $\mathrm{kg}$ of active ingredients per $\mathrm{kg}$ fruit and per hectare, figures for the pome fruit industry in 2009 were sourced from Hortgro Apple Statistics (2014). The pesticide model for pome fruit in 2010 is available in Appendix III.

\section{Irrigation}

A new SimaPro unit process for 2010 "Irrigation, pome fruit $\{Z A\} \mid$ market for | Alloc Def, U" was created from the global dataset "Irrigation $\{$ RoW\}| market for | Alloc Def, $U$ using South African specific inputs of:

- Water, unspecified natural origin, ZA;

- $\quad$ Diesel $\{Z A\} \mid$ market for | Alloc Def, $U$ and;

- Electricity, low voltage $\{Z A\} \mid$ market for | Alloc Def, $U$

Water usage per hectare was taken from irrigation design calculations, Van der Walt (2017), Pfister et al. (2011) and the Hortgro 2006/2007 pome fruit budgets. The values per hectare are in Table 9. 


\begin{tabular}{|l|r|r|}
\hline Data source & Apples [m3/ha] & Pears [m3/ha] \\
\hline Irrigation calculations (CROPWAT) & 9200 & \\
\hline Irrigation consumption Berg River & 5928 & 5928 \\
\hline Pfister et al (2011) & 4590 & 4728 \\
\hline Horgro 2006/2007 budget & 6412 & 6275 \\
\hline Average per commodity: & 6532 & 5644 \\
\cline { 2 - 3 } Weighted average: & \multicolumn{2}{|c|}{6222} \\
\cline { 2 - 3 }
\end{tabular}

Table 9: Water consumption per ha for 2010.

The results from Pfister et al. (2011) differ from the 2000 figures due to an increase in yield per hectare. Using the value of $6222 \mathrm{~m}^{3}$ for water consumption per hectare results in approximately $0.58 \mathrm{kWh}$ per $1 \mathrm{~m}^{3}$ of water pumped.

The electricity mix for the year 2010 according to the first Integrated Resource Plan $2010-2030$ (Department of Energy, 2011: 28) was made up of the following technologies:

- Coal: $90 \%$;

- Nuclear: $5 \%$ and;

- Hydro: $5 \%$.

The ecoinvent v. 3.3 unit process dataset "Electricity, high voltage $\{Z A\} \mid$ production mix | Alloc Def, U" has the following technologies as part of the country electricity mix:

- Hard coal: 93\%

- Nuclear: $5 \%$;

- Hydro: $2 \%$

This unit process approximates the IRP electricity mix for 2010 and therefore represents the South African electricity mix for this period.

\section{Other inputs}

The difference in the consumption of diesel between the ecoinvent v 3.3 unit process datasets of fertiliser and pesticide application and the CCC total value is accounted for in the unit process dataset "Diesel, combustion $\{Z A\} \mid 2010$ | processing | Alloc Def, U”. This dataset represents the diesel combustion from the use of agricultural machinery in various farming activities and is modified from the ecoinvent v. 3.3 unit process dataset "Diesel, burned in building machine \{GLO\}| processing | Alloc Def, U". The dataset has the "Diesel $\{Z A\} \mid$ market for | Alloc Def, U" as input which is valid for the year 2010 according to data sources used.

Transport of fertilisers and agro-chemicals to the farm was included in dataset "Transport, lorry 20-28t, fleet average/ZA U". For the delivery of fruit to the packhouse, the distance from the farm to the Packhouse facilities is estimated at $50 \mathrm{~km}$ and the Ecoinvent 2 process "Transport, lorry 
20-28t, fleet average/ZA U" is used. South Africa currently complies with EURO 2 vehicle emission standards which were achieved in 2006. The adoption of the later EURO standards has not occurred due to a delay in converting to cleaner fuels at refineries ${ }^{11}$. ecoinvent v. 3.3 does not have transport datasets with EURO 2 emission standards and therefore the ecoinvent v. 2.2 version of the dataset is used which takes into account the various emission standards before 2007 in the EU.

\subsubsection{Packhouse}

For the packhouse boundary the SimaPro datasets has two outputs which are:

- Pome fruit (ZA) at packhouse 2010 | local and export market | Alloc Def, $U$ and;

- Pome fruit (ZA) at packhouse 2010 | fruit for processing | Alloc Def, U.

The percentage of the total intake that goes directly for packing or to the CA store varies from year to year, therefore for this model it is assumed that $25 \%$ of the fruit taken in for packing annually is first stored in the CA store. The total amounts for Packhouse inputs in Table 10 were obtained from the CCC database which were extrapolated to industry figures for 2000 . The incoming fruit is sorted into four categories; local and export market, processing (juicing or canning) and waste. An economic allocation was used to allocate $90 \%$ of environmental burdens to export and local fruit and the remainder of $10 \%$ to the fruit sent for processing. The fruit making up the waste component is a combination of incoming fruit not conforming to certain criteria for packing due to size or damage during transit or packing and is approximately $1 \%$ of total fruit intake in the packhouse.

In the Packhouse, electricity is used for the operation of the conveyor belts, lighting and other machinery. Electricity use per ton fruit packed (local and export) is approximately $22 \mathrm{kWh}$ according to the CCC data. This is considerably lower than the range of $30 \mathrm{kWh}$ to $45 \mathrm{kWh}$ of electricity used per ton fruit packed in the study done by Bouwer, Von Broembsen \& Dodd (2008). The results of the CCC packhouse model as well as the Bouwer et al. (2008) packhouse model with new electricity consumption values are shown in Section 5.2 to illustrate the differences.

11 http://www.sapia.org.za/Key-Issues/Cleaner-fuels-II 


\begin{tabular}{|c|c|c|c|}
\hline \multirow{21}{*}{ 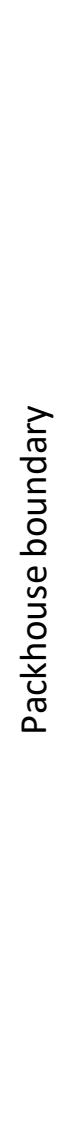 } & Input material/process & UoM & Total \\
\hline & $\begin{array}{l}\text { Total Tonnes output } \\
\text { (Export, local, processing and waste fruit) }\end{array}$ & tons & $5.32 \mathrm{E}+05$ \\
\hline & Fruit for Processing & tons & $5.84 \mathrm{E}+04$ \\
\hline & Fruit for Export & tons & $2.87 \mathrm{E}+05$ \\
\hline & Fruit for Local & tons & $1.81 \mathrm{E}+05$ \\
\hline & Waste fruit & tons & $5.40 \mathrm{E}+03$ \\
\hline & Grid Electricity & kWh & $1.19 \mathrm{E}+07$ \\
\hline & Direct Diesel usage & $\mathrm{L}$ & $6.34 \mathrm{E}+04$ \\
\hline & Direct LPG usage & $\mathrm{kg}$ & $1.35 \mathrm{E}+05$ \\
\hline & Corrugated cardboard (cartons \& pallet covers) & $\mathrm{kg}$ & $2.33 \mathrm{E}+07$ \\
\hline & Paper labels & $\mathrm{kg}$ & $6.06 \mathrm{E}+05$ \\
\hline & Polystyrene & $\mathrm{kg}$ & $1.36 \mathrm{E}+06$ \\
\hline & Polypropylene & $\mathrm{kg}$ & $3.10 \mathrm{E}+04$ \\
\hline & PET & $\mathrm{kg}$ & $1.56 \mathrm{E}+05$ \\
\hline & LDPE & $\mathrm{kg}$ & $1.72 \mathrm{E}+06$ \\
\hline & HDPE & kg & $5.36 \mathrm{E}+02$ \\
\hline & Wooden bins & units & $1.28 \mathrm{E}+05$ \\
\hline & Plastic bins & units & $2.14 \mathrm{E}+04$ \\
\hline & Wooden pallets (disposable \& reusable) & units & $4.29 \mathrm{E}+05$ \\
\hline & Packaging waste recycled & kg & $7.94 \mathrm{E}+05$ \\
\hline & Packaging waste sent to landfill & $\mathrm{kg}$ & $9.74 \mathrm{E}+05$ \\
\hline
\end{tabular}

Table 10: Total values for Packhouse boundary sourced from CCC database 2011-2014 extrapolated to industry figures for 2010

The corrugated cardboard input is represented by the ecoinvent dataset "Corrugated board box \{GLO\}| market for corrugated board box | Alloc Def, U" and all plastic packaging by the following ecoinvent v. 3.0 datasets:

- Polystyrene, general purpose $\{G L O\} \mid$ market for | Alloc Def, $U$

- Polyethylene terephthalate, granulate, amorphous $\{G L O\} \mid$ market for | Alloc Def, $U$

- Packaging film, low density polyethylene $\{G L O\} \mid$ market for | Alloc Def, $U$

- Polypropylene, granulate \{GLO\}| market for | Alloc Def, U

- Polyethylene, high density, granulate $\{G L O\} \mid$ market for | Alloc Rec, U.

Wooden bins, disposable and re-usable wooden pallets are captured in the 'EUR-flat pallet \{GLO\}| market for | Alloc Def, U' dataset. The lifespan of a wooden bin is 10 years. Plastic bins are made from polypropylene and have a lifespan of 30 years ("Jumbo Bins in the Fruit Growing Industry | Mpact Plastic Containers", n.d.). 


\section{Infrastructure}

Estimations were made for packhouse area using Google Maps, information on company websites $^{12}$ and direct communication with packhouses. The length of the conveyor belts in packhouses were modelled based on research by König (2015: 28) on the Rekopane packhouse in Kakamas, Northern Cape. $20 \mathrm{~m}$ of conveyor belts were assumed for $800 \mathrm{~m}^{2}$ of packhouse area. The weighted averages for packhouse area and length of conveyor belts per $\mathrm{kg}$ fruit according to the annual intake in tonnes (Table 11) were used in the SimaPro process model. The uncertainty for packhouse area and conveyor belt length is high as the packhouse area estimations could include other facilities such as storage areas for packaging. According to the Life Cycle Inventories of Building Products by Kellenberger et al. (2007), the life expectancy for building infrastructure is 50 years and 25 years for the conveyor belts.

\begin{tabular}{|c|c|c|c|c|c|c|}
\hline Location & Company & \begin{tabular}{|l} 
Fruit \\
tonnages \\
[tonnes] \\
\end{tabular} & Area $\left[\mathrm{m}^{2}\right]$ & $\begin{array}{l}\text { Area } \\
{\left[\mathrm{m}^{2} / \mathrm{kg} / \text { year }\right]}\end{array}$ & $\begin{array}{l}\text { Conveyor belt } \\
{[\mathrm{m}]}\end{array}$ & $\begin{array}{l}\text { Conveyor } \\
\text { belt } \\
{[\mathrm{m} / \mathrm{kg} / \mathrm{yr}]}\end{array}$ \\
\hline Ceres & Ceres Fruit Growers & $1.08 \mathrm{E}+05$ & $3.22 \mathrm{E}+04$ & $2.98 \mathrm{E}-04$ & $8.05 \mathrm{E}+02$ & 7.45E-06 \\
\hline Elgin & TAD & $1.00 \mathrm{E}+05$ & $1.78 \mathrm{E}+04$ & $1.78 \mathrm{E}-04$ & $4.45 \mathrm{E}+02$ & $4.45 \mathrm{E}-06$ \\
\hline Ceres & Du Toits & $7.37 \mathrm{E}+04$ & $2.43 E+04$ & $3.30 \mathrm{E}-04$ & $6.08 \mathrm{E}+02$ & $8.24 \mathrm{E}-06$ \\
\hline Ceres & Graaf Fruit & $1.58 \mathrm{E}+04$ & $6.02 \mathrm{E}+03$ & $3.81 \mathrm{E}-04$ & $1.51 \mathrm{E}+02$ & $9.51 \mathrm{E}-06$ \\
\hline Grabouw & Kromco & $7.00 \mathrm{E}+04$ & $1.60 \mathrm{E}+04$ & $2.29 \mathrm{E}-04$ & $4.00 E+02$ & $5.71 \mathrm{E}-06$ \\
\hline Vyeboom & Fruitways - Melpack & $2.29 \mathrm{E}+04$ & $4.80 \mathrm{E}+03$ & $2.10 \mathrm{E}-04$ & $1.20 \mathrm{E}+02$ & $5.24 \mathrm{E}-06$ \\
\hline Stellenbosch & Timberlea & $3.99 \mathrm{E}+03$ & $8.36 \mathrm{E}+02$ & $2.10 \mathrm{E}-04$ & $2.09 \mathrm{E}+01$ & $5.24 \mathrm{E}-06$ \\
\hline & Average: & $5.63 E+04$ & $1.46 \mathrm{E}+04$ & $2.62 \mathrm{E}-04$ & $3.64 \mathrm{E}+02$ & $6.55 \mathrm{E}-06$ \\
\hline
\end{tabular}

Table 11: Packhouse areas and conveyor belt lengths

\section{Water}

Water usage in packhouses is for drenching, sorting and packing of the fruit. The water does not form part of the product and therefore the meter readings in and out the packhouse are similar. The source of this water and methods of treatment and disposal vary. Sources include municipal water and treated water from onsite boreholes and dams. The waste water treatment ranges from municipal waste water treatment plants, natural filtration and discharge to water courses. All water is re-used throughout the packing period using onsite treatment and filtration facilities.

Five centralised packhouses in the Western Cape were contacted and three of the five responded with their water consumption figures. The water consumption per ton fruit packed and annual tonnages packed are in Table 12.

\footnotetext{
12 http://www.graaff-fruit.com/packing/
} 


\begin{tabular}{|l|r|r|c|}
\hline Packhouse & Litres/ton fruit & $\begin{array}{l}\text { kTonnes } \\
\text { packed }\end{array}$ & \multicolumn{1}{l|}{ Years } \\
\hline Ceres Fruit Growers & 680.23 & 125.13 & 2016 \\
\hline Du Toits & 767.18 & 73.69 & $2012-2016$ \\
\hline Kromco & 260.83 & 70.00 & $2015 / 2016$ \\
\hline
\end{tabular}

Table 12: Average water consumption per ton fruit in packhouses (2010 - 2015)

\section{Waste}

Waste from the packhouse is made up of the organic waste from the damaged fruit which cannot be used for processing or market as well as the inorganic packaging waste. The disposable wooden pallets are also a waste stream after a packing season and usually burned. These processes are captured in SimaPro under "Waste and emissions to treatment". The ecoinvent unit process datasets used for the organic waste and disposable wooden pallets are as follows:

- Biowaste $\{$ RoW $\} \mid$ market for | Alloc Def, $U$ : the treatment of organic waste via landfill and anaerobic digestion with transport to these waste facilities.

- Waste wood, untreated $\{$ RoW $\} \mid$ treatment of waste wood, untreated, municipal incineration | Alloc Def, U

From the CCC data it is unclear what materials make up the packaging waste sent to a landfill or recycling facility. The ratio of the different packaging materials either sent to landfill or recycling facility is calculated using the amount of the packaging materials used during the year. The ratio of cardboard and paper to plastics is $88 \%: 12 \%$. The unit process datasets used for waste from packhouse are:

- Waste plastic, mixture $\{$ RoW $\} \mid$ treatment of waste plastic, mixture, sanitary landfill | Alloc Def, U;

- Mixed plastics (waste treatment) \{GLO\}| recycling of mixed plastics | Alloc Def, U;

- Waste paperboard $\{$ RoW\}| treatment of, sanitary landfill | Alloc Def, $U$ and;

- Recycling cardboard |market for|ZA, Alloc Def, U.

The only landfill waste treatment option in SimaPro is sanitary landfills in Europe which are not representative of waste management processes in South Africa. No data for waste water volumes and treatment is available for packhouses and this data is excluded.

\section{Other inputs}

Fuels used in the packhouse boundary include Liquefied Petroleum Gas (LPG) and diesel which are used for the forklifts. The unit process dataset "Diesel, combustion $\{Z A\} \mid 2010$ | processing | Alloc Def, U" is used to account for diesel combustion in the packhouse. Electricity is used for all machinery associated with pumping, operation of the conveyor belts and lighting. 


\subsubsection{CA and CS facilities}

For the SimaPro model the CA and Cold Store facilities are modelled in the following datasets:

- $\quad$ Pome fruit (ZA) | CA Storage | 2010, U

- $\quad$ Pome fruit (ZA) | Cold Store | 2010, U

There is a separation between the CA store and the CS facilities. The Cold store is a short term refrigerated storage for the fruit after arriving at the packhouse facilities and just before shipping for the palletised fruit. The CA store is gas tight in order to maintain a low oxygen environment for extended storage of the fruit before packing to allow regulated marketing over a longer period of time (Bodegom et al., 2013: 20). CA stores are also cooled to approximately $0.5^{\circ} \mathrm{C}$ (Bodegom et al., 2013: 39). All of these facilities are usually at the same site so no transport between them is required $^{13}$. All the data from the CCC database for the CA and CS facilities are in Table 13:

\begin{tabular}{|c|c|c|c|}
\hline \multirow{11}{*}{ 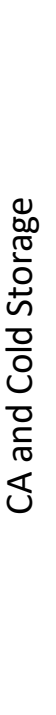 } & Input material/process & UoM & Total 2010 \\
\hline & CA Store - Total tonnage stored & tons & $2.82 \mathrm{E}+05$ \\
\hline & CA Store - Number of days stored & days & $2.69 \mathrm{E}+03$ \\
\hline & CA Store - Grid Electricity & kWh & $4.93 \mathrm{E}+07$ \\
\hline & $\begin{array}{c}\text { CA Store - Refrigerant leakage } \\
\text { (Ammonia) }\end{array}$ & kg & $2.18 \mathrm{E}+04$ \\
\hline & Cold Store - Total tonnage stored & tons & $7.47 \mathrm{E}+05$ \\
\hline & Cold Store - Number of days stored & days & $2.37 \mathrm{E}+03$ \\
\hline & Cold Store - Grid electricity & kWh & 1.17E+08 \\
\hline & Cold Store - Refrigerant leakage & & \\
\hline & (Ammonia) & $\mathrm{kg}$ & 4.19E+04 \\
\hline & (HCFC-22/R-22) & $\mathrm{kg}$ & $1.04 \mathrm{E}+03$ \\
\hline
\end{tabular}

Table 13: Inputs for CA and Cold store boundary from CCC database from 2011 - 2014 extrapolated to industry figures for 2010 .

The sample sizes include 18 CA stores and 25 CS stores over the period 2011 to 2014 . Only pome fruit is stored in a CA store but any number of other fruit packaged at a facility moves through the CS. The refrigerant leakage values in the CCC database for the CS are for the facility and not on a commodity level. In this case a pro-rata allocation is done for the pome fruit. Some of the more 'efficient' storage facilities had no leakages for the year recorded.

\footnotetext{
13 Discussion with Koos Bouwer of Koos Bouwer Consulting: http://kbcindustrial.co.za/
} 
CA and CS infrastructure is separately accounted for in the CA and CS process models in SimaPro based on data received from Ceres Fruit Growers (CFG) ${ }^{14}$, Kromco $^{15}$ and the Du Toit Group $^{16}$ in Table 14 and Table 15.

\begin{tabular}{|l|l|r|r|r|}
\hline Location & Company & Capacity $(\mathbf{k g})$ & $\begin{array}{l}\text { Refrigerated } \\
\text { Area }\left[\mathrm{m}^{2}\right]\end{array}$ & $\begin{array}{l}\text { Area per kg fruit } \\
{\left[\mathrm{m}^{2}\right]}\end{array}$ \\
\hline Ceres & Ceres Fruit Growers & $5.54 \mathrm{E}+07$ & $3.84 \mathrm{E}+04$ & $6.92 \mathrm{E}-04$ \\
\hline Ceres & Du Toits & $3.27 \mathrm{E}+07$ & $1.53 \mathrm{E}+04$ & $4.68 \mathrm{E}-04$ \\
\hline Grabouw & Kromco & $3.44 \mathrm{E}+07$ & $1.50 \mathrm{E}+04$ & $4.36 \mathrm{E}-04$ \\
\hline
\end{tabular}

Table 14: Refrigeration area of CA Stores

\begin{tabular}{|l|l|r|r|l|}
\hline Location & Company & Capacity $\mathbf{( k g )}$ & $\begin{array}{l}\text { Refrigerated } \\
\text { Area }\left[\mathrm{m}^{2}\right]\end{array}$ & $\begin{array}{l}\text { Area per kg fruit } \\
{\left[\mathrm{m}^{2}\right]}\end{array}$ \\
\hline Ceres & Ceres Fruit Growers & $4.56 \mathrm{E}+07$ & $6.01 \mathrm{E}+04$ & $1.32 \mathrm{E}-03$ \\
\hline Ceres & Du Toits & $5.75 \mathrm{E}+05$ & $2.05 \mathrm{E}+03$ & $3.56 \mathrm{E}-03$ \\
\hline Grabouw & Kromco & $1.69 \mathrm{E}+07$ & $1.83 \mathrm{E}+04$ & $1.08 \mathrm{E}-03$ \\
\hline
\end{tabular}

Table 15: Refrigeration area of CS

Electricity consumption in CA and CS facilities is mainly for the operation of the refrigeration equipment and in the case of the CA store, for additional equipment such as scrubbers and pumps for air addition. The CCC data indicates a weighted average electricity consumption of $1.16 \mathrm{kWh}$ per cold unit (fruit stored for 133 days) for the CA and $4.26 \mathrm{kWh}$ per cold unit for the CS (fruit stored for 39 days). This is in stark contrast to the range of 5 to $15 \mathrm{kWh}$ per cold unit determined by Bouwer, Von Broembsen \& Dodd (2008). GWP results using electricity values from CCC and Bouwer et al. (2008) for the 2010 LCl model are available in Section 5.2. The electricity consumption and number of storage days for each facility from the $\mathrm{CCC}$ database and Bouwer et al. (2008) are in Table 16.

\begin{tabular}{|c|c|c|c|}
\hline CA Store inventory & UoM & $\begin{array}{c}2010 \text { (Bouwer et al., } \\
\text { 2008) }\end{array}$ & 2010 CCC \\
\hline Tonnages & Tonnes & $2.82 \mathrm{E}+05$ & $2.82 \mathrm{E}+05$ \\
\hline Electricity, low voltage $\{Z A\} \mid$ market for | Alloc Def, $U$ & kWh & $1.69 \mathrm{E}+08$ & $4.93 \mathrm{E}+07$ \\
\hline Number of days stored & days & $6.00 E+01$ & $1.33 \mathrm{E}+02$ \\
\hline Cold Store inventory & UoM & $\begin{array}{c}2010 \text { (Bouwer et al., } \\
\text { 2008) }\end{array}$ & 2010 CCC \\
\hline Tonnages & Tonnes & $7.47 \mathrm{E}+05$ & 7.47E+05 \\
\hline Electricity, low voltage $\{Z A\} \mid$ market for $\mid$ Alloc Def, $U$ & kWh & $2.61 \mathrm{E}+08$ & 1.17E+08 \\
\hline Number of days stored & days & $3.50 \mathrm{E}+01$ & $3.90 \mathrm{E}+01$ \\
\hline
\end{tabular}

Table 16: Updated and original grid electricity consumption values for CA and CS facilities for the year 2010.

\footnotetext{
${ }^{14}$ Rahim Hassan, Engineering Manager - Rahim.hassan@cfg.co.za

15 Constant Smit, Operations Manager - constants@kromco.co.za

${ }^{16}$ Andre van Wyk, Packhouse Manager - andrevw@dutoit.com
} 


\subsection{Past: $2000-2003$}

This section describes the data collection and modelling of the pome fruit sector used in the retrospective ALCA.

\subsubsection{System Description and Data}

For the year 2000 at farm level, the primary source of data for the $2000 \mathrm{LCl}$ is the commercial enterprise budgets (Combuds) produced by the Western Cape Department of Agriculture (WCDoA). The Combuds are ideally suited for an LCA on pome fruit farms as the data is regionally representative on a per hectare basis, is publically available and provides a partial mass balance for pome fruit cultivation and yields. However, the Combuds for 2000 lack detailed data and do not have the input quantities. The earliest budgets, containing the detailed information required, is for year 2007. These are used on the advice from the manager of Agricultural Economics Services at the WCDoA ${ }^{17}$, due to the quantities not changing substantially over a period of 6 years. In addition to this, macro-economic data and statistics from the industry body Hortgro and literature available for this period are consulted.

For the Packhouse, CA and CS boundaries, no records exist for the period due to a number of reasons. The period until 1994 was characterised by a single marketing channel for export namely the Deciduous Fruit Board and later Unifruco. This environment meant that all pack houses packed fruit to the same standard under the same regulations and therefore there was no need for comparisons as pooling systems were used for the pay-out to growers. The period of deregulation from 1995 to 2000 led to the change-over to individual packing and exporting to international retailers. From that period onwards it became more important to measure inputs and outputs of the pack houses as part of cost and efficiency optimisation. Data collection for these inputs and outputs therefore only started after the year $2000^{18}$.

The model for the year 2000 is built in SimaPro using a combination of Ecoinvent version 2.2 and v. 3 unit process datasets which have the required temporal validity. The LCl for 2000 is available in Appendix I.

\subsubsection{Farm boundary}

The Combud for the year 2007 (Western Cape Department of Agriculture, 2007) provides estimated annual production costs and production inputs per hectare for apple and pear cultivation from establishment to year $6+$ for apples and year $8+$ for pears. The production inputs such as electricity, diesel and fertiliser are allocated pro-rata according to the age distribution of orchards during this period. The Key Deciduous Fruit Statistics 2000 handbook from the

\footnotetext{
17 Mfusi Mjonono: MfusiM@elsenburg.com

http://www.elsenburg.com/services-and-programmes/agricultural-economics-services\#s=Production--Micro-Economics

18 Piet van Bodegom, Consulting Engineer: pietvb@mweb.co.za
} 
Deciduous Fruit Producers Trust (now Hortgro) provides the total tonnages and land occupation for pome fruit in this year (Deciduous Fruit Producers Trust, 2000). For the year 2000 the tonnages per hectare for apples and pears are in Table 17.

\begin{tabular}{|l|r|r|r|}
\hline Fruit & $\begin{array}{l}\text { Total production } \\
\text { [tonnes] }\end{array}$ & Total hectares [Ha] & Tonnes/Ha \\
\hline Apples & 581195 & 22901 & 25.37 \\
\hline Pears & 277336 & 13495 & 20.55 \\
\hline
\end{tabular}

The SimaPro dataset created for the farm in 2000 is:

- Pome fruit (ZA) | Production | 2000

Production data quantities in the 2007 budget is totalled for all years and then allocated pro-rata according to the orchard age profile for the year 2006. Orchard age profiles for the year 2000 were not available and it was recommended that 2006 data be used as age profiles did not differ to a large degree during the 6 year time period ${ }^{19}$. In order to obtain a representative year of production, the total production input quantities across the life time of an orchard were multiplied by a factor based on the apple and pear yield for the year 2000 (all years and 25 years + ) and the yields up to 25 years (59.7\% of total yields for year 2000$)$.

\begin{tabular}{|l|r|r|r|r|r|r|}
\hline & $\mathbf{0 - 3}$ years & 4-10 years & $\mathbf{1 1 - 1 5}$ years & $\mathbf{1 6 - 2 5}$ years & $\mathbf{2 5}$ years & Total ha \\
\hline Apples & $7.1 \%$ & $20.6 \%$ & $15.9 \%$ & $16.1 \%$ & $40.3 \%$ & 22901 \\
\hline Pears & $9.9 \%$ & $25.0 \%$ & $18.3 \%$ & $23.3 \%$ & $23.5 \%$ & 13495 \\
\hline Weighted average & $8 \%$ & $22 \%$ & $17 \%$ & $19 \%$ & $34 \%$ & 19413 \\
\hline
\end{tabular}

Table 18: Age grouping of apple and pear orchards as percentage of total hectares for 2006 (Greef \& Kotze, 2007: 8)

The age groupings for apple and pear orchards in Table 18, as a percentage of total hectares, is derived for pome fruit using a weighted average of the total hectares.

\section{Land Transformation}

The following inputs from nature are used:

- Transformation, from grassland; which indicates natural land converted to agricultural land. This value is calculated from the annual change in plantings from 1999 to 2000 of 763 ha (DFPT, 2000);

- Transformation, from permanent crop, fruit, intensive and;

\footnotetext{
19 Mariette Kotze: Manager Information Services at Hortgro. e-mail: mariette@hortgro.co.za
} 
- Transformation, to permanent crop, fruit, intensive.

The transformation of natural land to agricultural land is not recorded as such. The only indication is the difference in hectares from one year to the next and could be expansion on existing agricultural land. For the year 2000 LCA it is assumed that the land transformed to pome fruit orchards is natural land. For the land occupied by the farm, the raw material: Occupation, permanent crop, fruit, intensive is used. A lifespan of 25 years is specified for the orchard.

\section{Fertilisers}

The SimaPro fertiliser datasets used for fertilisers in the "Pome fruit (ZA) | Production | 2000" model according to the 2007 Combuds are:

- Ammonium nitrate, as $\mathrm{N}$, at regional storehouse/RER U;

- Urea, as N, at regional storehouse/RER U;

- Monoammonium phosphate, as P2O5, at regional storehouse/RER U;

- Potassium chloride, as $\mathrm{K} 2 \mathrm{O}$, at regional storehouse/RER U;

- Potassium nitrate, as $\mathrm{N}$, at regional storehouse/RER U;

- Calcium nitrate, as N, at regional storehouse/RER U;

- Sodium borates, at plant/US U;

- Magnesium sulphate, at plant/RER U;

- Calcium chloride, $\mathrm{CaCl} 2$, at regional storage/CH U;

The fertiliser datasets are modelled at regional storehouse which includes transport from the production facilities to the regional store or market. For fertiliser application, the SimaPro process "Fertilising, by broadcaster/ZA U" was copied and modified from the ecoinvent v. 2.2 process "Fertilising, by broadcaster/CH U" to include the South African diesel dataset. This new unit process "Fertilising, by broadcaster/ZA U" is used to represent the application of non-soluble fertilisers such as lime as well as other activities making use of agricultural machinery (harvesting and pruning).

The SimaPro processes for lime include the following:

- Lime, hydrated, loose, at plant/CH U: this is loose lime for agricultural use and not slaked lime used for construction.

The emissions of $\mathrm{N}_{2} \mathrm{O}$ from managed soils result from Nitrogen $(\mathrm{N})$ inputs and $\mathrm{N}$ mineralisation occurring through a direct pathway, where it is released from soils where $\mathrm{N}$ has been applied, or two indirect pathways namely (IPCC, 2006: 11.6):

1. Following volatilisation of $\mathrm{NH}_{3}$ and $\mathrm{NO}_{x}$ from managed soils and from fossil fuel combustion and biomass burning, and the subsequent redeposition of these gases and their products $\mathrm{NH}_{4}{ }^{+}$and $\mathrm{NO}_{3}{ }^{-}$to soils and waters and;

2. After leaching and runoff of $\mathrm{N}$, mainly as $\mathrm{NO}_{3}^{-}$, from managed soils. 
For emissions to air, soil and water from fertiliser application, the formulae from Nemecek \& Kagi (2007) with updates to the dinitrogen monoxide emissions from Nemecek et al. (2014) are used and are based on the IPCC formulae in Volume 4, Chapter 11.

\section{Pesticides and Agro-chemicals}

Quantities of pesticides used on farms in the 2007 Combuds is available at a per hectare level. The product name is stated on the Combud and the active ingredient can be determined. The SimaPro model "Application of plant protection products, by field sprayer/CH U" is used to create the new dataset "Pesticides, pome fruit 2000 |production \& application / ZA U" which includes the pesticide production process, transport to the farm and application.

The pesticide model for pome fruit in 2000 is available in Appendix III.

\section{Irrigation}

A new SimaPro process model "Irrigating/ha/ZA Unit 2000" is created from the Swiss model “Irrigating/ha/CH U' using South African specific inputs of:

- Water, unspecified natural origin, ZA;

- Diesel $\{Z A\} \mid$ market for | Alloc Def, $U$ and;

- Electricity, low voltage $\{Z A\} 2000$ | market for | Alloc Def, U.

This model requires the $\mathrm{m}^{3}$ of water consumed per hectare per year and the $\mathrm{kWh}$ of electricity required for pumping.

Firstly, the water requirement for 1 hectare of pome fruit varies considerably depending on multiple factors such as the growth phase of the trees, regional climate, evapo-transpiration and soil characteristics. For the purpose of this research, 4 different sources of information around water requirements for pome fruit are used.

The first source is the "Gross seasonal water usage" formula which is used for irrigation design applications. The formulae are as follows:

- $\quad$ Nett seasonal water usage = Evapotranspiration $(E T / h a / y e a r) ~-~ E f f e c t i v e ~ r a i n f a l l{ }^{20}$ (“AQUASTAT - FAO's Information System on Water and Agriculture", n.d.)

- Gross seasonal water usage = Nett seasonal water usage/irrigation system efficiency (FAO: Natural Resources Management and Environment, n.d.)

\footnotetext{
${ }^{20}$ Rainfall that is available in the root zone of the plant for uptake and not that which is below the root zone or above ground run-off (Brouwer \& Heibloem, 1986).
} 
Total evapotranspiration (ET) in mm over a season for 3 apple varieties (full bearing) in 3 pome fruit growing regions; Koue Bokkeveld, Elgin and Ceres were acquired from personal communication from T. Volschenk ${ }^{21}$, Volschenk, de Villiers \& Beukes (2003) and Gush \& Taylor (2014). The calculations using these parameters for 3 regions are available in Appendix IV. The results of the calculations are in Table 19.

\begin{tabular}{|c|c|}
\hline Geographical area & $\begin{array}{l}\text { Gross seasonal water } \\
\text { usage }\left[\mathrm{m}^{3} / \mathrm{ha}\right]\end{array}$ \\
\hline Koue Bokkeveld & 10481 \\
\hline Elgin & 5619 \\
\hline Ceres & 11220 \\
\hline
\end{tabular}

The second source of water consumption information is a Master thesis at the University of Cape Town by Van der Walt (2017). This research determines the irrigation requirements for a variety of crops within the Berg River catchment. The annual irrigation requirement for 1540.21 hectares of pome fruit trees is $9.13 \mathrm{Mm}^{3}$ which is approximately $5928 \mathrm{~m}^{3}$ per hectare.

A third source of water usage data for pome fruit is the global study by Pfister et al. (2011) which determines the environmental impacts of water use in global crop production. The arithmetic mean of the full irrigation water consumption, derived from the CROPWAT model, and deficit irrigation calculations is determined to quantify the expected water consumption of each crop $\mathrm{BW}_{\text {expected. }}$ This was calculated per country in order to take into account the regional nature of water consumption (Pfister et al., 2011: 5762). To take this result further, the competitive pressure on regional water availability due to water scarcity is indicated by the Water Stress Index (WSI) for a specific location. The WSI-weighted water consumption is an indicator for the amount of water deficient to downstream human users and ecosystems and is calculated by multiplying the $\mathrm{BW}_{\text {expected }}$ by the WSI in the specific location and indicated by Relevant for Environmental Deficiency (RED) water. The RED water for South Africa was not used in this research as the electricity consumption for pumping irrigation water is dependent on actual water consumption. The $\mathrm{BW}_{\text {expected }}$ values for apples and pears per ton and per hectare are in Table 20 for apple and pear crops in South Africa. The average tonnages per ha of each commodity for the year 2000 is in Table 17.

21 Soil Scientist (Irrigation), Soil and Water Science Programme, ARC Infruitec-Nietvoorbij, P/B X5026, Stellenbosch, 7599, Tel +27 21 8093345) 


\begin{tabular}{|l|r|l|}
\hline Commodity & $\begin{array}{l}\text { BWexpected (South Africa) } \\
{\left[\mathrm{m}^{3} / \mathrm{t}\right]}\end{array}$ & $\begin{array}{l}\text { BWexpected (South Africa) } \\
{\left[\mathrm{m}^{3} / \mathrm{ha}\right]}\end{array}$ \\
\hline Apples & 140 & 3545 \\
\hline Pears & 155 & 3175 \\
\hline Average & 147 & 3407 \\
\hline
\end{tabular}

Table 20: Blue Water expected water consumption per ton and per hectare for South African pome fruit (Pfister et al., 2011)

The Hortgro 2006/2007 pome fruit budget background data (Hortgro, 2007) was the fourth source of water consumption information. The consumption figures per hectare varied depending on the growth phase of the trees and is used to determine water and electricity costs in Table 21.

\begin{tabular}{|l|r|r|}
\hline Growth phase & \multicolumn{1}{|l|}{ Apples } & \multicolumn{1}{l|}{ Pears } \\
\hline Irrigation volume - cubic metres per ha/year: Establishment & 2100 & 2100 \\
\hline Irrigation volume - cubic metres per ha/year: Year 2 (maintenance) & 4200 & 3570 \\
\hline Irrigation volume - cubic metres per ha/year: Year 3 & 7000 & 4200 \\
\hline Irrigation volume - cubic metres per ha/year: Year 4+ & 7000 & 7000 \\
\hline
\end{tabular}

Table 21: Water consumption per ha per pome fruit growth phase (Hortgro, 2007).

The electricity consumption of $0.3 \mathrm{kWh}$ per $\mathrm{m}^{3}$ water pumped is calculated based on the crop water requirements and the following assumptions:

- Pump efficiency of $70 \%$;

- 50 m pumping head and;

- Irrigation system efficiency of $80 \%$ (includes young and full bearing trees).

Using these four sources for water data, the weighted average, based on total hectares for apples and pears, is approximately $6500 \mathrm{~m}^{3}$ per hectare. A total of $2000 \mathrm{kWh}$ of electricity is used per hectare to pump water. The energy mix in the year 2000 , is represented by the ecoinvent $v .3$ dataset "Electricity, low voltage $\{Z A\} 2000 \mid$ market for | Alloc Def, U". The total operational output available for distribution in 2000 was $198 \mathrm{GWh}$. Table 22 shows the primary energy allocation to the grid mix in the year 2000 according to the National Energy Regulator (NERSA), 2000) and the ecoinvent country grid mix for South Africa.

Transmission losses are $7.4 \%$ of total energy available for distribution across high, medium and low voltage supply (ESKOM, 2000: 124) and this is replicated in the ecoinvent dataset. 


\begin{tabular}{|l|l|l|}
\hline Primary energy sources & NERSA, 2000 & $\begin{array}{l}\text { Electricity, high voltage, at } \\
\text { grid/ZA U 2000 }\end{array}$ \\
\hline Coal & $90 \%$ & $91 \%$ \\
\hline Nuclear & $4 \%$ & $6 \%$ \\
\hline Hydro & $1 \%$ & $1 \%$ \\
\hline Pumped storage & $3 \%$ & $1 \%$ \\
\hline Gas turbines & $1 \%$ & $1 \%$ \\
\hline
\end{tabular}

Table 22: Primary energy allocation comparison between NERSA and ecoinvent dataset for South Africa grid mix in year 2000.

\section{Other inputs}

The difference in the consumption of diesel between the Ecoinvent process models of fertiliser and pesticide application and the 2007 Combud total value is accounted for in process model Diesel, combustion $\{Z A\} \mid 2000$ | processing | Alloc Def, U. This dataset represents the diesel combustion from the use of agricultural machinery in various farming activities and is modified from the Ecoinvent process model "Diesel, burned in building machine \{GLO\}| processing | Alloc Def, U". The temporal validity of the dataset is from 1996 to 2014 . The diesel use in the 2007 Combud is stated in cost per hectare. This value is divided by the price per litre of diesel $(0.3 \%$ sulphur) at the coast in 2006 of R7.7022.

The distance from the farm to regional Packhouse facilities is estimated at $50 \mathrm{~km}$ using the ecoinvent v. 2.2 process "Operation, lorry 20-28t, fleet average/CH U" with no Euro specific standard. In 2000, South African heavy duty vehicles and fuel quality conformed to Euro 1 emission standards (Stone \& Bennett, 2000). In the ecoinvent v_2.2 database, the vehicle datasets conforming to specific Euro emission standards are only available from Euro 3, therefore the dataset "Operation, lorry $20-28$ t, fleet average/CH U" is used which includes the Euro 1 emission standard.

\subsubsection{Packhouse boundary}

The SimaPro model for the packhouse boundary for the year 2000 is a single dataset with two outputs:

- Pome fruit (ZA) at packhouse 2000 | local and export market | Alloc Def, U and;

- Pome fruit (ZA) at packhouse 2000 | for processing | Alloc Def, U.

The data used for the model is in Table 23. Pome fruit tonnages are allocated to export and local markets and processing (including dried fruit). Approximately $41 \%$ of the total fruit tonnes from farm gate was processing grade (canning, juicing, drying or other channels) according to

22 http://www.energy.gov.za/files/esources/petroleum/historyprice2006.html 
Deciduous Fruit Producers Trust (2000). The 2000 packhouse inventory model is an economic allocation between the processing and export and local market output based on the ZAR per ton in ZAR 2010. For the year $2000,90 \%$ of the environmental burdens were allocated to the export and local market fruit with the rest allocated to the fruit sent for processing. The percentage of the total intake that goes directly for packing or to the CA store from the farm varies from year to year. For this model it is assumed that $25 \%$ of the fruit taken in for packing annually is first stored in the CA store and the other $75 \%$ comes directly from the farm ${ }^{23}$. This assumption is also in place for the 2010 and 2020 model.

\begin{tabular}{|c|c|c|c|}
\hline \multirow{19}{*}{ 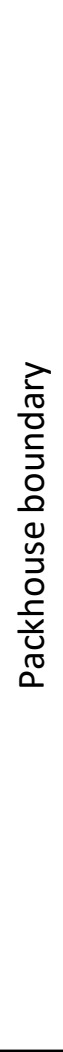 } & Input material/process & UoM & 2000 \\
\hline & $\begin{array}{l}\text { Total Tonnes output } \\
\text { (Processing, export, local and waste) }\end{array}$ & tonnes & $8.59 \mathrm{E}+05$ \\
\hline & Fruit for Processing & tonnes & $3.22 \mathrm{E}+05$ \\
\hline & Fruit for Export market & tonnes & $2.32 \mathrm{E}+05$ \\
\hline & Fruit for Local market & tonnes & $2.11 \mathrm{E}+05$ \\
\hline & Waste & tonnes & $9.33 \mathrm{E}+04$ \\
\hline & Grid Electricity & kWh & $1.66 \mathrm{E}+07$ \\
\hline & Direct Diesel usage & $\mathrm{L}$ & $1.02 \mathrm{E}+05$ \\
\hline & Direct LPG usage & $\mathrm{kg}$ & $2.17 \mathrm{E}+05$ \\
\hline & Corrugated cardboard (cartons \& pallet covers) & kg & $3.50 \mathrm{E}+07$ \\
\hline & Pulp trays & kg & $5.97 \mathrm{E}+05$ \\
\hline & Polystyrene trays & $\mathrm{kg}$ & $2.30 \mathrm{E}+06$ \\
\hline & Wooden bins & units & $8.86 \mathrm{E}+05$ \\
\hline & Wooden pallets (disposable \& reusable) & units & $6.92 \mathrm{E}+05$ \\
\hline & Packaging waste recycled & kg & $1.02 \mathrm{E}+06$ \\
\hline & Packaging waste sent to landfill & $\mathrm{kg}$ & $1.66 \mathrm{E}+06$ \\
\hline & Water & $\mathrm{m}^{3}$ & $2.92 \mathrm{E}+05$ \\
\hline & Floor area & $\mathrm{m}^{2}$ & $2.25 \mathrm{E}+05$ \\
\hline & Conveyor belt & $\mathrm{m}$ & $5.58 \mathrm{E}+03$ \\
\hline
\end{tabular}

Table 23: Total values for packhouse boundary for year 2000.

The electricity consumption per ton fruit packed is obtained from a benchmark study of energy usage in export fruit production, packing and cold storage operations by Bouwer, Von Broembsen \& Dodd (2008) due to the lack of available raw data prior to 2010. The unit of measure for energy intensity in packhouses is; kWh of electricity consumed per ton fruit packed. Electricity consumption in citrus and pome fruit packhouses ranged between 30 to $45 \mathrm{kWh}$ per ton fruit packed and the main contributors were electrical motors, lighting and carton glue machines.

\footnotetext{
${ }^{23}$ Richard Rose, Elgin Orchards.
} 
According to the packaging specialist at Two-A-Day ${ }^{24}$, pome fruit for local and export market was packed loosely in telescopic boxes such as the MK6 in Figure 14 with inner packaging consisting of pulp (kraft paper) or polystyrene trays. Plastic in the form of polypropylene or LDPE was not used and is thus excluded in the 2000 LCl. For corrugated cardboard, the amount used is based upon the cartons passed for export by the Perishable Products Export Control Board (PPECB) which is also extrapolated to the local market volumes. The carton equivalent used for the number of cartons passed for export is the MK6 carton. The generic MK6 telescopic carton with nett weight of 794 grams is used to calculate the corrugated cardboard consumption. The weights of pulp trays and polystyrene trays used in the cartons are calculated from the total boxes sent to the export and local markets. Calculations are in Appendix V. Plastic bins were only introduced into the fruit packaging industry around 2005 according to an industry expert ${ }^{25}$ and therefore only wooden bins are included in the year $2000 \mathrm{LCl}$. An example of a wooden bin typically used in the pome fruit industry is in Figure 15. The weight of a wooden bin is approximately $50 \mathrm{~kg}$ and can carry on average $400 \mathrm{~kg}$ of pome fruit. These bins are used approximately 1.4 times a season and have a lifespan of 10 years. The number of pallets used during the 2000 season was estimated based on the 2010 data. The white block wooden pallet (EUR 3) in Figure 16 was used for exported pome fruit. Disposable or blue block pallets were and still are used for the local market $(17 \mathrm{~kg})$. Approximately $75 \%$ of these disposal pallets were incinerated after a single season.

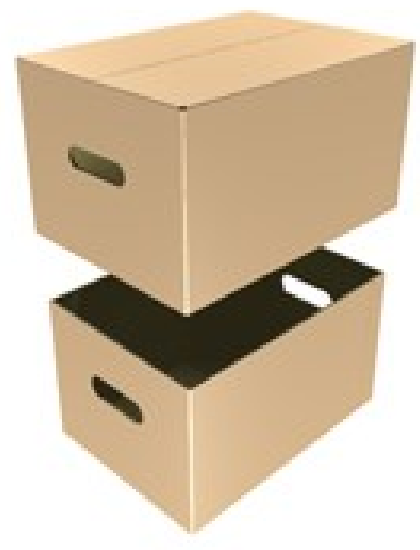

Figure 14: MK6 telescopic carton (APL, nd)

24 Danwill Philander: Packaging Specialist TAD. Tel no. 0218597500.

25 Piet van Bodegom: Independent consultant. pietvb@mweb.co.za 


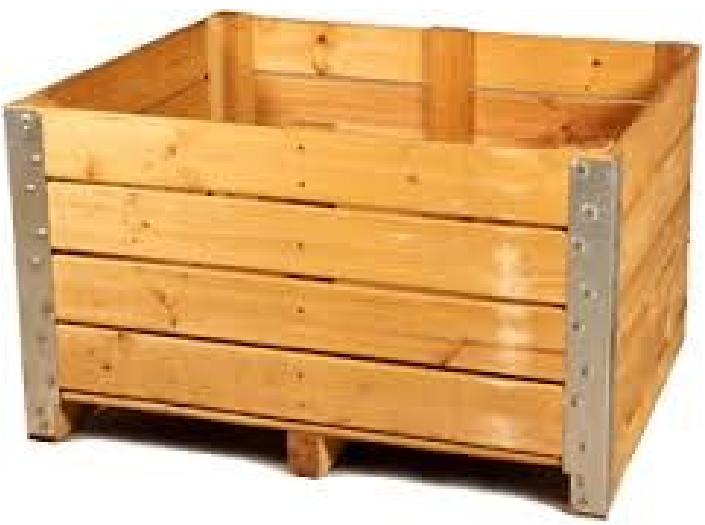

Figure 15: Wooden bin used for harvesting and storage in the CA Store. Source: Google images.

Water consumption per ton fruit packed is within the range of $260 \ell$ to $767 \ell$ and is captured as a triangular distribution within the model. The water consumption data is from Table 12 in the 2010 $\mathrm{LCl}$. Fuel use in terms of diesel and LPG is extrapolated from the $2010 \mathrm{LCl}$ due to unavailability of data. The infrastructure with regards to floor area and conveyor belt length has remained the same in the last 15 years and is extrapolated from the $2010 \mathrm{LCl}$.

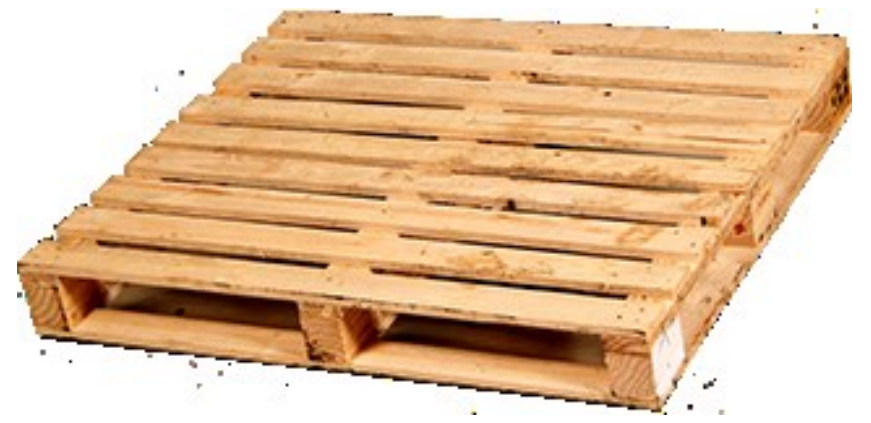

Figure 16: 2-way white block pallet $(23 \mathrm{~kg})$ used for export and local market. Source: Google images.

All packaging and fuel datasets in ecoinvent v. 2.2 include all activities at manufacturing plant and do not include transport to the Packhouse facility. For the transport activity the dataset "Transport, lorry 20-28t, fleet average/ZA U" is used for the distance of $100 \mathrm{~km}$ from manufacturing plant to packhouse facility.

\section{Waste}

The organic waste from packaging and storage in CA and cold storage is in the range of 15 to $20 \%$ according to (Milà Canals et al., 2007: 343). For the packhouse model the more conservative figure of $15 \%$ is used. The assumption is made that the organic waste is allocated equally between landfill disposal and composting. The disposable wooden pallets, which make up 64\% of total pallets used during the season, are burned after use. The ecoinvent v. 2.2 unit process datasets used for organic waste and disposable wooden pallets for the year 2000 are: 
- Disposal, municipal solid waste, $22.9 \%$ water, to sanitary landfill/CH U and Composting organic waste/RER $U$ for the organic waste component. Allocation of $50 \%$ organic waste to each process.

- Disposal, wood untreated, $20 \%$ water, to municipal incineration/CH U.

The incineration of disposable wooden pallets at the Packhouse facilities or for domestic use is modelled using the municipal incineration dataset. It is noted that the municipal incineration process in Europe has to comply to local air regulations with filters and scrubbers in flues which is not the case in the South African context. The process models used for waste from the packhouse are:

- Recycling cardboard/RER U

- Disposal, packaging cardboard, $19.6 \%$ water, to sanitary landfill/CH U

In the $2010 \mathrm{LCl}$ the packaging waste was $7 \%$ of total packaging used. This percentage was used for the packaging waste for the $2000 \mathrm{LCl}$ due to data unavailability. For paper based packaging the Paper Recycling Association of South Africa (PRASA) reported a 38\% recycling rate for the year $2000^{26}$ which was used to determine the amount of cardboard recycled in 2000.

No data for waste water volumes and treatment is available for packhouses during this period and this data was excluded from the inventory.

\subsubsection{CA and CS facilities}

For the year 2000, the CA and CS facilities are modelled in SimaPro in the following datasets:

- Pome fruit (ZA) | CA Storage | 2000, U

- $\quad$ Pome fruit (ZA) | Cold Store | 2000, U

Generally CS benchmarking information measures electricity use per square metre of floor space or per volume of warehouse space. However, the product mass of the fruit and duration stored are important factors in fruit refrigeration. The energy benchmark study by Bouwer, Von Broembsen \& Dodd (2008) introduced the concept of the cold unit which is the amount of electricity consumed in $\mathrm{kWh}$ per $1000 \mathrm{~kg}$ of fruit per day. CA and CS electricity usage determined in the study varied significantly from 5 to $15 \mathrm{kWh}$ per cold unit. For the model a triangle probability distribution is used to account for the range of values. For the CA store, the recommended storage duration for apples and pears across all varietals is approximately 6 months and the minimum period of storage for the fruit to qualify as CA fruit is 60 days (Bodegom et al., 2013: 50$55)$. For the CS, the average number of storage days is approximately 35 days ${ }^{27}$. The total values of the inputs to the CA and CS model are in Table 24.

${ }^{26} \mathrm{http}: / / w w w . p a c k a g i n g s a . c o . z a / s a s-p a p e r-r e c y c l i n g-r a t e-a s-g o o d-a s-d e v e l o p e d-c o u n t r i e s /$

27 Piet van Bodegom: Independent consultant. E-mail address: pietvb@mweb.co.za 


\begin{tabular}{|l|c|r|}
\hline CA Store inventory & UoM & Year 2000 \\
\hline Tonnage stored & Tonnes & $2.15 \mathrm{E}+05$ \\
\hline Building, hall, steel construction/CH/I U & $\mathrm{m}^{2}$ & $1.20 \mathrm{E}+05$ \\
\hline Electricity, low voltage, at grid/ZA U 2000 & $\mathrm{kWh}$ & $1.29 \mathrm{E}+08$ \\
\hline Number of days stored & days & $6.00 \mathrm{E}+01$ \\
\hline Refrigerant leakage: Ammonia & $\mathrm{kg}$ & $1.66 \mathrm{E}+04$ \\
\hline Cold Store inventory & Tonnes & $4.43 \mathrm{E}+05$ \\
\hline Tonnage stored & $\mathrm{m}^{2}$ & $5.65 \mathrm{E}+05$ \\
\hline Building, hall, steel construction/CH/I U & $\mathrm{kWh}$ & $1.55 \mathrm{E}+08$ \\
\hline Electricity, low voltage, at grid/ZA U 2000 & days & $3.50 \mathrm{E}+01$ \\
\hline Number of days stored & $\mathrm{kg}$ & $2.48 \mathrm{E}+04$ \\
\hline Refrigerant leakage: Ammonia
\end{tabular}

Table 24: Total values for CA and CS inventory.

Before 2010, the main refrigerants used in CA and CS were Freon (HCFC - 22 \& R-134a) and Ammonia (Bodegom et al., 2013). According to a fruit refrigeration industry expert ${ }^{28}, 99 \%$ of tonnages stored in the period around the year 2000 made use of Ammonia. Leakage figures are not available for this period, with the result that for the year 2000 model the values were extrapolated from the 2010 inventory. The floor area for the facilities in the $\mathrm{LCl}$ are also extrapolated from the $2010 \mathrm{LCl}$.

\subsection{Future: 2020}

This section describes the data collection and modelling of the pome fruit sector used for the prospective ALCA.

\subsubsection{System description and Data}

The data forecasts required to build the pome fruit LCI model for the year 2020 is based on current knowledge and future scenarios gathered from expert opinion. For the year 2020, literature is consulted to determine eco-efficiency trends in farming and agro-processing practises resulting in reduced $\mathrm{CO}_{2} \mathrm{e}$ emissions. At farm level the latest Hortgro pome fruit agricultural budgets are used together with expert opinion on forecasted inputs per hectare, whereas land occupation and yields are sourced from the Bureau for Food and Agricultural Policy (BFAP). The input quantities of water, fertilisers, diesel and pesticides will remain the same but the overall management of application will be more precision based. For the agro-processing boundaries, expert opinion is consulted on probable future inputs.

\footnotetext{
28 Jeff Wedgewood, Consulting Refrigeration Engineer: 0218724824
} 
The ecoinvent v. 3.3 datasets are used for the 2020 pome fruit model. Among the major model inputs, the electricity grid mix for 2020 is a new SimaPro unit process dataset based on the projected operational output in GWh including predicted new generation technologies.

\subsubsection{Farm boundary}

The forecast up to 2025 for land occupation and yields for pome fruit is obtained from BFAP. For apple production, BFAP forecasts a $2 \%$ increase on current bearing hectares and a $5.5 \%$ increase for total yields for 2020 based on 2015 figures. For pears a 3.5\% increase is forecasted for bearing hectares and $6.5 \%$ increase for total yields. This translates to 40 tonnes per bearing hectare for apples and 33 tonnes per bearing hectare for pears. Non-bearing hectares is approximated at $6 \%$ of total hectares for apples and pears for the year 2020 . The total projected yield and hectares for 2020 are in Table 25.

\begin{tabular}{|c|r|r|r|}
\hline Fruit & Total production & Total hectares & \multicolumn{1}{c|}{ Tonnes/ha } \\
\hline Apples & 971028 & 25556 & 38 \\
\hline Pears & 437545 & 13937 & 31 \\
\hline \multicolumn{2}{|c|}{ Table 25: Projections for land occupation and total yield for year 2020 derived from BFAP (2016: 108) }
\end{tabular}

The SimaPro unit process dataset for the farm in 2020 is:

- Pome fruit (ZA) | Production | 2020

The data from BFAP indicates that there is a substantial drive in the pome industry to improve yields of grade 1 and grade 2 fruit in reaction to rising input costs and to ensure economic sustainability of the industry. Tree densities are set to increase from the standard 1250 per hectare to between 1600 and 2000 by the year 2020. Tree configurations and trellising is becoming commonplace with examples in Figure 17 and Figure 18. These high-density plantings typically have yields of 100 tonnes per hectare for bearing hectares and this is forecasted to increase up to 150 tonnes per hectare in future. 


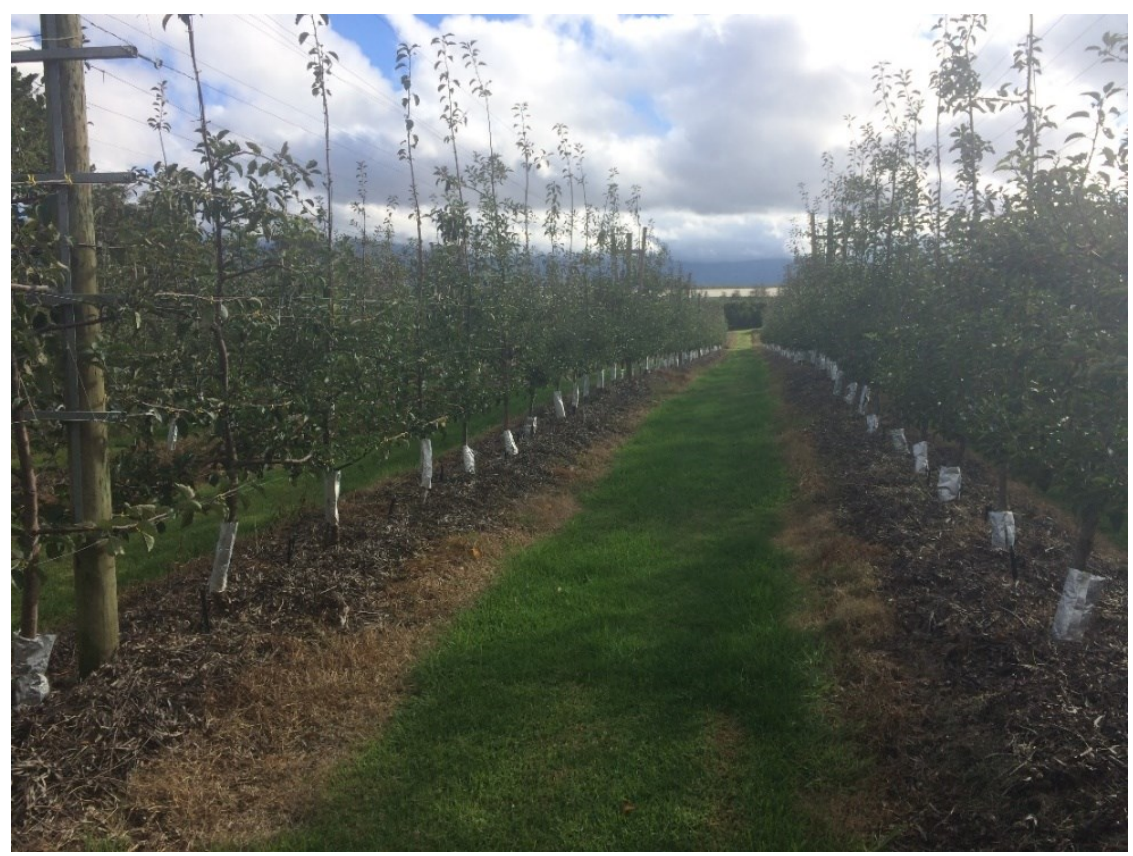

Figure 17: Single tree trellising for optimum picking.

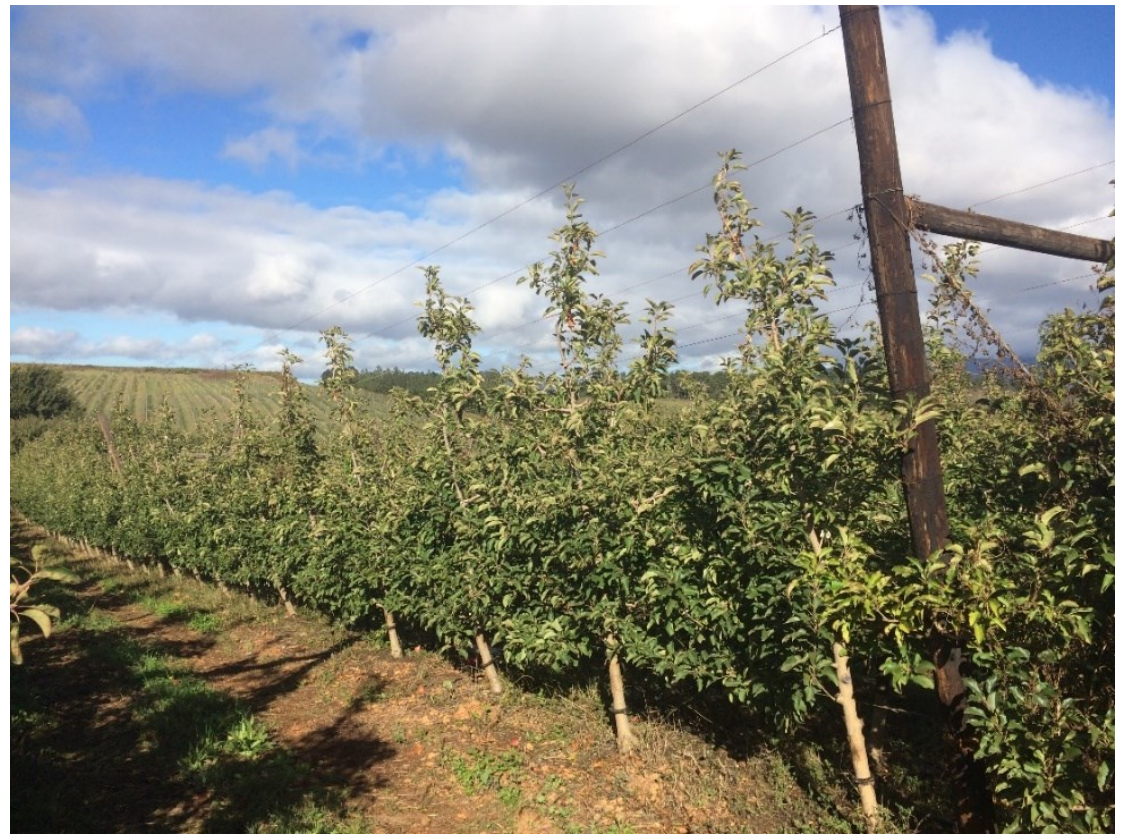

Figure 18: High density apple tree configuration

\section{Land transformation}

To account for the conversion of natural virgin land to agricultural land use from 2019 to 2020 is difficult to determine as the increase in hectares of pome orchards could be the conversion of existing agricultural land. With the ongoing extreme drought conditions from 2016, the expansion 
into natural land is highly unlikely due to water allocation constraints. With the hectares of LUC approaching zero up until 2020 it is assumed that negligible LUC will occur from 2019 to 2020.

The permanent cropland coverage in 2020 is allocated to the model using the following resources from nature:

- Transformation, from permanent crop, fruit, intensive.

- Transformation, to permanent crop, fruit, intensive.

To account for one year's worth of land occupation, the ecoinvent v. 3.3 unit process: Occupation, permanent crop, fruit, intensive was used. Once again, a lifespan of 25 years was specified for the orchard.

\section{Fertilisers}

According to Hortgro pome fruit budgets and experts in the industry ${ }^{29}$, the average application in $\mathrm{kg}$ of fertilisers per hectare approaching the year 2020 are as follows:

- Nitrogen: $153.4 \mathrm{~kg}$

- Phosphorus: $43.6 \mathrm{~kg}$

- Potassium: $76.03 \mathrm{~kg}$

The SimaPro unit processes used for fertilisers in the Pome fruit farm model for 2020 are:

- Nitrogen fertiliser, as $\mathrm{N}\{\mathrm{GLO}\} \mid$ market for | Alloc Def, $U$

- Phosphate fertiliser, as P2O5 \{GLO\}| market for | Alloc Def, U

- Potassium fertiliser, as K2O \{GLO\}| market for | Alloc Def, U

The amounts of pure $\mathrm{P}$ and $\mathrm{K}$ are converted to $\mathrm{P}_{2} \mathrm{O}_{5}$ and $\mathrm{K}_{2} \mathrm{O}$.

By 2020 fertigation will be more widely used. However, fertiliser application using a broadcaster will be more precision based with application closer to the tree instead of the entire surface area of the orchard. Application by hand will take place in the majority of cases. The SimaPro unit process "Fertilising, by broadcaster \{GLO\}| Market for | Alloc Def, U" is used to account for granular fertiliser application for $40 \%$ of the total hectares (bearing and non-bearing). In addition to N, P and K, lime and wood chips for mulching will be applied. The SimaPro unit process datasets used for these inputs are as follows:

- Lime $\{G L O\} \mid$ market for | Alloc Def, $U$

- Mulching $\{G L O\} \mid$ market for | Alloc Def, U.

The emissions to air, soil and water from fertiliser use and heavy metals are calculated for the year 2020 and are in Appendix II.

29 Peter Dall: International Pome Fruit Alliance

Nico Ferreira: Technical advisor TAD 


\section{Pesticides and Agro-chemicals}

Forecasted data for pesticide use in the pome fruit industry in 2020 is obtained from spray programs for Two-A-Day (TAD), a program for a farm in Mpumalanga and Hortgro agricultural budgets (2016). The SimaPro unit process dataset used for the pesticide production and application is:

- Pesticides Pome fruit 2020 | production and application | $\{Z A\} \mid$ Alloc Def, U.

The pesticide model for pome fruit in 2020 is available in Appendix III.

\section{Irrigation}

A new SimaPro unit process dataset for 2020 "Irrigation, pome fruit $\{Z A\} 2020$ | market for | Alloc Def, U" is created from the global dataset "Irrigation $\{$ RoW $\} \mid$ market for | Alloc Def, U using South African specific inputs of:

- Water, unspecified natural origin, ZA;

- Diesel $\{Z A\} \mid$ market for | Alloc Def, $U$ and;

- Electricity, low voltage $\{Z A\} 2020$ | market for | Alloc Def, U

Water availability and climate change has been identified as the greatest risk the fruit industry faces $^{30}$. Consequently there is a significant drive in developing water saving methodologies and these include amongst others the use of fixed (Figure 19) and draped nets ${ }^{31}$, short range microsprayers, soil probes to accurately measure soil moisture and the application of kaolin to reduce plant water demand without affecting yield and quality (BFAP, 2016: 107). Experts in the industry have indicated a $10 \%$ to $20 \%$ drop in overall water consumption per hectare compared to 2010 due to the ongoing drought from 2016 in pome fruit growing areas. These forecasted decreases in water consumption is applied to the 2010 value of $6222 \mathrm{~m}^{3}$ per hectare to obtain the minimum and maximum figures per hectare.

Electricity consumption is also expected to become more efficient. According to a study of pumping systems used in farm irrigation systems in the Western Cape (Bouwer, 2017) the overall pumping system efficiency ratio is $65 \%$ and can be increased to $90 \% 32$. Irrigation system efficiencies are also predicted to improve significantly into the future through application of the following practices:

- Optimum sizing and application of pumps to irrigation system;

- Improved water management and irrigation scheduling (use of short range micro-sprayers, mulching, netting installations, soil probes) and;

\footnotetext{
30 HORTGRO 2016 Science Symposium

31 http://www.hortgro-science.co.za/net-gain-amid-water-climate-challenges/

32 Efficiency ratio according to PSAT tool. Pump with efficiency ratio of 100 is at optimum.
} 
- Optimizing irrigation network designs and distribution systems to use electricity more efficiently.

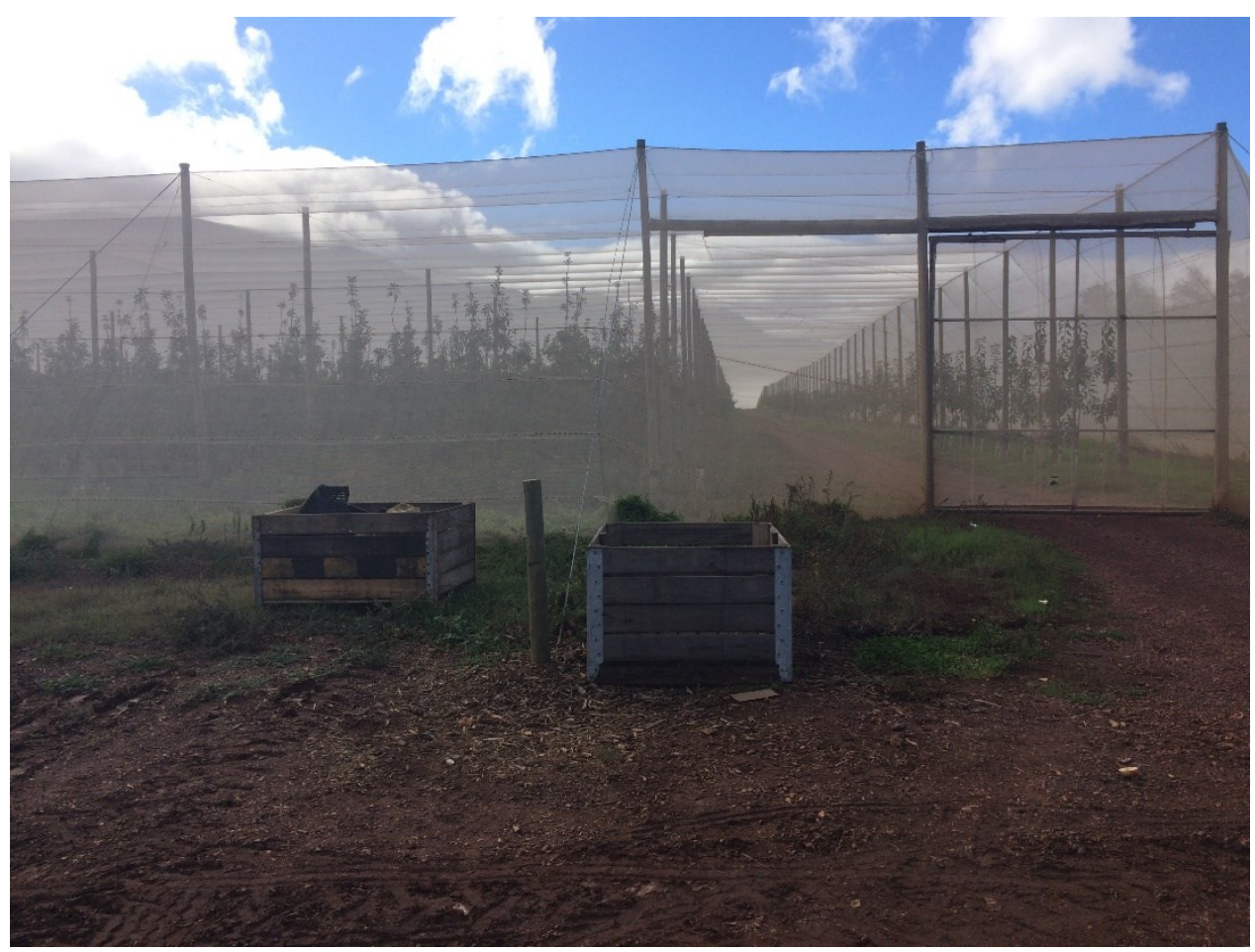

Figure 19: Fixed net installation.

For the 2020 irrigation model in SimaPro, the predicted electricity required to pump $1 \mathrm{~m}^{3}$ of water is $0.5 \mathrm{kWh}$ based on the Bouwer (2017) study with proposed system efficiencies included. This figure includes the borehole and irrigation pumps in series.

\section{Electricity}

The total GWh output from the national grid is predicted to be approximately $212000 \mathrm{GWh}$ in the year 2020. The total annual output from 2010 to 2016 is in Figure 20 from the Eskom annual integrated report figures. This trend is extrapolated to predict the output up until 2020. The grid mix in 2020 will consist of the following technologies (Department of Energy (DoE), 2013; Department of Environmental Affairs, 2014):

- Coal (existing and return to service);

- Nuclear;

- Hydro;

- Hydro pumped storage;

- Coal (Fluidised Bed Combustion \& Pulverised Coal);

- Open Cycle Gas Turbines diesel \& liquid fuels (existing);

- Open Cycle Gas Turbines (gas expansion);

- Onshore wind; 
- Concentrated Solar Power (CSP);

- Photovoltaic (PV);

- Imported hydro.

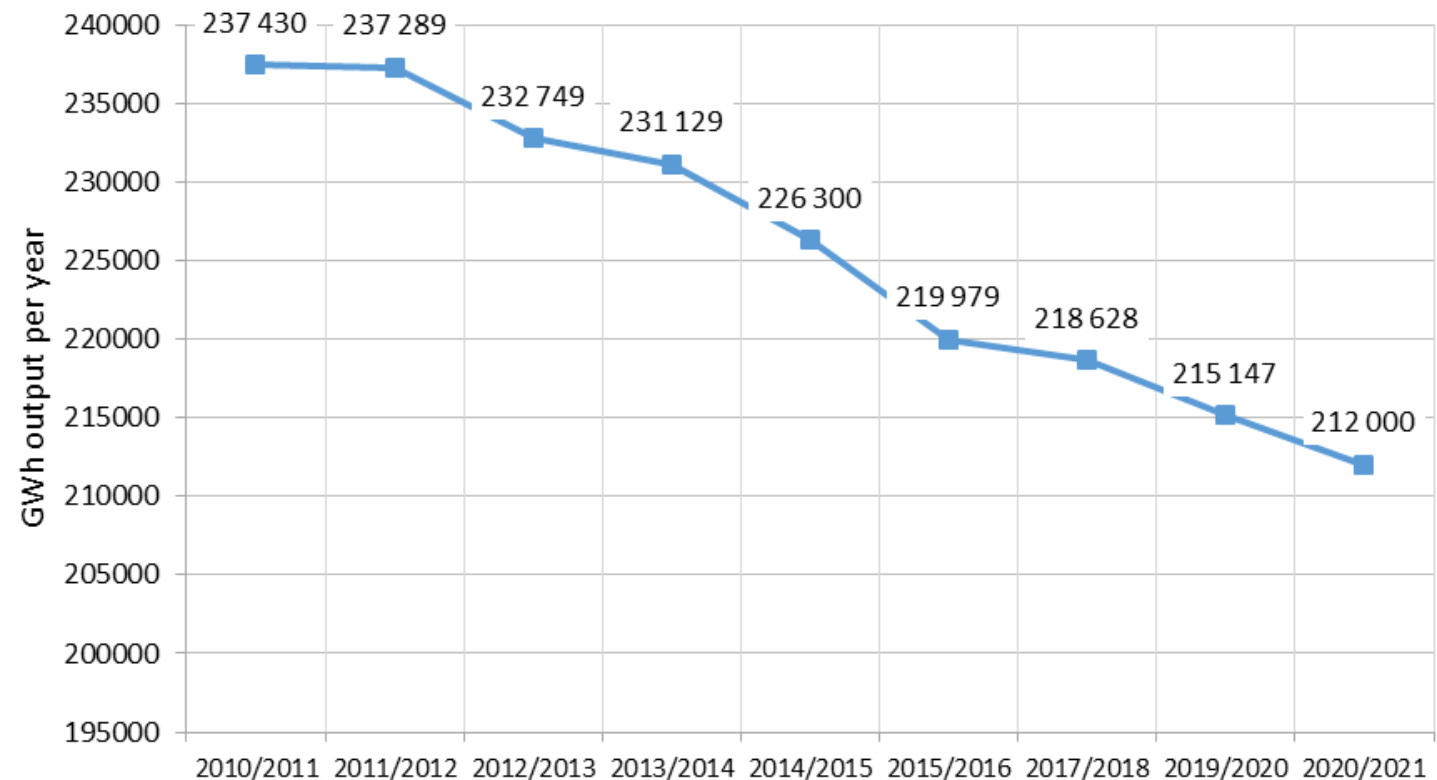

Figure 20: Projected total output in GWh from national grid derived from Eskom Annual reports.

The operational output in GWh of each of these technologies is included in the SimaPro unit process dataset also available in Appendix $\mathrm{VI}$ :

- Electricity, high voltage $\{Z A\} 2020$ | production mix | Alloc Def, U

The 'new' coal power plants Medupi and Kusile have improved thermal efficiency of approximately $40 \%$ compared with the existing power plants at $34 \%$. This is due to the use of supercritical boilers and turbines which operate under higher temperature and pressure resulting in less fuel use and less $\mathrm{CO}_{2} \mathrm{e}$ emissions ${ }^{33}$. The direct dry cooling technology in place also results in less water used for cooling the steam as it is a closed loop system unlike the wet cooling technology used in older plants. These factors are included in the 'new' coal SimaPro dataset which can be viewed in Appendix VI

- Electricity, high voltage $\{Z A\} \mid$ electricity production, NEW coal | Alloc Def, $U$.

As at June 2017, 3 of the 6 units at Medupi and Unit 1 at Kusile coal fired power stations were operational and synchronised to the national grid ${ }^{34}$. According to the Eskom new build program, the last remaining unit at Medupi will be synchronised to the grid by May 2020 and Unit 3 at Kusile

33 http://www.eskom.co.za/Whatweredoing/NewBuild/MedupiPowerStation/Documents/medupifactsheetsept2013.pdf

34 http://www.eskom.co.za/news/Pages/Junn1.aspx 
by August $2020^{35}$. This results in output of $56765 \mathrm{GWh}$ taking into account the estimated load factor of $85 \%$ (Department of Energy, 2013) in 2020. Hydro and hydro pumped storage values are taken from the projections in Department of Environmental Affairs (2014). It is predicted that the year 2020 grid mix will not include the expansion of open cycle gas turbines (OCGT) utilising liquefied natural gas (LNG) from Coega and Mossel Bay. There is a postponement in releasing the RFQ for the LNG-to-Power IPP awaiting the outcome of the latest IRP approval by cabinet $^{36}$.

The share of renewables in the year 2020 electricity mix according to the Independent Power Producers Procurement Programme (IPPPP) is $7 \mathrm{GW}$ (IPP Office, 2017: 20). This planned installed capacity results from the 7 successfully implemented bid windows $(1,2,3,3.5,4,1 S 1$ and 2S2) as at March 2017. However, Eskom has taken the stance since July 2016 to not enter into further power purchase agreements after bid window $2 \mathrm{~S}^{37}$. This has led to approximately $2.3 \mathrm{GW}$ of capacity awaiting financial closure in bid window 3.5 and 4 (Renewable Energy Independent Power Producers Programme, 2017). In September 2017, the Minster of Energy announced that all outstanding PPAs will be signed by 28 October 2017 at a tariff not exceeding $77 \mathrm{c} / \mathrm{kWh}^{38}$. With this as background and no clear indication of what installations will be operational by 2020 , it is predicted that the total renewable capacity will be approximately 4.1 GW.

For the PV electricity generation the ecoinvent unit process dataset "Electricity, high voltage $\{Z A\} \mid$ electricity production, photovoltaic, $570 \mathrm{kWp}$ open ground installation, multi-Si | Alloc Def, U" is used. The GWP result of this dataset, according to the IPPC $2013100 \mathrm{a}$ method, is $30.4 \mathrm{~g}$ $\mathrm{CO}_{2} \mathrm{e} / \mathrm{kWh}$ which is aligned with the result in the study by Ramdari \& Potts (2016).

Taking into account the projected capacity for each technology discussed, the predicted electricity mix for the year 2020 in GWh operational output is in Table 26.

\footnotetext{
35 http://www.eskom.co.za/news/Pages/NO22.aspx

36 https://www.ipp-gas.co.zal

${ }^{37}$ https://www.moneyweb.co.za/news/industry/eskom-takes-a-stand-against-private-power-generations/

38 https://www.moneyweb.co.za/news/south-africa/signing-renewable-ipps-by-october-not-that-simple/
} 


\begin{tabular}{|c|r|}
\hline Technology & \multicolumn{1}{|c|}{ GWh } \\
\hline Old coal & 116621 \\
\hline Nuclear & 13004 \\
\hline Hydro & 2366 \\
\hline Hydro pumped storage & 8475 \\
\hline Coal (Supercritical) - New & 56765 \\
\hline OCGT diesel \& liquid fuels (existing) & 950 \\
\hline Onshore wind & 5203 \\
\hline CSP & 2102 \\
\hline PV & 3874 \\
\hline Imported hydro & 2639 \\
\hline Total & $\mathbf{2 1 2} \mathbf{0 0 0}$ \\
\hline
\end{tabular}

Table 26: Projected annual generation in 2020 per technology type.

\section{Other inputs}

HDPE netting installations and draped nets will be used more extensively by 2020 . Approximately $10 \%$ of total hectares of pome fruit orchards will be covered. The netting has a lifetime of 25 years and is removed when a new orchard is established. Trellising of trees will also be more widespread and the ecoinvent dataset "Trellis system, wooden poles, soft wood, tar impregnated $\{G L O\} \mid$ market for | Alloc Def, U” is included in the $2020 \mathrm{LCl}$ for the farm.

Transport of fertilisers and agro-chemicals to the farm is excluded in this model as these inputs are stored in centralised storehouses (Two-A-Day, Kromco) close to the farms and collected when required. For the delivery of fruit to the packhouse, the distance from the farm to the Packhouse facilities is estimated at $50 \mathrm{~km}$ and the ecoinvent v. 2.2 process "Transport, lorry 20-28t, fleet average/ZA U" is used. It is not expected that South African refineries will be producing fuels of a higher EURO standard than the current Euro 2 standard currently available by 2020 .

\subsubsection{Packhouse boundary}

The SimaPro unit process datasets for the packhouse boundary for the year 2020 are:

- Pome fruit (ZA) at packhouse 2020 | local and export market | Alloc Def, U and;

- Pome fruit (ZA) at packhouse 2020 | for processing | Alloc Def, U.

Pome fruit tonnages are allocated to local markets, export and processing (including dried fruit) according to forecasts from BFAP (2016: 109). Approximately $33 \%$ of the total fruit tonnes from farm gate will fall into processing grade (canning, juicing, drying or other channels). For the year 2020 model an economic allocation is applied to the processing, export and local tonnages using 
the forecasted ZAR per ton for apples in 2020 in ZAR 2010. $90 \%$ of the environmental burdens are allocated to the export and local fruit with the remainder allocated to the fruit for processing. $25 \%$ of fruit intake into the packhouse is first stored in the CA Store and then packed. Input data for the packhouse model is in Table 27.

\begin{tabular}{|c|c|c|c|}
\hline \multirow{26}{*}{ 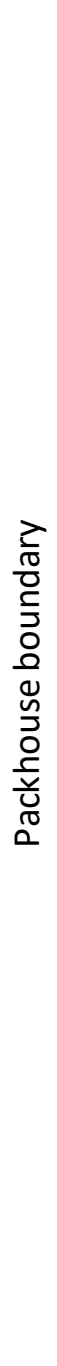 } & Input material/process & UoM & 2020 \\
\hline & Total Tonnes output & tonnes & $1.41 \mathrm{E}+06$ \\
\hline & Fruit for Processing & tonnes & $4.59 \mathrm{E}+05$ \\
\hline & Fruit for Export & tonnes & $6.53 \mathrm{E}+05$ \\
\hline & Fruit for Local & tonnes & $2.82 \mathrm{E}+05$ \\
\hline & Waste fruit & tonnes & $1.41 \mathrm{E}+04$ \\
\hline & Grid Electricity & $\mathrm{kWh}$ & $2.97 \mathrm{E}+07$ \\
\hline & PV Solar electricity & kWh & $3.63 \mathrm{E}+06$ \\
\hline & Direct Diesel usage & $\mathrm{L}$ & - \\
\hline & Direct LPG usage & $\mathrm{kg}$ & - \\
\hline & Corrugated cardboard (cartons \& pallet covers) & $\mathrm{kg}$ & $5.88 \mathrm{E}+07$ \\
\hline & Pulp trays & $\mathrm{kg}$ & $3.20 \mathrm{E}+04$ \\
\hline & Polystyrene trays & $\mathrm{kg}$ & $2.80 \mathrm{E}+05$ \\
\hline & Bio-based polypropylene & $\mathrm{kg}$ & $2.61 \mathrm{E}+05$ \\
\hline & Polypropylene & $\mathrm{kg}$ & - \\
\hline & PET & $\mathrm{kg}$ & - \\
\hline & LDPE & $\mathrm{kg}$ & $6.02 \mathrm{E}+05$ \\
\hline & HDPE & $\mathrm{kg}$ & $3.70 \mathrm{E}+06$ \\
\hline & Wooden bins & units & $9.35 \mathrm{E}+05$ \\
\hline & Plastic bins & units & $9.35 \mathrm{E}+05$ \\
\hline & Wooden pallets (disposable \& reusable) & units & $1.13 \mathrm{E}+06$ \\
\hline & Packaging waste recycled & $\mathrm{kg}$ & $3.49 \mathrm{E}+06$ \\
\hline & Packaging waste sent to landfill & $\mathrm{kg}$ & $7.14 \mathrm{E}+05$ \\
\hline & Water & $\mathrm{m}^{3}$ & $4.80 \mathrm{E}+05$ \\
\hline & Floor area & $\mathrm{m}^{2}$ & $3.69 \mathrm{E}+05$ \\
\hline & Conveyor belt & $\mathrm{m}$ & $9.16 \mathrm{E}+03$ \\
\hline
\end{tabular}

Table 27: Total inputs for packhouse boundary in year 2020.

According to an energy expert in the agro-processing industry, there will be an approximate 5\% improvement in energy consumption compared to the 30 to $45 \mathrm{kWh}$ per ton fruit packed in the study done by Bouwer, Von Broembsen \& Dodd (2008) by the year 2020. For this input a triangular probability distribution is used for the range specified. At the agro-processing boundary the installation of renewable Small Scale Embedded Generation (SSEG) electricity, specifically photovoltaic (PV), is a viable proposition and gaining substantial ground due to the energy profile of these facilities (Janse van Vuuren, 2015). Currently, photovoltaics mounted on packhouse roofs supplement the grid electricity demand. As at June 2017 there was $551 \mathrm{kWp}$ installed 
capacity on pome fruit packhouses according to the PQRS database ${ }^{39}$. PQRS has an extensive database on SSEG PV capacity in the commercial, industrial and domestic sectors in South Africa. It is predicted that by the year 2020 there will be approximately $1.25 \mathrm{MWp}$ installed capacity on packhouses packing pome fruit (Figure 21) using the compound annual growth rate (CAGR) of $23 \%$ annualised from 2013 to 2016 . This electricity input is modelled using the ecoinvent v. 3.3 dataset "Electricity, low voltage $\{Z A\} \mid$ electricity production, photovoltaic, $3 \mathrm{kWp}$ slanted-roof installation, multi-Si, panel, mounted | Alloc Def, U”.

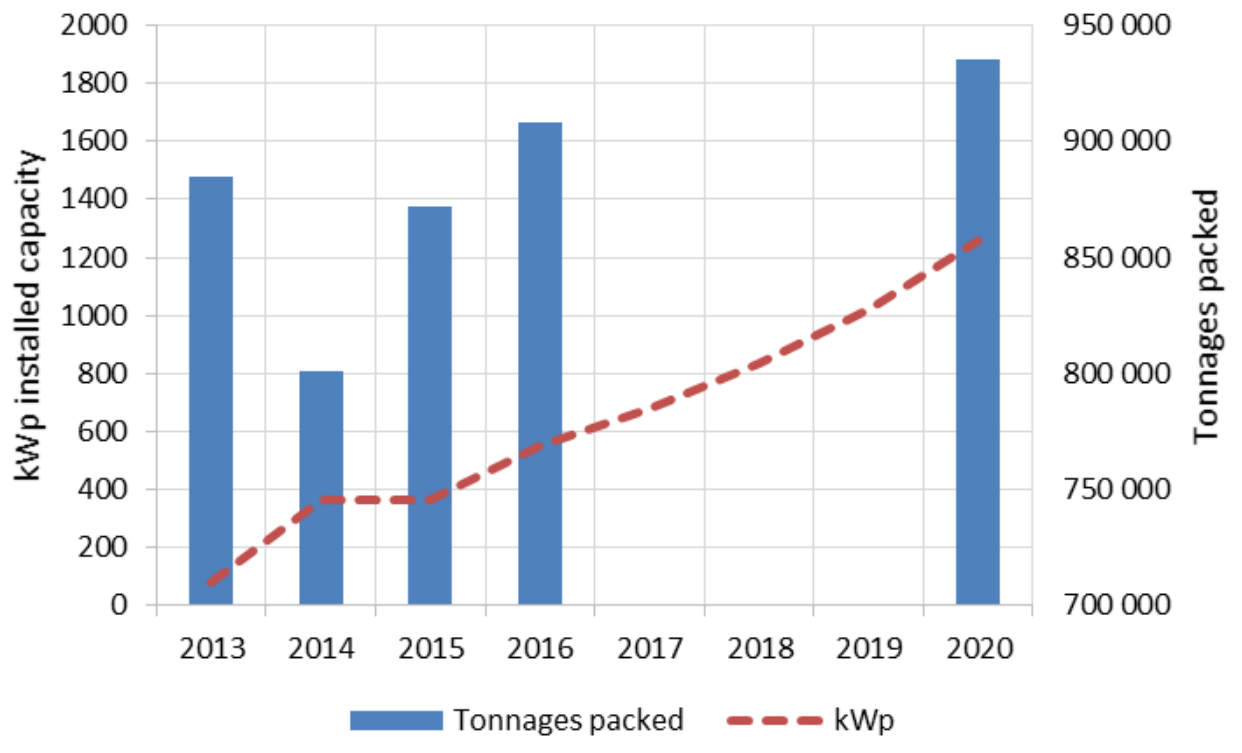

Figure 21: Predicted packhouse PV capacity by year 2020 using CAGR.

By 2020 it is predicted by an industry expert ${ }^{40}$ that approximately $3 \%$ of tonnages packed for the local and export market will make use of re-usable plastic containers (RPC). An LCA study by Singh, Chonhenchob \& Singh (2006) found that the RPC (Figure 22) requires 39\% less total energy, produces $95 \%$ less total solid waste and generates $29 \%$ less GHG emissions compared to the single use corrugated cardboard tray. The lifespan of an RPC is approximately 10 years (Kitinoja et al., 2013: 21) and made from high density polyethylene.

The supply chain factors that favour the adoption of the RPC in the local and export market is dependent on the following (Twede \& Clarke, 2004):

- Strong channel leader with cost savings incentive;

- Short supply chain (in time);

- Short shipping distance or network for repositioning;

- Efficient sorting, cleaning and tracking systems and;

- Industry consortia for standardization.

${ }^{39}$ http://pqrs.co.za/: Carel Ballack

40 Piet van Bodegom, Consulting Engineer: pietvb@mweb.co.za 
Concerning exports, the South African pome fruit supply chain complies with all factors required for RPC except for a short supply chain time and short shipping distance. Therefore the deployment of RPC would be more applicable to the local market. However, the risks of disease, less fruit pack out per pallet, cost and logistics has limited the widespread adoption of this packaging format in South Africa ${ }^{41}$.

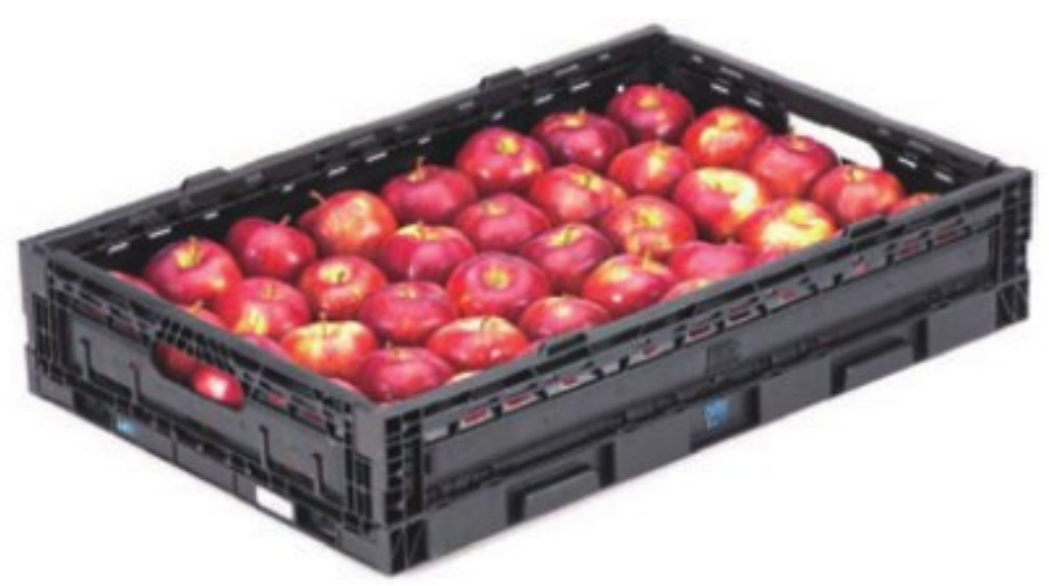

Figure 22: Reusable plastic container used for apples (Singh, Chonhenchob \& Singh, 2006).

Another packaging material that has been in use and gaining wide adoption since 2015, is laminated bio-based polypropylene. This material is used for the 'flow wrap' packaging format used for export apples and pears as shown in Figure 23. The 'flow wrap' packs are packs of 4 to 6 apples or pears with a total average weight of $1 \mathrm{~kg}$ which are then packed in corrugated cardboard cartons or RPC for the export market. This flow wrap packaging was used for $100 \%$ of the UK market volume $(87 \mathrm{kT})$ and $3 \%$ of the Far East and Asia market volume $(164 \mathrm{kT})$ in $2016^{42}$. It is predicted that by the year 2020 , this coverage will decrease by at least $30 \%$ due to some global initiatives such as the newly initiated UK Plastics Pact ${ }^{43}$ which aims to only import or manufacture plastic packaging which is $100 \%$ reusable, recyclable and compostable and eliminate all single use plastics by 2025 . The EU has also responded with the European Commission's Plastics Strategy 2018 which plans to introduce policy to incentive a plastic circular economy and extend producer and Extended Producer Responsibility Schemes (European Commission, 2018).

For the Packhouse model, this material is represented by the dataset:

- Polylactide, granulate $\{$ GLO\}| market for | Alloc Def, U.

\footnotetext{
41 Roshae Kenny: APL

42 Bryce Mclntyre: Senior Packaging Specialist, KaapAgri

43 http://www.wrap.org.uk/content/the-uk-plastics-pact
} 


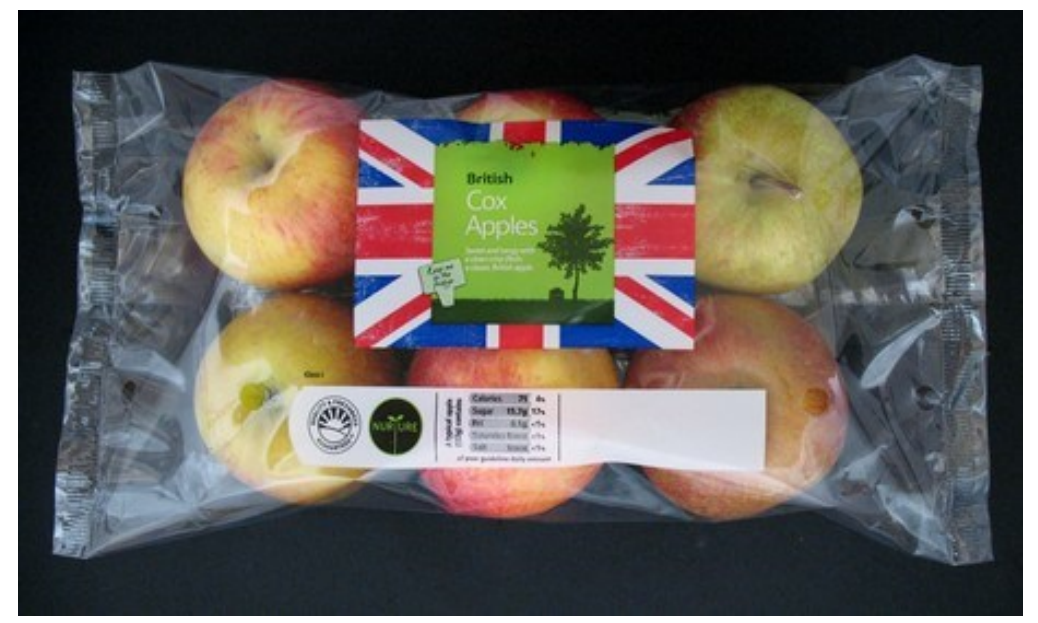

Figure 23: Example of apples packaged in flow wrap packaging format. Source: Freshplaza.com

Corrugated cardboard will still be used for the majority of volumes packed by 2020 . The MK6 carton format (Figure 14) is used to calculate the amount of corrugated cardboard used for the export and local tonnages. Pulp and polystyrene trays will still be used in the cartons for loose packed fruit for the local market, but this will decrease per ton packed due to the increasing use of LDPE bags. By 2020 there will be a wider adoption of plastic bins and the ratio of plastic to wooden bins will increase to 50\%. The number of pallets used during the 2020 season was estimated based on the 2010 data.

Water consumption per ton fruit packed is within the range of $260 \ell$ to $767 \ell$ and is captured as a triangular distribution within the model. It is predicted that only electrical forklifts will be in operation by 2020. The infrastructure, with regards to floor area and conveyor belt length per ton fruit, will remain constant and is extrapolated from the $2010 \mathrm{LCl}$.

\section{Waste}

The organic waste from packaging and storage in CA and cold storage is approximately $1 \%$ of total intake. It is assumed that all organic waste is composted or used for animal feed since there has been a growing trend within the CCC data that organic waste sent to landfill is on the decrease. The disposable wooden pallets, which will make up $64 \%$ of total pallets used during the season, are burned after use. The ecoinvent v. 3.3 unit process datasets used for organic waste and disposable wooden pallets for the year 2020 are:

- Biowaste $\{$ RoW\}| market for | Alloc Def, U and;

- Waste wood, untreated $\{$ RoW $\} \mid$ treatment of waste wood, untreated, municipal incineration | Alloc Def, U.

Packaging waste is $7 \%$ of total packaging used which is in line with the $2010 \mathrm{LCl}$ values. Corrugated cardboard packaging will make up $94 \%$ of the total weight of packaging used and the 
recycling rate of cardboard and paper by 2020 is forecasted to be in the range of $83 \%$ to $90 \%{ }^{44}$. Using these recycling rates, $83 \%$ of cardboard and plastic packaging waste is recycled in the model. The unit process datasets used for waste from the packhouse are:

- Mixed plastics (waste treatment) \{GLO\}| recycling of mixed plastics | Alloc Def, U;

- Waste plastic, mixture $\{$ RoW $\} \mid$ treatment of waste plastic, mixture, sanitary landfill | Alloc Def, U;

- Recycling cardboard |market for|ZA, Alloc Def, $U$ and;

- Waste paperboard $\{$ RoW\}| treatment of, sanitary landfill | Alloc Def, U.

\subsubsection{CA and CS facilities}

For the year 2020, the CA and CS facilities are modelled in the following datasets:

- Pome fruit (ZA) | CA Storage | 2020, U and;

- Pome fruit (ZA) | Cold Store | 2020, U.

It is predicted by an industry energy expert ${ }^{45}$ that the electricity consumption per cold unit in the CA and CS facilities will decrease by 10 to $15 \%$ on the baseline of 5 to $15 \mathrm{kWh}$ per cold unit, determined in the energy benchmark study by Bouwer, Von Broembsen \& Dodd (2008). A triangle probability distribution is used to account for the range of electricity consumption values. It is assumed that pome fruit is stored for a minimum period of 60 days in the CA Store and 35 days in the CS, which is in line with the year 2000 model. Due to the CA and CS facilities consuming the largest share of electricity during the agro-processing activities, the application of solar PV energy in this area is growing. Solar PV installations on CA and CS facilities have a total accumulated installed capacity in the pome industry of $2.61 \mathrm{MWp}$ as at June 2017 . This is projected to grow to approximately $3.59 \mathrm{MWp}$ by 2020 (Figure 24) based on the CAGR of $8 \%$ between 2013 and 2016 . The ecoinvent dataset used to represent polycrystalline solar panels mounted on slanted refrigeration facility roofs is:

- Electricity, low voltage $\{Z A\} \mid$ electricity production, photovoltaic, $3 \mathrm{kWp}$ slanted-roof installation, multi-Si, panel, mounted | Alloc Def, U.

The total values of the inputs to the CA and CS model is in Table 28.

\footnotetext{
44 Information provided by Roshae Kenny: APL Packaging
}

45 Koos Bouwer: KBC Industrial 


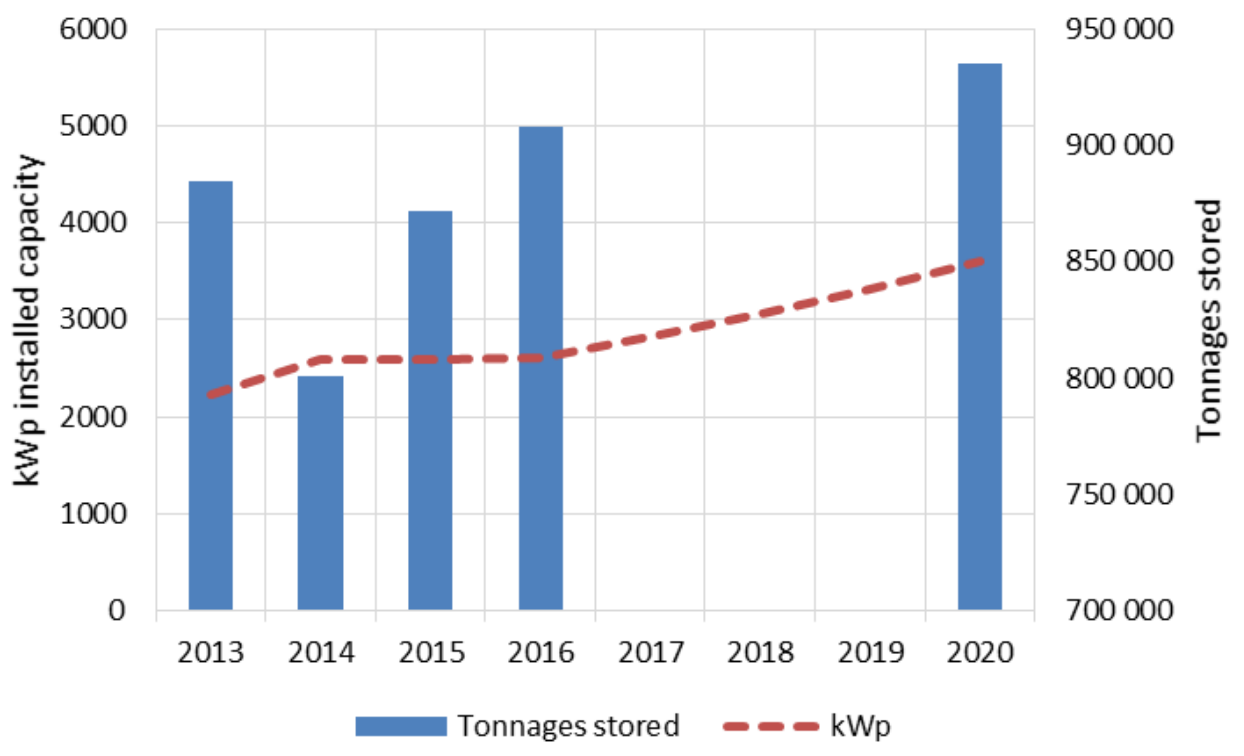

Figure 24: Projected installed capacity (kWp) of PV at cold rooms by year 2020.

By 2020 the main refrigerant used in both facilities will be Ammonia. The leakage figures are extrapolated from the 2010 inventory.

\begin{tabular}{|c|c|c|}
\hline CA Store inventory & UoM & 2020 \\
\hline Tonnages & Tonnes & $3.52 \mathrm{E}+05$ \\
\hline Building, hall, steel construction $\{$ GLO $\} \mid$ market for | Alloc Def, U & $\mathrm{m} 2$ & $1.97 \mathrm{E}+05$ \\
\hline Electricity, low voltage $\{Z A\} 2020 \mid$ market for| Alloc Def,U & kWh & $1.80 \mathrm{E}+08$ \\
\hline $\begin{array}{l}\text { Electricity, low voltage }\{Z A\} \mid \text { electricity production, photovoltaic, } \\
3 k W p \text { slanted-roof installation, multi-Si, panel, mounted | Alloc } \\
\text { Def, } U\end{array}$ & kWh & $5.20 \mathrm{E}+06$ \\
\hline Number of days stored & days & $6.00 \mathrm{E}+01$ \\
\hline Refrigerant leakage: Ammonia & $\mathrm{kg}$ & $2.73 \mathrm{E}+04$ \\
\hline \multicolumn{3}{|l|}{ Cold Store inventory } \\
\hline Tonnages & Tonnes & $9.35 \mathrm{E}+05$ \\
\hline Building, hall, steel construction $\{$ GLO $\} \mid$ market for | Alloc Def, U & $\mathrm{m} 2$ & $1.19 \mathrm{E}+06$ \\
\hline Electricity, low voltage $\{Z A\} 2020 \mid$ market for| Alloc Def,U & $\mathrm{kWh}$ & $2.81 \mathrm{E}+08$ \\
\hline $\begin{array}{l}\text { Electricity, low voltage }\{Z A\} \mid \text { electricity production, photovoltaic, } \\
3 k W p \text { slanted-roof installation, multi-Si, panel, mounted | Alloc } \\
\text { Def, } U\end{array}$ & kWh & $5.20 \mathrm{E}+06$ \\
\hline Number of days stored & days & $3.50 \mathrm{E}+01$ \\
\hline Refrigerant leakage: Ammonia & $\mathrm{kg}$ & $5.25 \mathrm{E}+04$ \\
\hline
\end{tabular}

Table 28: Inputs for CA and CS operations in year 2020. 


\section{Chapter 5 : Time series Attributional Life Cycle Assessment results}

The aim of the LCIA phase of the LCA methodology in this research is to examine the pome fruit product system from an environmental perspective, specifically for the impact category climate change. One of the features of the assessment phase is the creation of an LCIA profile from the results which provides information on the environmental impacts associated with the inputs and outputs of a system based on the functional unit (SANS, 2002b).

The framework of the LCIA phase consists of mandatory and optional elements which convert the $\mathrm{LCI}$ results to indicator results per functional unit. The elements of the LCIA for this research are shown in Figure 25.

The LCls for all time periods are in Appendix I. The category indicator and impact assessment method to be used in the research (Figure 25), accurately links the carbon emitted by all activities and flows in the $\mathrm{LCl}$ to the impact category climate change.

A normalization inventory is not available for the single issue characterisation methods in SimaPro used in this research namely; GHG Protocol and IPCC 2013 GWP 100a. However, the results are extrapolated to total tonnes $\mathrm{CO}_{2} \mathrm{e}$ emitted by the industry and then normalised to the total annual GHG emissions of South Africa for each of the years studied. The weighting step entails multiplying the normalised results of each of the impact categories with a weighting factor that expresses the relative importance of the impact category. However, only one impact category is taken into account in this research and therefore weighting is not considered 


\section{Life Cycle Impact Assessment}

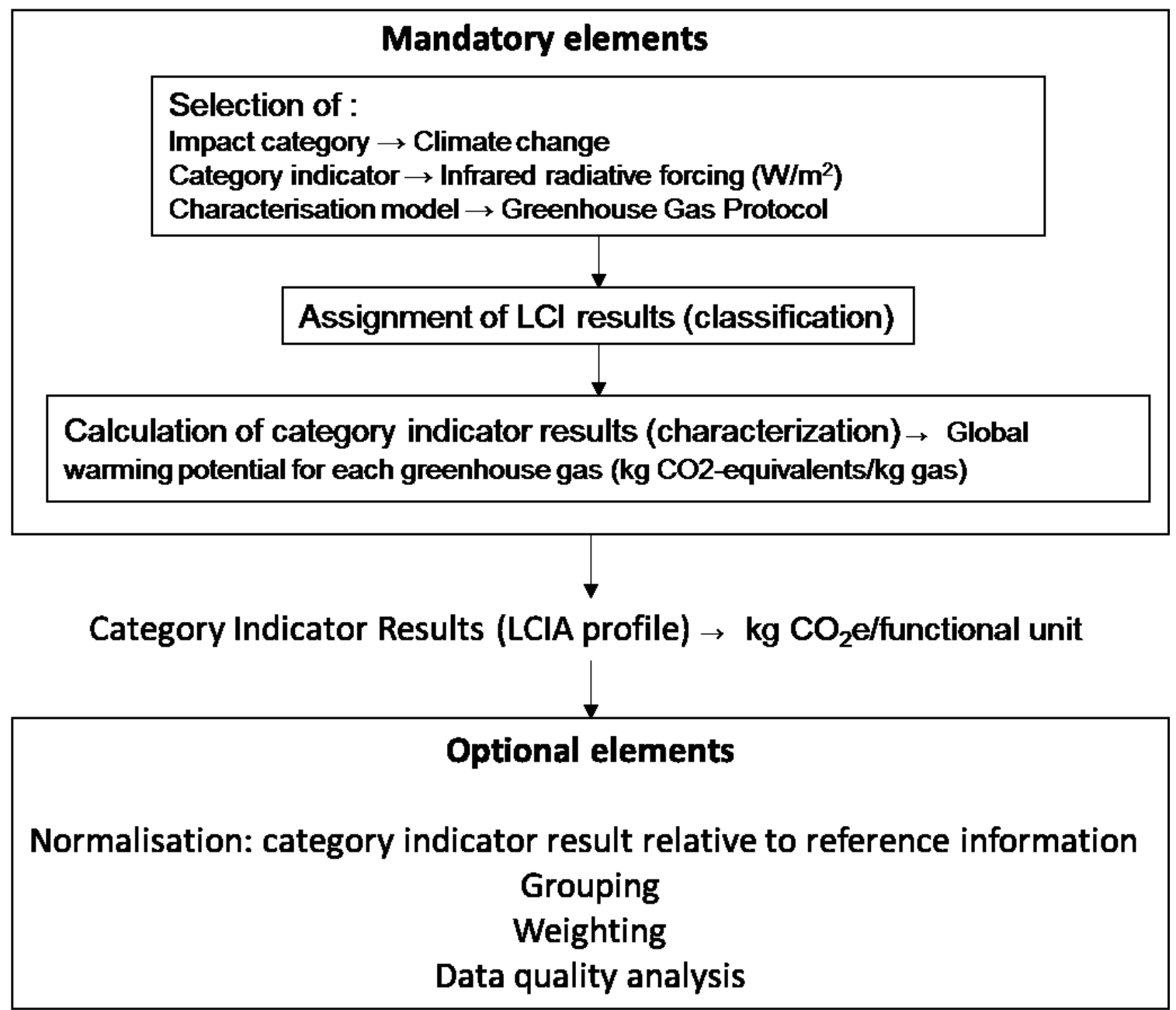

Figure 25: Elements of the LCIA phase for this research in determining the GWP (SANS, 2002b)

\subsection{Results for 2000}

The GWP result for pome fruit in the year 2000 is $1.46 \mathrm{~kg} \mathrm{CO}_{2} \mathrm{e} / \mathrm{kg}$ fruit according to the GHG Protocol method and $1.52 \mathrm{~kg} \mathrm{CO} 2 \mathrm{e} / \mathrm{kg}$ fruit using the IPPC method. As per the definition of the functional unit, "fruit" refers to the combined total of local and export apple and pear, $859 \mathrm{kT}$ in 2000 (as per Table 6).

The cumulative indicator results for the pome fruit and results per boundary (Farm, CA store, Packhouse and Cold Store) for each assessment method is in Table 29 and Table 30. 


\begin{tabular}{|l|r|r|r|}
\hline \multicolumn{1}{|c|}{ Boundary } & $\begin{array}{c}\text { Cumulative results } \\
\text { ( } \mathbf{k g ~ C O}_{2} \mathbf{e} / \mathbf{k g} \text { fruit) }\end{array}$ & $\begin{array}{r}\text { Per boundary contribution } \\
\text { (kg CO2e/kg fruit) }\end{array}$ & $\begin{array}{l}\text { Contribution per boundary } \\
\text { (\%) to total GWP }\end{array}$ \\
\hline Farm & 0.30 & 0.30 & $18 \%$ \\
\hline CA Store & 1.06 & 0.75 & $45 \%$ \\
\hline Packhouse & 1.01 & 0.16 & $10 \%$ \\
\hline Cold Store & 1.46 & 0.45 & $27 \%$ \\
\hline
\end{tabular}

Table 29: LCIA results for 2000 pome fruit value chain and boundaries using GHG Protocol impact assessment method.

\begin{tabular}{|l|r|r|r|}
\hline \multicolumn{1}{|c|}{ Boundary } & $\begin{array}{c}\text { Cumulative results } \\
\text { (kg CO} \mathbf{2} \text { /kg fruit) }\end{array}$ & $\begin{array}{r}\text { Per boundary contribution } \\
\text { (kg CO2e/kg fruit) }\end{array}$ & $\begin{array}{c}\text { Contribution per boundary } \\
\text { (\%) to total GWP }\end{array}$ \\
\hline Farm & 0.31 & 0.31 & $18 \%$ \\
\hline CA Store & 1.06 & 0.76 & $44 \%$ \\
\hline Packhouse & 1.08 & 0.22 & $13 \%$ \\
\hline Cold Store & 1.52 & 0.45 & $26 \%$ \\
\hline
\end{tabular}

Table 30: LCIA results for 2000 pome fruit value chain and boundaries using IPCC impact assessment method.

The GWP result for pome fruit in 2000 is less than the sum of the GWP results for each boundary. This is due to the fruit intake into the packhouse from the farm at $75 \%$ and from the CA at $25 \%$ of total yield as specified in Section 3.5. Therefore, the sum of the GWP of the boundaries would technically 'double count' some of the environmental burdens. In order to identify significant 'hotspots' in the value chain there is a drill down to the boundary and activity level.

At a value chain level, there is a $0.06 \mathrm{~kg} \mathrm{CO} 2 \mathrm{e} / \mathrm{kg}$ fruit difference in overall results between the two impact assessment methods. This is mainly due to the difference in $\mathrm{kg} \mathrm{CO}_{2} \mathrm{e}$ per $\mathrm{kg}$ fruit at the packhouse boundary, specifically the difference of $0.09 \mathrm{~kg} \mathrm{CO}_{2} \mathrm{e}$ in the packaging emissions. The GHG Protocol, in addition to emissions from fossil fuels and land transformation, also takes into account biogenic carbon emissions and $\mathrm{CO}_{2}$ uptake through biomass and other sources. The $\mathrm{CO}_{2}$ uptake component within the packhouse boundary is substantial and mainly due to the use of wooden bins and pallets for fruit handling and the corrugated cardboard as packaging material. Even though the GHG Protocol method uses the same characterisation factors as the IPCC 2013 method, the IPCC method only takes into account the emissions from fossil $\mathrm{CO}_{2} \mathrm{e}$ and $\mathrm{CO}_{2} \mathrm{e}$ from land transformation (IPCC, 2013) and excludes biogenic emissions and $\mathrm{CO}_{2}$ uptake.

The boundary ranking according to overall GWP contribution using the GHG Protocol method indicates that the CA Store contributes $45 \%$, the CS boundary $27 \%$ with the farm third at $18 \%$. Due to the relatively high $\mathrm{CO}_{2} \mathrm{e}$ uptake of the wooden bins and pallets, the overall contribution to $\mathrm{CO}_{2} \mathrm{e}$ emissions per $\mathrm{kg}$ fruit at the packhouse level was the lowest at $10 \%$. The IPCC method indicated that the CA Store contributes $44 \%$, the CS $26 \%$ and the farm $18 \%$ to total GHG emissions of the pome fruit value chain. The $\mathrm{GHG}$ emission contribution per $\mathrm{kg}$ fruit per boundary for both methods is in Figure 26. 


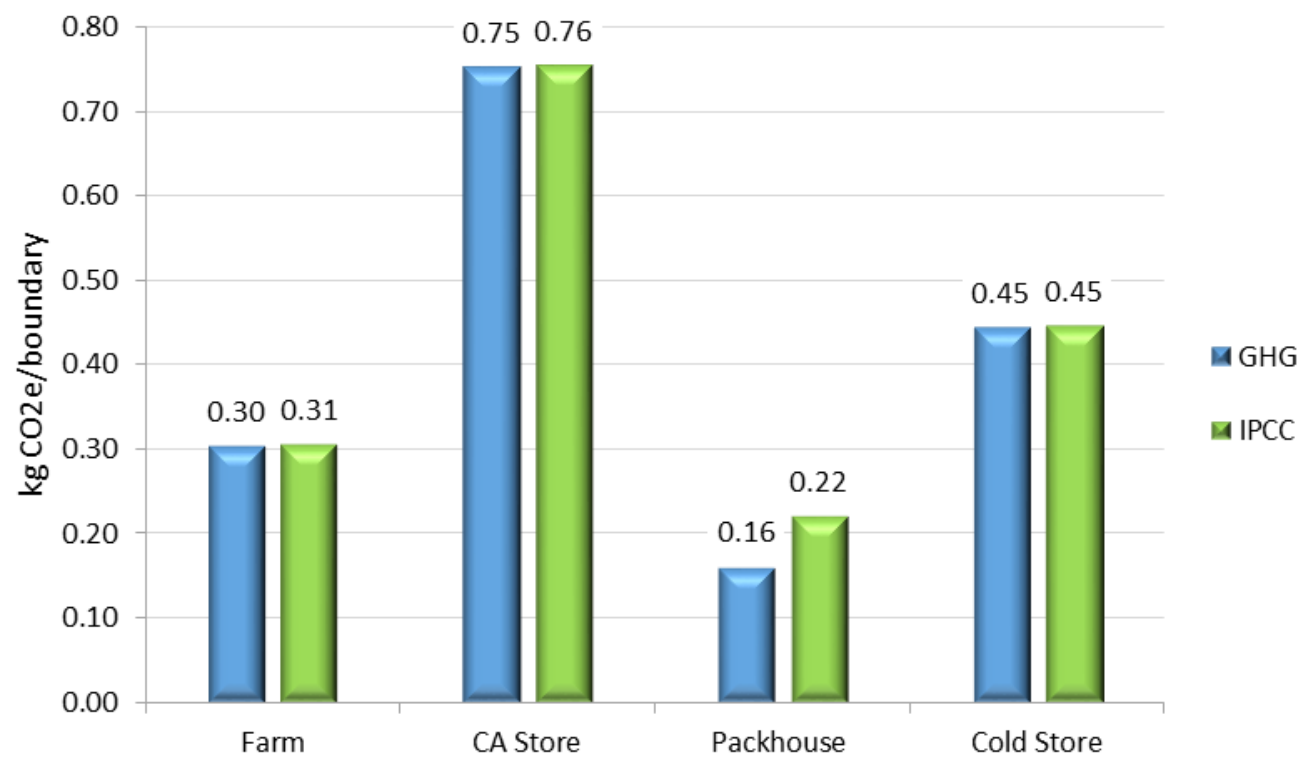

Figure 26: Impact category results for pome fruit value chain boundaries in year 2000 according to GHG Protocol and IPCC method.

Within the boundaries of the value chain, the contributions of the different activities to the total GWP of pome fruit is shown in Table 31 and Table 32.

\begin{tabular}{|l|r|r|}
\hline Activity & GHG Protocol & \multicolumn{2}{|c|}{$\begin{array}{c}\text { \% contribution to } \\
\text { value chain }\end{array}$} \\
\hline CA, Cold Store \& PH electricity & 1.23 & $74 \%$ \\
\hline Irrigation & 0.11 & $7 \%$ \\
\hline Diesel use at farm & 0.09 & $5 \%$ \\
\hline Waste (landfill \& recycled) & 0.09 & $6 \%$ \\
\hline Fertilisers (prod \& application) & 0.07 & $4 \%$ \\
\hline Other & 0.05 & $3 \%$ \\
\hline Packaging & 0.02 & $1 \%$ \\
\hline
\end{tabular}

Table 31: Contribution of activities across pome fruit value chain in year 2000 to total GWP according to GHG Protocol method. 


\begin{tabular}{|l|r|r|}
\hline Activity & kg CO2e/kg fruit & \multicolumn{1}{|c|}{$\begin{array}{c}\text { \% contribution to } \\
\text { value chain }\end{array}$} \\
\hline CA, Cold Store \& PH electricity & 1.23 & $71 \%$ \\
\hline Irrigation & 0.12 & $6.7 \%$ \\
\hline Diesel use on farm & 0.09 & $5.0 \%$ \\
\hline Packaging & 0.11 & $6.3 \%$ \\
\hline Fertiliser (prod \& application) & 0.07 & $4 \%$ \\
\hline Waste (landfill \& recycled) & 0.06 & $4 \%$ \\
\hline Other & 0.05 & $3 \%$ \\
\hline
\end{tabular}

Table 32: Contribution of activities across pome fruit value chain in year 2000 to total GWP (IPCC).

The contributions of the activities within the value chain to total GWP according to both impact assessment methods are in Figure 27. The electricity used in the CA, CS and packhouses contributes the most to overall GWP at $74 \%$ according to the GHG Protocol method and $71 \%$ using the IPCC method. The large contribution of the South African grid electricity component to the total GWP is due to the indicator result of $1.25 \mathrm{~kg} \mathrm{CO}_{2} \mathrm{e}$ per $\mathrm{kWh}$ in the year 2000 . Irrigation comes in as the second highest emitter under both impact assessment methods.

Besides the electricity and packaging contributions, the diesel use at farm was substantial, coming very close to the irrigation contribution for both methods. This diesel activity can possibly have a higher contribution of approximately $10 \%$ due to the diesel component of the activities 'Fertilising, by broadcaster/ZA U' and 'Pesticides, pome fruit 2000 |production \& application| ZA U' not being taken into account. The waste component indicator results differ slightly when comparing the IPCC and GHG Protocol methods. There is a difference of $0.03 \mathrm{~kg} \mathrm{CO}_{2} \mathrm{e}$ per $\mathrm{kg}$ pome fruit packed between the two method results with the GHG Protocol result having the higher value of $0.11 \mathrm{~kg}$ $\mathrm{CO}_{2} \mathrm{e}$. This is due to the large component of biogenic carbon released into the atmosphere when the disposable wooden pallets are incinerated after the season.

In this impact assessment the 'hot spots' identified are the electricity use throughout the value chain followed by the packaging materials and diesel use at farm level. The Sankey diagrams for both impact assessment methods are in Appendix VII. 


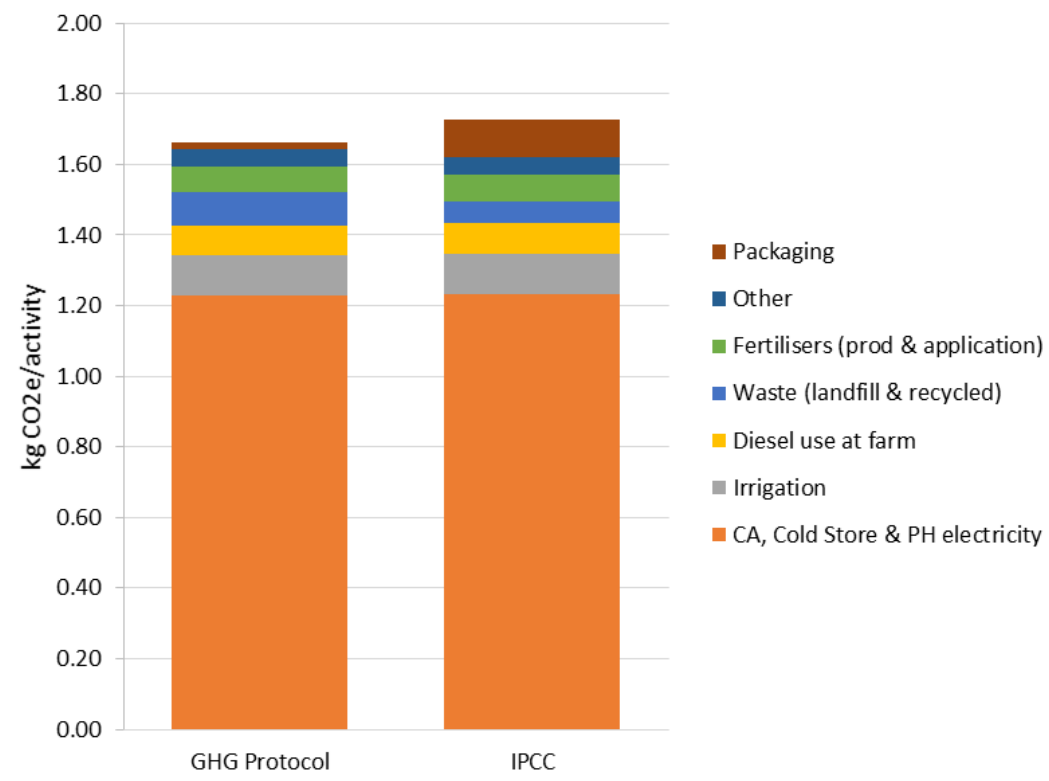

Figure 27: Contribution of processes within pome fruit value chain in year 2000 to total GWP according to GHG Protocol and IPCC impact assessment methods.

\subsection{Results for 2010}

The GWP results for 2010 pome fruit is divided into two sections. The first section shows the results using the CCC electricity consumption values for the packhouse, CA and CS and the second section the results using the electricity consumption values from (Bouwer, Von Broembsen \& Dodd, 2008) for the same boundaries. This is followed by a discussion and decision on the results that will be used going forward. As per the definition of the functional unit, "fruit" refers to the combined total of local and export apple and pear, $1115 \mathrm{kT}$ in 2010 (as per Table 10).

\subsubsection{Results for model using CCC data}

This model will be referred to as the $2010 \mathrm{CCC}$ model. The results for this model according to the GHG Protocol impact assessment method for the year 2010 is $0.73 \mathrm{~kg} \mathrm{CO} \mathrm{CO}_{2} \mathrm{e} / \mathrm{kg}$ fruit. According to the IPCC method the result is $0.81 \mathrm{~kg} \mathrm{CO} 2 \mathrm{e} / \mathrm{kg}$ fruit. All the boundaries assessed against the functional unit are in Figure 12 of this document.

The cumulative and per boundary indicator results using method GHG Protocol across the 2010 CCC pome fruit value chain from farm to CS is in Table 33 and according to the IPPC method in Table 34. 


\begin{tabular}{|l|r|r|r|}
\hline Boundary & $\begin{array}{c}\text { Cumulative results } \\
\text { (kg CO} \mathbf{2} / \mathbf{k g} \text { fruit) }\end{array}$ & $\begin{array}{r}\text { Per boundary contribution } \\
\text { (kg CO2e/kg fruit) }\end{array}$ & $\begin{array}{c}\text { Contribution per boundary } \\
\text { (\%) to total GWP }\end{array}$ \\
\hline Farm & 0.27 & 0.27 & $34 \%$ \\
\hline CA Store & 0.49 & 0.23 & $29 \%$ \\
\hline Packhouse & 0.52 & 0.08 & $11 \%$ \\
\hline Cold Store & $\mathbf{0 . 7 3}$ & 0.21 & $26 \%$ \\
\hline
\end{tabular}

Table 33: LCIA results for 2010 CCC pome fruit value chain (GHG Protocol).

\begin{tabular}{|l|r|r|r|}
\hline \multicolumn{1}{|c|}{ Boundary } & $\begin{array}{c}\text { Cumulative results } \\
\text { (kg CO} \mathbf{2} / \mathbf{k g} \text { fruit) }\end{array}$ & $\begin{array}{r}\text { Per boundary contribution } \\
\text { (kg CO2e/kg fruit) }\end{array}$ & $\begin{array}{r}\text { Contribution per boundary } \\
\text { (\%) to total GWP }\end{array}$ \\
\hline Farm & 0.28 & 0.28 & $32 \%$ \\
\hline CA Store & 0.50 & 0.22 & $26 \%$ \\
\hline Packhouse & 0.60 & 0.15 & $18 \%$ \\
\hline Cold Store & $\mathbf{0 . 8 1}$ & 0.21 & $24 \%$ \\
\hline
\end{tabular}

Table 34: LCIA results for 2010 CCC pome fruit value chain (IPCC).

There is a difference in the GWP results per $\mathrm{kg}$ fruit of $0.08 \mathrm{~kg} \mathrm{CO} \mathrm{CO}_{2} \mathrm{e}$ using the two impact assessment methods. This is due to the $\mathrm{CO}_{2}$ uptake of the wooden bins and pallets in the packhouse boundary which is taken into account in the GHG protocol impact assessment method. Of the boundaries assessed in the $2010 \mathrm{CCC}$ model, the farm boundary is the largest contributor to total $\mathrm{CO}_{2} \mathrm{e}$ emissions at $34 \%$ for the GHG Protocol method and $32 \%$ for the IPCC method. The CA and CS stores are a close second and third with the Packhouse boundary last at $11 \%$ according to the GHG Protocol and $18 \%$ according to IPCC.

The relative contributions of each boundary to the GWP result according to the GHG Protocol and IPCC method is in Figure 28.

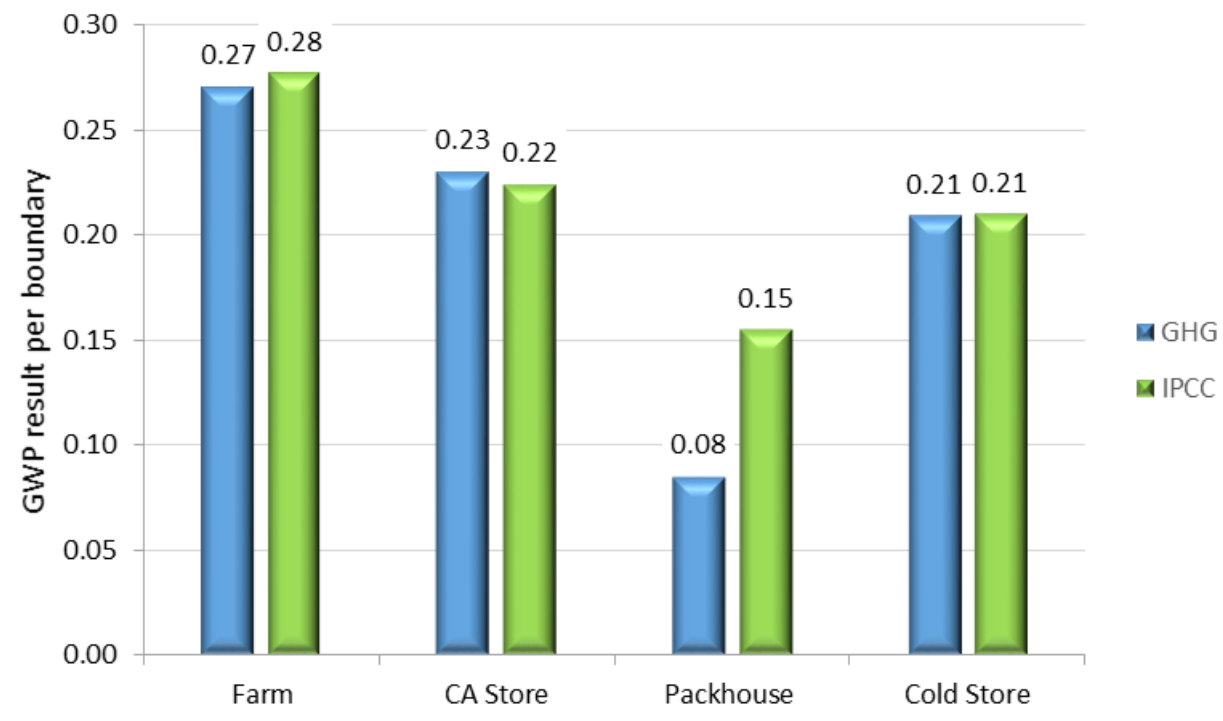


Figure 28: Impact category climate change results for 2010 CCC pome fruit value chain boundaries for 2010 according to GHG Protocol and IPPC method.

Within the boundaries of the value chain, the contributions of the different activities to total GWP is shown in Table 35 and Table 36 and Figure 29.

\begin{tabular}{|l|r|r|}
\hline Activity & kg CO2e/kg fruit & $\begin{array}{l}\text { \% contribution to } \\
\text { value chain }\end{array}$ \\
\hline CA, Cold Store \& PH electricity & 0.45 & $57 \%$ \\
\hline Irrigation & 0.17 & $21 \%$ \\
\hline Diesel use at farm & 0.04 & $5 \%$ \\
\hline Fertiliser (prod \& application) & 0.03 & $4 \%$ \\
\hline Packaging & 0.01 & $2 \%$ \\
\hline Waste (landfill \& recycled) & 0.03 & $4 \%$ \\
\hline Other & 0.07 & $9 \%$ \\
\hline
\end{tabular}

Table 35: Contribution of activities across 2010 CCC pome fruit value chain to total GWP according to GHG Protocol method.

\begin{tabular}{|l|r|r|}
\hline Activity & kg CO2e/kg fruit & $\begin{array}{c}\text { \% contribution to } \\
\text { value chain }\end{array}$ \\
\hline CA, Cold Store \& PH electricity & 0.45 & $53 \%$ \\
\hline Irrigation & 0.17 & $20 \%$ \\
\hline Packaging material & 0.11 & $13 \%$ \\
\hline Diesel use on farm & 0.04 & $4 \%$ \\
\hline Fertiliser (prod \& application) & 0.03 & $4 \%$ \\
\hline Waste (landfill \& recycled) & 0.00 & $1 \%$ \\
\hline Other & 0.05 & $5 \%$ \\
\hline
\end{tabular}

Table 36: Contribution of activities across 2010 CCC pome fruit value chain to total GWP according to IPCC method.

According to both impact assessment methods the ranking of the top two activities are the same namely; electricity use in the CA, CS and Packhouse and then irrigation. The consumption of the South African grid electricity contributes the most to the GWP of the 2010 pome fruit. This is due to the combustion of hard coal in the generation of grid electricity which constitutes $90 \%$ of the primary energy used according to the ecoinvent process model "Electricity, high voltage $\{Z A\} \mid$ market for | Alloc Def, U". According to the process model "Irrigation, pome fruit $\{Z A\} \mid$ processing | Alloc Def, U", more than $75 \%$ of the GHG emissions from this activity is due to electricity used for the pumping of water. The results are based on a pump with energy efficiency of approximately $70 \%$.

\footnotetext{
${ }^{46}$ Case study in Pome fruit industry Benchmark report by Koos Bouwer: koos@kbcindustrial.co.za
} 


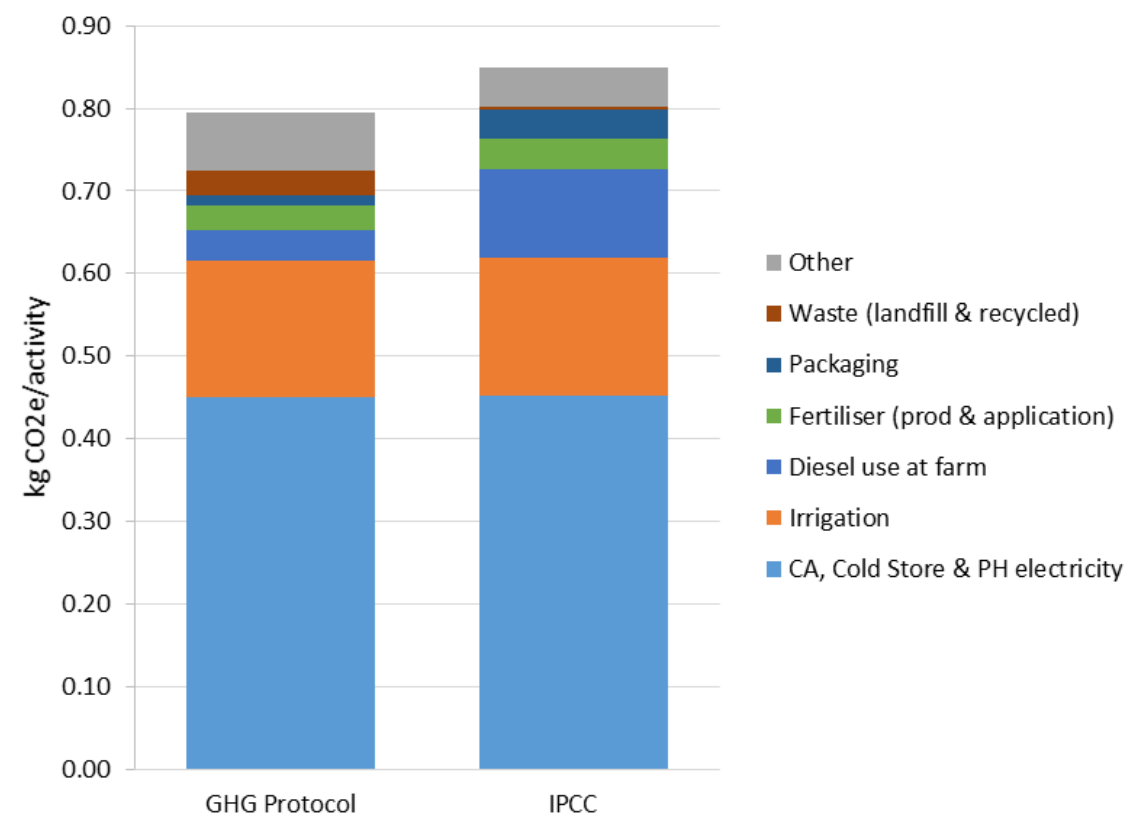

Figure 29: Contribution of processes within 2010 CCC pome fruit value chain to total GWP (GHG Protocol \& IPCC)

Packaging in the packhouse boundary comes in third, contributing $13 \%$ to total emissions, according to the IPPC method and fifth, contributing $2 \%$, according to the GHG Protocol. The contributions of diesel at farm level is similar in both results. Fertiliser use in both result outputs are similar but waste is not a large contributor in the IPCC method. The difference in the waste emissions is $0.02 \mathrm{~kg} \mathrm{CO} 2_{\mathrm{e}}$ per $\mathrm{kg}$ fruit more according to the GHG protocol than for the IPCC results due to biogenic carbon released from the organic waste, incineration of the disposable pallets and disposal of the corrugated cardboard.

The Sankey diagrams for the 2010 CCC value chain are in Appendix VII.

\subsubsection{Results for 2010 model using refined electricity consumption values}

This model is referred to as 2010 (electricity agro-processing) pome fruit. The GWP result for the 2010 (electricity agro-processing) pome fruit using the GHG Protocol method is $1.18 \mathrm{~kg}$ $\mathrm{CO}_{2} \mathrm{e} / \mathrm{kg}$ fruit. According to the IPCC method, the result is slightly higher at $1.23 \mathrm{~kg} \mathrm{CO} 2 \mathrm{e} / \mathrm{kg}$ fruit. The results for the pome fruit and per boundary for each impact assessment method are in Table 37 and Table 38. 


\begin{tabular}{|l|r|r|r|}
\hline Boundary & \multicolumn{1}{|c|}{$\begin{array}{c}\text { Cumulative results } \\
\text { ( } \mathrm{kg} \mathrm{CO}_{\mathbf{2}} \mathrm{e} / \mathbf{k g} \text { fruit) }\end{array}$} & $\begin{array}{c}\text { Per boundary contribution } \\
\text { (kg CO2e/kg fruit) }\end{array}$ & $\begin{array}{c}\text { Contribution per boundary } \\
\text { (\%) to total GWP }\end{array}$ \\
\hline Farm & 0.27 & 0.27 & $17 \%$ \\
\hline CA Store & 1.02 & 0.75 & $47 \%$ \\
\hline Packhouse & 0.73 & 0.11 & $7 \%$ \\
\hline Cold Store & 1.18 & 0.45 & $28 \%$ \\
\hline
\end{tabular}

Table 37: GWP results for 2010 (electricity agro-processing) value chain and boundaries using from GHG Protocol method.

\begin{tabular}{|l|r|r|r|}
\hline Boundary & $\begin{array}{c}\text { Cumulative results } \\
\text { (kg CO} \mathbf{2} / \mathbf{k g} \text { fruit) }\end{array}$ & $\begin{array}{c}\text { Per boundary contribution } \\
\text { (kg CO2e/kg fruit) }\end{array}$ & $\begin{array}{c}\text { Contribution per boundary } \\
\text { (\%) to total GWP }\end{array}$ \\
\hline Farm & 0.28 & 0.28 & $17 \%$ \\
\hline CA Store & 1.03 & 0.76 & $46 \%$ \\
\hline Packhouse & 0.77 & 0.15 & $9 \%$ \\
\hline Cold Store & 1.23 & 0.45 & $28 \%$ \\
\hline
\end{tabular}

Table 38: GWP results for 2010 (electricity agro-processing) value chain and boundaries from IPCC method.

The difference of $0.05 \mathrm{~kg} \mathrm{CO}_{2} \mathrm{e} / \mathrm{kg}$ fruit between the two methods is mainly due to the difference in the results for the packhouse from the $\mathrm{CO}_{2}$ uptake component of the packaging. The ranking of the individual boundaries according to GWP results are the same for both impact assessment methods with the CA store having the largest contribution to total GWP at $47 \%$, followed by the CS, Farm and lastly packhouse. The $\mathrm{CO}_{2}$ e emissions for each boundary is shown in Figure 30.

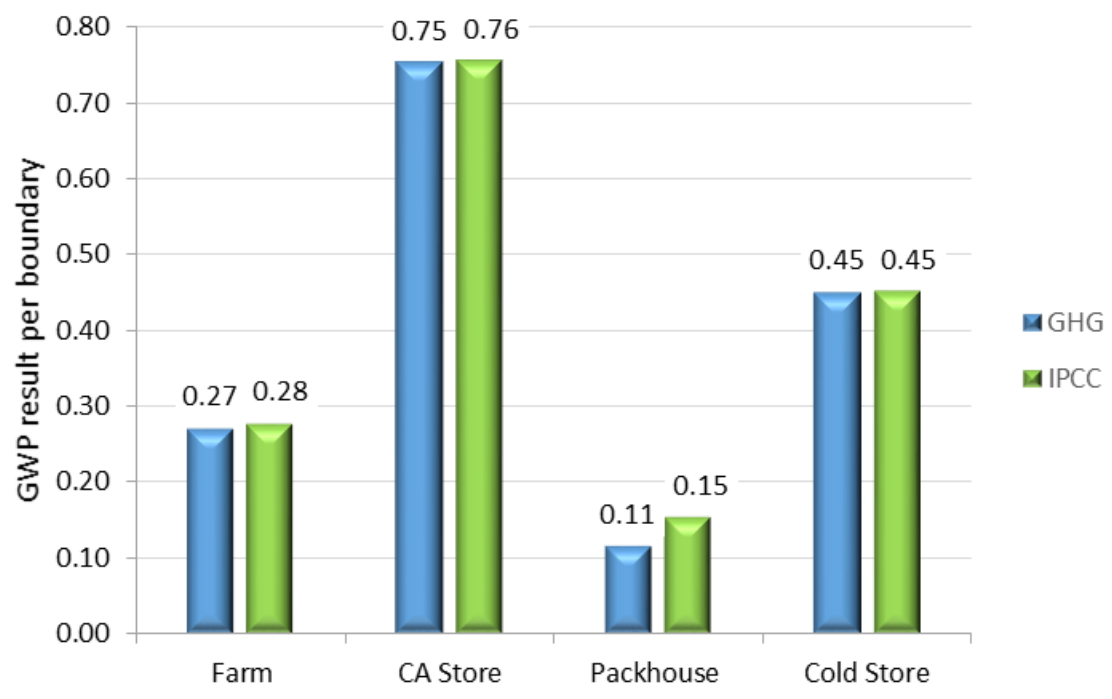

Figure 30: Impact category climate change results for 2010 (electricity agro-processing) pome fruit value chain boundaries according to the GHG Protocol and IPPC method.

The contributions of the activities vary from the 2010 CCC model results. The contribution of electricity consumption in the CA, CS and packhouse boundaries are around $20 \%$ higher than 
the 2010 CCC model. The ranking of the other activities remain the same as shown in Table 39 and Table 40.

\begin{tabular}{|l|r|r|}
\hline Activity & kg CO2e/ kg fruit & $\begin{array}{c}\text { \% contribution to } \\
\text { value chain }\end{array}$ \\
\hline CA, Cold Store \& PH electricity & 1.23 & $77 \%$ \\
\hline Irrigation & 0.17 & $10 \%$ \\
\hline Diesel use at farm & 0.04 & $2 \%$ \\
\hline Fertiliser (prod \& application) & 0.03 & $2 \%$ \\
\hline Packaging & 0.04 & $2 \%$ \\
\hline Waste (landfill \& recycled) & 0.03 & $2 \%$ \\
\hline Other & 0.06 & $4 \%$ \\
\hline
\end{tabular}

Table 39: Contribution of activities across 2010 (electricity agro-processing) pome fruit value chain to total GWP according to GHG Protocol method.

\begin{tabular}{|l|r|r|}
\hline Activity & kg CO2e/kg fruit & $\begin{array}{c}\text { \% contribution to } \\
\text { value chain }\end{array}$ \\
\hline CA, Cold Store \& PH electricity & 1.23 & $75 \%$ \\
\hline Irrigation & 0.17 & $10 \%$ \\
\hline Packaging material & 0.10 & $6 \%$ \\
\hline Diesel use on farm & 0.04 & $2 \%$ \\
\hline Fertiliser (prod \& application) & 0.03 & $2 \%$ \\
\hline Transport (fruit \& consumables) & 0.02 & $1 \%$ \\
\hline Other & 0.05 & $3 \%$ \\
\hline
\end{tabular}

Table 40: Contribution of activities across 2010 (electricity agro-processing) pome fruit value chain to total GWP according to IPCC method.

\subsubsection{Discussion and Conclusion}

A comparison of the 2010 CCC and 2010 (electricity agro-processing) GWP results for the packhouse, CA and CS boundaries are in Figure 31 and Figure 32. It is clearly evident that the range of grid electricity consumption values from Bouwer et al. (2008) for the packhouse, CA and CS has a considerable impact on the GWP indicator result for these boundaries and the overall pome fruit value chain for the year 2010 . 


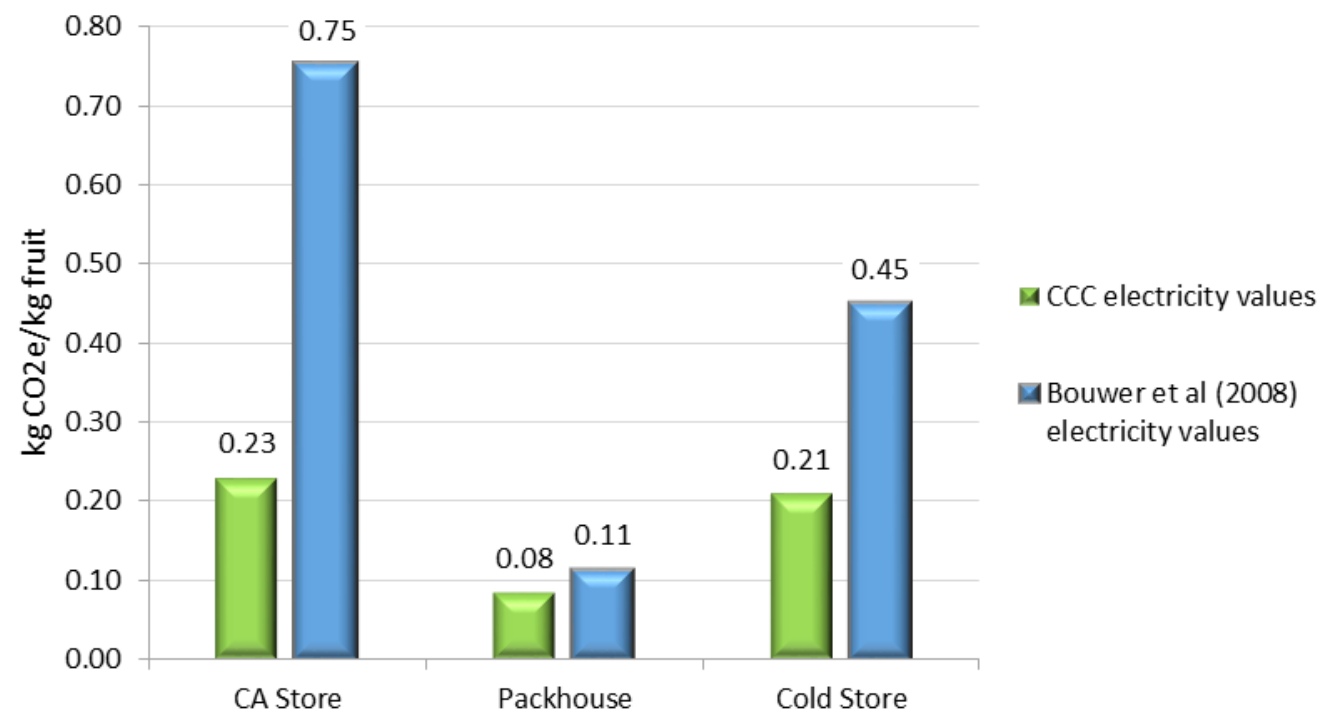

Figure 31: GWP results for year 2010 after adjusting electricity consumption of CA and CS (GHG Protocol).

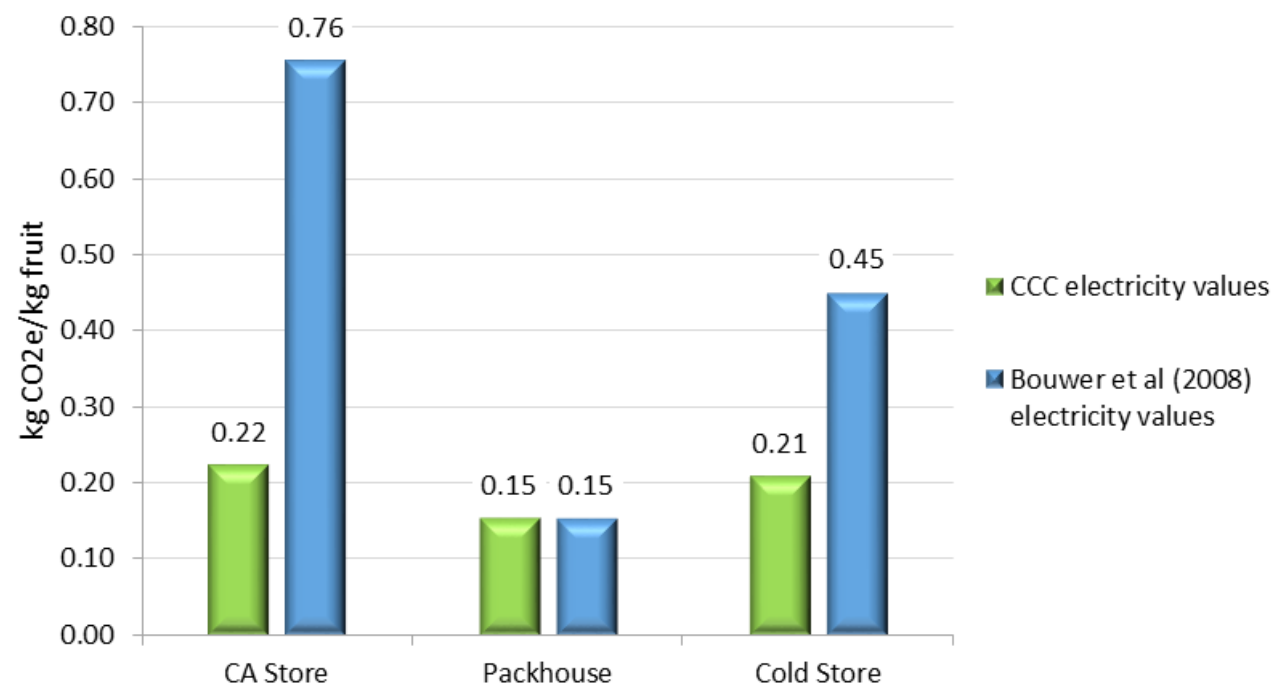

Figure 32: GWP results for year 2010 with adjustment to electricity consumption in CA and CS (IPCC).

The difference in electricity GWP values for each boundary are notable, especially for the CA and CS boundaries. All other GWP results of the inputs and outputs for these boundaries remain the same. The GWP results, using the original 2010 CCC and the 2010 (electricity agroprocessing) electricity consumption values, for the electricity input per boundary is in Table 41. 


\begin{tabular}{|c|c|c|c|c|}
\hline \multirow[t]{2}{*}{ Inputs } & \multicolumn{2}{|c|}{$\begin{array}{c}2010 \text { CCC } \\
\text { [kg CO2e/kg fruit] }\end{array}$} & \multicolumn{2}{|c|}{$\begin{array}{c}2010 \text { (electricity agro- } \\
\text { processing) } \\
\text { [kg CO2e/kg fruit] }\end{array}$} \\
\hline & GHG Protocol & IPCC & GHG Protocol & IPCC \\
\hline CA store: Electricity & 2.18E-01 & 2.19E-01 & 7.48E-01 & 7.51E-01 \\
\hline Packhouse: Electricity & 3.70E-02 & 3.72E-02 & 4.13E-02 & 4.15E-02 \\
\hline Cold store: Electricity & $1.96 \mathrm{E}-01$ & $1.96 \mathrm{E}-01$ & 4.36E-01 & 4.38E-01 \\
\hline
\end{tabular}

Due to the robust methods used in the Bouwer et al. (2008) study and the results being verified and reviewed in the industry, these results are seen as more accurate and credible than the values in the CCC database. Using the values from the study also allows for a consistent comparison in the time series results. The results for the 2010 model using the electricity consumption values for the agro-processing boundaries from Bouwer, Von Broembsen \& Dodd (2008) are considered the final LCIA result for the year 2010.

\subsection{Results for 2020}

The LCIA results for pome fruit in the year 2020 is $0.92 \mathrm{~kg} \mathrm{CO}{ }_{2} \mathrm{e} / \mathrm{kg}$ fruit according to the GHG Protocol method and $1.02 \mathrm{~kg} \mathrm{CO} 2 \mathrm{e} / \mathrm{kg}$ fruit using the IPPC method. Note that the GWP result for $1 \mathrm{~kg}$ of fruit is lower than the sum of the boundary contributions. This is due to $25 \%$ of the total intake into the packhouse coming from the CA store and the other $75 \%$ from the farm and then the flow of fruit from the CA through the Packhouse boundary (Figure 12). As per the definition of the functional unit, "fruit" refers to the combined total of local and export apple and pear, 1410 kT in 2020 (as per Table 27).

The GWP indicator results per boundary are in Table 42 and Table 43.

\begin{tabular}{|l|r|r|r|}
\hline \multicolumn{1}{|c|}{ Boundary } & $\begin{array}{c}\text { Cumulative results } \\
\text { (kg CO}{ }_{2} \mathrm{e} / \mathrm{kg} \text { fruit) }\end{array}$ & $\begin{array}{c}\text { Per boundary } \\
\text { contribution }\end{array}$ & $\begin{array}{c}\text { Contribution per } \\
\text { boundary (\%) to total }\end{array}$ \\
\hline Farm & 0.21 & 0.21 & $17 \%$ \\
\hline CA Store & 0.81 & 0.59 & $48 \%$ \\
\hline Packhouse & 0.57 & 0.08 & $6 \%$ \\
\hline Cold Store & 0.92 & 0.36 & $29 \%$ \\
\hline
\end{tabular}

Table 42: LCIA results accumulated and per boundary according to GHG Protocol method. 


\begin{tabular}{|l|r|r|r|}
\hline Boundary & $\begin{array}{c}\text { Cumulative results } \\
\text { (kg CO} \mathbf{2} / \mathbf{k g} \text { fruit) }\end{array}$ & $\begin{array}{c}\text { Per boundary contribution } \\
\text { (kg CO2e/kg fruit) }\end{array}$ & $\begin{array}{c}\text { Contribution per boundary } \\
\text { (\%) to total GWP }\end{array}$ \\
\hline Farm & 0.25 & 0.25 & $18 \%$ \\
\hline CA Store & 0.84 & 0.59 & $45 \%$ \\
\hline Packhouse & 0.66 & 0.13 & $10 \%$ \\
\hline Cold Store & 1.02 & 0.36 & $27 \%$ \\
\hline
\end{tabular}

Table 43: LCIA results accumulated and per boundary according to IPCC method.

There is a $0.09 \mathrm{~kg} \mathrm{CO}_{2} \mathrm{e}$ difference in the results using the two single issue methods. From a boundary perspective, the differences are evident at the farm and Packhouse boundaries. At the farm, the difference of $0.03 \mathrm{~kg} \mathrm{CO}_{2} \mathrm{e}$ is mainly due to the carbon uptake component of the trellising system which the GHG Protocol takes into account. The trellising system is erected when the orchard is established and has a lifetime beyond that of the orchard, meaning it can be re-used for multiple orchard lifetimes. The disposal of the trellis system is therefore not included in the $\mathrm{LCl}$ for year 2020. At the Packhouse, the difference of $0.07 \mathrm{~kg} \mathrm{CO}_{2} \mathrm{e}$ is again due to the packaging. The carbon uptake of the corrugated cardboard, bio-based PP, wooden bins and pallets contributes the most to this difference between the results of the two methods.

The GWP ranking of the boundaries is similar for both methods. According to the GHG Protocol method, the CA Store is the largest emitter at $48 \%$ of total emissions followed by the CS at $29 \%$, then the farm at $17 \%$ and lastly the Packhouse at $6 \%$. The IPCC method indicates that the CA store contributes $45 \%$ to total emissions, secondly the CS at $27 \%$, farm at $18 \%$ and Packhouse at $10 \%$. The driver of $\mathrm{CO}_{2} \mathrm{e}$ emissions is undoubtedly the grid electricity in all boundaries except for the Packhouse.

A more detailed break-down of the activities with significant GHG emissions within each boundary, indicate that grid electricity is the driver of GHG emissions for the CS, CA and for irrigation in the farm boundary. The activities and rankings per characterisation method are in Table 44 and Table 45 with the corresponding graph in Figure 33.

\begin{tabular}{|l|r|r|}
\hline Activity & kg CO2e/kg fruit & $\begin{array}{l}\text { \% contribution to } \\
\text { value chain }\end{array}$ \\
\hline CA, Cold Store \& PH grid electricity & 0.97 & $78 \%$ \\
\hline Irrigation & 0.11 & $9 \%$ \\
\hline Fertiliser (prod \& application) & 0.05 & $4 \%$ \\
\hline Diesel use at farm & 0.03 & $2 \%$ \\
\hline Waste (landfill \& recycled) & 0.02 & $2 \%$ \\
\hline N2O emissions to air and netting & 0.02 & $1 \%$ \\
\hline Packaging & 0.01 & $1 \%$ \\
\hline Other & 0.03 & $3 \%$ \\
\hline
\end{tabular}

Table 44: Contributions of activities to total GWP of pome fruit value chain according to GHG Protocol. 


\begin{tabular}{|l|r|r|}
\hline Activity & kg CO2e/kg fruit & $\begin{array}{c}\text { \% contribution to } \\
\text { value chain }\end{array}$ \\
\hline CA, Cold Store \& PH grid electricity & 0.97 & $73 \%$ \\
\hline Irrigation & 0.11 & $8 \%$ \\
\hline Packaging material & 0.08 & $6 \%$ \\
\hline Fertiliser (prod \& application) & 0.06 & $4 \%$ \\
\hline Diesel use on farm & 0.03 & $2 \%$ \\
\hline $\mathrm{N}_{2} \mathrm{O}$ emissions to air and netting & 0.02 & $1 \%$ \\
\hline Waste (landfill \& recycled) & 0.00 & $0 \%$ \\
\hline Other & 0.06 & $4 \%$ \\
\hline
\end{tabular}

Table 45: Contributions of activities to total GWP of pome fruit value chain according to IPCC method.

Note that the ranking of activities is very different after top two categories (electricity use in CA, $\mathrm{CS}$ and $\mathrm{PH}$ and irrigation) according to both characterisation methods. The packaging GWP contribution result according to the GHG Protocol is ranked relatively low compared to the higher ranking according to the IPCC method result. Fertiliser production and application is ranked quite high compared to the results of the other years 2000 and 2010 due to the higher dinitrogen monoxide emissions to air of $0.02 \mathrm{~kg} \mathrm{CO} 2 \mathrm{e} / \mathrm{kg}$ fruit. The nitrogen fertiliser application per hectare has increased steadily since the year 2000, giving rise to the higher contribution of $\mathrm{N}_{2} \mathrm{O}$ emissions.

The organic and inorganic waste activity does not feature in the IPCC method but ranks $5^{\text {th }}$ using the GHG Protocol method. The difference in result is $0.02 \mathrm{~kg} \mathrm{CO}{ }_{2} \mathrm{e} / \mathrm{kg}$ fruit packed. The biogenic carbon released from the organic waste and the incineration of the wooden pallets results in the higher value of GHG emitted in the GHG Protocol method. The Sankey diagrams for both methods are in Appendix VII. 


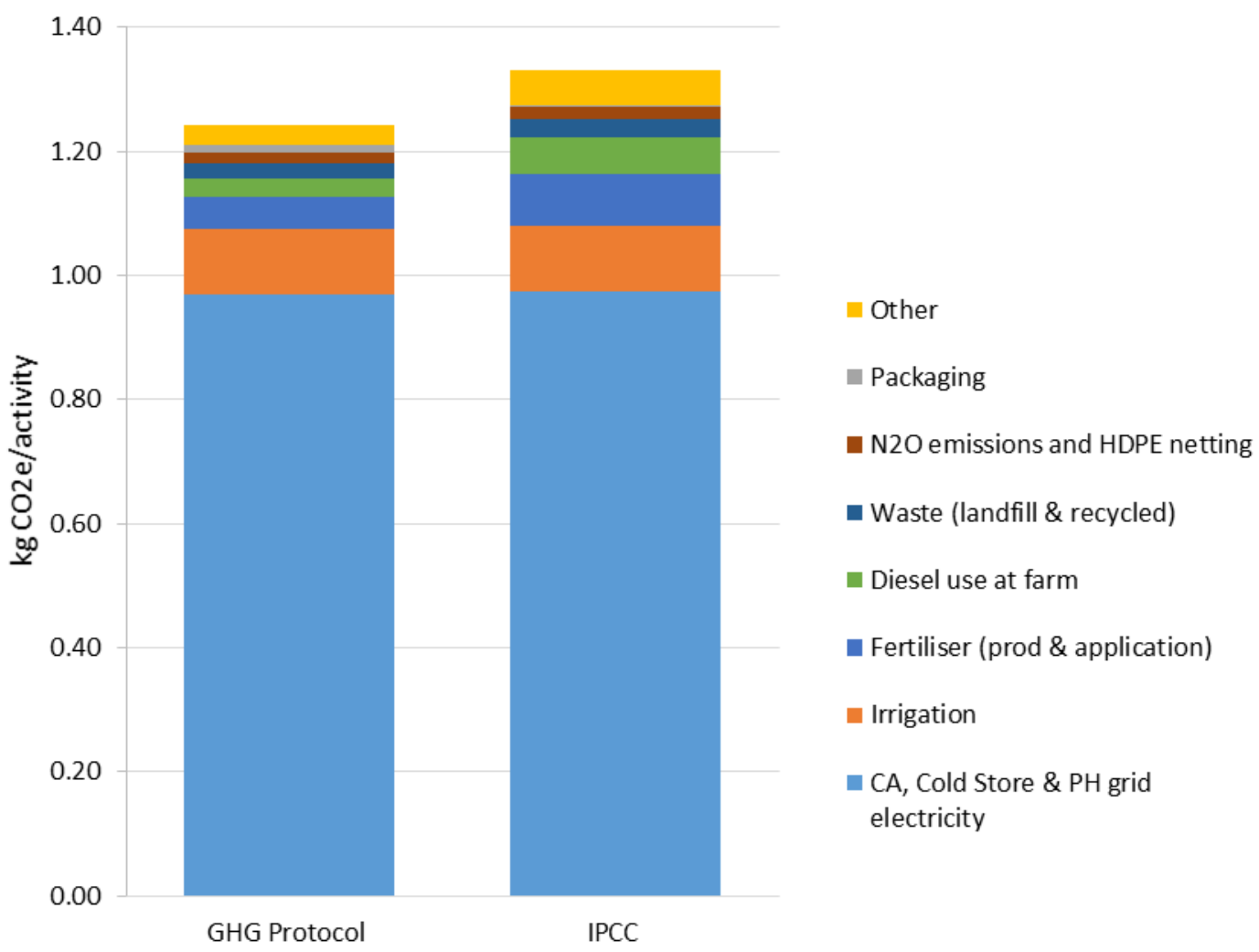

Figure 33: Contribution of activities in year 2020 according to GHG Protocol and IPCC method. 


\subsection{Eco-efficiency trends}

Eco-efficiency is an aspect of sustainability relating the environmental performance of a product system to its product system value (International Standards Organisation, 2012). An ecoefficiency assessment includes 5 phases:

- Goal and scope definition;

- Environmental assessment using an LCI and results from a LCIA;

- Product system value assessment;

- Quantification of eco-efficiency and;

- Interpretation.

A formal eco-efficiency assessment was not done within the scope of this research, however, eco-efficiency trends within the pome fruit value chain contributing to an improved environment were identified more generally. The pome fruit product system value for all fruit grades has increased annually at an above inflation rate $8.7 \%$ according to data supplied by the Bureau for Food and Agricultural Policy (BFAP) and pome fruit industry body Hortgro. Against this increase in value, four areas where eco-efficiency trends were observed are the irrigation practices in Table 46, diesel usage at farm in Table 47, fertiliser use per hectare in Table 48 and the Packhouse and CS facilities in Table 49.

\subsubsection{Irrigation}

\begin{tabular}{|l|l|l|l|}
\hline & $\mathbf{2 0 0 0}$ & $\mathbf{2 0 1 0}$ & $\mathbf{2 0 2 0}$ \\
\hline Yield (tonnes/ha) & 47 & 31 & 36 \\
\hline $\begin{array}{l}\text { Irrigation technologies } \\
(\mathrm{m} 3 / \mathrm{ha})\end{array}$ & $\begin{array}{l}\text { Micro-sprinkler long } \\
\text { range } \\
\approx 6500 \mathrm{~m} 3 / \mathrm{ha}\end{array}$ & $\begin{array}{l}\text { Micro sprinkler (long } \\
\text { and short range) } \\
\approx 6222 \mathrm{~m} 3 / \mathrm{ha}\end{array}$ & $\begin{array}{l}\text { Micro sprinkler short range. Soil } \\
\text { probes, optimization of irrigation } \\
\text { system. } \\
\approx 5200 \mathrm{~m} 3 / \mathrm{ha}\end{array}$ \\
\hline Pumping system efficiency & $70 \%$ & $70 \%$ & $75 \%$ \\
\hline $\begin{array}{l}\text { Grid electricity } \\
\text { (kg CO2e/kWh) }\end{array}$ & 1.25 & 1.25 & 1.15 \\
\hline \begin{tabular}{l} 
Other \\
\hline
\end{tabular} & & $\begin{array}{l}\text { Netting or draping of trees. } \\
\text { Plastic mesh for mulch. }\end{array}$ \\
\hline
\end{tabular}

Table 46: Irrigation practices for each time period.

\footnotetext{
${ }^{47}$ over lifespan of orchard including establishment phase

48 IPCC GWP 100a

49 http://www.hortgro-science.co.za/net-gain-amid-water-climate-challenges/
} 
5.4.2. Diesel usage

\begin{tabular}{|l|r|r|r|}
\hline & 2000 & 2010 & 2020 \\
\hline Diesel use per ha [L] & 487 & 398 & $180-270$ \\
\hline
\end{tabular}

Table 47: Diesel usage trends across time periods.

\subsubsection{Fertilisers}

\begin{tabular}{|c|c|c|c|}
\hline & 2000 & 2010 & 2020 \\
\hline $\begin{array}{l}\text { Tree density per } \\
\text { hectare }\end{array}$ & $941-989$ & $1229-1272$ & $1666-2000$ \\
\hline $\begin{array}{l}\text { Nitrogen applied per } \\
\text { hectare }[\mathrm{kg}]\end{array}$ & 67 & 103 & 153 \\
\hline $\begin{array}{l}\mathrm{N}_{2} \mathrm{O} \text { emissions to air } \\
\text { per hectare }[\mathrm{kg} / \mathrm{ha}]\end{array}$ & 1.12 & 2.24 & 2.58 \\
\hline
\end{tabular}

Table 48: Changes in nitrogen fertiliser application across time periods.

\subsubsection{Packhouse and cold storage}

\begin{tabular}{|l|l|l|l|}
\hline & $\mathbf{2 0 0 0}$ & $\mathbf{2 0 1 0}$ & $\mathbf{2 0 2 0}$ \\
\hline Electricity & $100 \%$ grid & $100 \%$ grid & $95 \%$ grid, 5\% PV \\
\hline Bins & Wooden & $\begin{array}{l}84 \% \text { Wooden } \\
16 \% \text { Plastic }\end{array}$ & $\begin{array}{l}50 \% \text { Wooden } \\
50 \% \text { Plastic }\end{array}$ \\
\hline Packaging & $\begin{array}{l}\text { Only cardboard and } \\
\text { trays (paper \& } \\
\text { polystyrene) used. } \\
\text { Fruit packed loose. }\end{array}$ & $\begin{array}{l}\text { Combination of } \\
\text { corrugated cardboard } \\
\text { and plastics (PP, PET, } \\
\text { LDPE). }\end{array}$ & $\begin{array}{l}\text { Flow wrap format made } \\
\text { from bio based PP and } \\
\text { corrugated cardboard. }\end{array}$ \\
\hline Transport (forklifts) & LDPE \& diesel & LDPE and electricity & Only electricity \\
\hline Waste & $15 \%$ & $1 \%$ & $1 \%$ \\
\hline $\begin{array}{l}\text { Packaging kg CO} 2 \mathrm{e} / \mathrm{kg} \\
\text { fruit (GHG Protocol) }\end{array}$ & 0.01 & 0.03 & 0.01 \\
\hline
\end{tabular}

Table 49: Changes in packhouse and cold storage inputs and outputs.

It is clear that there has been an increase in eco-efficiency in a number of farming and agroprocessing practices since 2000 which correlates to the declining $\mathrm{CO}_{2} \mathrm{e}$ emissions in the boundaries and overall value chain of South African pome fruit. 


\section{Chapter 6 : Interpretation and Discussion}

An LCA study begins with the goal and scope phase and ends with the interpretation phase (SANS, 2002c). The interpretation phase is the systematic procedure to identify, qualify and evaluate the results from the LCIA and present the information to meet the requirements as stated in the goal and scope. This phase consists of three elements, namely:

- Identification of the significant issues based on the results of the LCI and LCIA;

- Evaluations which considers completeness, sensitivity and consistency checks and;

- Conclusions and recommendations which is in Chapter 7 of the dissertation.

The goal and scope and interpretation phases frame the study whereas the LCI and LCIA phases produce information on the defined system (ibid: 3 ).

\subsection{Significant issues}

The GWP results ( $\mathrm{kg} \mathrm{CO} 2 \mathrm{e} / \mathrm{kg}$ fruit) for the year 2000, 2010 and 2020 for the pome fruit product system is in Table 50.

\begin{tabular}{|l|r|l|}
\hline \multirow{2}{*}{ Year } & \multicolumn{2}{|c|}{ (Kg CO $\mathbf{~ C O}_{\mathbf{2}} \mathbf{k g}$ pome fruit) } \\
\cline { 2 - 3 } & GHG Protocol & IPCC \\
\hline $\mathbf{2 0 0 0}$ & 1.46 & 1.52 \\
\hline $\mathbf{2 0 1 0}$ & 1.18 & 1.23 \\
\hline $\mathbf{2 0 2 0}$ & 0.92 & 1.02 \\
\hline
\end{tabular}

The results appear to decrease substantially from the year 2000 to 2020 . There is a $19 \%$ decline in GWP results between 2000 and 2010 and then a further $20 \%$ decline between 2010 and 2020 . This indicates a sustained decline in GWP intensity for South African pome fruit from the year 2000 to 2020. These results are normalised to the total $\mathrm{CO}_{2} \mathrm{e}$ emissions in South Africa for each year. For the year 2020, the national $\mathrm{CO}_{2} \mathrm{e}$ emissions are predicted to be approximately $700 \mathrm{Mt}$ ("Climate Action Tracker", n.d.). The annual GHG emissions of the pome fruit industry and total national $\mathrm{Mt}$ of $\mathrm{CO}_{2} \mathrm{e}$ for the years under study are in Table 51.

\begin{tabular}{|c|r|r|r|r|r|r|}
\hline Year & $\begin{array}{c}\text { kg CO2e/kg } \\
\text { pome fruit } \\
\text { (GHG) }\end{array}$ & $\begin{array}{c}\text { kg CO2e/kg } \\
\text { pome fruit } \\
\text { (IPCC) }\end{array}$ & Annual yield [T] & $\begin{array}{c}\text { kT CO } 2 \mathbf{e} \\
\text { (GHG) }\end{array}$ & $\begin{array}{c}\text { kT CO} \\
\text { (IPCC) }\end{array}$ & $\mathbf{M t ~ C O}_{2}$ (ZA) \\
\hline 2000 & 1.46 & 1.52 & 513949 & 750 & 781 & 420 \\
\hline 2010 & 1.18 & 1.23 & 754648 & 890 & 928 & 570 \\
\hline 2020 & 0.92 & 1.02 & 935286 & 860 & 954 & 700 \\
\hline
\end{tabular}

Table 51: Total kT CO2e of pome fruit industry and South African Mt $\mathrm{CO}_{2}$ e emissions for each year. 
The normalised GWP results for each year are in Figure 34 and follow the same trend of decline as the GWP indicator results from 2000 to 2020 . The decline in normalised GWP results between 2000 and 2010 is $13 \%$ and from 2010 to 2020 there is an indication of a possibly more accelerated decline of $19 \%$. It is evident that, depending on what the 2020 national $\mathrm{CO}_{2} \mathrm{e}$ emissions will be, there is an accelerating decline in the Climate change impact of South African pome fruit in the last 20 years.

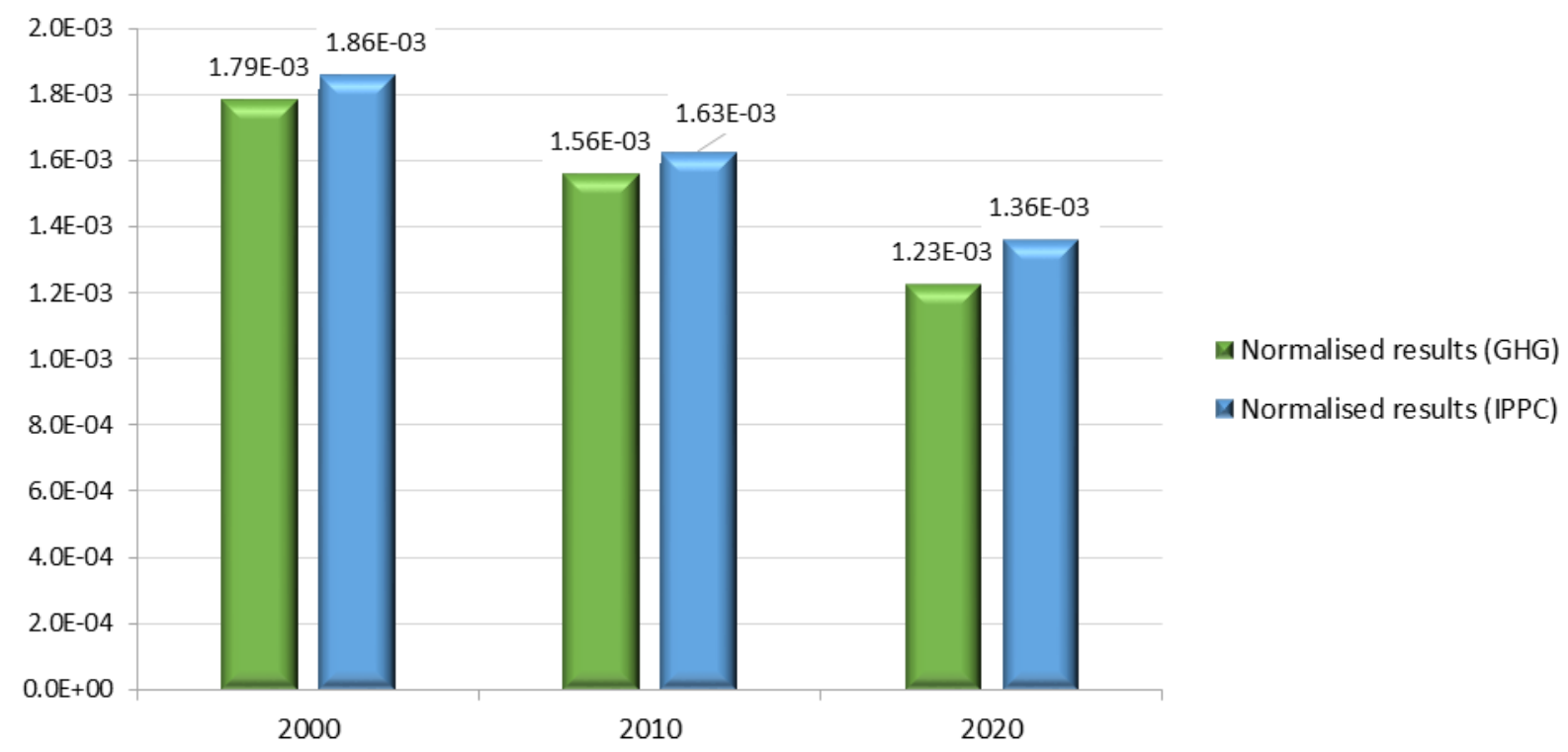

Figure 34: Normalised GWP results for pome fruit industry.

The GWP results per boundary for all years are in Figure 35 and Figure 36. The GWP results for the CS and CA facilities in the year 2000 and 2010 are the same due to the same electricity consumption and unchanged grid mix. The GWP result for these facilities drops in the year 2020 due to increased electricity efficiency per cold unit and the lower GWP result per kWh for the 2020 grid mix. The CA store is the most $\mathrm{CO}_{2} \mathrm{e}$ intensive due to the use of grid electricity for cooling and the duration of time the fruit is stored. This is the case for every year under study.

At the farm boundary, $\mathrm{CO}_{2} \mathrm{e}$ emissions show a decline according to the GHG Protocol and IPCC method. For the year 2020 less electricity, diesel and pesticides are used compared to 2000 and 2010. However, considerably more nitrogen is applied per hectare in 2020 which consequently leads to higher dinitrogen monoxide emissions. 


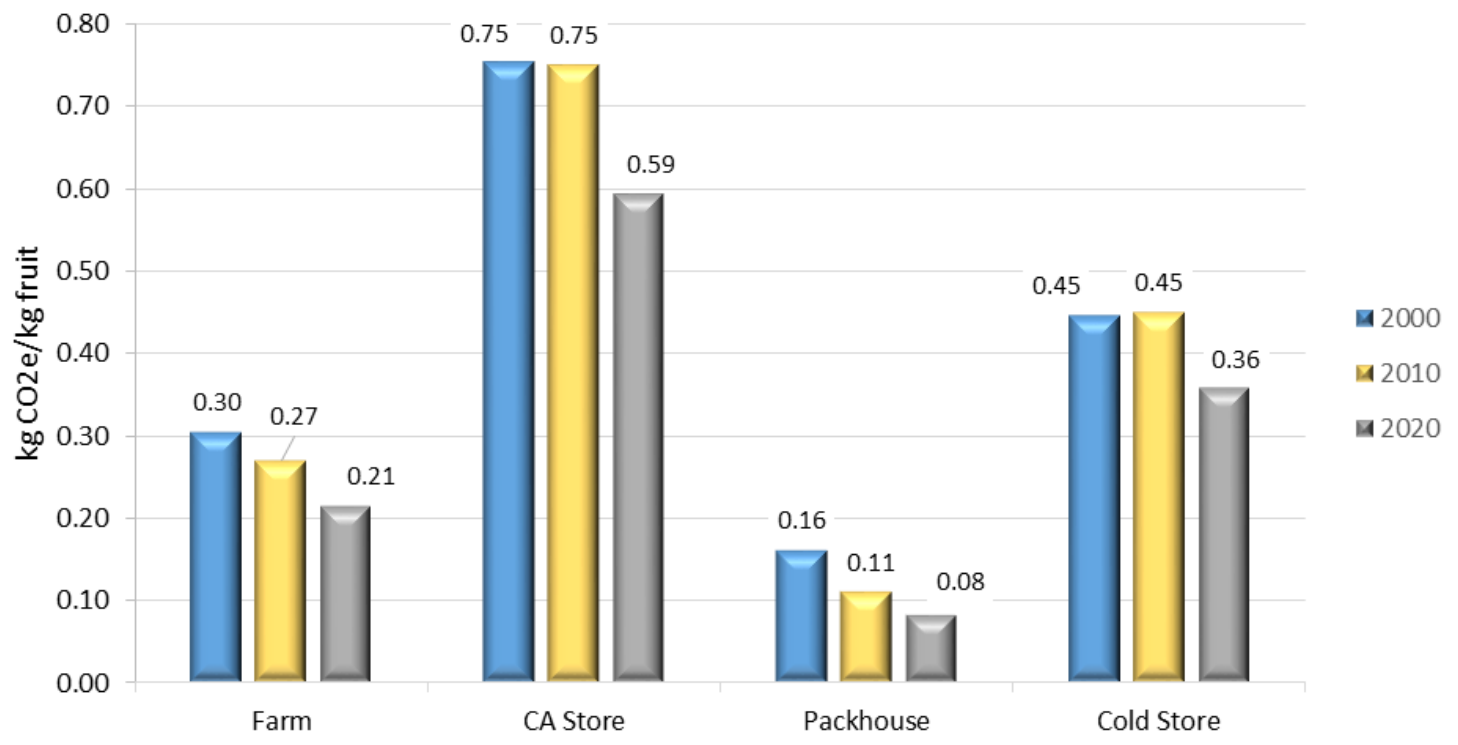

Figure 35: LCIA GWP indicator results for all boundaries using GHG Protocol method.

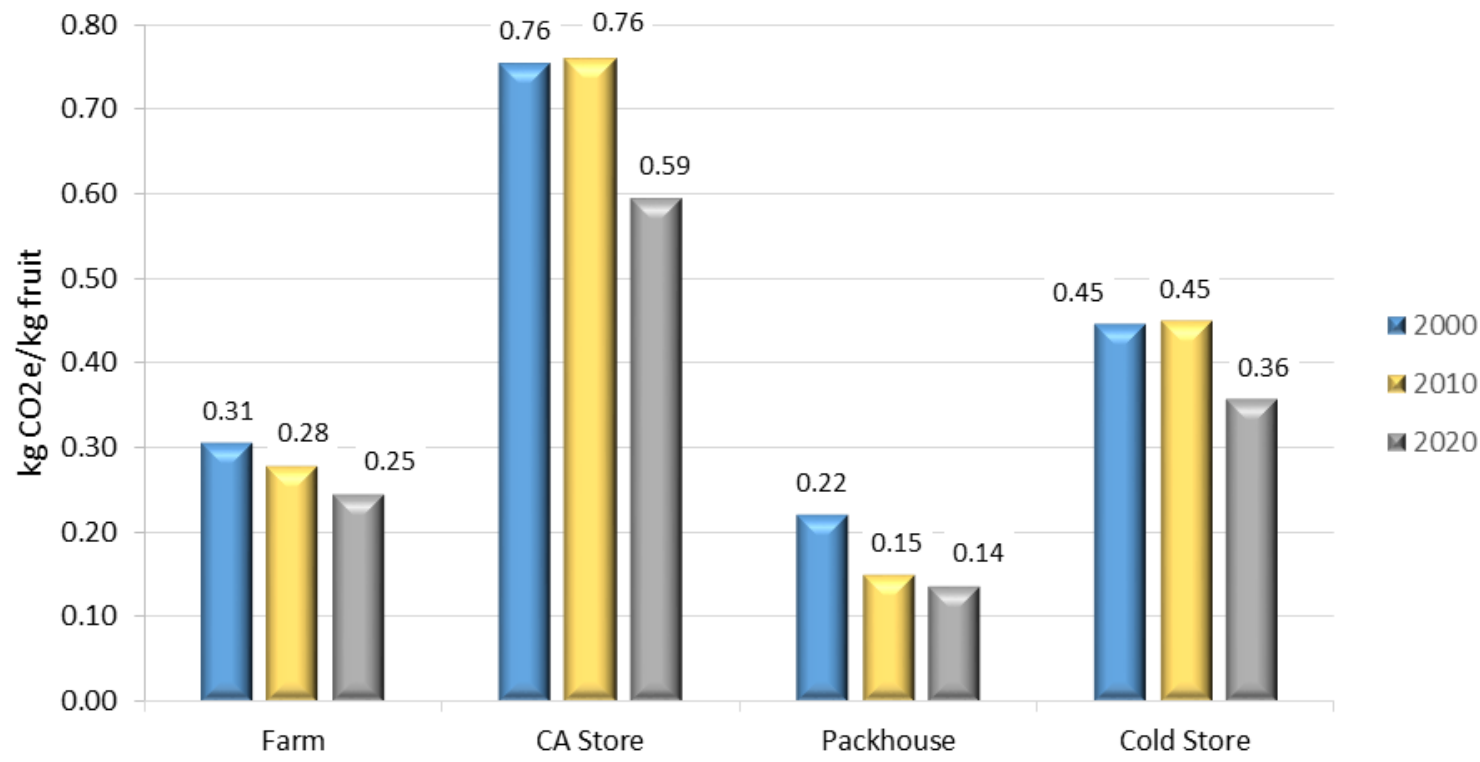

Figure 36: LCIA GWP indicator results for all boundaries using the IPCC method.

The increase in fertiliser use, with subsequent $\mathrm{N}_{2} \mathrm{O}$ emissions to air, leads to an additional 0.03 $\mathrm{kg} \mathrm{CO} 2 \mathrm{e} / \mathrm{kg}$ fruit at farm boundary. The other additional inputs in the $2020 \mathrm{LCl}$ are the trellis system and HDPE netting, which is an additional $0.01 \mathrm{~kg} \mathrm{CO} 2 \mathrm{e}$.

In the packhouse, the largest difference in $\mathrm{CO}_{2} \mathrm{e}$ emissions according to both impact assessment methods is from the packaging input between the years. There is a steady decline in the GWP results for packaging from 2000 to 2020. For the years 2000 and 2020, the total weight of corrugated cardboard used was calculated from the number of MK6 equivalent cartons inspected by the PPECB and the predicted tonnes of fruit for export and local market in 2020 . These 
calculations result in approximately $63 \mathrm{~kg}$ corrugated cardboard used per ton fruit packed whereas the year 2010 figure is $55 \mathrm{~kg}$ per ton fruit packed. Even with this input the year 2020 packaging GWP result is lower than 2010 due to less polystyrene and low density polyethylene consumed per ton fruit packed.

A comparison of the activity contribution to total GWP according to the GHG Protocol method for each year is shown in Figure 37.

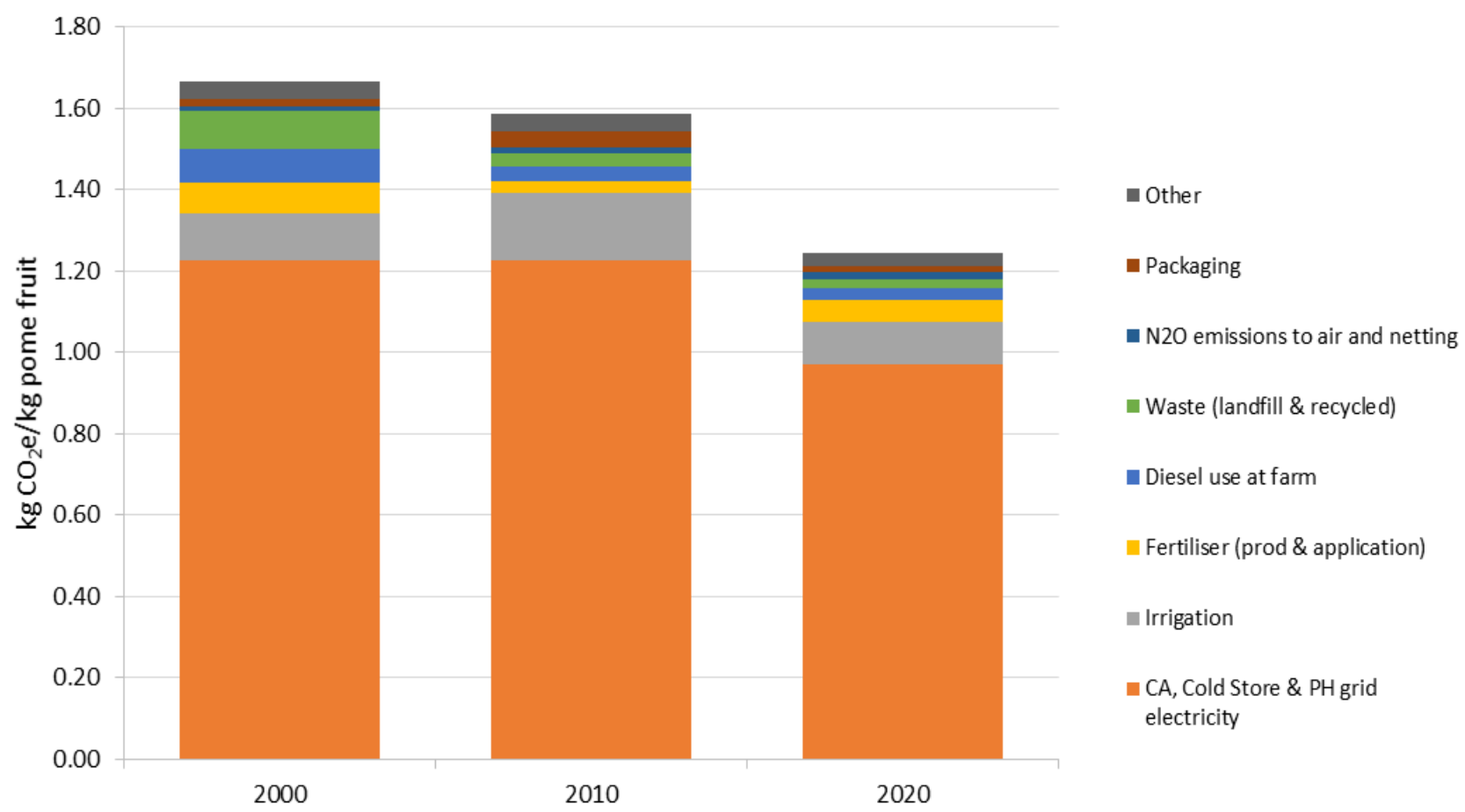

Figure 37: GWP results per activity in pome fruit value chain according to GHG Protocol method.

\subsection{Data quality and completeness check}

The objective of the completeness check is to ensure that all relevant information and data needed for the interpretation is available and complete. The structure of the $\mathrm{LCl}$ in 2010 was replicated for the years 2000 and 2020 and the dataset quantities were determined using credible sources and calculations which have gone through numerous iterations.

In many instances, non-regional datasets and emissions calculations were used in the models. Within the farm boundary, the emission calculations from the fertilization process according to Nemecek \& Kägi (2007) were based on Swiss parameters. The formulation of specific South African parameters could have important implications and it is therefore crucial for a more detailed investigation in this area. In addition, the active ingredients and quantities for each year was gathered either from literature or regional spray programmes which could vary from actual 
applications. This is also relevant to fertiliser programmes for the year 2000 and 2020 where commercial agriculture budgets were used from the WCDoA and Hortgro as well as information supplied by industry experts.

For the agro-processing boundaries, the CCC data for electricity consumption was found not to be aligned with values found in the industry specific literature. In this case values from the literature were used as they were based on actual measurements and subject to internal industry review. In other instances, dataset quantities for the year 2000 and 2020 were not available such as for diesel and LPG consumption in the packhouse and floor area of the packhouse, CA and CS. In these instances, the values were extrapolated from the 2010 values and assigned a higher uncertainty. However, the impact of these inputs on the overall GWP results for these boundaries and value chain is relatively small and do not require the goal or scope of the LCI and LCIA to be revisited.

Other inputs, which were Swiss or European specific, could have had a larger impact on the GWP results if they were region specific. These include the landfill and recycling datasets in the packhouse boundary and the domestic transport process models. These global datasets were allocated a higher uncertainty than the regional data.

The predictions made for the datasets and quantities in the year 2020 were based on research from BFAP, information gathered from industry experts and literature. The inputs and outputs were consequently allocated a higher uncertainty than for the year 2010. The inputs with high impact, such as the electricity grid mix for 2000 and 2020, were thoroughly researched to obtain a dataset which delivers a robust and credible LCIA result. Despite the higher uncertainty for the years 2000 and 2020, the results of these models are able to provide important and insightful implications for the industry.

\subsection{Sensitivity Analysis}

The objective of the sensitivity analysis is to assess the reliability of the final results taking into account uncertainties in the data, allocation methods and assumptions made. This sensitivity analysis will test the impact of two scenarios, namely; electricity consumption per $\mathrm{m}^{3}$ water pumped for irrigation and the proportion of fruit first stored in the CA facility before being packed.

\subsubsection{Irrigation electricity consumption}

For the years 2000 and 2020, electricity consumption for irrigation was obtained from agricultural budgets and expert opinion. The $\mathrm{kWh}$ required to pump $1 \mathrm{~m}^{3}$ of water can vary substantially for each farm. The LCl for 2000 has the value of $0.3 \mathrm{kWh}$ to pump $1 \mathrm{~m}^{3}$ of water with a head of $50 \mathrm{~m}$. For 2010 this value is $0.58 \mathrm{kWh}$ and for $20200.5 \mathrm{kWh}$. The value for 2000 is questionable as it falls below the range of values for the other years. 
The sensitivity of the year 2000 pome fruit is analysed using the value of $0.54 \mathrm{kWh}$ per $\mathrm{m}^{3}$ of water pumped. This is the average value for the years 2010 and 2020 . The results in Table 52 indicate a significant increase in GWP of the 2000 pome fruit when the higher irrigation electricity value is used.

\begin{tabular}{|c|c|c|c|c|}
\hline \multirow[t]{2}{*}{ Year } & \multicolumn{2}{|c|}{$0.3 \mathrm{kWh} / \mathrm{m}^{3}$} & \multicolumn{2}{|c|}{$0.54 \mathrm{kWh} / \mathrm{m}^{3}$} \\
\hline & GHG & IPCC & GHG & IPCC \\
\hline 2000 & 1.46 & 1.52 & 1.60 & 1.67 \\
\hline
\end{tabular}

The GWP for the farm boundary increases from 0.30 to $0.39 \mathrm{~kg} \mathrm{CO}_{2} \mathrm{e} / \mathrm{kg}$ fruit. This is a $30 \%$ increase in the GWP result for the farm boundary indicating that changes to irrigation electricity consumption has a significant impact. As a consequence, there is a $10 \%$ increase in the GWP result for the pome fruit across all boundaries as a result of increasing the electricity consumption per $\mathrm{m}^{3}$ of water pumped.

\subsubsection{Proportion of fruit intake into packhouse from CA store}

In Section 3.5 the assumption was made that $25 \%$ of fruit intake into the packhouse is first stored in the CA store and thereafter packed according to market requirements. This percentage can vary to a large degree with some facilities storing approximately $75 \%$ of the annual packhouse intake in CA before packing ${ }^{50}$. The sensitivity of the GWP result to the amount of fruit packed from the $\mathrm{CA}$ is therefore analysed. For this analysis it is assumed that $75 \%$ of fruit intake into the packhouse is first stored in the CA store while the other $25 \%$ is from the farm boundary.

The GWP of pome fruit for each for each scenario according to the GHG impact assessment method is shown in Figure 38. For both the GHG Protocol and IPCC impact assessment methods, there is an average of $44 \%$ increase in the GWP result for the pome fruit across all boundaries for every year when $75 \%$ of fruit intake into the packhouse is first stored in the CA store.

50 Nico Ferreira: Technical advisor, TAD. 


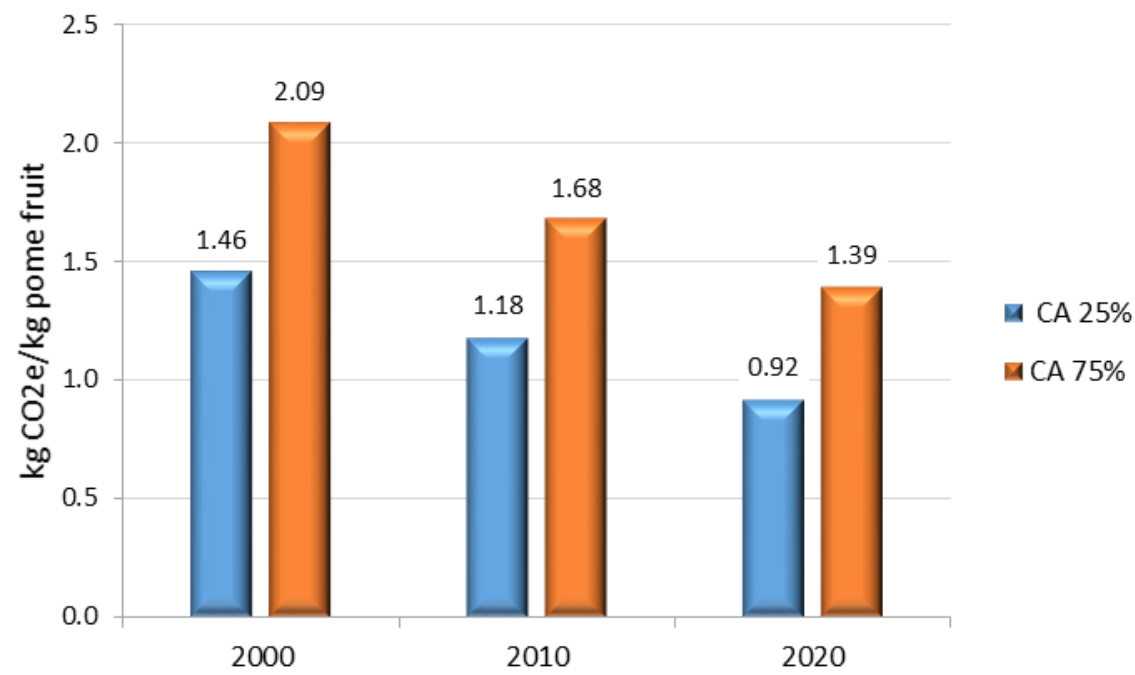

Figure 38: GWP results with both scenarios of $25 \%$ and $75 \%$ fruit intake from CA (GHG Protocol).

\subsection{Uncertainty analysis}

An uncertainty analysis, using a Monte Carlo simulation, is undertaken to determine the range of uncertainty of the results for the impact category climate change $\left(\mathrm{kg} \mathrm{CO}_{2} \mathrm{e}\right)$. Uncertainty is assigned to each dataset using an appropriate probability distribution with corresponding variance. The probability distributions available in SimaPro v. 8.3 are the lognormal, normal, triangle and uniform. In addition to the basic uncertainty allocation using the probability distributions, additional uncertainty is also applied to the datasets via data quality indicators. These additional uncertainties are based on the pedigree matrix approach (Wedema et al., 2013: 75). The Monte Carlo analysis sampling process has a number of calculation runs which is selected and affects the precision of the results. For the analysis, 1000 calculation runs were selected.

The median of the GWP indicator result for each year within a 95\% confidence interval is in Figure 39. The uncertainty analysis results indicate that the decreasing trend of GWP results for the pome fruit value chain from the year 2000 to 2020 is statistically significant. The uncertainty distributions of the GWP results for each year according to the IPCC impact assessment method are normal distributions and are presented in Appendix VIII. 


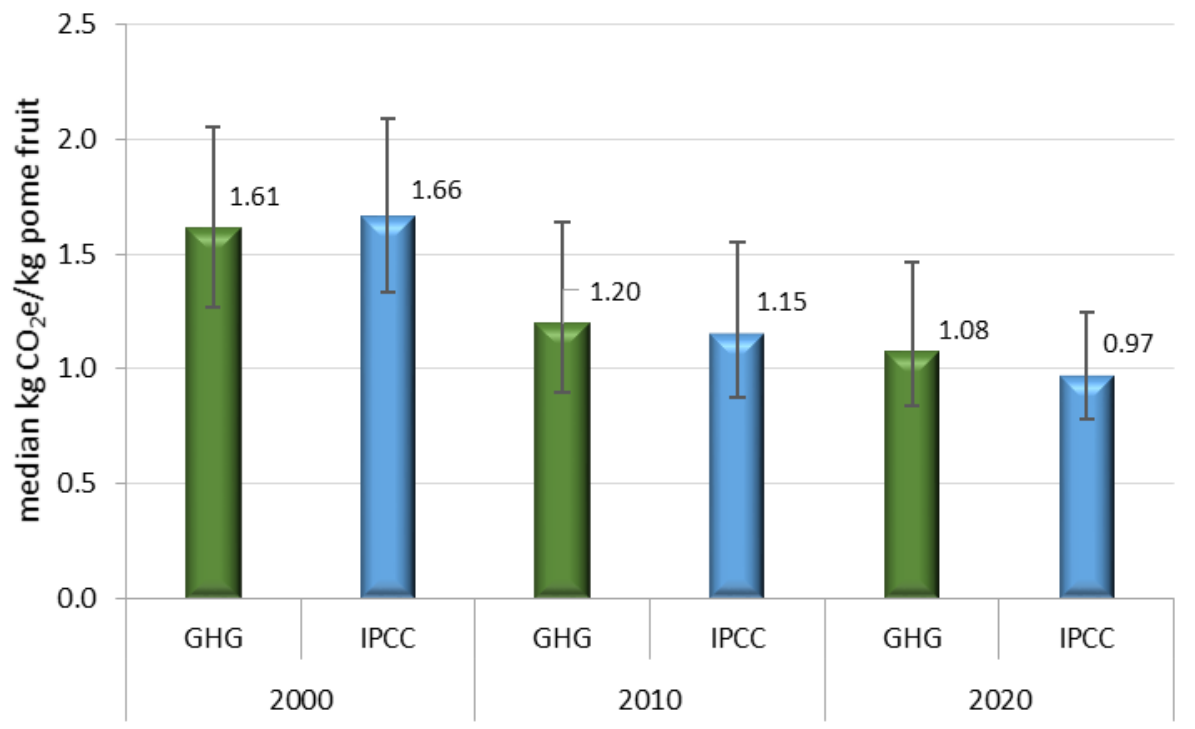

Figure 39: GWP results for pome fruit with error bars indicating the 95\% confidence interval.

\subsection{Data consistency}

The objective of the consistency check is to determine whether the assumptions, methods and data are consistent with the goal and scope. As discussed in Section 6.2, the LCls for each of the years are consistent in structure and flows into and out of the product. The LCl structure and corresponding LCIA results are consistent with the goal and scope of the study. Even through the $\mathrm{LCl}$ structure remains consistent, temporal differences are taken into account through the use of datasets from previous ecoinvent versions, datasets from the latest ecoinvent version and the creation of temporal specific datasets. Datasets are also regionalised using South African specific inputs where available. Even though different sources of the data was referenced, the input data and structure of the LCls remained consistent across all years.

The system boundaries for each year is consistent and an allocation by mass is applied in all models except for the packhouse boundary. In the case of the packhouse boundary, an economic allocation is applied for all years instead of a mass allocation. This is due to the mass ratio of the export and local market fruit to fruit for processing being different in each year which would render the GWP results incomparable due to the different allocations of the environmental burdens. The environmental burden allocation to packhouse output in all models is approximately $90 \%$ for export and local fruit and $10 \%$ for processed fruit using an economic allocation.

The two single issue impact assessments used in the research are the GHG Protocol v. 1.02 and the IPCC 2013 GWP 100a v 1.03. These impact assessment methods are applied in the LCIA step in all three LCls in order to make valid comparisons for each year under study. 


\subsection{Industry revenues and resulting carbon intensity and efficiency of the South African pome fruit industry}

Using the GWP results and industry revenue of the pome fruit industry, it is possible to determine the carbon intensity and carbon efficiency (ISO, 2012) of the industry for each of the years in question using Equation 1 and Equation 2

The GWP results per ton pome fruit for each year is in Table 53.

\begin{tabular}{|r|r|r|}
\cline { 2 - 3 } \multicolumn{1}{c|}{} & \multicolumn{2}{c|}{ (kg CO2e/ton pome fruit) } \\
\hline Year & GHG Protocol & IPCC \\
\hline 2000 & 1460 & 1520 \\
\hline $\mathbf{2 0 1 0}$ & 1180 & 1230 \\
\hline 2020 & 920 & 1020 \\
\hline
\end{tabular}

Table 53: GWP results per ton pome fruit.

The industry revenue for each of the years is calculated in 2010 ZAR adjusted for PPI in Table 54. The price per ton fruit is the weighted average price of export and local market fruit based on the tonnages per grade. The PPI for grouping 'Fruits and Vegetables' from Statistics South Africa is used to adjust the monetary values to 2010 ZAR.

\begin{tabular}{|l|r|r|r|}
\hline Year & Total tonnages & $\begin{array}{c}\text { ZAR per ton } \\
\text { (2010 ZAR) }\end{array}$ & $\begin{array}{c}\text { Industry revenue } \\
\text { (local \& export markets) } \\
\text { 2010 ZAR million }\end{array}$ \\
\hline $\mathbf{2 0 0 0}$ & 513949 & 2176.58 & 1119 \\
\hline $\mathbf{2 0 1 0}$ & 754648 & 5126.14 & 3868 \\
\hline $\mathbf{2 0 2 0}$ & 935286 & 8803.87 & 8233 \\
\hline
\end{tabular}

The data in Table 54 indicates that since the year 2000 there has been a $7.2 \%$ compound annual growth rate in the price received per ton of export and local pome fruit (ZAR 2010). However, input costs have grown significantly in the same time period which has led to the drive in increasing grade 1 and 2 yields per hectare in order to be economically sustainable. Since 2000 , there has been an $82 \%$ increase in product output coupled with an improvement in eco-efficiency as discussed in Section 5.4.

The carbon intensity and carbon efficiency results for each of the years is plotted in the graphs in Figure 40 and Figure 41. 


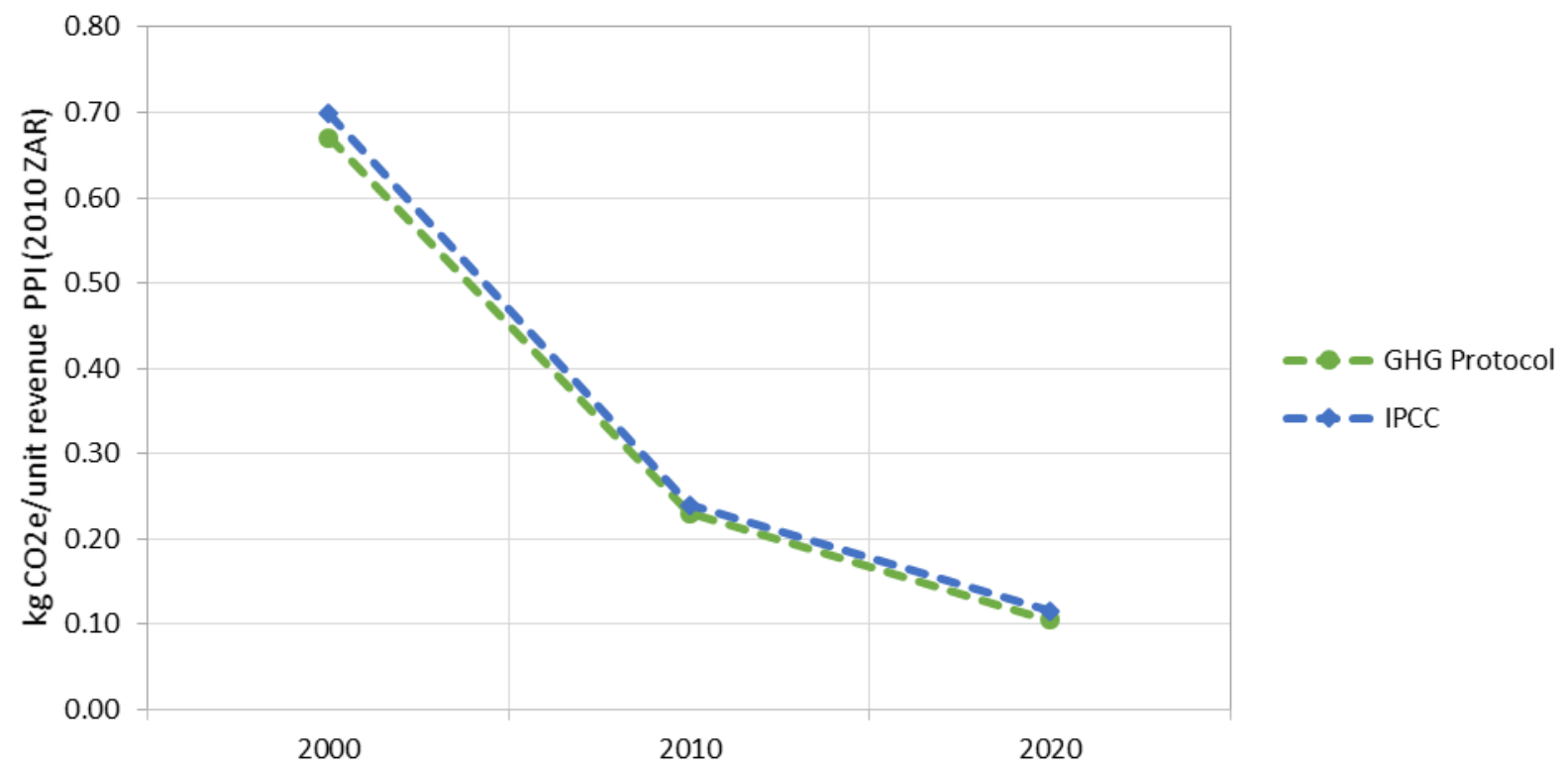

Figure 40: Carbon intensity trend since year 2000 for pome fruit industry.

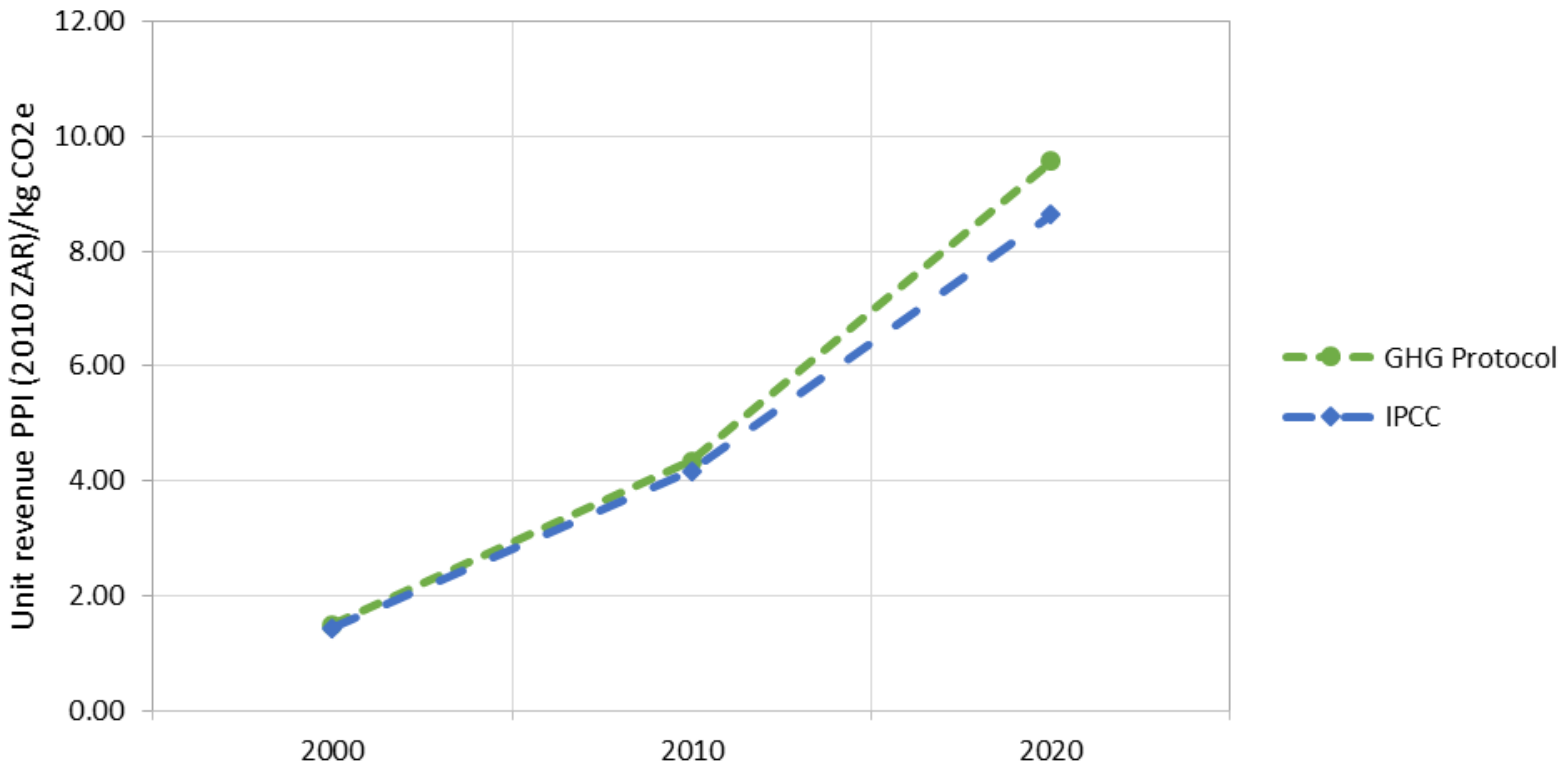

Figure 41: Carbon efficiency indicator trend since the year 2000 for pome fruit industry. 


\section{Chapter 7 : Conclusions and Recommendations}

To close off the dissertation, the key objectives of the research, as presented in Chapter 1, will now be reviewed in the light of a summary of the major findings of the research. The hypothesis developed in Chapter 3 is revisited to determine how the analysis and findings of this research supports it. This chapter first discusses the motivation behind carrying out the research in Section 7.1 followed by a summary of the objectives and major findings of the research in Section 7.2. Section 7.3 provides the validation of the hypotheses, followed by the recommendations in Section 7.4 .

\subsection{Research motivation}

South African products have in the past been categorised as having a relatively high embodied carbon content due to an energy and capital intensive development path and an associated set of economic activities termed the minerals-energy complex. This primary sector economy has been underpinned by the historically cheap price of electricity which has led to an electricity intensive economy and resulting in relatively high national GHG emissions. This current scenario is a risk for the South African fruit export market as there is a growing awareness around climate related issues of production and consumption globally, with the consequence that organisations and consumers are demanding products that have minimal impact on the natural environment. This pressure could potentially lead to the implementation of non-tariff trade barriers on South African pome fruit, negatively impacting the industry's contribution to GDP, foreign exchange earnings and employment creation. In addition, the agricultural sector in South Africa is the most vulnerable to climate change, and understanding the GHG emissions trends of this industry supports the development of mitigation and adaptation strategies to ensure economic, social and environmental sustainability.

\subsection{Objectives and Major findings}

The objectives of this research were the following:

i. To determine whether the GWP result of the South African pome fruit industry is high compared to other GWP results from LCAs done on pome fruit globally.

ii. To determine the trend in the carbon intensity of the South African pome fruit value chain from cultivation at farm to CS gate over a period of 20 years.

The first objective was achieved by a literature study where similar LCAs were conducted on apples and pears in different geographical regions. The results of the impact category climate change in the literature was then compared to the results of LCIA in this research for the relevant 
years in Chapter 5. The second objective was met through the development of LCls for each year in Chapter 4 . The climate change performance for each of the years was determined through a LCIA with the resulting GWP in $\mathrm{kg} \mathrm{CO}_{2} \mathrm{e} / \mathrm{kg}$ fruit in Chapter 5. To determine the carbon intensity of the industry for each of these years, the GWP results together with the gross industry revenue (2010 ZAR PPI) was used. In addition to these objectives, the carbon efficiency indicator was determined for each of the years along with the identification of trends in eco-efficiencies within the industry over the 20 year period.

\subsubsection{Conclusions drawn from Literature}

Very few international LCA studies had GWP results from more than one impact assessment method and of multiple boundaries within the pome fruit product system. Table 55 shows the GWP results from international literature as well as from this research. The LCA results from Milà i Canals, Burnip \& Cowell (2006) and Mouron, Scholz, et al. (2006) for the farm boundary in New Zealand and Switzerland, are compared to the results for the year 2000 in this research. It can therefore be concluded that pome fruit cultivation in South Africa around the year 2000 period had a high GWP compared to global results.

For the year 2010, the GWP results for farm and agro-processing boundaries by Stoessel et al. (2012), Liu et al. (2010) and Keyes, Tyedmers \& Beazley (2015) have the required temporal validity. The results of $0.27 \mathrm{CO}_{2} \mathrm{e} / \mathrm{kg}$ fruit at farm falls into the range from these LCAs and is already declining compared to the year 2000. For the agro-processing boundaries, the result for the packhouse was similar to the LCA by Liu et al. (2010). However the GWP results for the packhouse and cold storage combined by Keyes, Tyedmers \& Beazley (2015) was considerably lower than the results for these same boundaries in South Africa which highlights the considerable impact the CA and CS boundaries have on the overall GWP of South African pome fruit.

In conclusion, the GWP of South African pome fruit was relatively high compared to other global LCAs in the year 2000. From that point the GWP per boundary is comparable to international findings around the year 2010 except for the electricity intensive CA and CS boundaries. 


\begin{tabular}{|c|c|c|c|}
\hline Source & $\begin{array}{l}\text { Geographical } \\
\text { area }\end{array}$ & Boundaries & $\begin{array}{l}\mathrm{Kg} \mathrm{CO2e/kg} \\
\text { fruit }\end{array}$ \\
\hline \multirow{3}{*}{$\begin{array}{l}\text { Apple }\{\text { GLO\}| } \\
\text { production | Alloc Def, } \\
\text { U (Stoessel et al., } \\
2012)\end{array}$} & \multirow[t]{3}{*}{ Global } & $\begin{array}{l}\text { Seedling } \\
\text { production }\end{array}$ & \multirow{3}{*}{0.27} \\
\hline & & Farm & \\
\hline & & $\begin{array}{l}\text { Transport to } \\
\text { retailer }\end{array}$ & \\
\hline $\begin{array}{l}\text { (Milà i Canals, Burnip } \\
\text { \& Cowell, 2006) }\end{array}$ & New Zealand & Farm & $0.04-0.095$ \\
\hline $\begin{array}{l}\text { (Mouron, Nemecek, et } \\
\text { al., 2006) }\end{array}$ & Switzerland & Farm & $0.05-0.12$ \\
\hline \multirow[t]{3}{*}{ (Liu et al., 2010) } & \multirow[t]{3}{*}{ China } & Farm & $0.06-0.38$ \\
\hline & & $\begin{array}{l}\text { Processing } \\
\text { and cold } \\
\text { storage (no } \\
\text { packaging) }\end{array}$ & $0.005-0.16$ \\
\hline & & Transport & $0.003-0.007$ \\
\hline \multirow{2}{*}{$\begin{array}{l}\text { (Keyes, Tyedmers \& } \\
\text { Beazley, 2015) }\end{array}$} & \multirow[t]{2}{*}{ Canada } & Farm & 0.14 \\
\hline & & $\begin{array}{l}\text { Packaging \& } \\
\text { CS }\end{array}$ & 0.19 \\
\hline \multirow[t]{4}{*}{ ZA pome fruit $2000^{*}$} & \multirow[t]{12}{*}{ South Africa } & Farm & 0.30 \\
\hline & & $\mathrm{CA}$ & 0.75 \\
\hline & & Packhouse & 0.16 \\
\hline & & CS & 0.45 \\
\hline \multirow[t]{4}{*}{ ZA pome fruit $2010^{*}$} & & Farm & 0.27 \\
\hline & & CA & 0.75 \\
\hline & & Packhouse & 0.11 \\
\hline & & CS & 0.45 \\
\hline \multirow[t]{4}{*}{ ZA pome fruit $2020^{*}$} & & Farm & 0.21 \\
\hline & & CA & 0.59 \\
\hline & & Packhouse & 0.08 \\
\hline & & CS & 0.36 \\
\hline
\end{tabular}

Table 55: GWP results for boundaries in global pome fruit industry and in this research.

*Impact assessment results according to GHG Protocol method. 


\subsubsection{LCIA results and carbon intensity of the industry}

Across all years, the input to the value chain with the largest contribution to climate change was the national grid electricity. Electricity use in the agro-processing facilities and irrigation on farm was ranked first and second according to GWP results for all years. This ranking of results held true using both the GHG Protocol and IPCC impact assessment methods. The boundaries with the highest GWP per $\mathrm{kg}$ fruit result across all years were the CA and CS facilities. The sensitivity analysis indicated that increasing electricity consumption for irrigation at farm and the proportion of fruit first stored in the CA before being packed, leads to a $10 \%$ and $44 \%$ increase respectively in the GWP of the pome fruit across all boundaries. These findings are evidence of the significant impact the national grid electricity has on the GWP of South African pome fruit.

Taking into account all boundaries of the value chain, the GWP results for the years 2000, 2010 and 2020 indicate a 19\% decline in GHG emissions from the year 2000 to 2010 which was followed with a further $20 \%$ decline from 2010 to 2020 . When the results per functional unit were extrapolated to the annual market output and normalised to total $\mathrm{CO}_{2}$ emissions in South Africa for each of the years, it was evident that there is an accelerating decline from 2010 to 2020 of $19 \%$ compared to the $13 \%$ decline from 2000 to 2010 .

The results from the LCIA and gross industry revenue for each year (2010 ZAR, PPI) was used to determine the carbon intensity and carbon efficiency of the pome fruit industry. It was found that there has been a $66 \%$ decline in industry carbon intensity from 2000 to 2010 with a slower decline of $53 \%$ from 2010 to 2020 . In total there has been an $8.6 \%$ annualised decrease in carbon intensity from 2000 to 2020 and a $10.5 \%$ annualised increase in total gross industry revenue for the same period. Since the year 2000 there has also been an $84 \%$ absolute decrease in carbon intensity of the industry. From these findings it can be concluded that the carbon intensity of the South African pome fruit industry has indeed declined from the year 2000. With regards to the carbon efficiency indicator, it has increased by approximately $200 \%$ between 2000 and 2010 with a slower gain of $140 \%$ from 2010 to 2020 .

These trends indicate a relative decoupling of total pome fruit industry $\mathrm{CO}_{2} \mathrm{e}$ emissions from the growth in gross industry revenue between 2000 and 2020 as during this period total GHG emissions increased by $18 \%$ while the industry revenue grew by $113 \%$. Significantly, total GHG emissions related to the pome fruit industry may have peaked in the 2010-2020 period despite increasing production and sales revenue. 


\subsection{Validation of hypothesis}

This research aimed to test the following hypotheses set out in Chapter 1:

1. In the past the GWP of South African pome fruit was relatively high compared to other geographical regions.

An LCl was created for each of the three years under study. The indicator results in GWP were obtained for the value chain and per boundary for each of the years 2000, 2010 and 2020. A literature study on global pome fruit cultivation, agro-processing and distribution was also undertaken to compare the GWP results for each of the years in South Africa to global results. The global LCA results around the year 2000 for pome fruit cultivation in New Zealand and Switzerland indicated that the GWP of South African pome fruit at farm was relatively high. For the year 2010, the South African GWP result for pome fruit at farm was comparable to results in China and another global study. However, the agro-processing boundaries were high compared to the LCA done in China and Canada. From these comparisons for the years 2000 and 2010, it is evident that the GWP of South African pome fruit at farm level in 2000 was relatively high but this has declined to levels which are comparable to international results in 2010.

2. Since the year 2000 the GWP result has decreased, with a subsequent decline in the carbon intensity of the industry which is aligned with the downward trend of the carbon intensity of the South African economy ( $\mathrm{kg} \mathrm{CO} 2 \mathrm{e} / \mathrm{GDP} 2005 \mathrm{ZAR})$.

It was found that there has been a sustained decline in the GWP of South African pome fruit from the year 2000 to 2020 . This has been due to an increase in eco-efficiencies across the value chain, an increase in yields per hectare and the lower climate impact of the national electricity grid mix expected in 2020. The combination of these various factors have contributed to the declining GWP of South African pome fruit. The relationship between the GWP of the industry and gross economic revenue has indicated a decline in carbon intensity since 2000 along with an improvement in carbon efficiency leading to a relative decoupling of $\mathrm{CO}_{2} \mathrm{e}$ emissions from the economic growth of the industry (ZAR 2010, PPI). These findings are aligned with, but somewhat faster than, the decline in national $\mathrm{CO}_{2} \mathrm{e}$ intensity, as expressed by relative decoupling of $\mathrm{CO}_{2} \mathrm{e}$ emissions from economic growth ( $\left.\mathrm{kg} \mathrm{CO} \mathrm{CO}_{2} \mathrm{e} / \mathrm{Real} \mathrm{GDP}\right)$.

\subsection{Recommendations}

Based on the findings and conclusions made from the research results, the following recommendations are made. 


\subsubsection{Data accuracy}

The $2010 \mathrm{LCl}$ made use of data mainly from the CCC database. However, the accuracy of the electricity consumption for the agro-processing boundaries; packhouse, CA and CS were brought into question when compared to another energy benchmark study. It is understandable that electricity meters are not available at each facility and estimations are made when completing the CCC carbon calculator. Going forward it is recommended that during the sense checking of datasets, which eventually form part of the benchmark, the electricity consumption per ton fruit stored be compared to the energy benchmark study by Bouwer, Von Broembsen \& Dodd (2008) and queried if the differences are significant. This step will increase the accuracy of electricity consumption values for the $\mathrm{CA}$ and $\mathrm{CS}$ facilities and provide more credibility to the CCC benchmark.

\subsubsection{Reducing high GWP of electricity in South Africa}

Across all years and boundaries, the input with the largest impact on GWP is grid electricity use. The irrigation activity in the farm boundary and storage of fruit in the CA and CS facilities has the highest climate change impact due to the electricity intensity of these activities. Out of all boundaries the most electricity intensive per $\mathrm{kg}$ fruit stored is the CA store. Interventions will need to be focussed at this environmental 'hot spot' in order to make a significant impact on the climate change potential of South African pome fruit. Much has already been done to reduce electricity consumption through various interventions in all boundaries during the last 10 years, and more recently, rooftop PV installations are gaining ground in the industry. As the pome fruit industry has no control over the carbon-intensity of the national grid electricity mix, its main point of leverage will be to continue increasing the share of renewable energy sources within its own operations. Nationally though, it is imperative that the REIPPP continue to grow the proportion of renewable energy as part of the national grid mix into the future to ensure South African products and services have a lower climate impact. The risk of non-tariff trade barriers and potential border carbon adjustments on exported products will be reduced as well as the economic impact on business entities from the proposed carbon tax.

\subsubsection{Continuing along the decarbonisation path}

The LCIA results support the findings of increased eco-efficiency, specifically carbon efficiency in the industry since 2000. There are numerous guidelines to lessen the environmental burden, specifically climate impact of the pome fruit industry through the use of solar and other renewable energy sources as SSEG options, efficient water management, alternative packaging and the adoption of conservation agriculture practices to name a few. Further reducing the GWP of South African pome fruit will ensure the environmental, social and economic sustainability of the industry into the future. 


\section{References}

AQUASTAT - FAO's Information System on Water and Agriculture. n.d. Available:

http://www.fao.org/nr/water/aquastat/water_use_agr/index3.stm [2016, April 08].

BFAP. 2016. BFAP Baseline: Agricultural Outlook 2016 - 2025.

Blignaut, A. \& de Kock, L. 2015. Pome fruit Industry Report.

Bodegom, P. Van, Hurndall, R., Merwe, J.A. Van Der, Perks, A., Enterprises, P. \& Meadows, D. 2013. South African Controlled Atmosphere Storage Operator'S Manual.

Botha, T. \& von Blottnitz, H. 2006. A comparison of the environmental benefits of bagassederived electricity and fuel ethanol on a life-cycle basis. Energy Policy. 34(17):2654-2661. DOI: 10.1016/j.enpol.2004.12.017.

Bouwer, K. 2017. Energy assessment report: Agribusiness Western Cape.

Bouwer, J.., Von Broembsen, L.. \& Dodd, M.. 2008. A benchmark study of energy usage in export fruit production, packhouse and cold store operations. South African Fruit Journal. Available: http://www.hortgro-science.co.za/wp-content/uploads/2015/08/Bouwer-vonBroembsen-Dodd-Energy-usage1.pdf [2017, March 29].

Brent, A.C. 2004. A life cycle impact assessment procedure with resource groups as areas of protection. The International Journal of Life Cycle Assessment. 9(3):172-179. DOI: 10.1007/BF02994191.

Brent, A.C., Rohwer, M.B., Friedrich, E. \& Blottnitz, H. Von. 2002. Status of life cycle assessment and engineering research in South Africa. The International Journal of Life Cycle Assessment. 7(3):167-172. DOI: 10.1007/BF02994051.

Brent, A.C., O 'Kennedy, K., Hietkamp, S. \& Wise, R. 2009. Estimating the Carbon Emissions Balance for South Africa. SAJEMS NS. 12(263).

Brouwer, C. \& Heibloem, M. 1986. FAO Irrigation Water Management: Irrigation Water Needs. Available: http://www.fao.org/docrep/s2022e/s2022e03.htm\#chapter 3: effective rainfall [2016, March 01].

Buerke, A. \& Gaspar, C. 2014. Wissenschaftliche Gesellschaft für Marketing und Unternehmensführung.

Burton, J. \& Winkler, H. 2014. South Africa's planned coal infrastructure expansion : drivers , 
dynamics and impacts on greenhouse gas emissions.

Cerutti, A.K., Bruun, S., Beccaro, G.L. \& Bounous, G. 2011. A review of studies applying environmental impact assessment methods on fruit production systems. Journal of Environmental Management. 92(10):2277-2286. DOI: 10.1016/j.jenvman.2011.04.018.

Climate Action Tracker. n.d. Available: http://climateactiontracker.org/countries/southafrica.html [2016, August 22].

Collet, P., Hélias Arnaud, A., Lardon, L., Ras, M., Goy, R.A. \& Steyer, J.P. 2011. Life-cycle assessment of microalgae culture coupled to biogas production. Bioresource Technology. 102(1):207-214. DOI: 10.1016/j.biortech.2010.06.154.

Confronting Climate Change. 2017. Confronting Climate Change database 2011 - 2016 [Raw data].

Curran, M.A., Mann, M. \& Norris, G. 2005. The international workshop on electricity data for life cycle inventories. Journal of Cleaner Production. 13(8):853-862. DOI:

10.1016/j.jclepro.2002.03.001.

Dabrowski, J.M., Shadung, J.M. \& Wepener, V. 2014. Prioritizing agricultural pesticides used in South Africa based on their environmental mobility and potential human health effects.

Environment International. 62:31-40. DOI: 10.1016/j.envint.2013.10.001.

Deciduous Fruit Producers Trust. 2000. Key Deciduous Fruit Statistics 2000.

Department of Energy. 2011. IRP1 2010-2030.

Department of Energy. 2013. Draft 2012 Integrated Energy Planning Report: Annexure B Model Input and Assumptions.

Department of Energy (DoE). 2013. Integrated Resource Plan for Electricity (IRP) 2030.

Department of Environmental Affairs. 2014a. South Africa's Greenhouse Gas (GHG) Mitigation Potential Analysis. Pretoria.

Department of Environmental Affairs. 2014b. South Africa's Greenhouse Gas (GHG) Mitigation Potential Analysis. Pretoria.

Department of Environmental Affairs and Energy. 2013. South African Green Economy Modelling Report (SAGEM). DOI: 10.1038/320390c0.

Devers, L., Mathijs, E. \& Kleynhans, T.E. 2012. Comparative life cycle assessment of Flemish and Western Cape pork production. Agrekon. 51(4):105-128. Available: https://journals- 
co-za.ezproxy.uct.ac.za/content/agrekon/51/4/EJC130496 [2017, November 17].

Diop, N. \& Jaffee, S. 2004. Fruits and Vegetables: Global Trade and Competition in Fresh and Processed Product Markets. In Global Agricultural Trade and Developing Countries. M. Ataman Aksoy \& J. Beghin, Eds. The World Bank. 237-257. Available:

https://books.google.co.za/books?hl=en\&lr=\&id=Fm3bqFbXIEIC\&oi=fnd\&pg=PA237\&dq=D iop+\%26+Jaffee,+2004\&ots=b3e3Am1Bf9\&sig=djxJi5KWRN3RihG6olTimTE7Ysl\#v=onep age\&q=Diop \%26 Jaffee $\% 2 C 2004 \& f=$ false.

Ekvall, T. \& Andrae, A. 2006. Attributional and Consequential Environmental Assessment of the Shift to Lead-Free Solders (10 pp). The International Journal of Life Cycle Assessment. 11(5):344-353. DOI: 10.1065/lca2005.05.208.

ESKOM. 2000. ESKOM Annual Report.

European Commission. 2018. A European Strategy for Plastics in a Circular Economy. Available: http://ec.europa.eu/environment/circular-economy/pdf/plastics-strategy.pdf [2018, May 16].

FAO: Natural Resources Management and Environment. n.d. Chapter 5: Irrigation water requirements. Available: http://www.fao.org/docrep/w4347e/w4347e0c.htm [2016, April 08].

Finnveden, G. 2000. On the limitations of life cycle assessment and environmental systems analysis tools in general. The International Journal of Life Cycle Assessment. 5(4):229_ 238. DOI: 10.1007/BF02979365.

Flore, J., DeGrandt-Hoffman, G. \& Perry, R.L. 1984.

Friedrich, E. \& Trois, C. 2013. GHG emission factors developed for the collection, transport and landfilling of municipal waste in South African municipalities. Waste Management. 33(4):1013-1026. DOI: 10.1016/J.WASMAN.2012.12.011.

Friedrich, E., Pillay, S. \& Buckley, C.A. 2009. Carbon footprint analysis for increasing water supply and sanitation in South Africa: a case study. Journal of Cleaner Production. 17(1):1-12. DOI: 10.1016/j.jclepro.2008.03.004.

Frischknecht, R. \& Stucki, M. 2010. Scope-dependent modelling of electricity supply in life cycle assessments. International Journal of Life Cycle Assessment. 15(8):806-816. DOI: 10.1007/s11367-010-0200-7.

G.P., P. \& Hertwich, E.G. 2007. Policy Analysis CO 2 Embodied in International Trade with 
Implications for Global Climate Policy. DOI: 10.1021/es072023k.

Greef, P. \& Kotze, M. 2007. Subsector Study: Deciduous Fruit.

Greenhouse Gas Protocol. 2011. Product Life Cycle Accounting and Reporting Standard.

Available: http://www.ghgprotocol.org/sites/default/files/ghgp/standards/Product-Life-CycleAccounting-Reporting-Standard_041613.pdf [2018, April 23].

Gush, M.B. \& Taylor, N.J. 2014. The water use of selected fruit tree orchards (Volume 2 ):

Technical report on measurements and modelling.

Hortgro. 2007. Elektrisiteitskostes en verbruik_Hortgro budgets.

Hortgro. 2014. Key Deciduous Fruit Statistics 2014.

Hortgro. 2015. Key Deciduous Fruit Statistics 2015.

Houghton, J., Meira Filho, L., Callander, B., Harris, H., Kattenberg, A. \& Maskell, A. 1996.

Climate change 1995: The science of climate change: contribution of working group I to the second assessment report of the Intergovernmental Panel on Climate Change.

Inglesi-Lotz, R. \& Blignaut, J.N. 2012. Electricity intensities of the OECD and South Africa: A comparison. Renewable and Sustainable Energy Reviews. 16(7):4491-4499. DOI: 10.1016/j.rser.2012.04.004.

International Energy Agency (IEA). 2015. South Africa: Indicators CO2 emissions. Available: http://www.iea.org/statistics/statisticssearch/report/?\&country=SOUTHAFRIC\&year=2012\& product=Indicators [2015, May 12].

International Standards Organisation. 2006. ISO 14044:2006, Environmental management — Life cycle assessment - Requirements and guidelines. Available: https://www.iso.org/obp/ui/\#iso:std:iso:14044:ed-1:v1:en [2017, August 21].

International Standards Organisation. 2012.

IPCC. 2006. Volume 4 Chapter 11: N2O Emissions From Managed Soils and CO2 Emissions From Urea and Lime application.

IPCC. 2013. Climate Change 2013: The Physical Science Basis. Available: www.climatechange2013.org [2015, June 29].

IPCC. 2014. Part B: Regional Aspects - Africa. In Climate Change 2014: Impacts, Adaptation and Vulnerability - Contributions of the Working Group II to the Fifth Assessment Report of the Intergovernmental Panel on Climate Change. 1199-1265. Available: https://ipcc- 
wg2.gov/AR5/images/uploads/WGIIAR5-Chap22_FINAL.pdf.

IPP Office. 2017. Independent Power Producers Procurement Programme (IPPPP): Overview as at March 2017.

Janse van Vuuren, P. 2015. Solar photovoltaic (PV) systems on packhouses: the business case for an apple packhouse.

Janse van Vuuren, P., Pineo, C. \& Basson, L. 2016. Solar Energy in Agri-processing.

Jumbo Bins in the Fruit Growing Industry | Mpact Plastic Containers. n.d. Available:

http://www.mpcsa.co.za/jumbo-bins-white-paper.php [2017, June 15].

Kangueehi, G.N. 2014. Nutrient requirement and distribution of intensively grown "Brookfield Gala" apple trees. Stellenbosch.

Kellenberger, D., Althaus, H.-J., Künniger, T., Lehmann EMPA, M., Niels Jungbluth, D. \& Thalmann Bau-und Umweltchemie, P. 2007. Swiss Centre for Life Cycle Inventories Life Cycle Inventories of Building Products.

Keyes, S., Tyedmers, P. \& Beazley, K. 2015. Evaluating the environmental impacts of conventional and organic apple production in Nova Scotia, Canada, through life cycle assessment. Journal of Cleaner Production. 104:40-51. DOI:

10.1016/J.JCLEPRO.2015.05.037.

Kitinoja, L., Brown, P.D., Zagory, D., Barrett, D.M., Chahine-Tsouvalakis, H., Holcroft, D. \& Dubois, C. 2013. Returnable Plastic Crate (RPC) systems can reduce postharvest losses and improve earnings for fresh produce operations. Available: http://postharvest.org/RPCs PEF 2013 White paper 13-01 pdf final.pdf [2017, June 15].

König, A. 2015. Environmental Hotspots and the Potential of Clean Technologies in the South African Fruit Supply Chain.

Landu, L. \& Brent, A. 2007. Environmental life cycle assessment of water supply in South Africa: The Rosslyn industrial area as a case study. Water SA. 32(2):249-256. DOI: 10.4314/wsa.v32i2.5250.

Liu, Y., Langer, V., Høgh-Jensen, H. \& Egelyng, H. 2010. Life Cycle Assessment of fossil energy use and greenhouse gas emissions in Chinese pear production. Journal of Cleaner Production. 18(14):1423-1430. DOI: 10.1016/j.jclepro.2010.05.025.

Lundie, S. \& Peters, G.. 2005. Life cycle assessment of food waste management options. Journal of Cleaner Production. 13(3):275-286. DOI: 10.1016/J.JCLEPRO.2004.02.020. 
Marvuglia, A., Benetto, E., Rege, S. \& Jury, C. 2013. Modelling approaches for consequential life-cycle assessment (C-LCA) of bioenergy: Critical review and proposed framework for biogas production. Renewable and Sustainable Energy Reviews. 25:768-781. DOI: 10.1016/j.rser.2013.04.031.

Mashoko, L., Mbohwa, C. \& Thomas, V.M. 2010. LCA of the South African sugar industry. Journal of Environmental Planning and Management. 53(6):793-807. DOI: 10.1080/09640568.2010.488120.

Medlock, K.B. \& Soligo, R. 2001. Economic development and end-use energy demand. Energy Journal. 22(2):77-105. DOI: 10.5547/ISSN0195-6574-EJ-Vol22-No2-4.

Merven, B., Moyo, A., Stone, A., Dane, A. \& Winkler, H. 2014. Socio-economic implications of mitigation in the power sector including carbon taxes in South Africa. (September). Available: http://www.erc.uct.ac.za/Research/publications/14-Merven-etalSocioeconomic_implications.pdf.

Milà Canals, L., Cowell, S.J., Sim, S. \& Basson, L. 2007. Comparing Domestic versus Imported Apples: A Focus on Energy Use. Environmental Science and Pollution Research. 14(145):338-344. DOI: 10.1065/espr2007.04.412.

Milà i Canals, L., Burnip, G.M. \& Cowell, S.J. 2006. Evaluation of the environmental impacts of apple production using Life Cycle Assessment (LCA): Case study in New Zealand. Agriculture, Ecosystems \& Environment. 114:226-238. DOI: 10.1016/j.agee.2005.10.023.

Mouron, P., Nemecek, T., Scholz, R.W. \& Weber, O. 2006. Management influence on environmental impacts in an apple production system on Swiss fruit farms: Combining life cycle assessment with statistical risk assessment. Agriculture, Ecosystems and Environment. 114(2-4):311-322. DOI: 10.1016/j.agee.2005.11.020.

Mouron, P., Scholz, R.W., Nemecek, T. \& Weber, O. 2006. Life cycle management on Swiss fruit farms: Relating environmental and income indicators for apple-growing. Ecological Economics. 58(3):561-578. DOI: 10.1016/j.ecolecon.2005.08.007.

National Agricultural Marketing Council. 2014. SA Fruit Trade Flow.

National Treasury. 2013. Carbon Tax Policy Paper.

NERSA. 2000. Electricity Supply Statistics for South Africa. Available: http://www.nersa.org.za/Admin/Document/Editor/file/News and Publications/Publications/Archived Issues/Electricity Supply Statistics/ESS2000_o.pdf 
[2017, March 06].

Notten, P. \& Mason, K. 2010. Life Cycle Assessment of Milk Production in the Western Cape.

Notten, P. \& Petrie, J. 2003. An Integrated Approach To Uncertainty Assessment In LCA. 6. Available: file://c/Documents and Settings/Jack/My Documents/1 Research/EndNote/References.Data/PDF/integrated-1717283331/integrated.pdf.

Ntombela, S. 2012. South African Fruit Trade Flow June 2012.

OECD. 2013. OECD Economic Surveys - South Africa. DOI: 10.1787/eco_surveys-jpn-2009-en.

Ortmann, F.G. 2005. Modelling the South African fresh fruit export supply chain.

Pfister, S., Bayer, P., Koehler, A. \& Hellweg, S. 2011. Environmental impacts of water use in global crop production: hotspots and trade-offs with land use. Environmental Science \& Technology. 45(13):5761-8. DOI: 10.1021/es1041755.

Pineo, C. 2015. Regional Resource Flow Model : Grain Sector Report.

du Plessis, M. 2007. WWF AGRICULTURE: FACTS \& TRENDS South Africa.

PPECB. 2014. PPECB Annual report 2013-2014.

PRé. 2013. Introduction to LCA with SimaPro.

Ramdari, S. \& Potts, M. 2016. Development of a Life Cycle Inventory for utilily scale photovoltaic installations in South Africa.

Raugei, M. \& Frankel, P. 2009. Life cycle impacts and costs of photovoltaic systems: Current state of the art and future outlooks. Energy. 34(3):392-399. DOI:

10.1016/J.ENERGY.2009.01.001.

Renewable Energy Independent Power Producers Programme. 2017. Available: https://www.ipp-projects.co.za/ProjectDatabase.

Sandén, B. a. \& Karlström, M. 2007. Positive and negative feedback in consequential life-cycle assessment. Journal of Cleaner Production. 15:1469-1481. DOI:

10.1016/j.jclepro.2006.03.005.

SANS. 2002a. Environmental management — Life cycle assessment - Goal and scope definition and inventory analysis.

SANS. 2002b. Environmental management — Life cycle assessment - Life cycle impact assessment.

SANS. 2002c. Environmental management - Life cycle assessment - Life cycle interpretation. 
Sathre, R. \& Masanet, E. 2013. Prospective life-cycle modeling of a carbon capture and storage system using metal-organic frameworks for CO2 capture. RSC Advances. 3(15):4964. DOI: $10.1039 / \mathrm{c} 3 r a 40265 \mathrm{~g}$.

Singh, S.P., Chonhenchob, V. \& Singh, J. 2006. Life cycle inventory and analysis of re-usable plastic containers and display-ready corrugated containers used for packaging fresh fruits and vegetables. Packaging Technology and Science. 19(5):279-293. DOI:

10.1002/pts.731.

Spielmann, M., Scholz, R.W., Tietje, O. \& Haan, P. de. 2005. Scenario Modelling in Prospective LCA of Transport Systems. International Journal of Life Cycle Assessment. 10(5):325-335. DOI: 10.1065/lca2004.10.188.

Statistics South Africa. n.d. Available: http://www.statssa.gov.za/.

Statistics South Africa. 2014. Producer Price Index: Methods, Sources and Theory. Available: http://www.statssa.gov.za/cpi/documents/PPI_Methods_sources_and_theory_V_1.2.pdf [2017, May 02].

Stern, D.I. 2003. International Society for Ecological Economics Internet Encyclopaedia of Ecological Economics The Environmental Kuznets Curve David I. Stern. World Development. 11(7):449-452. DOI: 10.1080/1350485042000207216.

Stevens, L. \& Witi, J. 2013. GHG Inventory for South Africa: 2000 - 2010.

Stoessel, F., Juraske, R., Pfister, S. \& Hellweg, S. 2012. Life cycle inventory and carbon and water footprint of fruits and vegetables: application to a Swiss retailer. Environmental science \& technology. 46.

Stone, A. \& Bennett, K. 2000. A BULK MODEL OF EMISSIONS FROM SOUTH AFRICAN DIESEL COMMERCIAL VEHICLES. Available: http://www.erc.uct.ac.za/sites/default/files/image_tool/images/119/Paperspre2004/01Stone-Bennett_Diesel_emissions.PDF [2017, March 08].

Strauss, K., Brent, A. \& Hietkamp, S. 2006. Characterisation and Normalisation Factors for Life Cycle Impact Assessment Mined Abiotic Resources Categories in South Africa: The manufacturing of catalytic converter exhaust systems as a case study (10 pp). The International Journal of Life Cycle Assessment. 11(3):162-171. DOI:

10.1065/lca2004.10.183.

Twede, D. \& Clarke, R. 2004. Supply Chain Issues in Reusable Packaging. Journal of Marketing 
Channels. 12(1):7-26. DOI: 10.1300/J049v12n01_02.

Umwelt Bundesamt. 2013. Umweltbewusstsein in Deutschland 2014. Available: papers3://publication/uuid/1AFAF3CE-5359-4C4C-A25D-9E0A420BECE8.

Volschenk, T., de Villiers, J. \& Beukes, O. 2003. The Selection and Calibration of a model for Irrigation scheduling of Deciduous Fruit Orchards.

Waisman, H., Segafredo, L., Bataille, C., Williams, J., Pharabod, I. \& Oury, C. 2015. Pathways to deep decarbonization.

Van der Walt, M.W. 2017. Development of a land use-based spatial water requirements model for the Berg Water Management Area. University of Cape Town.

Ward, J.D., Sutton, P.C., Werner, A.D., Costanza, R., Mohr, S.H. \& Simmons, C.T. 2016. Is Decoupling GDP Growth from Environmental Impact Possible? PloS one. 11(10):e0164733. DOI: 10.1371/journal.pone.0164733.

Weidema, B. 2003. Market information in life cycle assessment. Available: https://pdfs.semanticscholar.org/2b06/55763a78b9ebf78b548cc32af5c436e9907c.pdf [2017, November 17].

Weidema, B., Bauer, C., Hishchier, R. \& Mutel, C. 2013. Ecolnvent: Swiss Centre for Life Cycle Inventories Overview and methodology (final)(v3). V. 3. Zurich: Ecolnvent.

Weidema, B.P., Bauer, C., Hischier, R., Mutel, C., Nemecek, T., Reinhard, J., Vadenbo, C.O. \& Wenet, G. 2013. Data quality guideline for the ecoinvent.

Weinzettel, J., Reenaas, M., Solli, C. \& Hertwich, E.G. 2008. Life cycle assessment of a floating offshore wind turbine. Renewable Energy. 34:742-747. DOI:

10.1016/j.renene.2008.04.004.

Wender, B.A. \& Seager, T.P. 2011. Towards prospective life cycle assessment: Single wall carbon nanotubes for lithium-ion batteries. In Proceedings of the 2011 IEEE International Symposium on Sustainable Systems and Technology. 1-4. DOI:

10.1109/ISSST.2011.5936889.

Western Cape Department of Agriculture. 2007. Pome fruit Commercial Enterprise Budget 2006.

Yang, Y. \& Elliot-Campbell, J. 2017. Improving attributional life cycle assessment for decision support: The case of local food in sustainable design. Journal of Cleaner Production. 145:361-366. DOI: 10.1016/J.JCLEPRO.2017.01.020. 


\section{Appendices}

Appendix I: Life Cycle Inventory models for South African pome fruit

Appendix II: Emissions to air, soil and water

Appendix III: Datasets for pesticides

Appendix IV: Irrigation consumption calculations

Appendix V: Packhouse packaging calculations for year 2000

Appendix VI: Electricity mix 2020 datasets

Appendix VII: Sankey diagrams

Appendix VIII: Uncertainty distributions 


\section{Appendix I : Life Cycle Inventory models for South African pome fruit industry}

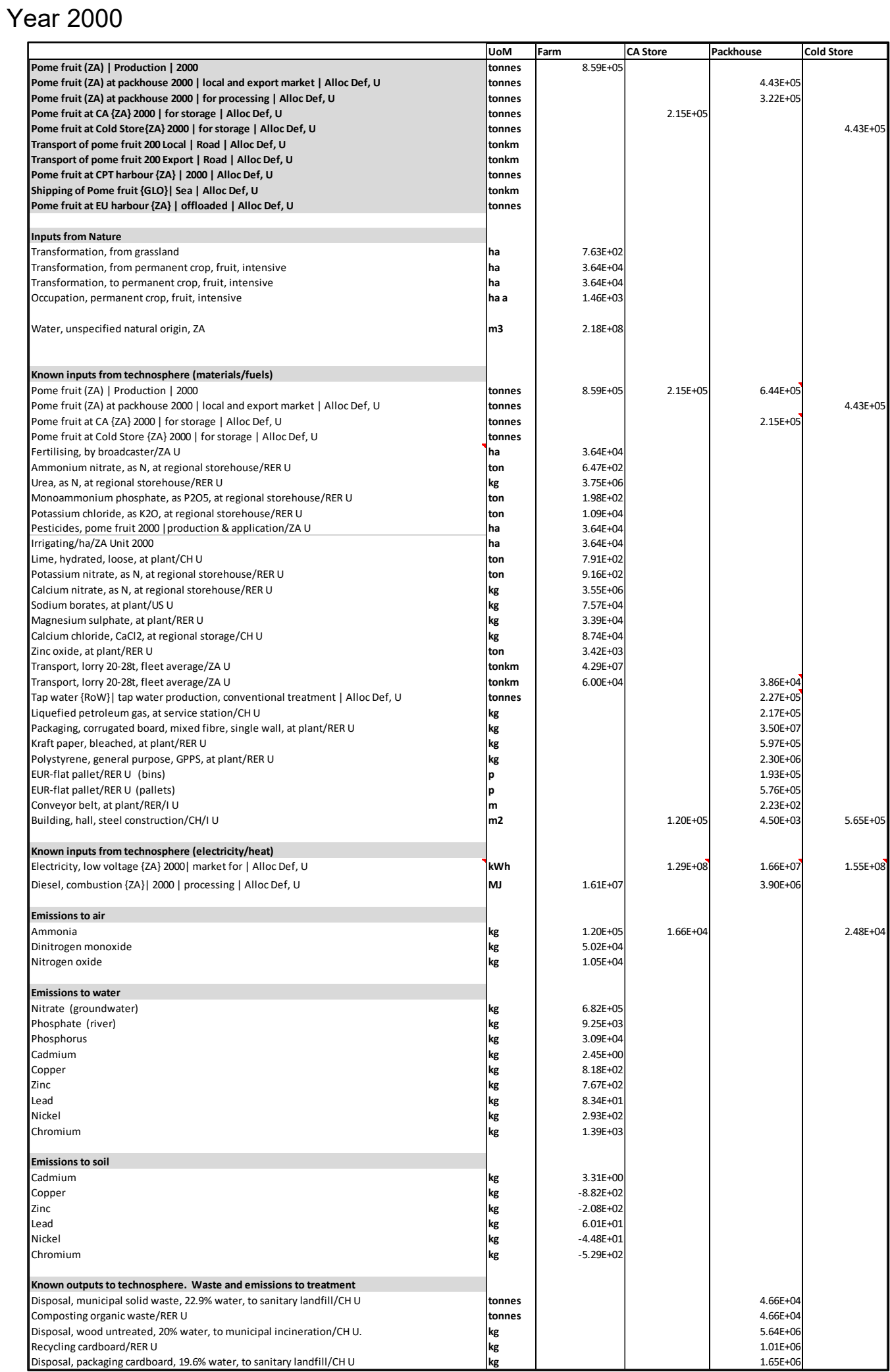




\begin{tabular}{|c|c|c|c|c|c|}
\hline & UoM & Farm & CAStore & Packhouse & Cold Store \\
\hline Pome fruit (ZA) | Production | 2010 & tonnes & $1.13 E+06$ & & & \\
\hline Pome fruit (ZA) at packhouse 2010 | local and export market | Alloc Def, U & tonnes & & & $7.47 E+05$ & \\
\hline Pome fruit (ZA) at packhouse 2010 | for processing | Alloc Def, U & tonnes & & & $3.69 \mathrm{E}+05$ & \\
\hline Pome fruit at CA $\{Z A\} 2010$ | for storage | Alloc Def, U & tonnes & & $2.82 \mathrm{E}+05$ & & \\
\hline Pome fruit at Cold Store $\{Z A\} 2010$ | for storage | Alloc Def, U & tonnes & & & & $7.47 \mathrm{E}+05$ \\
\hline Transport of pome fruit 2010 Local | Road | Alloc Def, U & tonkm & & & & \\
\hline Transport of pome fruit 2010 Export | Road | Alloc Def, U & tonkm & & & & \\
\hline Pome fruit at CPT harbour $\{Z A\}|2010|$ Alloc Def, U & tonnes & & & & \\
\hline Shipping of Pome fruit $\{G L O\} \mid$ Sea | Alloc Def, U & tonkm & & & & \\
\hline Pome fruit at EU harbour $\{Z \mathrm{ZA}\}$ | offloaded | Alloc Def, U & tonnes & & & & \\
\hline \multicolumn{6}{|l|}{ Inputs from Nature } \\
\hline Transformation, from grassland & ha & $7.21 \mathrm{E}+02$ & & & \\
\hline Transformation, to permanent crop, fruit, intensive & ha & $3.29 E+04$ & & & \\
\hline Occupation, permanent crop, fruit, intensive & ha a & $1.32 \mathrm{E}+03$ & & & \\
\hline Transformation, from permanent crop, fruit, intensive & ha & $3.29 \mathrm{E}+04$ & & & \\
\hline \multicolumn{6}{|l|}{ Known inputs from technosphere (materials/fuels) } \\
\hline Pome fruit (ZA) | Production | 2010 & tonnes & & $2.82 \mathrm{E}+05$ & $8.45 E+05^{2}$ & \\
\hline Pome fruit (ZA) at packhouse 2010 | local and export market | Alloc Def, U & tonnes & & & & $7.47 \mathrm{E}+05$ \\
\hline Pome fruit at CA $\{Z A\} 2010$ | for storage | Alloc Def, U & tonnes & & & $2.82 E+05$ & \\
\hline Pome fruit at Cold Store $\{$ ZA $\} 2010$ | for storage | Alloc Def, U & tonnes & & & & \\
\hline Transport of pome fruit 2010 Export | Road | Alloc Def, U & tonkm & & & & \\
\hline Pome fruit at CPT harbour $\{Z A\}|2010|$ Alloc Def, U & tonnes & & & & \\
\hline Shipping of Pome fruit $\{G L O\} \mid$ Sea | Alloc Def, $U$ & tonkm & & & & \\
\hline Fertilising, by broadcaster $\{Z A\} \mid$ processing | Alloc Def, $U$ & ha & $3.29 \mathrm{E}+04$ & & & \\
\hline Nitrogen fertiliser, as $\mathrm{N}\{\mathrm{GLO}\} \mid$ market for | Alloc Def, $\mathrm{U}$ & kg & $2.35 E+06$ & & & \\
\hline Phosphate fertiliser, as P2O5 $\{\mathrm{GLO}\} \mid$ market for | Alloc Def, U & kg & $1.67 E+06$ & & & \\
\hline Potassium fertiliser, as $\mathrm{K} 2 \mathrm{O}\{\mathrm{GLO}\} \mid$ market for | Alloc Def, $\mathrm{U}$ & kg & $3.33 E+06$ & & & \\
\hline Pesticides Pome fruit 2010 | production and application I \{ZA\}| Alloc Def, U & ha & $3.29 E+04$ & & & \\
\hline Irrigation, pome fruit $\{Z A\} \mid$ market for | Alloc Def, $U$ & m3 & $2.05 E+08$ & & & \\
\hline Lime $\{G L O\} \mid$ market for | Alloc Def, U & kg & $1.00 E+07$ & & & \\
\hline Compost $\{\mathrm{GLO}\} \mid$ market for | Alloc Rec, $\mathrm{U}$ & kg & $8.31 E+06$ & & & \\
\hline Manure, solid, cattle $\{G L O\} \mid$ market for | Alloc Rec, U & kg & $1.38 E+05$ & & & \\
\hline Manure, liquid, cattle $\{$ GLO\}| market for | Alloc Rec, U & kg & $4.20 E+03$ & & & \\
\hline Transport, lorry 20-28t, fleet average/ZA U & tonkm & $1.64 E+06$ & & & \\
\hline Transport, lorry 20-28t, fleet average/ZA U & tonkm & $2.67 E+06$ & & $5.75 E+06$ & \\
\hline Tap water $\{$ RoW\} $\mid$ tap water production, conventional treatment | Alloc Def, U & m3 & & & $6.35 \mathrm{E}+05$ & \\
\hline Liquefied petroleum gas \{RoW\}| market for | Alloc Def, U & kg & & & $2.85 \mathrm{E}+05$ & \\
\hline Corrugated board box $\{\mathrm{GLO}\} \mid$ market for corrugated board box | Alloc Def, U & kg & & & $4.92 E+07$ & \\
\hline Kraft paper, bleached $\{G L O\} \mid$ market for | Alloc Def, U & kg & & & $1.28 \mathrm{E}+06$ & \\
\hline Polystyrene, general purpose $\{G L O\} \mid$ market for | Alloc Def, $U$ & kg & & & $2.87 \mathrm{E}+06$ & \\
\hline Polyethylene terephthalate, granulate, amorphous $\{\mathrm{GLO}\} \mid$ market for | Alloc Def, $U$ & kg & & & $3.30 \mathrm{E}+05$ & \\
\hline Packaging film, low density polyethylene $\{G L O\} \mid$ market for | Alloc Def, $U$ & kg & & & $3.65 \mathrm{E}+06$ & \\
\hline Polypropylene, granulate $\{G L O\} \mid$ market for | Alloc Def, U & kg & & & $1.11 \mathrm{E}+05$ & \\
\hline Polyethylene, high density, granulate $\{G L O\} \mid$ market for | Alloc Rec, U & kg & & & $1.14 \mathrm{E}+03$ & \\
\hline EUR-flat pallet $\{G L O\} \mid$ market for | Alloc Def, $U$ (wooden bins) & p & & & $5.91 \mathrm{E}+05$ & \\
\hline EUR-flat pallet $\{G L O\} \mid$ market for | Alloc Def, $U$ (disposable \& reusable wooden pallets) & $\mathrm{p}$ & & & 7.56E+05 & \\
\hline Conveyor belt $\{G L O\} \mid$ market for | Alloc Def, $U$ & m & & & $2.88 \mathrm{E}+02$ & \\
\hline Building, hall, steel construction \{GLO\}| market for | Alloc Def, U & $\mathrm{m} 2$ & & $3.16 \mathrm{E}+03$ & $5.77 E+03$ & $1.90 \mathrm{E}+04$ \\
\hline Transport, lorry >28t, fleet average/ZA U & tonkm & & & & \\
\hline Transport, freight, sea, transoceanic ship $\{G L O\} \mid$ processing | Alloc Def, U & tonkm & & & & \\
\hline \multicolumn{6}{|l|}{ Known inputs from technosphere (electricity/heat) } \\
\hline Electricity, low voltage $\{Z A\} \mid$ market for| Alloc Def,U & $\mathrm{kWh}$ & & $1.69 E+08$ & $2.80 \mathrm{E}+07$ & $2.61 \mathrm{E}+08$ \\
\hline Diesel, combustion $\{Z A\} \mid 2010$ | processing | Alloc Def, U & Mu & $3.29 \mathrm{E}+08$ & & $5.12 E+06$ & \\
\hline Emissions to air & & & & & \\
\hline Ammonia & $\mathrm{kg}$ & $1.33 E+06$ & $2.18 \mathrm{E}+04$ & & 4.19E+04 \\
\hline Dinitrogen monoxide & kg & $7.36 \mathrm{E}+04$ & & & \\
\hline Nitrogen oxide & $\mathrm{kg}$ & $1.55 \mathrm{E}+04$ & & & \\
\hline Methane, chlorodifluoro-, HCFC-22 & $\mathrm{kg}$ & & & & $1.04 \mathrm{E}+03$ \\
\hline Emissions to water & & & & & \\
\hline Nitrate (groundwater) & kg & $7.86 \mathrm{E}+05$ & & & \\
\hline Phosphate (groundwater) & kg & $1.97 E+03$ & & & \\
\hline Phosphate (river) & kg & $8.89 E+03$ & & & \\
\hline Phosphorus & $\mathrm{kg}$ & $2.79 E+04$ & & & \\
\hline Cadmium & kg & $8.08 E+00$ & & & \\
\hline Copper & kg & $9.84 \mathrm{E}+02$ & & & \\
\hline Zinc & kg & $1.19 \mathrm{E}+03$ & & & \\
\hline Lead & kg & $1.28 \mathrm{E}+02$ & & & \\
\hline Nickel & kg & 4.13E+02 & & & \\
\hline Chromium & kg & $1.36 \mathrm{E}+03$ & & & \\
\hline Mercury & kg & $2.87 \mathrm{E}-02$ & & & \\
\hline Emissions to soil & & & & & \\
\hline Cadmium & kg & $5.24 \mathrm{E}+01$ & & & \\
\hline Copper & $\mathrm{kg}$ & $-1.41 \mathrm{E}+03$ & & & \\
\hline Zinc & kg & $-8.24 \mathrm{E}+02$ & & & \\
\hline Lead & kg & $8.80 \mathrm{E}+01$ & & & \\
\hline Nickel & kg & $-1.05 E+02$ & & & \\
\hline Chromium & kg & $-5.28 \mathrm{E}+01$ & & & \\
\hline Mercury & kg & $-6.94 E-02$ & & & \\
\hline Known outputs to technosphere. Waste and emissions to treatment & & & & & \\
\hline Biowaste \{RoW\}| market for | Alloc Def, U & ton & & & $1.13 E+04$ & \\
\hline Waste wood, untreated $\{$ RoW $\} \mid$ treatment of waste wood, untreated, municipal incineration | $A$ & $\mathbf{k g}$ & & & $9.90 \mathrm{E}+06$ & \\
\hline Waste plastic, mixture $\{$ RoW\}| treatment of waste plastic, mixture, sanitary landfill | Alloc Def, $U$ & kg & & & $2.48 \mathrm{E}+05$ & \\
\hline Mixed plastics (waste treatment) $\{G L O\} \mid$ recycling of mixed plastics | Alloc Def, $U$ & kg & & & $2.02 E+05$ & \\
\hline Waste paperboard \{RoW\}| treatment of, sanitary landfill | Alloc Def, U & $\mathrm{kg}$ & & & $1.81 \mathrm{E}+06$ & \\
\hline Recycling cardboard |market for| ZA, Alloc Def, U & kg & & & $1.48 \mathrm{E}+06$ & \\
\hline
\end{tabular}




\section{Year 2020}

\begin{tabular}{|c|c|c|c|c|c|}
\hline & UoM & Farm & CA Store & Packhouse & Cold Store \\
\hline Pome fruit (ZA) | Production | 2020 & tonnes & $1.41 \mathrm{E}+06$ & & & \\
\hline Pome fruit (ZA) at packhouse 2020 | local and export market | Alloc Def, U & tonnes & & & 9.35E+05 & \\
\hline Pome fruit (ZA) at packhouse 2020 | for processing | Alloc Def, U & tonnes & & & $4.59 \mathrm{E}+05$ & \\
\hline Pome fruit at CA $\{Z A\} 2020$ | for storage | Alloc Def, U & tonnes & & $3.52 E+05$ & & \\
\hline Pome fruit at Cold Store $\{Z A\} 2020$ | for storage | Alloc Def, U & tonnes & & & & $9.35 E+05$ \\
\hline \multicolumn{6}{|l|}{ Inputs from Nature } \\
\hline Transformation, from grassland & ha & $0.00 E+00$ & & & \\
\hline Transformation, to permanent crop, fruit, intensive & ha & $3.73 E+04$ & & & \\
\hline Occupation, permanent crop, fruit, intensive & ha a & $1.49 \mathrm{E}+03$ & & & \\
\hline Transformation, from permanent crop, fruit, intensive & ha & $3.73 E+04$ & & & \\
\hline \multicolumn{6}{|l|}{ Known inputs from technosphere (materials/fuels) } \\
\hline Pome fruit (ZA) | Production | 2020 & tonnes & & $3.52 \mathrm{E}+05$ & 1059951 & \\
\hline Pome fruit (ZA) at packhouse 2020 | local and export market | Alloc Def, U & tonnes & & & & $9.35 \mathrm{E}+05$ \\
\hline Pome fruit at CA $\{Z A\} 2020$ | for storage | Alloc Def, U & tonnes & & & 348622 & \\
\hline Pome fruit at Cold Store $\{Z A\} 2020$ | for storage | Alloc Def, U & tonnes & & & & \\
\hline Fertilising, by broadcaster $\{Z A\} \mid$ processing | Alloc Def, $U$ & ha & $1.49 \mathrm{E}+04$ & & & \\
\hline Nitrogen fertiliser, as $\mathrm{N}\{\mathrm{GLO}\} \mid$ market for | Alloc Def, $\mathrm{U}$ & kg & $5.72 E+06$ & & & \\
\hline Phosphate fertiliser, as P2O5 \{GLO\}| market for | Alloc Def, U & kg & $3.72 E+06$ & & & \\
\hline Potassium fertiliser, as $\mathrm{K} 2 \mathrm{O}\{\mathrm{GLO}\} \mid$ market for | Alloc Def, U & kg & $3.51 \mathrm{E}+06$ & & & \\
\hline Pesticides Pome fruit 2010 | production and application | $\{$ ZA $\} \mid$ Alloc Def, U & ha & $3.73 E+04$ & & & \\
\hline Irrigation, pome fruit $\{Z A\} \mid$ market for | Alloc Def, $U$ & $\mathrm{~m} 3$ & $1.97 E+08$ & & & \\
\hline Lime $\{G L O\} \mid$ market for | Alloc Def, U & kg & $8.67 E+06$ & & & \\
\hline Mulching $\{G L O\} \mid$ market for | Alloc Def, U & tonnes & $9.24 E+04$ & & & \\
\hline Zinc oxide $\{\mathrm{GLO}\} \mid$ market for | Alloc Def, U & kg & $3.07 E+05$ & & & \\
\hline Polyethylene, high density, granulate $\{\mathrm{GLO}\} \mid$ market for | Alloc Def, U & tonnes & $8.20 \mathrm{E}+01$ & & & \\
\hline Trellis system, wooden poles, soft wood, tar impregnated $\{G L O\} \mid$ market for | & & & & & \\
\hline Alloc Def, $U$ & ha & 24738.00 & & & \\
\hline Transport, lorry 20-28t, fleet average/ZA U & tonkm & $7.04 E+07$ & & & \\
\hline Transport, lorry 20-28t, fleet average/ZA U & tonkm & & & $6.36 \mathrm{E}+06$ & \\
\hline Tap water $\{$ RoW\}| tap water production, conventional treatment | Alloc Def, U & tonnes & & & $4.80 E+05$ & \\
\hline Polylactide, granulate $\{G L O\} \mid$ market for | Alloc Def, U & kg & & & $2.61 \mathrm{E}+05$ & \\
\hline Corrugated board box $\{\mathrm{GLO}\} \mid$ market for corrugated board box | Alloc Def, $\mathrm{U}$ & kg & & & $5.88 \mathrm{E}+07$ & \\
\hline Kraft paper, bleached $\{G L O\} \mid$ market for | Alloc Def, U & kg & & & $3.20 \mathrm{E}+04$ & \\
\hline Polystyrene, general purpose $\{G L O\} \mid$ market for | Alloc Def, U & kg & & & $2.80 \mathrm{E}+05$ & \\
\hline Packaging film, low density polyethylene $\{G L O\} \mid$ market for | Alloc Def, $U$ & kg & & & $6.02 E+05$ & \\
\hline Polypropylene, granulate $\{\mathrm{GLO}\} \mid$ market for | Alloc Def, U & kg & & & $9.35 \mathrm{E}+05$ & \\
\hline Polyethylene, high density, granulate $\{G L O\} \mid$ market for | Alloc Rec, U & kg & & & $1.23 E+05$ & \\
\hline EUR-flat pallet $\{G L O\} \mid$ market for | Alloc Def, U (wooden bins) & p & & & $3.70 E+05$ & \\
\hline EUR-flat pallet $\{G L O\} \mid$ market for | Alloc Def, U (disposable \& reusable wooden pall & p & & & $9.45 E+05$ & \\
\hline Conveyor belt \{GLO\}| market for | Alloc Def, U & m & & & $3.66 \mathrm{E}+02$ & \\
\hline Building, hall, steel construction $\{G L O\} \mid$ market for | Alloc Def, U & $\mathrm{m} 2$ & & $3.95 E+03$ & $7.38 \mathrm{E}+03$ & $2.38 \mathrm{E}+04$ \\
\hline \multicolumn{6}{|l|}{ Known inputs from technosphere (electricity/heat) } \\
\hline Electricity, low voltage $\{\mathrm{ZA}\} 2020 \mid$ market for| Alloc Def,U & kWh & $1.12 \mathrm{E}+08$ & $1.80 \mathrm{E}+08$ & $2.97 \mathrm{E}+07$ & $2.81 E+08$ \\
\hline Electricity, low voltage $\{Z A\} \mid$ electricity production, photovoltaic, $3 \mathrm{kWp}$ slanted-roo & kWh & & $5.20 E+06$ & $3.63 E+06$ & $5.20 \mathrm{E}+06$ \\
\hline Diesel, combustion $\{Z \mathrm{ZA}\} \mid 2010$ | processing | Alloc Def, U & MJ & 339284210.71 & & & \\
\hline \multicolumn{6}{|l|}{ Emissions to air } \\
\hline Ammonia & kg & $2.29 \mathrm{E}+05$ & $2.73 E+04$ & & $5.25 \mathrm{E}+04$ \\
\hline Dinitrogen monoxide & kg & $9.62 E+04$ & & & \\
\hline Nitrogen oxide & kg & $2.02 E+04$ & & & \\
\hline \multicolumn{6}{|l|}{ Emissions to water } \\
\hline Nitrate (groundwater) & kg & $1.30 \mathrm{E}+06$ & & & \\
\hline Phosphate (river) & kg & $1.21 \mathrm{E}+04$ & & & \\
\hline Phosphorus & kg & $3.16 \mathrm{E}+04$ & & & \\
\hline Cadmium & kg & $9.61 \mathrm{E}+00$ & & & \\
\hline Copper & kg & $1.16 \mathrm{E}+03$ & & & \\
\hline Zinc & kg & $1.46 \mathrm{E}+03$ & & & \\
\hline Lead & kg & $1.49 \mathrm{E}+02$ & & & \\
\hline Nickel & kg & $5.00 E+02$ & & & \\
\hline Chromium & kg & $1.54 E+03$ & & & \\
\hline Mercury & kg & & & & \\
\hline \multicolumn{6}{|l|}{ Emissions to soil } \\
\hline Cadmium & kg & 7.61E+01 & & & \\
\hline Copper & kg & $-1.76 \mathrm{E}+03$ & & & \\
\hline Zinc & kg & $-1.22 \mathrm{E}+03$ & & & \\
\hline Lead & kg & $1.00 E+02$ & & & \\
\hline Nickel & kg & $-1.31 E+02$ & & & \\
\hline Chromium & kg & $-9.28 \mathrm{E}+01$ & & & \\
\hline Mercury & kg & & & & \\
\hline \multicolumn{6}{|l|}{ Known outputs to technosphere. Waste and emissions to treatment } \\
\hline Biowaste $\{$ RoW\} | market for | Alloc Def, U & ton & & & $1.41 E+04$ & \\
\hline Waste wood, untreated $\{$ RoW $\} \mid$ treatment of waste wood, untreated, municipal inc & kg & & & $9.26 \mathrm{E}+06$ & \\
\hline Mixed plastics (waste treatment) \{GLO\}| recycling of mixed plastics | Alloc Def, U & kg & & & $2.17 \mathrm{E}+05$ & \\
\hline Waste plastic, mixture $\{$ RoW $\} \mid$ treatment of waste plastic, mixture, sanitary landfill & kg & & & $4.45 E+04$ & \\
\hline Recycling cardboard | market for| ZA, Alloc Def, U & kg & & & $3.40 E+06$ & \\
\hline Waste paperboard \{RoW\}| treatment of, sanitary landfill | Alloc Def, U & kg & & & $6.97 \mathrm{E}+05[$ & \\
\hline
\end{tabular}




\section{Appendix II : Emissions to air, water and soil}

\section{Fertiliser emissions}

\section{Emissions to air}

\section{Ammonia $\left(\mathrm{NH}_{3}\right)$}

1 Ammonia $\left(\mathrm{NH}_{3}\right)$ to air for mineral fertilizers $\mathrm{kg} / \mathrm{ha}$

\begin{tabular}{|l|c|c|c|}
\hline & Yr 2000 & Yr 2010 & Yr 2020 \\
\hline kg N applied (kg/ha) & $8.24 \mathrm{E}+01$ & $1.05 \mathrm{E}+02$ & 153.4 \\
\hline Emission factor & \multicolumn{3}{|c|}{$4 \%$} \\
\hline Ammonia to air (kg/Ha) & $3.30 \mathrm{E}+00$ & $4.20 \mathrm{E}+00$ & $6.14 \mathrm{E}+00$ \\
\hline & & & \\
Total ammonia to air (kg) & $1.20 \mathrm{E}+05$ & $1.38 \mathrm{E}+05$ & $2.29 \mathrm{E}+05$ \\
\hline
\end{tabular}

2 Ammonia $\left(\mathrm{NH}_{3}\right)$ to air for solid manure $\mathrm{kg} / \mathrm{ha}$

\begin{tabular}{|l|l|r|r|r|}
\cline { 2 - 5 } \multicolumn{1}{c|}{} & Variables & Yr 2000 & Yr 2010 & Yr 2020 \\
\hline $\mathrm{NH}_{3 \mathrm{~m}}=17 / 14 *\left(0.787 \mathrm{TAN}_{\mathrm{m}} * \mathrm{M}\right.$ & $\operatorname{TAN}_{\mathrm{m}}$ & 0 & $4.90 \mathrm{E}+00$ & 0 \\
\cline { 2 - 6 }+0.757$) * 0.75 * \mathrm{~A}_{\mathrm{m}}$ & $\mathrm{M}$ & 0 & $6.14 \mathrm{E}-03$ & 0 \\
\cline { 2 - 6 } & $\mathrm{A}_{\mathrm{m}}$ & 0 & $1.00 \mathrm{E}+00$ & 0 \\
\hline \multicolumn{2}{|c|}{ Ammonia to air (kg/ha) } & 0 & $7.11 \mathrm{E}-01$ & 0 \\
\hline \multicolumn{2}{|c|}{ Total ammonia to air (kg) } & 0 & $2.34 \mathrm{E}+04$ & \\
\hline
\end{tabular}

3 Ammonia $\left(\mathrm{NH}_{3}\right)$ to air for slurry and liquid manure $\mathrm{kg} / \mathrm{ha}$

\begin{tabular}{|c|c|c|c|c|}
\hline & Variables & Yr 2000 & Yr 2010 & Yr 2020 \\
\hline \multirow{4}{*}{$\begin{array}{l}\mathrm{NH}_{3 \mathrm{~s}}=17 / 14 *(-9.5+19.4 \\
\left.\operatorname{TAN}_{\mathrm{s}}+1.1 \mathrm{SD}_{\mathrm{m}}\right) *(0.0214 \mathrm{~S}+ \\
0.358) * \mathrm{~A}_{\mathrm{s}}\end{array}$} & TAN $_{S}$ & 0 & $4.30 \mathrm{E}+00$ & 0 \\
\hline & $S D_{m}$ & 0 & $7.12 \mathrm{E}+00$ & 0 \\
\hline & $S$ & 0 & $1.95 \mathrm{E}-04$ & 0 \\
\hline & $A_{s}$ & 0 & 1 & 0 \\
\hline \multicolumn{2}{|c|}{ Ammonia to air (kg/ha) } & 0 & $3.55 \mathrm{E}+01$ & 0 \\
\hline \multicolumn{2}{|c|}{ Total ammonia to air (kg) } & 0 & 1.17E+06 & 0 \\
\hline
\end{tabular}

4 Dinitrogen monoxide $\left(\mathrm{N}_{\mathbf{2}} \mathrm{O}\right)$ to air (Nemecek et. al, 2014)

\begin{tabular}{|l|l|r|r|r|}
\hline & Variables & Yr 2000 & Yr 2010 & Yr 2020 \\
\hline \multirow{2}{*}{$\begin{array}{l}\mathrm{N} 2 \mathrm{O}=44 / 28 *\left(0.01 *\left(\mathrm{~N}_{\text {TOT }}\right.\right. \\
\left.+\mathrm{N}_{\mathrm{Cr}}\right)+0.01 * 14 / 17 * \mathrm{NH}_{3}+\end{array}$} & $\mathrm{N}_{\text {TOT }}$ & $8.24 \mathrm{E}+01$ & $1.05 \mathrm{E}+02$ & $1.53 \mathrm{E}+02$ \\
\cline { 2 - 5 } $\left.0.0075 * 14 / 62 * \mathrm{NO}_{3}-\right)$ & $\mathrm{NH}_{3(\mathrm{~kg} / \mathrm{ha})}$ & 2.6628 & $4.05 \mathrm{E}+01$ & $6.14 \mathrm{E}+00$ \\
\cline { 2 - 5 } & $\mathrm{N}_{\mathrm{Cr}}$ & 0 & 0 & 0 \\
\cline { 2 - 5 } & $\mathrm{NO}_{3}$ & $1.87 \mathrm{E}+01$ & $2.39 \mathrm{E}+01$ & $3.49 \mathrm{E}+01$ \\
\hline & $\mathrm{N}_{2} \mathrm{O}(\mathrm{kg} / \mathrm{ha})$ & $1.38 \mathrm{E}+00$ & $2.24 \mathrm{E}+00$ & $2.58 \mathrm{E}+00$ \\
\cline { 2 - 5 } & $\begin{array}{l}\text { Total N20 } \\
\text { to air }\end{array}$ & $5.02 \mathrm{E}+04$ & $7.36 \mathrm{E}+04$ & $9.62 \mathrm{E}+04$ \\
\cline { 2 - 5 }
\end{tabular}


$5 \mathrm{NO}_{\mathrm{x}}$ to air

\begin{tabular}{|l|r|r|r|}
\hline Variables & Yr 2000 & Yr 2010 & Yr 2020 \\
\hline $\mathrm{N}_{2} \mathrm{O}$ emissions $(\mathrm{kg} / \mathrm{ha})$ & $1.38 \mathrm{E}+00$ & $2.24 \mathrm{E}+00$ & $2.58 \mathrm{E}+00$ \\
\hline Emission factor & \multicolumn{3}{|c|}{0.21} \\
\hline Nox to air $(\mathrm{kg} / \mathrm{ha})$ & $2.90 \mathrm{E}-01$ & $4.70 \mathrm{E}-01$ & $5.42 \mathrm{E}-01$ \\
\hline Nox to air $\mathrm{Kg}$ & $1.05 \mathrm{E}+04$ & $1.55 \mathrm{E}+04$ & $2.02 \mathrm{E}+04$ \\
\hline
\end{tabular}

Emissions to water

1 Nitrate $\left(\mathrm{NO}_{3}^{-}\right)$leaching into groundwater

\begin{tabular}{|l|l|r|r|r|}
\hline & Variables & Yr 2000 & Yr 2010 & Yr 2020 \\
\hline \multirow{3}{*}{$\mathrm{NO}_{3}-\mathrm{N}_{\mathrm{av}} * \mathrm{~S}_{\mathrm{Im}} * \mathrm{~L}_{\text {rate }}$} & $\mathrm{N}_{\mathrm{av}}$ & $8.24 \mathrm{E}+01$ & $1.05 \mathrm{E}+02$ & 153.4 \\
\cline { 2 - 6 } & $\mathrm{S}_{\mathrm{Im}}$ & \multicolumn{3}{|c|}{$65 \%$} \\
\cline { 2 - 6 } & $\mathrm{L}_{\text {rate }}$ & \multicolumn{3}{|c|}{$35 \%$} \\
\hline & NO3- (kg/ha & $1.87 \mathrm{E}+01$ & $2.39 \mathrm{E}+01$ & $3.49 \mathrm{E}+01$ \\
\cline { 2 - 5 } & Total kg & $6.82 \mathrm{E}+05$ & $7.86 \mathrm{E}+05$ & $1.30 \mathrm{E}+06$ \\
\cline { 2 - 5 }
\end{tabular}

2 Phosphorus leaching to groundwater (phosphate)

\begin{tabular}{|c|c|c|c|c|}
\hline Formula & Variables & Yr 2000 & Yr 2010 & Yr 2020 \\
\hline \multirow{2}{*}{$\mathrm{F}_{\mathrm{gw}}=1+0.2 / 80 * \mathrm{P}_{2} \mathrm{O}_{5 \mathrm{sl}}$} & $\mathrm{P}_{2} \mathrm{O}_{5 \mathrm{sl}}$ & NA & 3.37E-04 & 0 \\
\hline & $F_{g w}$ & NA & $1.00 \mathrm{E}+00$ & 0 \\
\hline \multirow{3}{*}{$P_{g w}=P_{g w l} * F_{g w}$} & $P_{g w l}$ & 0.06 & 0.06 & 0.06 \\
\hline & $\mathrm{Pg}_{\mathrm{w}}(\mathrm{kg} / \mathrm{ha})$ & 0 & $6.00 \mathrm{E}-02$ & 0 \\
\hline & $\mathrm{Pg}_{\mathrm{w}}$ (total) & 0 & $1.97 \mathrm{E}+03$ & 0 \\
\hline
\end{tabular}

Table 3:

P content (kg/m $\mathbf{m}^{3}$ or $\mathrm{kg} /$ ton) (source: Konig (2015); GRUDAP 2009)

\begin{tabular}{|l|r|}
\hline Slurry & 1.8 \\
\hline Solid manure & 3.2 \\
\hline
\end{tabular}

3 Phosphorus run-off to surface waters (Phosphate to river)

\begin{tabular}{|c|c|c|c|c|}
\hline Formula & Variables & Yr 2000 & Yr 2010 & Yr 2020 \\
\hline \multirow{4}{*}{$\begin{array}{l}\mathrm{F}_{\mathrm{ro}}=1+(0.2 / 80) * \mathrm{P}_{2} \mathrm{O}_{5} \mathrm{~min}+ \\
(0.7 / 80) * \mathrm{P}_{2} \mathrm{O}_{5} \mathrm{sl}+ \\
(0.4 / 80) * \mathrm{P}_{2} \mathrm{O}_{5 \text { man }}\end{array}$} & $\mathrm{P}_{2} \mathrm{O}_{5 \min }$ & $6.48 \mathrm{E}+00$ & $3.25 \mathrm{E}+01$ & $9.98 \mathrm{E}+01$ \\
\hline & $\mathrm{P}_{2} \mathrm{O}_{5 \mathrm{sl}}$ & 0 & $3.51 \mathrm{E}-07$ & 0 \\
\hline & $\mathrm{P}_{2} \mathrm{O}_{5 \text { man }}$ & 0 & $1.97 \mathrm{E}-02$ & 0 \\
\hline & $\mathrm{F}_{\text {ro }}$ & $1.02 \mathrm{E}+00$ & $1.08 \mathrm{E}+00$ & $1.25 \mathrm{E}+00$ \\
\hline \multirow[t]{3}{*}{$\mathrm{P}_{\mathrm{ro}}=\mathrm{P}_{\mathrm{rol}} * \mathrm{~F}_{\mathrm{ro}}$} & $P_{\text {rol }}$ & \multicolumn{3}{|c|}{0.25} \\
\hline & $P_{\text {ro }}\left(\mathrm{kg} /\left(\mathrm{ha}{ }_{\mathrm{f}}\right.\right.$ & $2.54 \mathrm{E}-01$ & 2.70E-01 & $3.12 \mathrm{E}-01$ \\
\hline & Total kg & $9.25 E+03$ & $8.89 E+03$ & $1.16 \mathrm{E}+04$ \\
\hline
\end{tabular}


4 Phosphorus emissions from erosion from water to surface waters (Phosphorus to rivers)

\begin{tabular}{|l|l|r|r|r|}
\hline Formula & Variables & Yr 2000 & Yr 2010 & Yr 2020 \\
\hline \multirow{3}{*}{$\mathrm{P}_{\mathrm{er}}=\mathrm{S}_{\mathrm{er}}{ }^{*} \mathrm{P}_{\mathrm{ts}}{ }^{*} \mathrm{~F}_{\mathrm{r}}{ }^{*} \mathrm{~F}_{\mathrm{sr}}$} & $\mathrm{S}_{\mathrm{er}}$ & $2.40 \mathrm{E}+03$ & $2.40 \mathrm{E}+03$ & $2.40 \mathrm{E}+03$ \\
\cline { 2 - 5 } & $\mathrm{P}_{\mathrm{ts}}$ & \multicolumn{3}{|c|}{0.00095} \\
\cline { 2 - 5 } & $\mathrm{F}_{\mathrm{r}}$ & \multicolumn{3}{|c|}{1.86} \\
\cline { 2 - 5 } & $\mathrm{F}_{\mathrm{sr}}$ & \multicolumn{3}{|c|}{0.2} \\
\cline { 2 - 5 } & $\mathrm{P}_{\mathrm{er}} \mathbf{~ k g / ( h a * a}$ & $8.48 \mathrm{E}-01$ & $8.48 \mathrm{E}-01$ & $8.48 \mathrm{E}-01$ \\
\hline & Total kg & $\mathbf{3 . 0 9 E}+04$ & $\mathbf{2 . 7 9 E}+04$ & $3.16 \mathrm{E}+04$ \\
\hline
\end{tabular}




\section{Definitions}

Fertilizer emissions

\begin{tabular}{|c|c|c|}
\hline $\mathrm{NH}_{3 \mathrm{~s}}$ & emission of $\mathrm{NH}_{3}$ from slurry (liquid manure) & $\mathrm{kg} / \mathrm{ha}$ \\
\hline $\mathrm{TAN}_{s}$ & Total content of ammonium- $\mathrm{N}$ in slurry & 1 ton $=1000$ litres \\
\hline $\mathrm{SD}_{\mathrm{m}}$ & Saturation deficit of the air in month $m$ & $\mathrm{SDm}=\left(1-\mathrm{rH}_{\mathrm{m}}\right)^{*} 6.112^{*} \mathrm{e}\left({ }_{\mathrm{m}}^{(17.67 \mathrm{~T}} \mathrm{m} /\left(243.5+\mathrm{T} \mathrm{m}^{\prime}\right)\right.$ \\
\hline $\mathrm{rH}_{\mathrm{m}}$ & Average relative humidity in month $m$ & $\%$ \\
\hline $\mathrm{T}_{\mathrm{m}}$ & Average temperature in month $m$ & oC \\
\hline$A_{s}$ & Fraction of total area where slurry is spread & $\%$ \\
\hline$S$ & Quantity of slurry spread & t/ha of fertilised surface \\
\hline $\mathrm{NH}_{3 \mathrm{~m}}$ & emissions of NH3 from solid manure & kg NH3/ha \\
\hline $\mathrm{TAN}_{\mathrm{m}}$ & Total content of ammonium- $\mathrm{N}$ in solid manure & $\mathrm{kg} \mathrm{NH} \mathrm{H}_{4}-\mathrm{N} / \mathrm{t}$ \\
\hline $\mathrm{M}$ & quantity of solid manure spread & t/ha of fertilised surface \\
\hline$A_{m}$ & fraction of the total area where solid manure is spread & $\%$ \\
\hline $\mathrm{N}_{\mathrm{av}}$ & available mineral and organic nitrogen & $\mathrm{kg} / \mathrm{ha}$ \\
\hline $\mathrm{NH}_{3}$ & losses of nitrogen in the form of ammonia & $\mathrm{kg} / \mathrm{ha}$ \\
\hline $\mathrm{N}_{\mathrm{cr}}$ & nitrogen contained in the crop residues & $\mathrm{kg} / \mathrm{ha}$ \\
\hline $\mathrm{N}_{\mathrm{bf}}$ & nitrogen contained in nitrogen fixing crops (legumes) & $\mathrm{kg} / \mathrm{ha}$ \\
\hline $\mathrm{NO}_{3}^{-}$ & losses of nitrogen in the form of nitrate & $\mathrm{kg} / \mathrm{ha}$ \\
\hline$S_{\operatorname{lm}}$ & $\begin{array}{l}\text { Nitrogen mineralisation potential ( } \mathrm{kg} / \mathrm{ha} / \mathrm{month} \text { ) of leaching } \\
\text { month (Dec-April) divided by total } \mathrm{N} \text { mineralisation potential } \\
\text { per year (Ecolnvent report p. } 30 \text { ) }\end{array}$ & $\%$ \\
\hline Lrate & $\begin{array}{l}\text { Average leaching rate [\%] in leaching month (Dec-Apr) } \\
\text { according to Ecoinvent report p.32, Tab. } 4.6 \text { for permanent, } \\
\text { intensive meadow }\end{array}$ & $\%$ \\
\hline $\mathrm{P}_{2} \mathrm{O}_{5 \mathrm{sl}}$ & Content of $\mathrm{P}_{2} \mathrm{O}_{5}$ contained in liquid slurry & $\mathrm{kg} / \mathrm{ha}$ \\
\hline$F_{\mathrm{gw}}$ & Correction factor for fertilization by slurry & \\
\hline$P_{g w}$ & quantity of P leached to groundwater & $\mathrm{kg} /\left(\mathrm{ha}^{*} \mathrm{a}\right)$ \\
\hline$P_{g w l}$ & $\begin{array}{l}\text { average quantity of P leached to groundwater for a land use } \\
\text { category: } \\
0.06 \mathrm{~kg} \mathrm{P/(ha*a)} \mathrm{for} \mathrm{a} \mathrm{permanent} \mathrm{pasture} \mathrm{or} \mathrm{orchards} \mathrm{in} \mathrm{this} \\
\text { case }\end{array}$ & \\
\hline $\mathrm{F}_{\mathrm{ro}}$ & correction factor for fertilization by $\mathrm{P}$ & factor \\
\hline $\mathrm{P}_{2} \mathrm{O}_{5 \min }$ & Quantity of $\mathrm{P}_{2} \mathrm{O}_{5}$ in mineral fertilizers & $\mathrm{kg} / \mathrm{ha}$ \\
\hline $\mathrm{P}_{2} \mathrm{O}_{5}$ man & Quantity of $\mathrm{P}_{2} \mathrm{O}_{5}$ in solid manure & $\mathrm{kg} / \mathrm{ha}$ \\
\hline$P_{\text {ro }}$ & Quantity of P lost through run-off to rivers & $\mathrm{kg} /\left(\mathrm{ha}^{*} \mathrm{a}\right)$ \\
\hline$P_{\text {rol }}$ & $\begin{array}{l}\text { Average quantity of } \mathrm{P} \text { lost through run-off for a land use } \\
\text { category: for } 0.25 \text { for intensive permanent pastures and } \\
\text { meadows. }\end{array}$ & $\mathrm{kg} /\left(\mathrm{ha}^{*} \mathrm{a}\right)$ \\
\hline $\mathrm{S}_{\mathrm{er}}$ & quantity of soil eroded & $\mathrm{kg} /\left(\mathrm{ha}^{*} \mathrm{a}\right)$ \\
\hline$P_{\text {ts }}$ & Quantity of P in the top soil: value of $0.00095 \mathrm{~kg} P / \mathrm{kg}$ & $\mathrm{kg} P / \mathrm{kg}$ soil \\
\hline $\mathrm{F}_{\mathrm{r}}$ & Enrichment factor for $P$ : value 1.86 used & factor \\
\hline $\mathrm{F}_{\mathrm{sr}}$ & Fraction of eroded soil reaching the river: value 0.2 used & factor \\
\hline$P_{\text {er }}$ & quantity of $\mathrm{P}$ emmited through erosion to rivers & kg P/(ha*a) \\
\hline
\end{tabular}




\section{Heavy metals}

\begin{tabular}{|c|c|c|}
\hline HM-N & Heavy metal contents of $N$ fertilizers (Desaules \& Studer, 1993) & $\mathrm{mg} / \mathrm{kg}$ \\
\hline HM-P & Heavy metal contents of P fertilizers (Desaules \& Studer, 1993) & $\mathrm{mg} / \mathrm{kg}$ \\
\hline HM-K & Heavy metal contents of K fertilizers (Desaules \& Studer, 1993) & $\mathrm{mg} / \mathrm{kg}$ \\
\hline HM-sm & Heavy metal content of cattle solid manure (Freiermuth, 2006) & $\mathrm{mg} / \mathrm{kg} \mathrm{DM}$ \\
\hline HM-Im & Heavy metal content of cattle liquid manure (Freiermuth, 2006) & $\mathrm{mg} / \mathrm{kg} \mathrm{DM}$ \\
\hline HM-pm & Heavy metal content of plant material (Freiermuth, 2006) & $\mathrm{mg} / \mathrm{kg} \mathrm{DM}$ \\
\hline$M_{\text {leach i }}$ & Agricultural related heavy metal $i$ emission to water & $\mathrm{mg} / \mathrm{ha}$ \\
\hline $\mathrm{m}_{\text {leach } \mathrm{i}}$ & average amount of heavy metal emission & $\mathrm{mg} / \mathrm{ha}$ \\
\hline$A_{i}$ & $\begin{array}{l}\text { allocation factor for the share of agricultural inputs in the total } \\
\text { inputs for heavy metal i }\end{array}$ & $\mathrm{mg} / \mathrm{ha}$ \\
\hline$M_{\text {erosion }}$ & agricultural related heavy metal emissions through erosion & $\mathrm{mg} / \mathrm{ha}$ \\
\hline $\mathrm{c}_{\text {toti }}$ & total heavy metal content in the soil (Keller \& Desaulles, 2001) & $\mathrm{mg} / \mathrm{kg}$ soil \\
\hline $\mathrm{B}$ & Amount of soil erosion (Oberholzer et al. 2006) & $\mathrm{kg} / \mathrm{ha}$ \\
\hline $\mathrm{a}$ & Accumulation factor 1.86 for $P$ (Prasuhn, 2006) & factor \\
\hline$f_{\text {erosion }}$ & $\begin{array}{l}\text { erosion factor considering distance to water bodies with } \\
\text { average value of } 0.2\end{array}$ & factor \\
\hline$M_{\text {soili }}$ & Heavy metal emissions to agricultural soil & $\mathrm{mg} / \mathrm{ha}$ \\
\hline$M_{\text {agroi }}$ & $\begin{array}{l}\text { total input of heavy metal from agricultural production in } \\
\mathrm{mg} / \text { (ha*year) (fertilisers + seeds + pesticides) }\end{array}$ & $\mathrm{mg} / \mathrm{ha*}$ year \\
\hline$M_{\text {deposition }}$ & $\begin{array}{l}\text { total input of heavy metal from atmospheric deposition in } \\
\mathrm{mg} / \text { (ha*year) }\end{array}$ & mg/ha*year \\
\hline
\end{tabular}




\section{Appendix III : Datasets for pesticides}

1. Pesticides for year 2010 (data from Dabrowski, Shadung \& Wepener (2014)).

\begin{tabular}{|c|c|c|c|c|c|}
\hline Active ingredients & Total qty 2009 & Qty fruit 2009 & Qty per kg & Total ha 2009 & Qty per ha \\
\hline & (kg) & (kg) & (kg/kg fruit) & (ha) & (kg/ha) \\
\hline Mancozeb & 333333.00 & \multirow{11}{*}{753167000} & \begin{tabular}{|r|}
$4.43 \mathrm{E}-04$ \\
\end{tabular} & \multirow{11}{*}{21100} & $1.58 \mathrm{E}+01$ \\
\hline Glyphosate & 81862.00 & & 1.09E-04 & & $3.88 \mathrm{E}+00$ \\
\hline Copper oxychloride & 62526.00 & & $8.30 \mathrm{E}-05$ & & $2.96 \mathrm{E}+00$ \\
\hline Imidacloprid & 14616.00 & & $1.94 \mathrm{E}-05$ & & $6.93 \mathrm{E}-01$ \\
\hline MCPA & 4275.00 & & $5.68 \mathrm{E}-06$ & & 2.03E-01 \\
\hline Simazine & 499.02 & & $6.63 \mathrm{E}-07$ & & 2.37E-02 \\
\hline Paraquat & 38640.00 & & $5.13 \mathrm{E}-05$ & & $1.83 \mathrm{E}+00$ \\
\hline Cyanamide & 15631.00 & & $2.08 \mathrm{E}-05$ & & $7.41 \mathrm{E}-01$ \\
\hline Chlorpyrifos & 17020.00 & & $2.26 \mathrm{E}-05$ & & 8.07E-01 \\
\hline Thiamethoxam & 750.79 & & 9.97E-07 & & $3.56 \mathrm{E}-02$ \\
\hline Carbaryl & 2341.69 & & $3.11 \mathrm{E}-06$ & & $1.11 \mathrm{E}-01$ \\
\hline Total & 571494.50 & & 7.59E-04 & & 27 \\
\hline
\end{tabular}

\section{Calculations}

\begin{tabular}{|c|c|c|c|c|}
\hline & WHP & HP & Qi (tons) & Qtot \\
\hline Simazine & 0.2801 & 64 & 83.17 & \multirow{5}{*}{19003400} \\
\hline Thiram & 0.049 & & & \\
\hline Thiamethoxam & 0.0431 & 36 & 22.75 & \\
\hline Carbaryl & 0.0279 & 36 & 14.73 & \\
\hline Acephate & 0.0091 & & & \\
\hline
\end{tabular}




\section{Pesticides, CCC pome fruit 2010 |production \& application |\{ZA\} | Alloc Def, U 1 ha}

\begin{tabular}{|c|c|c|c|}
\hline \multicolumn{4}{|l|}{ Known inputs from technosphere } \\
\hline Name & Amount & Unit & Comments \\
\hline Triazine-compound, unspecified \{GLO\}| market for | Alloc Def, & 0.02365 & $\mathrm{~kg}$ & \multirow{5}{*}{$\begin{array}{l}\text { Dabrowski et. al (2014) } \\
\text { - total pesticide use 2009: } 747051.634 \mathrm{~kg}(76.5 \%= \\
571494.5 \mathrm{~kg} \text { table } 6 \mathrm{pg} .38) \\
\text { - apple production 2009: } 753167 \text { tons } \\
\text { - total hectares: } 21100\end{array}$} \\
\hline [thio]carbamate-compound $\{\mathrm{GLO}\} \mid$ market for | Alloc Def, U & 0.110981 & $\mathrm{~kg}$ & \\
\hline Mancozeb $\{$ GLO\}| market for | Alloc Def, U & 15.798 & $\mathrm{~kg}$ & \\
\hline Glyphosate $\{$ GLP $\}$ | market for | Alloc Def, U & 3.880 & $\mathrm{~kg}$ & \\
\hline Pesticide, unspecified $\{$ GLO\}| market for | Alloc Def, U & 7.272929 & $\mathrm{~kg}$ & \\
\hline $\begin{array}{l}\text { Agricultural machinery, unspecified }\{G L O\} \mid \text { market for | Alloc } \\
\text { Def, } U\end{array}$ & 0.53 & $\mathrm{~kg}$ & \multirow[t]{4}{*}{$\begin{array}{l}\text { From process Application of plant protection product, } \\
\text { by field sprayer }\{Z A\} \mid \text { processing | Alloc Def, } U\end{array}$} \\
\hline Shed $\{$ GLO\}| market for | Alloc Def, $U$ & 0.00198 & $\mathrm{~m} 2$ & \\
\hline Tractor, 4-wheel, agricultural $\{\mathrm{GLO}\} \mid$ market for | Alloc Def, U & 0.321 & $\mathrm{~kg}$ & \\
\hline Diesel $\{Z A\} \mid$ market for | Alloc Def, U & 1.76 & $\mathrm{~kg}$ & \\
\hline \multicolumn{4}{|l|}{ Emissions to air } \\
\hline Name & Amount & Unit & Comments \\
\hline Carbon monoxide, fossil & $9.80 \mathrm{E}-03$ & $\mathrm{~kg}$ & \multirow{18}{*}{$\begin{array}{l}\text { From process Application of plant protection product, } \\
\text { by field sprayer }\{Z A\} \mid \text { processing | Alloc Def, } U\end{array}$} \\
\hline Sulfur dioxide & $1.78 \mathrm{E}-03$ & $\mathrm{~kg}$ & \\
\hline Cadmium & $1.76 \mathrm{E}-08$ & $\mathrm{~kg}$ & \\
\hline Nickel & $1.23 \mathrm{E}-07$ & $\mathrm{~kg}$ & \\
\hline PAH, polycyclic aromatic hydrocarbons & $5.80 \mathrm{E}-06$ & $\mathrm{~kg}$ & \\
\hline Ammonia & $3.53 \mathrm{E}-05$ & $\mathrm{~kg}$ & \\
\hline Nitrogen oxides & 7.91E-02 & $\mathrm{kg}$ & \\
\hline Zinc & $1.76 \mathrm{E}-06$ & $\mathrm{~kg}$ & \\
\hline Selenium & $1.76 \mathrm{E}-08$ & $\mathrm{~kg}$ & \\
\hline Benzo(a)pyrene & $5.29 \mathrm{E}-08$ & $\mathrm{~kg}$ & \\
\hline Dinitrogen monoxide & 0.000212 & $\mathrm{~kg}$ & \\
\hline Benzene & $1.29 \mathrm{E}-05$ & $\mathrm{~kg}$ & \\
\hline Carbon dioxide, fossil & $5.49 \mathrm{E}+00$ & $\mathrm{~kg}$ & \\
\hline Particulates, $<2.5$ um & $4.63 \mathrm{E}-03$ & $\mathrm{~kg}$ & \\
\hline Methane, fossil & $2.28 \mathrm{E}-04$ & $\mathrm{~kg}$ & \\
\hline Chromium & $8.82 \mathrm{E}-08$ & $\mathrm{~kg}$ & \\
\hline Copper & $3.00 \mathrm{E}-06$ & $\mathrm{~kg}$ & \\
\hline $\begin{array}{l}\text { NMVOC, non-methane volatile organic compounds, } \\
\text { unspecified origin }\end{array}$ & $6.75 \mathrm{E}-03$ & $\mathrm{~kg}$ & \\
\hline
\end{tabular}




\section{Pesticides for year 2000}

\section{Pesticides, pome fruit 2000 |production \& application $|\{Z A\}|$ Alloc Def, U 1 ha}

\begin{tabular}{|c|c|c|c|}
\hline \multicolumn{4}{|l|}{ Known inputs from technosphere } \\
\hline Name & Amount & Unit & Comments \\
\hline [thio]carbamate-compounds, at regional storehouse/RER U & 0.008154 & $\mathrm{~kg}$ & \multirow[t]{7}{*}{2007 Apple and Pear Combuds } \\
\hline Mancozeb, at regional storage/RER U & 6.399 & $\mathrm{~kg}$ & \\
\hline Captan, at regional storage/RER U & 1.117 & $\mathrm{~kg}$ & \\
\hline Glyphosate, at regional storehouse/RER U & 4.952 & $\mathrm{~kg}$ & \\
\hline Pesticide unspecified, at regional storehouse/RER U & 6.286049 & $\mathrm{~kg}$ & \\
\hline White mineral oil, at plant/RNA & 2.979445 & $\mathrm{~kg}$ & \\
\hline MCPA, at regional storehouse/RER U & 5.94E-03 & & \\
\hline Agricultural machinery, general, production/CH/I U & 0.53 & $\mathrm{~kg}$ & \multirow{4}{*}{$\begin{array}{l}\text { Application of plant protection products, by field } \\
\text { sprayer/ZA U } 2000\end{array}$} \\
\hline Shed/CH/I U & 0.00198 & $\mathrm{~m} 2$ & \\
\hline Tractor, production/CH/I U & 0.321 & $\mathrm{~kg}$ & \\
\hline Diesel $\{Z A\} \mid$ market for $\mid$ Alloc Def, $U$ & 1.76 & $\mathrm{~kg}$ & \\
\hline \multicolumn{4}{|l|}{ Emissions to air } \\
\hline Name & Amount & Unit & Comments \\
\hline Carbon monoxide, fossil & $9.80 \mathrm{E}-03$ & $\mathrm{~kg}$ & \multirow{18}{*}{$\begin{array}{l}\text { Application of plant protection products, by field } \\
\text { sprayer/ZA U } 2000\end{array}$} \\
\hline Sulfur dioxide & $1.78 \mathrm{E}-03$ & $\mathrm{~kg}$ & \\
\hline Cadmium & $1.76 \mathrm{E}-08$ & $\mathrm{~kg}$ & \\
\hline Nickel & $1.23 \mathrm{E}-07$ & $\mathrm{~kg}$ & \\
\hline PAH, polycyclic aromatic hydrocarbons & $5.80 \mathrm{E}-06$ & $\mathrm{~kg}$ & \\
\hline Ammonia & $3.53 \mathrm{E}-05$ & $\mathrm{~kg}$ & \\
\hline Nitrogen oxides & $7.91 \mathrm{E}-02$ & $\mathrm{~kg}$ & \\
\hline Zinc & $1.76 \mathrm{E}-06$ & $\mathrm{~kg}$ & \\
\hline Selenium & $1.76 \mathrm{E}-08$ & $\mathrm{~kg}$ & \\
\hline Benzo(a)pyrene & $5.29 \mathrm{E}-08$ & $\mathrm{~kg}$ & \\
\hline Dinitrogen monoxide & 0.000212 & $\mathrm{~kg}$ & \\
\hline Benzene & $1.29 \mathrm{E}-05$ & $\mathrm{~kg}$ & \\
\hline Carbon dioxide, fossil & $5.49 \mathrm{E}+00$ & $\mathrm{~kg}$ & \\
\hline Particulates, $<2.5$ um & 4.63E-03 & $\mathrm{kg}$ & \\
\hline Methane, fossil & $2.28 \mathrm{E}-04$ & $\mathrm{~kg}$ & \\
\hline Chromium & $8.82 \mathrm{E}-08$ & $\mathrm{~kg}$ & \\
\hline Copper & $3.00 \mathrm{E}-06$ & $\mathrm{~kg}$ & \\
\hline $\begin{array}{l}\text { NMVOC, non-methane volatile organic compounds, } \\
\text { unspecified origin }\end{array}$ & $6.75 \mathrm{E}-03$ & $\mathrm{~kg}$ & \\
\hline
\end{tabular}




\section{Pesticides for year 2020}

\section{Pesticides, CCC pome fruit 2020 |production \& application $|\{Z A\}|$ Aloc Def, U 1 ha}

\begin{tabular}{|c|c|c|c|}
\hline \multicolumn{4}{|l|}{ Known inputs from technosphere } \\
\hline Name & Amount & Unit & Comments \\
\hline [thio]carbamate-compound $\{$ GLO $\} \mid$ market for | Alloc Def, $\mathrm{U}$ & 1.08 & $\mathrm{~kg}$ & \multirow{4}{*}{$\begin{array}{c}\text { Spray programme: } \\
\text { - TAD } \\
\text { - Hortgro }\end{array}$} \\
\hline Mancozeb $\{$ GLO\}| market for | Alloc Def, U & 16.630 & $\mathrm{~kg}$ & \\
\hline Pesticide, unspecified $\{$ GLO $\} \mid$ market for | Alloc Def, U & 1.766 & $\mathrm{~kg}$ & \\
\hline Pyrethroid-compound \{RoW\}| production | Alloc Def, U & 0.144 & $\mathrm{~kg}$ & \\
\hline $\begin{array}{l}\text { Agricultural machinery, unspecified }\{\text { GLO }\} \mid \text { market for | Alloc } \\
\text { Def, } U\end{array}$ & 0.53 & $\mathrm{~kg}$ & \multirow[t]{4}{*}{$\begin{array}{l}\text { From process Application of plant protection product, } \\
\text { by field sprayer }\{Z A\} \mid \text { processing | Alloc Def, } U\end{array}$} \\
\hline Shed $\{$ GLO\} $\mid$ market for | Alloc Def, $\mathrm{U}$ & 0.00198 & $\mathrm{~m} 2$ & \\
\hline Tractor, 4-wheel, agricultural $\{\mathrm{GLO}\} \mid$ market for | Alloc Def, U & 0.321 & $\mathrm{~kg}$ & \\
\hline Diesel $\{Z A\} \mid$ market for | Alloc Def, $U$ & 1.76 & & \\
\hline \multicolumn{4}{|l|}{ Emissions to air } \\
\hline Name & Amount & Unit & Comments \\
\hline Carbon monoxide, fossil & $9.80 \mathrm{E}-03$ & $\mathrm{~kg}$ & \multirow{18}{*}{$\begin{array}{l}\text { From process Application of plant protection product, } \\
\text { by field sprayer }\{Z A\} \mid \text { processing | Alloc Def, } U\end{array}$} \\
\hline Sulfur dioxide & $1.78 \mathrm{E}-03$ & $\mathrm{~kg}$ & \\
\hline Cadmium & $1.76 \mathrm{E}-08$ & $\mathrm{~kg}$ & \\
\hline Nickel & $1.23 \mathrm{E}-07$ & $\mathrm{~kg}$ & \\
\hline PAH, polycyclic aromatic hydrocarbons & $5.80 \mathrm{E}-06$ & $\mathrm{~kg}$ & \\
\hline Ammonia & $3.53 \mathrm{E}-05$ & $\mathrm{~kg}$ & \\
\hline Nitrogen oxides & $7.91 \mathrm{E}-02$ & $\mathrm{~kg}$ & \\
\hline Zinc & $1.76 \mathrm{E}-06$ & $\mathrm{~kg}$ & \\
\hline Selenium & $1.76 \mathrm{E}-08$ & $\mathrm{~kg}$ & \\
\hline Benzo(a)pyrene & $5.29 \mathrm{E}-08$ & $\mathrm{~kg}$ & \\
\hline Dinitrogen monoxide & 0.000212 & $\mathrm{~kg}$ & \\
\hline Benzene & $1.29 \mathrm{E}-05$ & $\mathrm{~kg}$ & \\
\hline Carbon dioxide, fossil & $5.49 \mathrm{E}+00$ & $\mathrm{~kg}$ & \\
\hline Particulates, $<2.5$ um & 4.63E-03 & $\mathrm{kg}$ & \\
\hline Methane, fossil & $2.28 \mathrm{E}-04$ & $\mathrm{~kg}$ & \\
\hline Chromium & $8.82 \mathrm{E}-08$ & $\mathrm{~kg}$ & \\
\hline Copper & $3.00 \mathrm{E}-06$ & $\mathrm{~kg}$ & \\
\hline $\begin{array}{l}\text { NMVOC, non-methane volatile organic compounds, } \\
\text { unspecified origin }\end{array}$ & $6.75 \mathrm{E}-03$ & $\mathrm{~kg}$ & \\
\hline
\end{tabular}




\section{Appendix IV : Irrigation water consumption calculations}

\section{Irrigation design calculation}

Net seasonal water usage $=\quad$ ET (evapotranspiration) - effective rainfall

Gross seasonal water usage $=\quad$ Nett seasonal water usage/irrigation effectivity

\section{Evapotranspiration (ET)/yr}

\begin{tabular}{|c|c|c|}
\hline Varietal & ET & Year \\
\hline ET for golden delicious: & $\begin{array}{l}\text { circa: } 948 \mathrm{~mm}( \pm 51 \mathrm{~mm}) \\
\text { circa: } 791 \mathrm{~mm}( \pm 21 \mathrm{~mm}) \\
\text { circa: } 894 \mathrm{~mm}( \pm 8 \mathrm{~mm})\end{array}$ & $\begin{array}{l}2005 / 2006 \\
2006 / 2007 \\
2007 / 2008\end{array}$ \\
\hline $\begin{array}{l}\text { ET for golden delicious: } \\
\text { ET for Granny Smith: }\end{array}$ & $\begin{array}{l}414.8 \mathrm{~mm} \\
614.8 \mathrm{~mm}\end{array}$ & $\begin{array}{l}2000 / 2001 \\
2000 / 2001\end{array}$ \\
\hline ET for pink lady: $\quad 2.3$ ha & $\begin{array}{ll}952 \mathrm{~mm} & 9520 \mathrm{~kL} / \mathrm{ha} \\
966 \mathrm{~mm} & 9660 \mathrm{~kL} / \mathrm{ha}\end{array}$ & $\begin{array}{l}2008 / 2009 \\
2009 / 2010\end{array}$ \\
\hline $\begin{array}{l}\text { Average } \\
\text { Median }\end{array}$ & $\begin{array}{l}797 \mathrm{~mm} / \mathrm{yr} \\
894 \mathrm{~mm} / \mathrm{yr}\end{array}$ & \\
\hline
\end{tabular}

Effective rainfall http://www.fao.org/docrep/s2022e/s2022e03.htm\#chapter 3: effective rainfall

Average monthly rainfall from $1990-2012$
\begin{tabular}{|l|r|r|}
\hline Koue bokkeveld & $17.83 \mathrm{~mm}$ & Effective rainfall \\
Elgin & $71.24 \mathrm{~mm}$ & $3.1 \mathrm{~mm}$ \\
Ceres & $22.91 \mathrm{~mm}$ & $37.2 \mathrm{~mm}$ \\
Average & $37 \mathrm{~mm}$ & $5.3 \mathrm{~mm}$ \\
\hline
\end{tabular}

Net seasonal water requirement for pome fruit orchards from 3 areas:

$$
\begin{array}{cc}
\text { Gross seasonal water requirement: } & 920 \mathrm{~mm} \\
9200 \mathrm{~kL} / \mathrm{yr}
\end{array}
$$

Note: Field application efficiency for micro sprayers $=85 \%$ (FAO, n.d.) 
2. Crop water requirements in the Berg River catchment.

\begin{tabular}{|l|}
\hline \\
\hline Other Crops \\
\hline Sub-Tropical Fruit \\
\hline Herbs \\
\hline Prickly Pears \\
\hline Nuts \\
\hline Oil Seeds \\
\hline Pepo \\
\hline Grains \\
\hline Berries \\
\hline Pome Fruit \\
\hline Planted Pasture \\
\hline Vegetables \\
\hline Tree Fruit (Other) \\
\hline Citrus \\
\hline Grapes (Table) \\
\hline Stone Fruit \\
\hline Grapes (Wine) \\
\hline Grapes (AII) \\
\hline Total: \\
\hline
\end{tabular}

\begin{tabular}{|c|c|c|c|c|}
\hline $\begin{array}{l}\text { Area } \\
\text { Cultivated } \\
\text { (Ha) }\end{array}$ & $\begin{array}{l}\text { Evapotranspiration } \\
\left(\mathrm{Mm}^{3}\right)\end{array}$ & $\begin{array}{l}\text { Effective } \\
\text { Rainfall }\left(\mathbf{M m}^{3}\right)\end{array}$ & $\begin{array}{l}\text { Irrigation } \\
\left(\mathrm{Mm}^{3}\right)\end{array}$ & $\begin{array}{l}\text { \% Green } \\
\text { Water }\end{array}$ \\
\hline 1.27 & 0.01 & 0.00 & 0.01 & 17 \\
\hline 1.52 & 0.02 & 0.00 & 0.01 & 15 \\
\hline 5.35 & 0.03 & 0.00 & 0.03 & 10 \\
\hline 8.59 & 0.06 & 0.02 & 0.03 & 39 \\
\hline 5.69 & 0.08 & 0.01 & 0.07 & 8 \\
\hline 42.55 & 0.23 & 0.06 & 0.16 & 29 \\
\hline 24.88 & 0.18 & 0.01 & 0.16 & 8 \\
\hline 2715.22 & 6.56 & 5.47 & 1.09 & 83 \\
\hline 324.16 & 1.92 & 0.35 & 1.58 & 18 \\
\hline 1540.21 & 12.02 & 2.89 & 9.13 & 24 \\
\hline 835.30 & 12.24 & 1.88 & 10.36 & 15 \\
\hline 1552.81 & 11.26 & 0.34 & 10.92 & 3 \\
\hline 1400.60 & 14.37 & 3.41 & 10.96 & 24 \\
\hline 1641.46 & 19.54 & 4.88 & 14.66 & 25 \\
\hline 4726.74 & 25.72 & 10.96 & 14.77 & 43 \\
\hline 7246.73 & 57.18 & 19.90 & 37.28 & 35 \\
\hline 52827.46 & 269.36 & 140.22 & 129.14 & 52 \\
\hline 57554.20 & 295.09 & 151.18 & 143.91 & 51 \\
\hline 74900.54 & 430.77 & 190.43 & 240.35 & 44 \\
\hline
\end{tabular}




\section{Appendix V : Packhouse packaging calculations for year 2000}

\begin{tabular}{|c|c|c|}
\hline PPECB cartons exported 2000 (DFPT, 2000) & No. cartons & Tonnes \\
\hline Apples & 14223741.00 & 165506.25 \\
\hline Pears & 8642876.00 & 90292.00 \\
\hline Total exported: & 22866617.00 & 255798.25 \\
\hline Local market 2000 & No. cartons & Tonnes \\
\hline Apples & 16860985.12 & 196193.00 \\
\hline Pears & 4847331.33 & 50640.00 \\
\hline Total local market: & 21708316.45 & 246833.00 \\
\hline
\end{tabular}

\begin{tabular}{l|r|r|}
\hline Pulp and polystyrene trays & Indiv. Weight [g] & Total weight [kg] \\
\hline Apples (Polystyrene) & 14.6 & 2269185.01 \\
\hline Pears (Pulp) & 11.9 & 642133.87 \\
\hline Total & & 2911318.88 \\
\cline { 2 - 3 }
\end{tabular}

Average pulp trays per MK6 carton: 4

Average polystyrene trays per MK6 carton: 5 


\section{Appendix VI : SimaPro models for electricity mix in year 2020}

\section{Electricity production mix}

\begin{tabular}{|c|c|c|c|c|}
\hline Electricity, high voltage $\{Z A\} 2020 \mid$ production mix | Alloc Def, U & & kWh & not defined & $\begin{array}{l}\text { Electricity country mix } \mid \text { High } \\
\text { dVoltagelTransformationIProduction mix }\end{array}$ \\
\hline \multicolumn{5}{|l|}{ Avoided products } \\
\hline \multicolumn{5}{|l|}{ Resources } \\
\hline \multicolumn{5}{|l|}{ Electricity/heat } \\
\hline Electricity, high voltage $\{Z \mathrm{ZA}\} \mid$ electricity production, hard coal $\mid$ Alloc Def, $U$ & 0.564977 & kWh & Undefined & Production Volume Amount: 119775058360 \\
\hline Electricity, high voltage $\{Z A\} \mid$ electricity production, NEW coal $\mid$ Alloc Def, U & 0.252883 & kWh & Undefined & Production Volume Amount: 53611200000 \\
\hline Electricity, high voltage $\{Z A\} \mid$ electricity production, hydro, pumped storage $\mid$ Alloc Def, U & 0.039978 & kWh & Undefined & Production Volume Amount: 8475300000 \\
\hline Electricity, high voltage $\{Z \mathrm{ZA}\} \mid$ electricity production, hydro, reservoir, non-alpine region $\mid$ Alloc Def, $U$ & 0.01116 & $\mathrm{kWh}$ & Undefined & Production Volume Amount: 2365970880 \\
\hline Electricity, high voltage $\{Z \mathrm{Z}\} \mid$ electricity production, nuclear, pressure water reactor $\mid$ Alloc Def, $U$ & 0.06134 & $\mathrm{kWh}$ & Undefined & Production Volume Amount: 13004000474.4 \\
\hline Electricity, high voltage $\{Z A\} \mid$ electricity production, oil | Alloc Def, $U$ & 0.004481 & $\mathrm{kWh}$ & Undefined & Production Volume Amount: 950028400 \\
\hline Electricity, high voltage $\{\mathrm{ZA}\} \mid$ electricity production, wind, $>3 \mathrm{MW}$ turbine, onshore $\mid$ Alloc Def, $U$ & 0.001718 & $\mathrm{kWh}$ & Undefined & Production Volume Amount: 364241000 \\
\hline Electricity, high voltage $\{\mathrm{ZA}\} \mid$ electricity production, wind, 1-3MW turbine, onshore $\mid$ Alloc Def, $U$ & 0.022876 & kWh & Undefined & Production Volume Amount: 4839927682 \\
\hline Electricity, high voltage $\{Z A\} \mid$ electricity production, photovoltaic, $570 \mathrm{kWp}$ open ground installation, & 0.028191 & kWh & Undefined & $\begin{array}{l}\text { One PV ground installation of } 570 \mathrm{kWp}=2.22525 \mathrm{E}-8 \\
\text { to deliver } 1 \mathrm{kWh} \text {. } \\
\text { Lifetime*capacity }{ }^{*} \text { annual yield }=\mathrm{kWh} / \mathrm{unit} .1 / \mathrm{kWh} / \mathrm{unit} \text {. } \\
\mathrm{CSP} \text { output included in } \mathrm{PV} \text { dataset. } \\
\text { Production volume: } 3874118760\end{array}$ \\
\hline Electricity, high voltage $\{$ ZA $\} \mid$ import from MZ | Alloc Def, $U$ & 0.012446 & $\mathrm{kWh}$ & Undefined & Production Volume Amount: 2638512000 \\
\hline
\end{tabular}

\section{'New' Coal dataset}

\begin{tabular}{|c|c|c|c|}
\hline Electricity, high voltage $\{\mathrm{ZA}\} \mid$ electricity production, NEW coal $\mid$ Alloc Def, $U$ & 1 kWh & 100 not defined & $\begin{array}{l}\text { Electricity by } \\
\text { fuellCoall Transform } \\
\text { ation }\end{array}$ \\
\hline
\end{tabular}

Resources

\begin{tabular}{|l|l|l|l|l|l|l|l|l|}
\hline Water, cooling, unspecified natural origin, ZA & in water & 0.046082 & $\mathrm{~m} 3$ & Lognormal & 1.8704 & $11 \%$ less water consumed \\
\hline
\end{tabular}

\section{Materials/fuels}

Water, decarbonised, at user \{GLO\}| market for |Alloc Def, $U$

Light fuel oil $\{$ RoW\}| market for | Alloc Def, $U$

SOx retained, in hard coal flue gas desulfurisation \{GLO\}| market for | Alloc Def, $U$

Water, completely softened, from decarbonised water, at user \{GLO\}| market for | Alloc Def, $U$

Hard coal power plant $\{$ GLO\}| market for | Alloc Def, $U$

Hard coal $\{$ ZA $\} \mid$ market for | Alloc Def, $U$

\begin{tabular}{|l|r|r|l|l|}
\hline & 2.015226 & $\mathrm{~kg}$ & Log \\
\hline & & 0.000192 & $\mathrm{~kg}$ & Log \\
\hline & 0.00172 & $\mathrm{~kg}$ & Log \\
\hline \multicolumn{1}{|l|}{ Def, U } & 0.060457 & $\mathrm{~kg}$ & Log \\
\hline & & $1.33 \mathrm{E}-11$ & $\mathrm{p}$ & Log \\
\hline
\end{tabular}

\begin{tabular}{|l|r|l|}
\hline Lognormal & 1.5916 & $11 \%$ less water consumed \\
\hline Lognormal & 1.3632 & \\
\hline Lognormal & 1.133 & \\
\hline Lognormal & 1.5916 & $11 \%$ less water consumed \\
\hline Lognormal & 3.3678 & \\
\hline Undefined & & $15 \%$ less hard coal used produce $1 \mathrm{kWh}$ \\
\hline
\end{tabular}

\begin{tabular}{|c|c|c|c|c|c|c|}
\hline Phenol & low. pop. & $1.49 \mathrm{E}-09$ & $\mathrm{~kg}$ & Lognormal & 2.1169 & \\
\hline Carbon dioxide, fossil & low. pop. & 0.916081 & $\mathrm{~kg}$ & Lognormal & 1.3325 & $15 \%$ less $\mathrm{CO} 2$ emmissions \\
\hline \begin{tabular}{|l|} 
Potassium- 40 \\
\end{tabular} & low. pop. & 0.00026 & $\mathrm{kBg}$ & Lognormal & 3.5349 & \\
\hline Protactinium-234 & low. pop. & $1.16 \mathrm{E}-05$ & $\mathrm{kBq}$ & Lognormal & 3.1032 & \\
\hline Water/m3 & & 0.00145 & $\mathrm{~m} 3$ & Lognormal & 1.8704 & $11 \%$ less water consumed \\
\hline Cumene & low. pop. & $5.07 \mathrm{E}-10$ & $\mathrm{~kg}$ & Lognormal & 2.012 & \\
\hline Furan & low. pop. & $4.65 \mathrm{E}-13$ & $\mathrm{~kg}$ & Lognormal & 2.1169 & \\
\hline Selenium & low. pop. & $1.86 \mathrm{E}-07$ & $\mathrm{~kg}$ & Lognormal & 5.6431 & \\
\hline \begin{tabular}{|l|} 
Nickel \\
\end{tabular} & low. pop. & $2.26 \mathrm{E}-07$ & $\mathrm{~kg}$ & Lognormal & 5.6431 & \\
\hline Radium-228 & low. pop. & $6.67 \mathrm{E}-05$ & $\mathrm{kBq}$ & Lognormal & 3.5349 & \\
\hline Lead & low. pop. & $4.19 \mathrm{E}-07$ & $\mathrm{~kg}$ & Lognormal & 5.6431 & \\
\hline Chromium & low. pop. & $9.25 \mathrm{E}-08$ & $\mathrm{~kg}$ & Lognormal & 5.6431 & \\
\hline Radium-226 & low. pop. & 0.000207 & $\mathrm{kBq}$ & Lognormal & 3.4908 & \\
\hline Acenaphthene & low. pop. & $4.74 \mathrm{E}-11$ & $\mathrm{~kg}$ & Lognormal & 2.1169 & \\
\hline Antimony & low. pop. & $1.35 \mathrm{E}-08$ & $\mathrm{~kg}$ & Lognormal & 5.6431 & \\
\hline \begin{tabular}{|l} 
Arsenic \\
\end{tabular} & low. pop. & $1.13 \mathrm{E}-07$ & $\mathrm{~kg}$ & Lognormal & 5.6431 & \\
\hline PAH, polycyclic aromatic hydrocarbons & low. pop. & $8.45 \mathrm{E}-08$ & $\mathrm{~kg}$ & Lognormal & 3.2097 & \\
\hline Znc & low. pop. & $4.69 \mathrm{E}-07$ & $\mathrm{~kg}$ & Lognormal & 5.6431 & \\
\hline Hydrogen chloride & low. pop. & 0.000299 & $\mathrm{~kg}$ & Lognormal & 2.5475 & \\
\hline Particulates, $>10$ um & low. pop. & 0.000231 & $\mathrm{~kg}$ & Lognormal & 1.6725 & \\
\hline Mercury & low. pop. & 3.05E-08 & $\mathrm{kg}$ & Lognormal & 5.6431 & \\
\hline Propane & low. pop. & 2.34E-07 & $\mathrm{kg}$ & Lognormal & 1.7607 & \\
\hline Dioxin, 2,3,7,8 Tetrachlorodibenzo-p- & low. pop. & $1.2 \mathrm{E}-13$ & $\mathrm{~kg}$ & Lognormal & 3.2097 & \\
\hline Hydrocarbons, aliphatic, alkanes, unspecified & low. pop. & $1.52 \mathrm{E}-06$ & $\mathrm{~kg}$ & Lognormal & 1.7607 & \\
\hline Cobalt & low. pop. & 3.77E-08 & $\mathrm{kg}$ & Lognormal & 5.6431 & \\
\hline Ethene, tetrachloro- & low. pop. & $3.99 \mathrm{E}-09$ & $\mathrm{~kg}$ & Lognormal & 2.3285 & \\
\hline Methane, fossil & low. pop. & $1.02 \mathrm{E}-05$ & $\mathrm{~kg}$ & Lognormal & 1.723 & \\
\hline Uranium-234 & low. pop. & $2.28 \mathrm{E}-05$ & $\mathrm{kBq}$ & Lognormal & 3.3124 & \\
\hline Nitrogen oxides & low. pop. & 0.003502 & $\mathrm{~kg}$ & Lognormal & 1.133 & $15 \%$ less Nox emmissions \\
\hline Aldehydes, unspecified & low. pop. & $8.84 \mathrm{E}-08$ & $\mathrm{~kg}$ & Lognormal & 2.1169 & \\
\hline Ethane, 1,1,1-trichloro-, HCFC-140 & low. pop. & $1.86 \mathrm{E}-09$ & $\mathrm{~kg}$ & Lognormal & 2.1169 & \\
\hline Copper & low. pop. & $9.27 \mathrm{E}-08$ & $\mathrm{~kg}$ & Lognormal & 5.6431 & \\
\hline
\end{tabular}


Appendices

\begin{tabular}{|c|c|c|c|c|c|c|}
\hline Benzene & low. pop. & $1.57 \mathrm{E}-06$ & $\mathrm{~kg}$ & Lognormal & 1.8099 & \\
\hline Sulfate & low. pop. & $4.45 \mathrm{E}-09$ & $\mathrm{~kg}$ & Lognormal & 2.3285 & \\
\hline Actinides, radioactive, unspecified & low. pop. & 0.000193 & $\mathrm{kBq}$ & Lognormal & 3.1032 & \\
\hline \begin{tabular}{|l|} 
Dinitrogen monoxide \\
\end{tabular} & low. pop. & $1.49 \mathrm{E}-05$ & $\mathrm{~kg}$ & Lognormal & 1.723 & \\
\hline NMVOC, non-methane volatile organic compounds, unspecified origin & low. pop. & $1.05 \mathrm{E}-05$ & $\mathrm{~kg}$ & Lognormal & 2.1169 & \\
\hline lodine & low. pop. & $1.79 \mathrm{E}-06$ & $\mathrm{~kg}$ & Lognormal & 2.5475 & \\
\hline Cyanide & low. pop. & $2.32 \mathrm{E}-07$ & $\mathrm{~kg}$ & Lognormal & 2.3285 & \\
\hline Particulates, $>2.5$ um, and $<10 u m$ & low. pop. & $9.6 \mathrm{E}-06$ & $\mathrm{~kg}$ & Lognormal & 1.6725 & \\
\hline Magnesium & low. pop. & $1.02 \mathrm{E}-06$ & $\mathrm{~kg}$ & Lognormal & 5.3847 & \\
\hline Ethane & low. pop. & $2.74 \mathrm{E}-07$ & $\mathrm{~kg}$ & Lognormal & 1.7607 & \\
\hline Thorium-234 & low. pop. & $1.16 \mathrm{E}-05$ & $\mathrm{kBq}$ & Lognormal & 3.1032 & \\
\hline Xylene & low. pop. & $6.16 \mathrm{E}-06$ & $\mathrm{~kg}$ & Lognormal & 1.7607 & \\
\hline Benzo(a)pyrene & low. pop. & $4.86 \mathrm{E}-12$ & $\mathrm{~kg}$ & Lognormal & 1.7607 & \\
\hline \begin{tabular}{|l|} 
Manganese \\
\end{tabular} & low. pop. & $4.04 \mathrm{E}-07$ & $\mathrm{~kg}$ & Lognormal & 5.6431 & \\
\hline Thorium-230 & low. pop. & $1.16 \mathrm{E}-05$ & $\mathrm{kBq}$ & Lognormal & 3.3124 & \\
\hline Hydrocarbons, aliphatic, alkanes, cyclic & low. pop. & $5.38 \mathrm{E}-08$ & $\mathrm{~kg}$ & Lognormal & 2.1169 & \\
\hline Butane & low. pop. & $1.26 \mathrm{E}-07$ & $\mathrm{~kg}$ & Lognormal & 1.7607 & \\
\hline Sulfur dioxide & low. pop. & 0.006485 & $\mathrm{~kg}$ & Lognormal & 1.133 & $15 \%$ less SO2 emissions \\
\hline Thorium-232 & low. pop. & $5.45 \mathrm{E}-05$ & $\mathrm{kBq}$ & Lognormal & 3.5349 & \\
\hline Vanadium & low. pop. & $1.67 \mathrm{E}-07$ & $\mathrm{~kg}$ & Lognormal & 5.6431 & \\
\hline Molybdenum & low. pop. & $1.3 \mathrm{E}-08$ & $\mathrm{~kg}$ & Lognormal & 5.6431 & \\
\hline Propene & low. pop. & 1.07E-07 & $\mathrm{kg}$ & Lognormal & 1.7607 & \\
\hline Polonium-210 & low. pop. & 0.001388 & $\mathrm{kBq}$ & Lognormal & 3.5349 & \\
\hline \begin{tabular}{|l|} 
Uranium-238 \\
\end{tabular} & low. pop. & 0.000179 & $\mathrm{kBq}$ & Lognormal & 3.5349 & \\
\hline Lead-210 & low. pop. & 0.000782 & $\mathrm{kBq}$ & Lognormal & 3.5349 & \\
\hline Toluene & low. pop. & $7.5 \mathrm{E}-07$ & $\mathrm{~kg}$ & Lognormal & 1.7607 & \\
\hline Hexane & low. pop. & $6.26 \mathrm{E}-09$ & $\mathrm{~kg}$ & Lognormal & 2.3285 & \\
\hline \begin{tabular}{|l|} 
Hydrocarbons, chlorinated \\
\end{tabular} & low. pop. & $1.88 \mathrm{E}-08$ & $\mathrm{~kg}$ & Lognormal & 2.3285 & \\
\hline Hydrocarbons, aliphatic, unsaturated & low. pop. & $1.44 \mathrm{E}-06$ & $\mathrm{~kg}$ & Lognormal & 1.7607 & \\
\hline \begin{tabular}{|l|} 
Methane, monochloro-, R-40 \\
\end{tabular} & low. pop. & $4.93 \mathrm{E}-08$ & $\mathrm{~kg}$ & Lognormal & 2.1169 & \\
\hline Pentane & low. pop. & $9.82 \mathrm{E}-07$ & $\mathrm{~kg}$ & Lognormal & 1.7607 & \\
\hline Boron & low. pop. & $4.32 \mathrm{E}-06$ & $\mathrm{~kg}$ & Lognormal & 5.6431 & \\
\hline Thorium-228 & low. pop. & $3.72 \mathrm{E}-05$ & $\mathrm{kBq}$ & Lognormal & 3.5349 & \\
\hline Methane, dichloro-, HCC-30 & low. pop. & $2.7 \mathrm{E}-08$ & $\mathrm{~kg}$ & Lognormal & 2.3285 & \\
\hline Formaldehyde & low. pop. & $4.1 \mathrm{E}-07$ & $\mathrm{~kg}$ & Lognormal & 1.7607 & \\
\hline Cadmium & low. pop. & $1.17 \mathrm{E}-08$ & $\mathrm{~kg}$ & Lognormal & 5.6431 & \\
\hline Carbon disulfide & low. pop. & $1.21 \mathrm{E}-08$ & $\mathrm{~kg}$ & Lognormal & 3.1032 & \\
\hline Bromine & low. pop. & $3.53 \mathrm{E}-06$ & $\mathrm{~kg}$ & Lognormal & 2.3395 & \\
\hline Strontium & low. pop. & $6.68 \mathrm{E}-07$ & $\mathrm{~kg}$ & Lognormal & 5.6431 & \\
\hline Particulates, $<2.5$ um & low. pop. & $8 \mathrm{E}-05$ & $\mathrm{~kg}$ & Lognormal & 1.6725 & \\
\hline \begin{tabular}{|l|} 
Acrolein \\
\end{tabular} & low. pop. & $2.7 \mathrm{E}-08$ & $\mathrm{~kg}$ & Lognormal & 3.3124 & \\
\hline Chloroform & low. pop. & $9.12 \mathrm{E}-09$ & $\mathrm{~kg}$ & Lognormal & 2.1169 & \\
\hline Barium & low. pop. & $7.32 \mathrm{E}-07$ & $\mathrm{~kg}$ & Lognormal & 5.6431 & \\
\hline Hydrogen fluoride & low. pop. & $3.19 \mathrm{E}-05$ & $\mathrm{~kg}$ & Lognormal & 2.5475 & \\
\hline Chromium VI & low. pop. & $1.58 \mathrm{E}-08$ & $\mathrm{~kg}$ & Lognormal & 4.1167 & \\
\hline Carbon monoxide, fossil & low. pop. & $9.95 \mathrm{E}-05$ & $\mathrm{~kg}$ & Lognormal & 5.1652 & \\
\hline Radon-222 & low. pop. & 0.00562 & $\mathrm{kBq}$ & Lognormal & 3.5349 & \\
\hline Styrene & low. pop. & $2.3 \mathrm{E}-09$ & $\mathrm{~kg}$ & Lognormal & 2.1169 & \\
\hline Radon-220 & low. pop. & 0.005722 & $\mathrm{kBq}$ & Lognormal & 3.5349 & \\
\hline Beryllium & low. pop. & $1.95 \mathrm{E}-09$ & $\mathrm{~kg}$ & Lognormal & 5.1439 & \\
\hline \begin{tabular}{|l} 
Ethane, 1,2-dichloro- \\
\end{tabular} & low. pop. & $3.71 \mathrm{E}-09$ & $\mathrm{~kg}$ & Lognormal & 2.3285 & \\
\hline Benzene, ethyl- & low. pop. & $8.75 \mathrm{E}-09$ & $\mathrm{~kg}$ & Lognormal & 2.1169 & \\
\hline \multicolumn{7}{|l|}{ Emissions to water } \\
\hline Water, ZA & & \multicolumn{2}{|c|}{$0.052312 \mathrm{~m} 3$} & Lognormal & \multicolumn{2}{|l|}{\begin{tabular}{|c|}
1.8704 \\
\end{tabular}} \\
\hline \multicolumn{7}{|l|}{ Waste to treatment } \\
\hline
\end{tabular}




\section{Appendix VII : Sankey diagrams (IPPC GWP 2013 100a)}

$\underline{\text { Year } 2000}$

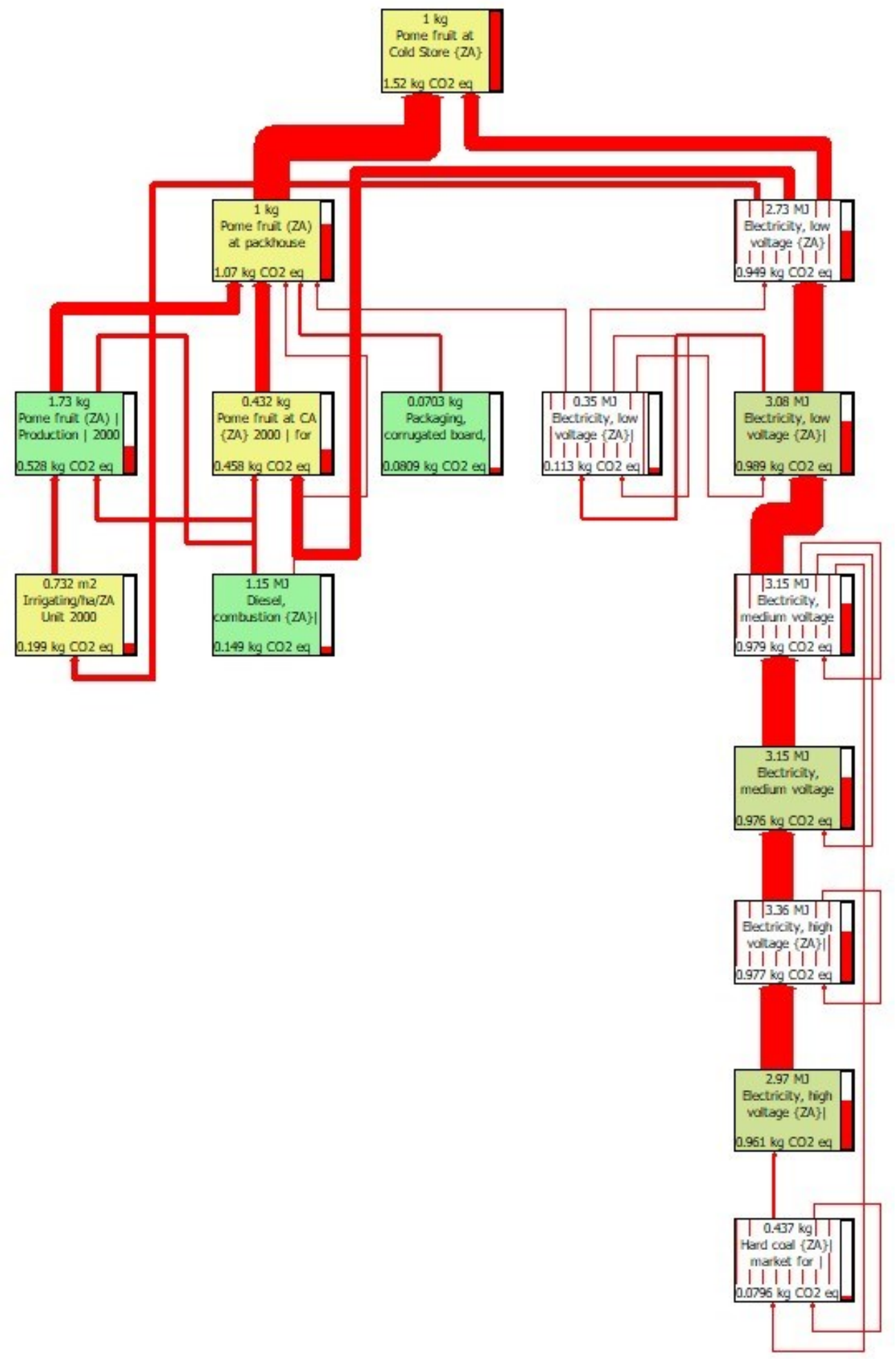


$\underline{\text { Year } 2010 \text { (CCC data) }}$

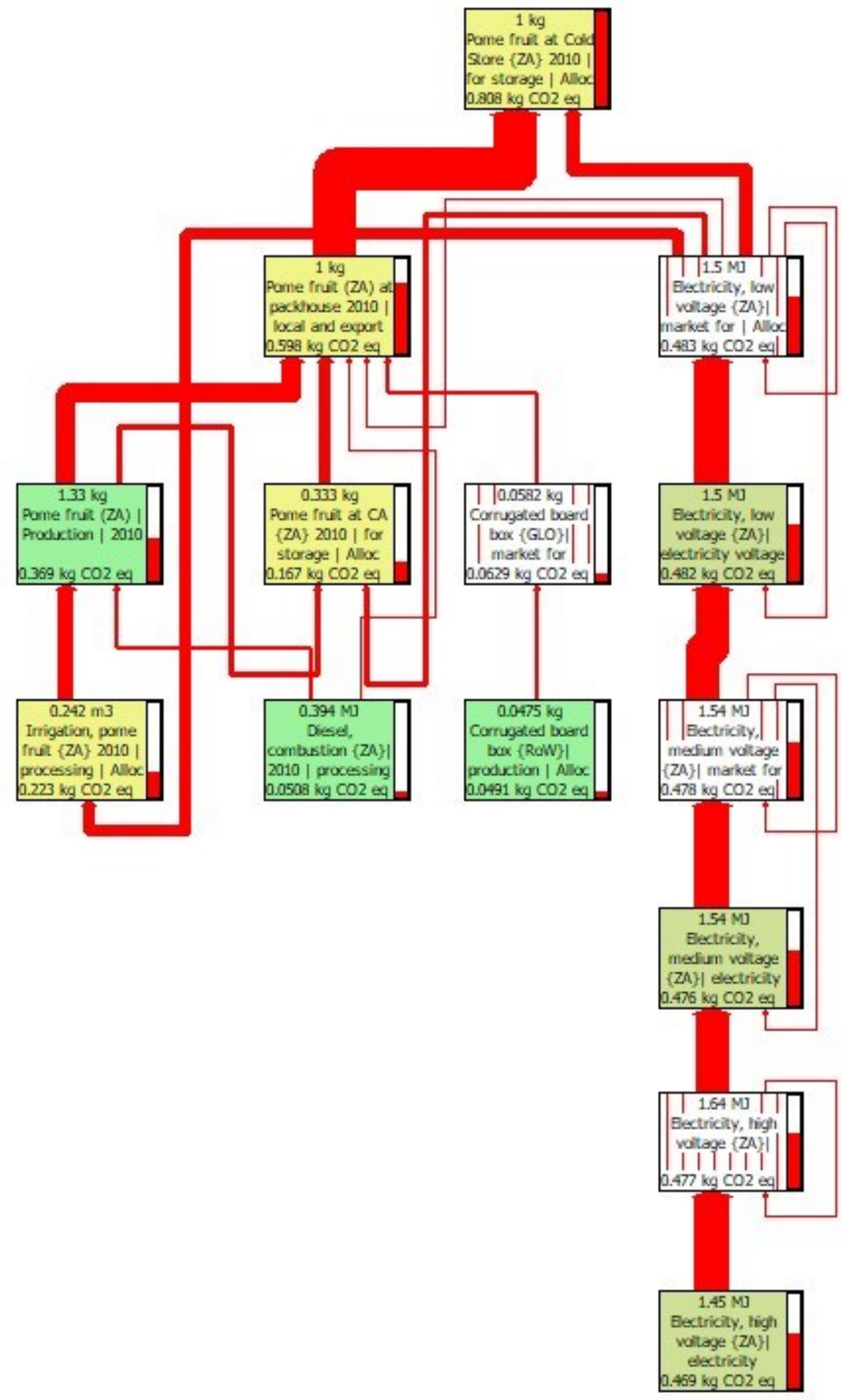


Year 2010 (Bouwer et al. (2008))

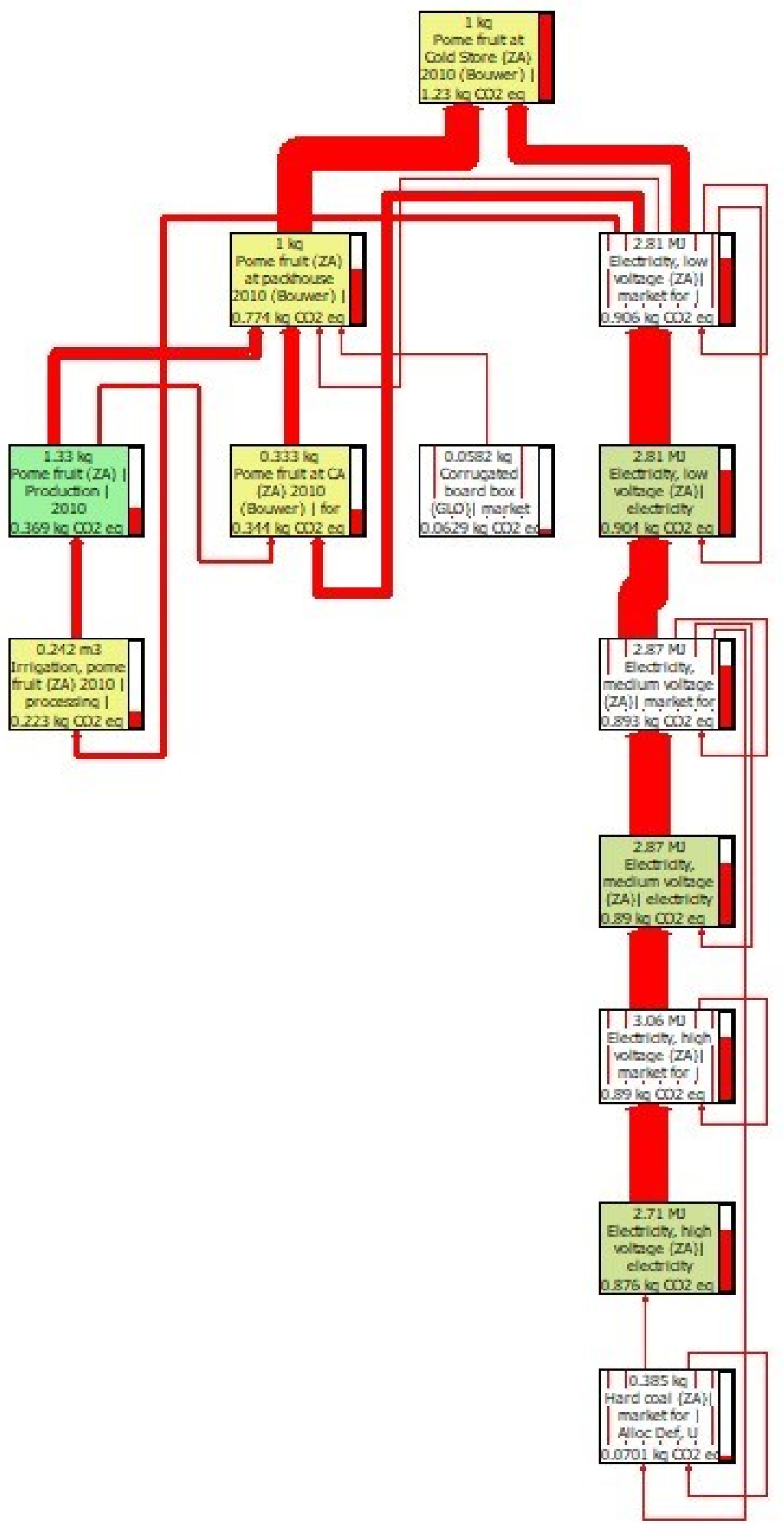


$\underline{\text { Year } 2020}$

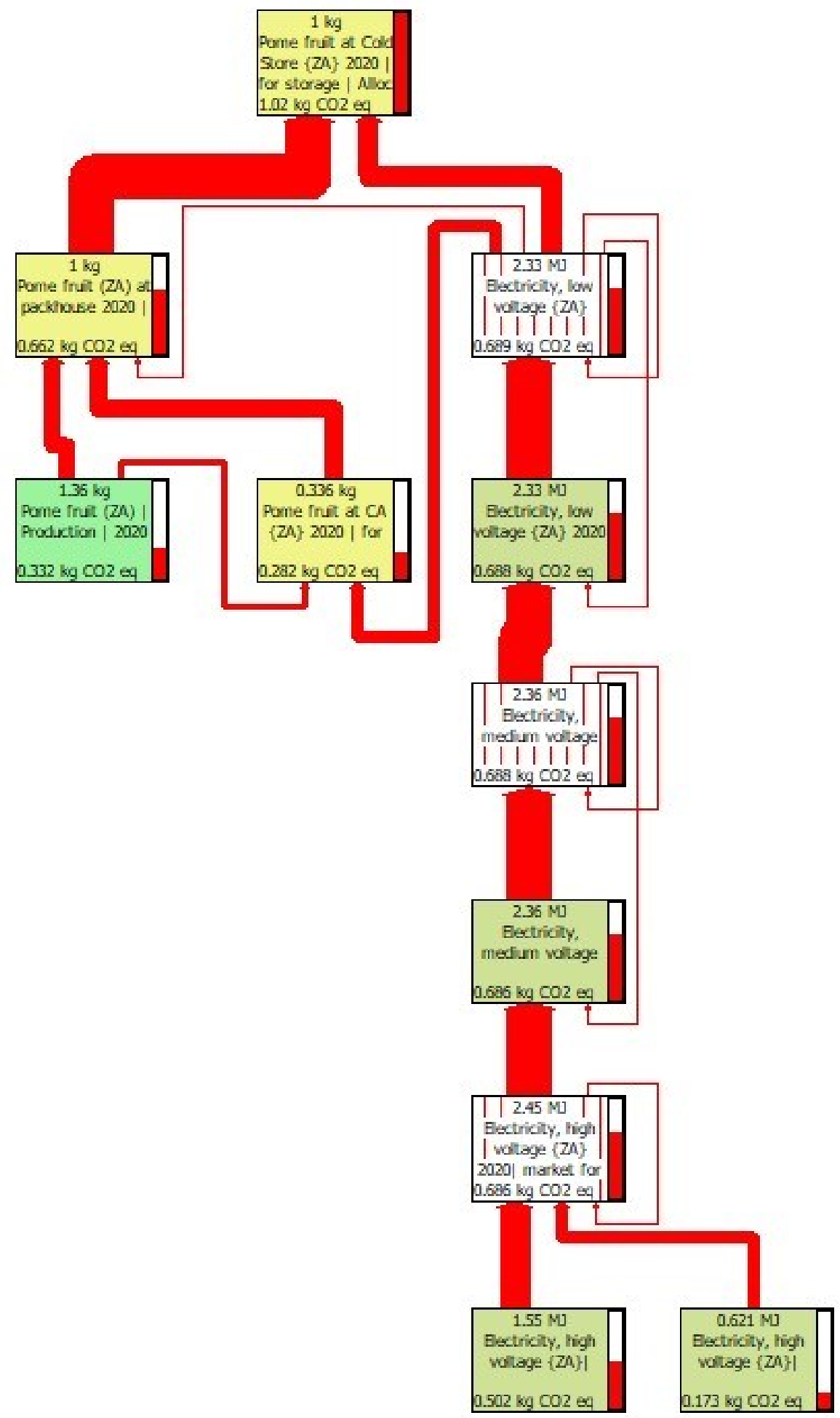


Appendix VIII : Uncertainty distributions

Year 2000

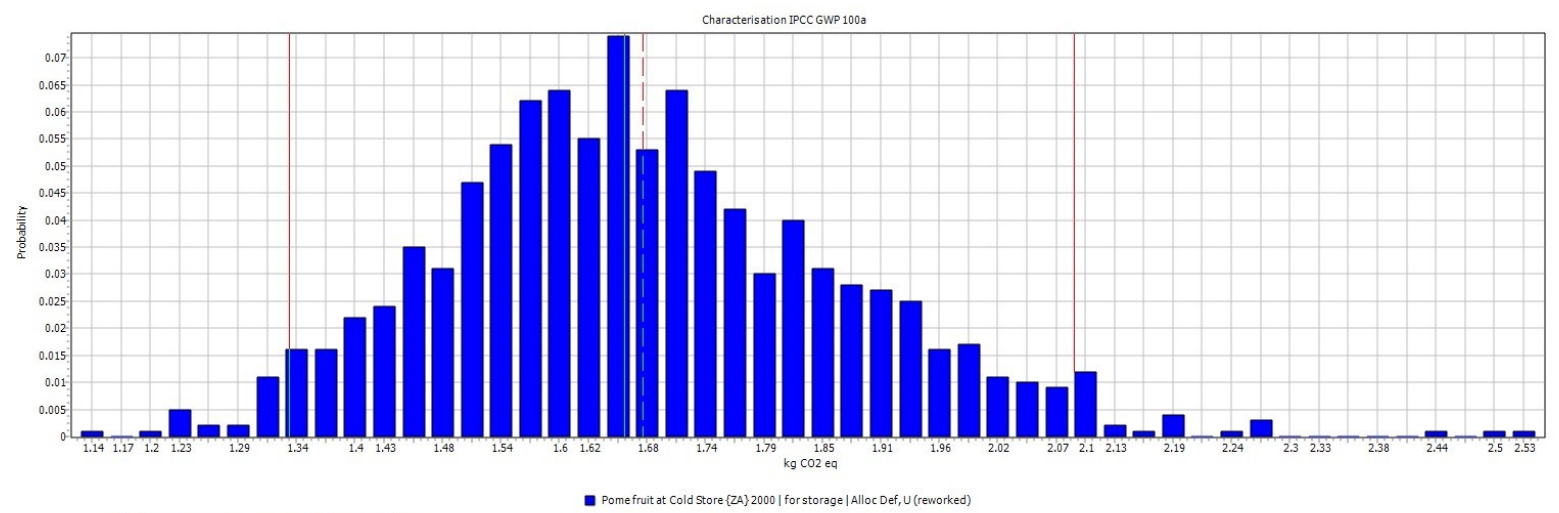

$\underline{\text { Year } 2010}$

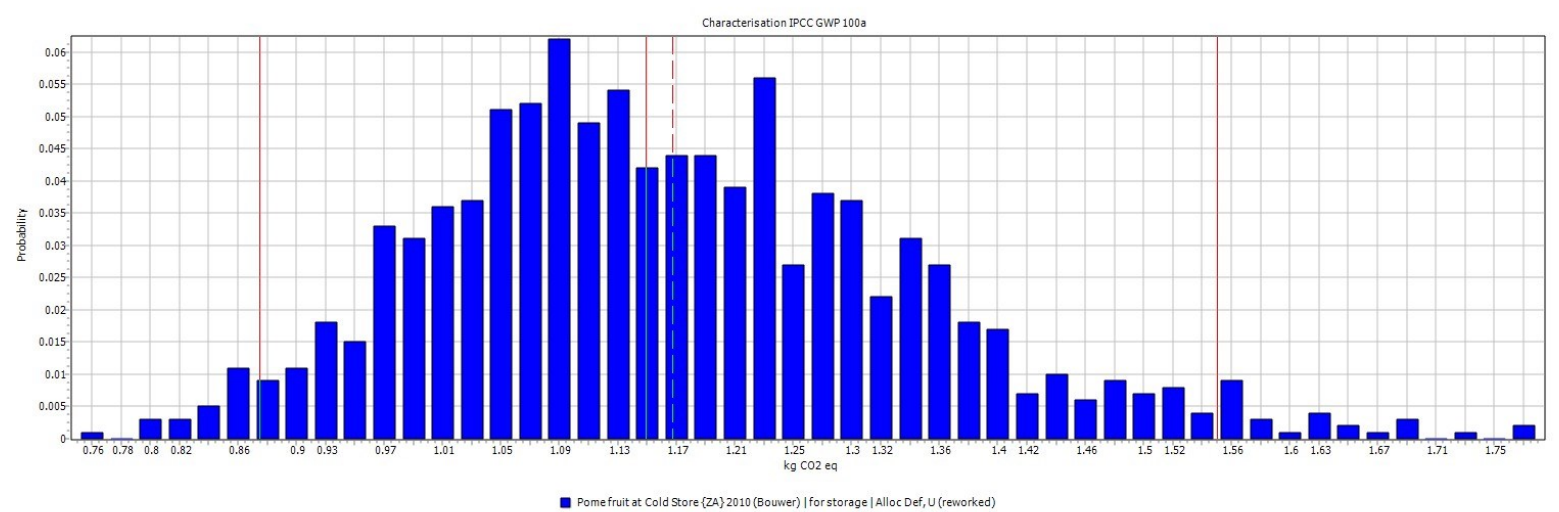

\section{$\underline{\text { Year } 2020}$}

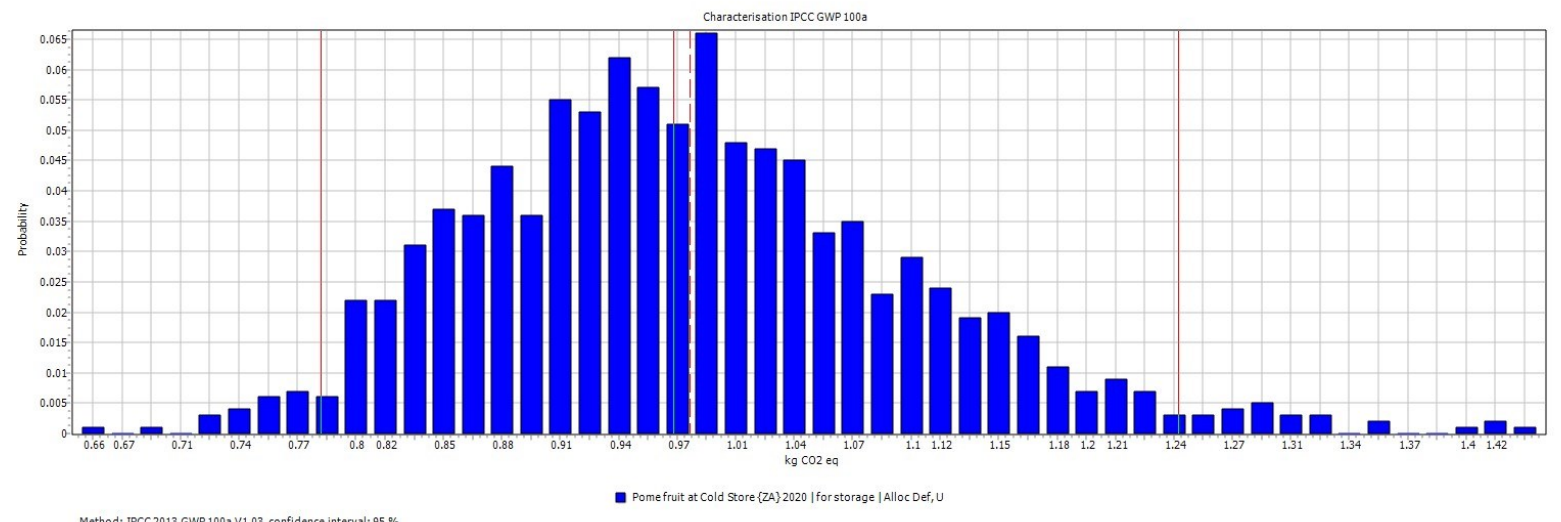

